Monatsschr Kinderheilkd 2011 • [Suppl 4] 159:311-365

DOI 10.1007/s00112-011-2508-1

(c) Springer-Verlag 2011

\section{Abstracts der 49. Jahrestagung der Österreichischen Gesellschaft für Kinder- und Jugendheilkunde}

\author{
6.10.-8.10.2011, Congress Center Villach \\ „Pädiatrie - quo vadis?"
}

Liebe Kolleginnen und Kollegen!

Die 49. Jahrestagung der Österreichischen Gesellschaft für Kinderund Jugendheilkunde findet von 6. bis 8. Oktober $2011 \mathrm{im}$ Congress Center Villach, im Dreiländereck mit Italien und Slowenien, statt. Unsere traditionelle Jahrestagung wird wieder Gelegenheit für einen intensiven medizinischen Erfahrungsaustausch in den unterschiedlichsten Spezialitäten unseres Fachgebietes bieten. Die Involvierung der Österreichischen Gesellschaft für Prä-und Perinatale Medizin und der Österreichischen Gesellschaft für Kinder- und Jugendchirurgie spiegelt die Notwendigkeit wieder, den interdisziplinären Austausch aktiv zu betreiben, um unser gemeinsames Anliegen, das Wohl des Kindes, durchzusetzen.

Das Motto der Tagung „Pädiatrie - quo vadis?" soll die Herausforderungen unterstreichen, welche unser großes Fachgebiet in den nächsten Jahren für uns bereithält.

Von einander und miteinander zu lernen ist das Ziel: mit den Themenschwerpunkten Neuropädiatrie, Jugendmedizin und Psychosomatik werden wir uns intensiv auseinandersetzen. Weitere Themenschwerpunkte in allen Teilbereichen unseres Faches zeigen den großen Wissensgewinn aber auch den Weiterbildungsbedarf, den wir in allen unseren Spezialitäten aufweisen. Der wissenschaftliche Schwerpunkt im Rahmen des Kongresses wird auch durch freie Vorträge, Postersitzungen und den Young Investigators Corner bestimmt.

Wir freuen uns in diesem Zusammenhang über die zahlreichen eingereichten Abstracts. So ist es uns gelungen drei Posterwalks mit jeweils drei Präsentationszügen sowie drei freie Vortragssitzungen mit wissenschaftlich interessanten Beiträgen zu füllen und wir sind besonders stolz, für diese Schwerpunkte 200 Referenten begrüßen zu dürfen.

Aus all diesen Beiträgen ist ein umfangreicher und wissenschaftlich hochkarätiger Abstractband entstanden, welchen wir Ihnen erstmals auf CD präsentieren möchten.

Wir hoffen, mit dieser Kongressgestaltung Ihre Bedürfnisse und Wünsche getroffen zu haben und freuen uns, Sie in Villach zur Jahrestagung begrüßen zu dürfen.

Mit herzlichen Grüßen

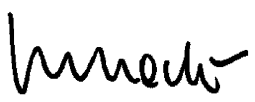

Prim. Univ.-Prof.

Dr. Robert Birnbacher

Kongresspräsident

\section{G Olcueds}

Prim. Univ.-Prof.

Dr. Klaus Schmitt

Präsident der ÖGKJ

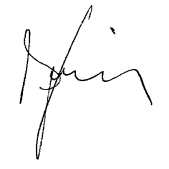

$O A$

Dr. Harald Kenzian

Kongresssekretär

\section{Inhaltsverzeichnis}

1 Kardiologie...............................312

2 Dermatologie ............................316

3 Endokrinologie und Diabetes ...............316

4 Ernährung...............................319

5 Gastroenterologie........................320

6 Genetik...................................321

7 Hämatoonkologie.......................322

8 Immunologie............................329

9 Infektiologie ............................331

10 Intensivmedizin ..............................334

11 Jugendmedizin .........................335

12 Neonatologie.............................336

13 Nephrologie..............................343

14 Neuropädiatrie .......................... 348

15 Pneumologie ...........................352

16 Psychosomatik ............................354

17 Rheumatologie..........................355

18 Schlafmedizin ...............................356

19 Sonographie.................................357

20 Sport ..................................359

21 Stoffwechsel...............................359

22 Young investigators corner...............361

Autorenverzeichnis......................365 


\section{Kardiologie}

\subsection{Kardiale Gefährdung und plötzlicher Herztod (Sudden Cardiac Death) im Sport sowie Empfehlungen zur Prävention}

\section{R. Eyermann}

Kinder- und Jugendmedizin, Kinderkardiologie, Sportmedizin, München

Sudden Cardiac Death (SCD) ist dsefiniert als nichttraumatisches unerwartetes Ereignis durch plötzlichen Herzstillstand, tragisch. Die Inzidenz ist bei scheinbar gesunden Adoleszenten pro Jahr sportlicher Aktivität bei ca. 1:2500oo. Epidemiologisch ist SCD häufiger bei Jungen, Afroamerikanern, Wettkämpfern von Football und Basketball. Meiste SCD treten in der Zeit von 15-21 Uhr, während/kurz nach Training/ Wettkampf auf.

Ätiologisch ist SCD bei jüngeren Sporttreibenden durch präexistente nichterkannte Herzerkrankungen verursacht (ca. 90\% durch strukturelle Herzerkrankungen, ca. $10 \%$ durch primär elektrophysiologische Störungen): Häufig sind dabei Hypertrophe Kardiomyopathie (HCM) $36 \%$, Koronaranomalien $23 \%$, idiopathische LVH $10 \%$; weniger häufig rupturiertes Aortenaneurysma, Myokarditis, Aortenstenose (AS), KHK, Arrhythmogene rechtsventrikuläre Dysplasie (ARVD); selten WPWSyndrom, Long QT-Syndrom (LQTS), Mitralklappenprolaps (MKPS), Commotio cordis, Drugs.

In Screeningevaluationen $(\mathrm{n}=115)$ sind bei SCD-Betroffenen in vorherigen medizinischen Evaluationen nur in 3\% kardiovaskuläre Erkrankungen aufgedeckt, in $0,9 \%$ korrekte Korrelationen zum SCD hergestellt worden.

Kardiovaskuläre Anamnese, bedeutsamstes Screeningelement, Mindestinhalt:

- Früherer Thoraxschmerz, Synkope oder Near-Synkope, unerwartete unklare Kurzatmigkeit oder Fatigue assoziiert mit Belastung,

- Früheres Herzgeräusch oder Hypertonie,

- Positive FA auf SCD, kardiovaskuläre Events <50 Jahre sowie HCM, Marfan-Syndrom,

-LQTS, signifikante Arrhythmien.

Medizinische Untersuchung, Mindestinhalt:

- Auskultation im Liegen und Stehen, vor allem zur Detektion von Geräuschen dynamischer linksventrikulärer Ausflusstraktobstruktion (LVOTO),

- Femoralispulse zum Ausschluss Aortenisthmusstenose (ISTA bzw. CoA),

- Evaluation auf Stigmata Marfan-Syndrom,

- Blutdruck (RR)-Messung im Sitzen.

Weitere Diagnostik. EKG und Echo sind in den USA im RoutineScreening aufgrund niedriger Inzidenz, hoher Rate an falsch-positiven Befunden und Kosten nicht empfohlen. Zukünftige Involvierung von Gentests sind bei jungen High-Risk-Sporttreibenden zu erwarten.

Konklusion. Junge Sporttreibende sollten gescreent und bei kardiovaskulären Abnormitäten fachkardiologisch weiterevaluiert und ihre Belastbarkeit nach den Guidelines von American College of Cardiology (ACC)/American College of Sports Medicine (ACSM) eingestuft werden. Die meisten Kinder mit kardiovaskulären Befunden können an den meisten, aber nicht an allen, physischen Aktivitäten teilnehmen.
1.2 Kinderkardiologie quo vadis? Die Frequenzspektralanalyse der Herz-Raten-Variabilität(HRV)-Messung als ergänzende Interpretationsmöglichkeit zur reinen Rhythmusanalyse eines LZ-EKGs. Aussagekraft und prognostische Wertigkeit?

N. Genser' ${ }^{1}$ P. Hausschild ${ }^{2}$

${ }^{1}$ Facharzt für Kinder- und Jugendheilkunde, Kufstein, ${ }^{2}$ Akademie für Chronbiologie und Chronmedizin

Einleitung. Die Messung der Herz-Raten-Variabilität (HRV) hat bei Erwachsenen durch die Frequenzspektralanalyse eine neue Aussagekraft und prognostische Wertigkeit erfahren, u. a. als prognostischer Faktor bei Sterberate post Myokardinfarkt oder bei Diabetes mellitus. Andere Anwendungen sind Depressionen, Schlafstörungen und Stressmanagement (Burn-out). Bei Kindern und Jugendlichen kommt die Anwendung einer Langzeitanalyse (autochrones Bild, ACB) noch nicht routinemäßig zum Einsatz.

Methodik. Hier werden beispielhaft mögliche Anwendungsgebiete vorgestellt, wie z. B. Kinderkardiologie (Leistungsminderung, Synkopen, Arrhythmien, Ergometrie), bei Patienten mit ADHS und bei Entspannungstechniken wie Qigong. Die HRV Messungen wurden mit einem speziellen 24-h-Langzeit-EKG-Rekorder (HeartManâ, Fa. Heart Balance, Wien) aufgezeichnet. Zur Auswertung dienen neben dem ACB auch einzelne Parameter der Zeit- und der Frequenzanalyse, die üblicherweise in Studien angewendet werden.

Ergebnisse. Im ACB erhält man Informationen über mögliche emotionale und geistige Anspannung, sowie über die Entspannungs- und Erholungsfähigkeit des Patienten. Es zeigen sich deutliche intra- und interindividuelle Unterschiede wie z. B. in den verschiedenen Schlafphasen (Tiefschlaf, REM-Phasen) und diversen Tagesaktivitäten (Schule, Lesen, TV, PC).

Schlussfolgerung. In Zukunft könnten HRV-Messungen nicht nur bei verschiedenen neuropsychiatrischen (Depression, ADHS, Stress) oder kardiologischen Erkrankungen herangezogen werden, sondern auch als Prognosefaktor bei verschiedenen Erkrankungen (wie z. B. postoperativer Verlauf nach Herzoperationen, Einschätzung einer orthostatischen Dysfunktion etc.).

\subsection{Kann man mittels Messung der Herz-Raten-Variabilität (HRV) die Entspannungsfähigkeit bei Kindern und Jugendlichen während Qigong zeigen?}

N. Genser' ${ }^{1}$ C. Kaspar², P. Hauschild ${ }^{3}$, Z. Sebkova-Thaller ${ }^{2}$

${ }^{1}$ Facharzt für Kinder- und Jugendheilkunde, Kufstein, ${ }^{2}$ Qigongweg - Zentrum Augsburg, ${ }^{3}$ Akademie für Chronbiologie und Chronmedizin

Einleitung. Mit der Spektralanalyse einer HRV-Messung (autochrones Bild) kann man geistige und emotionale Anspannung sowie Entspannung aufzeigen. Qigong (QG) ist eine asiatische Entspannungstechnik die v. a. bei vielen Kampfsportarten zur Entspannung und Erholung, aber auch zur Anspannung und Konzentration eingesetzt wird. Wie wirkt sich QG üben auf die Entspannungsfähigkeit von Kindern und Jugendlichen aus? Schaffen es die Kinder und Jugendlichen eine Entspannung zu erreichen und kann man diese mittels HRV-Messung sichtbar machen?

Methodik. Sechs QG-erfahrene Kinder und Jugendliche (4 Mädchen und 2 Jungen im Alter von 8-17 Jahren, im Mittel 11,9 Jahre) und 8 QGunerfahrene (3 w/5 m, 8-17 Jahre, im Mittel 11,2 Jahre) übten QG anhand einer standardisierten Übungsreihe (der Zyklus „Der Tag geht auf", Dauer ca. 30 min). HRV-Messungen wurden mit einem speziellen Langzeit-EKG-Rekorder (HeartManâ, Fa. Heart Balance, Wien) aufgezeichnet.

Ergebnisse. In Zeiten, in denen man Übungsanleitungen konzentriert zuhört, sowie in der Pause vor und nach dem Üben, zeigten alle Übenden eine emotionale und geistige Anspannung bzw. Konzentration. Dazwischen kam es aber bei fast allen Übenden phasenweise zu einer 
Entspannung, wobei QG-Erfahrene besser und länger entspannt waren als QG-Unerfahrene.

Schlussfolgerung. Unsere HRV-Messungen zeigen, dass auch Kinder und Jugendliche während QG üben in eine Entspannung eintreten können, wobei es interindividuelle Unterschiede gibt. So eine Entspannungsfähigkeit zu messen kann hilfreich sein, v. a. in Sportarten, in denen mentale Stärke wichtig ist, aber auch bei Patienten mit Hyperaktivität oder Leistungsminderung, um deren allgemeine Anpassung und Erholungsfähigkeit auf innere und äußere Reize zu messen.

\subsection{Myokardprobenaufbereitung zur Langzeitlagerung für genetische, epigenetische, RNA- und Protein-Analysen}

S. Greber-Platzer ${ }^{1}$, K. Diener ${ }^{1}$, A. Dangl2

Medizinische Universität Wien, Univ. Klinik für Kinder- und Jugendheilkunde, ${ }^{1}$ Abteilung für Pädiatrische Pulmologie, Allergie und Endokrinologie, ${ }^{2}$ Abteilung für Pädiatrische Kardiologie

Ziel der Studie. Bei angeborenen Herzfehlern (CHD) werden Mutationen verschiedener sog. herzspezifischer Gene nachgewiesen, die als krankheitsverursachend angesehen werden. Dennoch liegt meist eine unklare Penetranz bei genetischer Prädisposition vor, ebenso sind Art und Schwere des Herzfehlers unterschiedlich ausgeprägt. Bisher ist bekannt, dass es sich um Herzentwicklungsstörung in der Embryogenese handelt, wobei meist Transkriptionsfaktoren und weniger Strukturproteine betroffen sind. Dennoch liegen die genauen Triggermechanismen und das Zusammenspiel verschiedener Faktoren, die letztendlich Art und Schwere des Herzfehlers begründen, im Unklaren. Internationale Studien diskutieren auch einzelne oder mehrfache Spontanmutationen, die dann als Mosaikform im Myokard zu finden sind.

Um aus Myokardproben von Patienten mit CHD-Analysen genetischer Mutationen für eine Vielzahl herzspezifischer Gene, epigenetischer Veränderungen, aber auch direkter Messung der mRNA und Proteinmenge wie -struktur durchführen zu können, sind Voraussetzungen eine richtige Probengewinnung, -präparation und -lagerung. Das heißt, um ein Maximum an Stabilität von RNA, DNA und Protein in Myokardgewebe zu gewährleisten, sind optimal angepasste Prozeduren zur Probenaufbereitung und -lagerung notwendig.

Mit dieser Studie wurde methodisch das Vorgehen für eine Myokardprobenpräparation und -lagerung analysiert, um ein Optimum an Qualität und Quantität der Proben über einen längeren Zeitraum zu gewährleisten. Zu diesem Zweck wurden Myokardproben gelagert nach der konventionellen Technik bei $-80^{\circ} \mathrm{C}$ für DNA-Untersuchungen und in flüssigem Stickstoff $\left(-196^{\circ} \mathrm{C}\right)$ für RNA- und Proteinbestimmungen mit der neuen Methode des Einsatzes eines Stabilisierungsreagens (QIAGEN AllProtect), das die Proben durchtränkt und dann eine Lagerung ausschließlich bei $-80^{\circ} \mathrm{C}$ ermöglicht, hinsichtlich Stabilität von DNA, RNA und Protein verglichen.

Methode. Myokardmaterial, angefallen als Abfallprodukt beim herzchirurgischen Eingriff, wurde sofort nach der Exzision in kleine, gleich große Probenstücke geteilt und in leere oder mit Stabilisierungspuffer vorgefüllte Tubes gegeben. Entsprechend der konventionellen Technik wurden die Tubes mit Myokardstückchen entweder in Flüssigstickstoff oder bei $-80^{\circ} \mathrm{C}$ aufbewahrt, während die Tubes mit Stabilisierungspuffer über 24 Stunden zur Durchtränkung des Gewebes bei $4^{\circ} \mathrm{C}$ stehenblieben und dann erst auf $-80^{\circ} \mathrm{C}$ aufbewahrt wurden. Messpunkte für DNA, RNA und Protein waren Zeitpunkt o und 4 Monate. Die Isolation erfolgte durch den QIAGEN AllPrep DNA/RNA/Protein-Mini Kit. Die quantitative und qualitative Bestimmung wurde mit dem Nanodrop Spectrophotometer ND-10oo und dem Agilent Bioanalyzer durchgeführt.

Ergebnisse. Nach 4 Monaten Lagerung war DNA stabil und RNA gemessen als „RNA integrity number“ (RIN) erniedrigt gegenüber dem Ausgangswert in beiden Methoden, während die Proteinqualität durch den Stabilisierungspuffer besser erhalten blieb.

Schlussfolgerung. Myokardproben müssen unmittelbar nach der chirurgischen Entnahme präpariert und sofort in Stabilisierungspuffer gelagert werden, wenn man strukturelle und funktionelle Protein- analysen durchführen möchte. Die Abnahme der RNA Quantität kann durch einen Stabilisierungspuffer nicht verhindert werden, so dass RNA am besten sofort isoliert und in stabile Lagerungsbedingungen überführt werden sollte. Für DNA Analysen können Myokardproben sowohl bei $-80^{\circ} \mathrm{C}$ mit oder ohne Stabilisierungspuffer aufbewahrt werden. Die erhobenen Daten werden nochmals nach einem längeren Zeitraum (geplant sind 12 und 24 Monate) verifiziert, um die Aussagen hinsichtlich Qualität und Quantität zu bestätigen.

1.5 Kardiale Resynchronisation zur Behandlung der Herzinsuffizienz bei dilatativer Kardiomyopathie bei einem 1,5 Jahre alten Mädchen

J. Hauser ${ }^{1}$, C. Pees' ${ }^{1}$ C. Khazen², I. Michel-Behnke ${ }^{1}$

${ }^{1}$ Universitätsklinik für Kinder- und Jugendheilkunde, Wien, ${ }^{2}$ Universitätsklinik für Chirurgie, Wien

Hintergrund. Die kardiale Resynchronisation (CRT) durch biventrikuläre Herzschrittmacherstimulation gehört zur erweiterten Therapie der Herzinsuffizienz im Erwachsenenalter. Für Kinder liegen vielversprechende Berichte sowohl bei Vitien, als auch bei Kardiomyopathien vor. Wir berichten über die Anwendung dieses Verfahrens bei einem Mädchen mit dilatativer Kardiomyopathie (DCM) nach Myokarditis, bei dem eine Herztransplantation nicht vorgesehen ist.

Patientin: Erstvorstellung im Alter von 2 Monaten kardial dekompensiert mit DCM. Ätiologisch wurde eine Virusmyokarditis (HHV6) diagnostiziert und eine Herzinsuffizienztherapie eingeleitet. Mehrere Episoden mit klinischer Verschlechterung erforderten eine Pulstherapie mit Milrinon und Levosimendan. Im Alter von 1,5 Jahren wurde bei progredienter Mitralklappeninsuffizienz die Mitralklappe rekonstruiert und ein CRT-Schrittmacher implantiert.

Methode. Im Rahmen der Mitralklappenrekonstruktion wurden epikardiale Schrittmacherelektroden auf dem rechten Vorhof (Medtronic 5071), dem rechten Ventrikel und dem linken Ventrikel platziert (Enpath Myopore). Als Aggregat wurde ein Consulta (Medtronic) abdominal implantiert. Die AV-Zeit wurde optimiert, das interventrikuläre Delay nach echokardiographischer Evaluierung auf $20 \mathrm{~ms}$ programmiert.

Ergebnis. Im Laufe von 6 Monaten nach Beginn der CRT zeigte sich eine rückläufige Ventrikelgröße $(50 \times 46 \mathrm{~mm})$, die EF stieg von 15 auf $50 \%$. Das NYHA-Stadium verbesserte sich von III auf I, die BNP-Werte sanken von $>35.000$ auf $2000 \mathrm{pg} / \mathrm{ml}$. Die postkapilläre pulmonale Hypertonie ist derzeit nicht mehr nachweisbar.

Schlussfolgerung. Ergänzend zur medikamentösen Herzinsuffizienztherapie kann auch bei Kindern die CRT angeboten werden. Die epikardiale Elektrodenplatzierung erlaubt den Einsatz dieses Verfahrens ab dem Säuglingsalter. Die frühzeitige Indikationsstellung erlaubt ein Bridging zur Transplantation, ebenso wie eine Destination-Therapie.

\subsection{Referenzwerte der "tricuspid annular peak systolic velocity" (TAPSV) bei 860 gesunden Kindern, Berechnung von z-score Werten und Vergleich mit Referenzwerten der „tricuspid annu- lar plane systolic excursion" (TAPSE)}

B. Heinzl $I^{1}$, M. Köstenberger ${ }^{1}$, B. Nagel' ${ }^{1}$, A. Avian² ${ }^{2}$, W. Ravekes ${ }^{3}$, P. Fritsch' ${ }^{1}$, V. Halb ${ }^{1}$, T. Rehak ${ }^{1}$, A. Gamillscheg ${ }^{1}$

${ }^{1}$ Medizinische Universität Graz, Universitätsklinik für Kinder- und Jugendheilkunde, Klinische Abteilung für Pädiatrische Kardiologie, ${ }^{2}$ Medizinische Universität Graz, Institut für medizinische Informatik, Statistik und Dokumentation, ${ }^{3}$ Division of Pediatric Cardiology, Johns Hopkins University School of Medicine, Baltimore, MD, USA

Ziel. Die TAPSV ist ein echokardiographischer Gewebedoppler-Parameter zur Bestimmung der rechtsventrikulären (RV) Funktion bei Erwachsenen. Wir untersuchten altersabhängige Veränderungen der TAPSV-Werte im Kindesalter mit dem Ziel altersspezifische Normwerte zu erheben. 
Methodik. Eine prospektive Studie wurde durchgeführt bei 860 herzgesunden Kindern (Alter: 1 LT bis 18 LJ; KOF: o,14 bis 2,30 m², w: 431, $\mathrm{m}:$ 429). Eine stufenweise lineare Regressionsanalyse wurde durchgeführt um die TAPSV auf Basis des Alters, Geschlechtes und der KOF zu berechnen. Eine mögliche Korrelation dieser TAPSV-Werte mit bekannten Normwerten der mittels M-Mode erhobenen systolischen RV Funktion (TAPSE) wurde untersucht.

Resultate. Die TAPSV zeigt bei Neugeborenen einen mittleren Normalwert von 7,2 cm/s (Z-score $\pm 2: 4,8-9,5 \mathrm{~cm} / \mathrm{s})$ mit einem Anstieg bis zu einem mittleren Normalwert von $14,3 \mathrm{~cm} / \mathrm{s}$ (Z-score $\pm 2:$ : 10,6$18,6 \mathrm{~cm} / \mathrm{s}$ ) bei 18 -jährigen Jugendlichen. Es wurde eine positive Korrelation von TAPSV zu Alter und KOF mit einem nicht linearen Altersanstieg nachgewiesen. Geschlechterspezifische Unterschiede wurden nicht gefunden. Eine positive Korrelation liegt vor zwischen TAPSV und TAPSE-Werten bei Kindern und Jugendlichen.

Konklusion. TAPSV Normalwerte inklusive z-scores im Kindes- und Jugendalter wurden erstellt und Perzentilenkurven berechnet um Referenzdaten für Studien mit herzkranken Kindern zur Verfügung zu stellen.

\subsection{Erwachsene mit angeborenen Herzfehlern (EMAH) mit und ohne Down-Syndrom: klinisches Spektrum und Langzeitverlauf}

B. Heinzl' ${ }^{1}$, T. Breuer' ${ }^{1}$, V. Gebauer ${ }^{1}$, R. Maier ${ }^{2}$, M. Köstenberger ${ }^{3}$, T. Rehak' ${ }^{1}$, P. Fritsch $^{1}$, A. Gamillscheg ${ }^{1}$, B. Nagel ${ }^{1}$

${ }^{1}$ Medizinische Universität Graz, Universitätsklinik für Kinder- und Jugendheilkunde, Klinische Abteilung für Pädiatrische Kardiologie, ${ }^{2}$ Medizinische Universität Graz, Universitätsklinik für Innere Medizin, ${ }^{3}$ Medizinische Universität Graz, Universitätsklinik für Kinder- und Jugendheilkunde

Hintergrund. Es existieren kaum Daten über Erwachsene mit angeborenen Herzfehlern (EMAH) und Down-Syndrom (DS).

Methodik. Bei allen EMAH mit DS und ohne Syndrom, die im Zeitraum 2008-2010 gesehen wurden, analysierten wir folgende Parameter retrospektiv: Herzfehler, NYHA-Stadien, Operationen, postoperative Komplikationen, Rhythmusstörungen, Echo-Restbefunde, kardiale Medikamente.

Ergebnisse. Die 32 EMAH mit DS [12w, 20m; Alter 28,8 (20,3-53,3) Jahre] hatten folgende Herzfehler: part. oder kompl. AVSD ( $\mathrm{n}=12 ; 3$ mit Eisenmenger), VSD $(n=9)$, ASD II $(n=4)$, TOF $(n=4)$, DORV $(n=2)$ und MKP $(n=1)$. Bei 26 Pat. wurden 32 Korrekturoperationen durchgeführt. Sieben davon waren Palliativoperationen vorausgegangen (BT-Shunt $n=3$, PA-Band $n=4$ ), bei einem Pat. wurde ein ASD II interventionell verschlossen. Im Erwachsenenalter erfolgten 2 der Korrekturoperationen (ASD I, ASD II), 1 Reoperation (Subaortenstenose bei AVSD) und 1 Intervention (Coilverschluss eines BT-Shunts). 6 Pat. hatten $5 \mathrm{~d}-17 \mathrm{~J}$. postoperativ eine Schrittmacher(SM)-pflichtige Rhythmusstörung (SSS: $\mathrm{n}=3$; kompletter AVB:n=3), 1 Pat. hatte postop. Vorhofflattern. 6 Pat. hatten einen hämodynamisch wirksamen Echo-Restbefund. Im Vergleich von EMAH ohne Syndrom [n=415 (204W, 211m); 26,5 (17,3-60,8) J.] zeigte sich, dass Patienten mit DS signifikant häufiger ein NYHA Stadium $\geq 2$ und häufiger SM-pflichtige Rhythmusstörungen $(\mathrm{p}<0,005)$ und seltener Reoperationen $(\mathrm{p}<\mathrm{O}, \mathrm{O} 1)$ als Pat. ohne DS hatten. Anzahl kardialer Medikamente, bedeutsame Echo-Restbefunde, und postop. Komplikationen zeigten keine Unterschiede zwischen den Gruppen.

Diskussion. Die Langzeit Prognose bei DS-Pat. mit operierten Herzfehlern ist gut. Sie haben signifikant schlechtere NYHA-Stadien, häufiger relevante SM-pflichtige bradykarde Rhythmusstörungen und seltener Reoperationen aufgrund hämodynamisch relevanter Restbefunde als Pat. ohne DS.
1.8 Langzeitverlauf von Patienten mit kongenitalen valvulären Pulmonalstenosen nach Ballonvalvuloplastie

S. Hettegger ${ }^{1}$, M. Koestenberger ${ }^{1}$, B. Heinzl' ${ }^{1}$, A. Fandl' ${ }^{1}$ K. Finding ${ }^{1}$, B. Nagel', T. Rehak ${ }^{1}$, A. Gamillscheg ${ }^{1}$, P. Fritsch ${ }^{1}$

${ }^{1} A b t$. für pädiatrische Kardiologie, Univ. Klinik für Kinder- und Jugendheilkunde, Medizinische Universität Graz, ${ }^{2}$ Univ. Klinik für Chirurgie, Medizinische Universität Graz

Einleitung. Die Ballonvalvuloplastie (BVP) ist bei Patienten mit angeborenen valvulären Pulmonalstenosen eine anerkannte therapeutische Intervention. Studien über den Langzeitverlauf dieser Patienten sind allerdings selten.

Methoden. 92 Patienten mit angeborenen valvulären Pulmonalstenosen bei denen eine BVP an der medizinischen Universität Graz zwischen 1986 und 2010 durchgeführt wurden, wurden retrospektiv analysiert.

Ergebnisse. Bei 91/92 Patienten konnte die Intervention komplikationslos beendet werden. Ein Patient erlitt während des Eingriffs Rhythmusstörungen. Ein Patient verstarb drei Monate postinterventionell nach einer Patch-Operation am zehnten postoperativen Tag. Bei 91 Patienten konnte der maximale systolische Gradient im Mittel von $50,0 \pm 22,2(15-133) \mathrm{mmHg}$ auf $19,8 \pm 12,1(0-56) \mathrm{mmHg}$ gesenkt werden, was einer mittleren Reduktion des Gradienten von $30,5 \pm 18,1 \mathrm{mmHg}$ entspricht. Bei 4 Patienten war vor der ersten Intervention eine erstgradige Pulmonlinsuffizienz (PI) diagnostiziert worden. Keiner der Patienten hatte eine höhergradige PI vor der ersten BVP. Nach der BVP war bei keinem Patienten eine höhergradige PI vorhanden, bei 5 Patienten (5,5\%) wurde eine erstgradige PI, festgestellt. Bei 9o/91 Patienten konnte im Mittel nach 113,7 $\pm 77,4$ (o-274) Monaten ein Followup durchgeführt werden. Der mittlere systolische Druckgradient der letzten Follow-up-Untersuchung betrug 20,4 $\pm 13,6$ (4-85) $\mathrm{mmHg}$. Bei $4 / 90(4,4 \%)$ Patienten war der Gradient $\geq 50 \mathrm{mmHg}$. Ein PI Grad von o, 1, 2, 3 wurde bei 59 (65,6\%), 23 (25,6\%), 7 (7,8\%), 1 (1,1\%) diagnostiziert. Bei $18 / 90$ (20,0\%) Patienten musste nach einem mittleren Intervall von $34,3 \pm 37,9$ (3-95) Monaten eine Re-BVP $(n=12)$ oder eine Operation $(n=6)$ durchgeführt werden. 4 dieser $18(22,2 \%)$ Patienten hatten die BVP bereits im Neugeborenenalter.

Schlussfolgerungen. Die BVP stellt eine sehr effektive und sichere therapeutische Intervention bei kongenitalen valvulären Pulmonalstenosen dar. Bei $20 \%$ der Patienten sind allerdings Re-Interventionen nötig. Höhergradige PI finden sich bei 10\% der Patienten.

\subsection{Rein interventionelle Therapie der Pulmonalatresie: Akuter- gebnisse und Follow-up}

E. Kitzmüller, A. Hanslik, E. Mlczoch, I. Michel-Behnke

Klinik für Kinder- und Jugendheilkunde, Abteilung für Pädiatrische Kardiologie, Medizinische Universität Wien

Einleitung. Neben der Standardversorgung mittels chirurgischem BTShunt stellt die interventionelle Eröffnung der Pulmonaklappenatresie (PA) eine Alternative dar. Passager ist häufig eine additive Perfusion der Pulmonalstrombahn erforderlich, die durch einen BT Shunt erreicht wird. Eine rein interventionelle Behandlung (BVP + Ductusstent) wird in der Literatur nur spärlich diskutiert.

Zielsetzung. Darstellung unserer Ergebnisse der ausschließlich interventionellen Behandlung der PA.

Methodik. Retrospektive Analyse.

Ergebnisse. Von 2004-2011 wurde bei 16 Pat (4w/12m) mit PA (4) oder funktioneller PA (12) interventionell (4-mal RFP+BVP, 12-mal BVP) eine antegrade Pulmonalperfusion erfolgreich hergestellt. Die Ballon-/ Klappenratio betrug im Median o,9 $(0,5-1,5)$ Bei 10 Pat war zur additiven Pulmonalperfusion ein Ductusstenting erforderlich. Das Alter beim Eingriff betrug im Median 2 Tage (1-42), das Gewicht 3,7 kg (1,8-4,9). Die Nachbeobachtungszeit betrug im Median 1,04a (4od bis 6,8a). Alle Pat überlebten den komplikationslosen Eingriff. 2 Pat benötigten eine Nach- 
dilatation der Pulmonalklappe nach 4,5 und 9 Monaten. Von primär 12 hypoplastischen rechten Ventrikeln zeigten 10 eine Normalisierung der Größenparameter; ein RV ist nach 2 Jahren grenzwertig klein, einer für eine Beurteilung noch zu früh nach der Intervention. 1o Pat haben keine oder eine triviale Pulmonalklappeninsuffizienz, 5 eine moderate und 1 eine höhergradige. Ein Reststenosegradient unter $30 \mathrm{mmHg}$ liegt bei 12 Pat vor, bei 4 unter $50 \mathrm{mmHg}$.

Schlussfolgerungen. Die ausschließlich interventionelle Behandlung der PA/kritischen PS ist technisch möglich. Eine biventrikulären Zirkulation ist auch bei primär hypoplastischen Ventrikeln häufig.

\subsection{Perkutaner Pulmonalklappenersatz - Melody - The Vienna Experience}

I. Michel-Behnke', E. Kitzmüller ${ }^{1}$, H. Gabriel ${ }^{2}$

${ }^{1}$ Abteilung Pädiatrische Kardiologie, Kinderherzzentrum, Medizinische Universität Wien, ${ }^{2}$ Abteilung Kardiologie, Medizinische Universität Wien

Hintergrund. Der perkutane Pulmonalklappenersatz (PPVI) durch klappentragende Stents stellt eine Alternative zur Reoperation der RVOT-stenose/-insuffizienz dar. Die Indikation zur Katheterintervention ist bei progredienter Druck- bzw. Volumenbelastung des rechten Ventrikels gegeben. Wir berichten über die Erfahrungen unseres Zentrums mit der Implantation der Melody-Klappe.

Patienten. Von 5/09-4/11 wurde bei 12 Patienten ein PPVI durchgeführt, $10 \mathrm{~m}, 2 \mathrm{w}$, Alter: $\mathrm{m}=20,3 \mathrm{~J}(10-37,8)$. Alle Patienten waren wegen Vitien voroperiert: Ross-Operation $(n=6)$, Fallot $(n=3)$, Pat-VSD $(n=2)$, Truncus $(\mathrm{n}=1)$. Gewicht: $\mathrm{m}=67,1 \mathrm{~kg}(39,3-96,5)$. Alle Patienten hatten einen Homograft in Pulmonalposition, die Zahl der Voroperationen lag bei 1-4. Neun Pat. hatten eine therapiebedürftige Stenose, zwei eine Insuffizienz und bei einem lag ein kombiniertes Pulmonalklappenvitium vor.

Methode. Die PPVI erfolgte transvenös über die V. femoralis. Vor Implantation wurde eine Koronardarstellung zum Ausschluss einer Interferenz mit dem RVOT vorgenommen. Die Stenose im RVOT wurde bei 9 Pat. vordilatiert. Bei allen Pat. erfolgte ein Prestenting. Die Klappenimplantation erfolgte nach Standardverfahren mit einem Ensemble-Deliverysystem.

Ergebnis. Alle Implantationen verliefen erfolgreich. Es wurden je 6 Pat. mit einem 20 bzw. $22 \mathrm{~mm}$ Ballon implantiert, eine Nachdilatation erfolgte bei 8 Pat. Der residuelle Druckgradient betrug 4-16 $\mathrm{mmHg}$ zum Ende der Untersuchung, eine triviale PI war bei 2 Patienten nachweisbar. Im Follow-up 2 Mo bis $2 \mathrm{~J}$ wurde kein Patient reinterveniert; der Echogradient im Doppler betrug 18-40 mmHg (med $22 \mathrm{mmHg}$ ). Bei 3 Patienten wurden nach 6 bzw. 12 Mo Stentfrakturen ohne Klappendysfunktion dokumentiert.

Schlussfolgerung. Der perkutane Pulmonalklappenersatz ist bei korrekter Indikationsstellung ein sicheres Verfahren. Das Prestenting trägt zur Reduktion von Stentfrakturen bei. Im mittelfristigen Verlauf weist die Stentklappe eine sehr gute Funktionalität auf.

\subsection{Akuter Myokardinfarkt bei einem Jugendlichen}

M. Mischkreu', C. Lichtenstein'; T. Ovsenk ${ }^{2}$; H. Krappinger ${ }^{2}$; I. Michel-Blenke, E. Kitzmüller ${ }^{3}$, P.A. Hauk ${ }^{3}$, R. Birnbacher

${ }^{1}$ Abteilung für Kinder- und Jugendheilkunde, LKH Villach, ${ }^{2}$ Medizinische Abteilung, LKH Villach, ${ }^{3}$ Abteilung für Kinderkardiologie, AKH Wien

Wir berichten über einen 15-jährigen Knaben, der mit dem Notarzt mit der Diagnose kardiogener Schock, vermutlich bei STEMI, an unsere pädiatrische Intensivstation eingeliefert wurde. Im EKG zeigten sich typische ST-Streckenhebungen über der gesamten Brustwand, sowie tiefe QS-Zacken von V1 bis V5. In der Echokardiographie keine anatomischen Auffälligkeiten, kein Pleuraerguss, globale milde Kontraktilitätsabschwächung ohne sichtbare lokale Wandbewegungsstörung. Aufgrund der Diskrepanz zwischen ausgeprägtem EKG-Befund, der mit einem ausgedehnten anteroseptalen Myokardinfarkt vereinbar war, und der geringen globalen Kontraktilitätsverminderung in der Echokardiographie sowie der Klinik wurde die wahrscheinlichere Diagnose einer fulminanten Myokarditis angenommen. In den weite- ren engmaschigen Kontrollen entwickelte sich dann eine hochgradige, lokalisierte Wandbewegungsstörung apicoseptal bei gleichbleibender stabilen Kreislaufsituation und gleichbleibenden EKG Veränderungen. Die bereits initial erhöhten Herzfermente stiegen weiter an.

Aufgrund dieser raschen Verschlechterung wurde der Patient $8 \mathrm{~h}$ nach Aufnahme an unserer Abteilung mit dem Hubschrauber an das AKH Wien verlegt. Die Herzkatheteruntersuchung zeigte einen Komplettverschluss der LAD. Eine Rekanalisierung des Gefäßes mittels lokaler Lyse und Ballonkatheterdilatation wurde versucht, aber unmittelbar post interventionem konnte keine komplette Wiederanfärbung der LAD dargestellt werden. Es erfolgte eine systemische Heparinisierung und Therapie mit Abciximab (Reopro ${ }^{\circ}$ ) für 12 Stunden. Der Patient blieb kardiorespiratorisch stabil: Die systolische Funktion zeigte eine progrediente Besserung. Eine Ursache für das seltene Ereignis eines Myokardinfarkts im Jugendalter konnte trotz umfangreicher Diagnostik bislang nicht gefunden werden.

Diskussion. Ein Myokardinfarkt im Kindes- und Jugendalter, ist außer bei angeborenen Fehlbildungen am Herzen (z. B. Bland-White-Garland-Syndrom), äußerst selten. Bei unserem Patienten ist die Ursache bisher noch nicht geklärt. Eine fulminante nekrotisierende Myokarditis kann dieselbe Symptomatik verursachen und kommt wesentlich häufiger vor. Eine „typische“ Symptomatik und ein typischer Verlauf des Myokardinfarkts im Kindes- und Jugendalter kann wegen der Seltenheit der Diagnose nicht festgelegt werden. Deshalb sollte, wenn ein Myokardinfarkt differentialdiagnostisch in Frage kommt, auch bei diskrepanten Befunden zum Ausschluss der lebensbedrohlichen Diagnose eine PCA überlegt und allenfalls rasch realisiert werden.

\subsection{3-jährige Schwangere mit Ventrikelseptumdefekt und pulmonaler Hypertension: what to do?}

T. Rehak' ${ }^{1}$ R. Maier ${ }^{2}$, A. Gamillscheg ${ }^{1}$, M. Koestenberger ${ }^{1}$, B. Nagel ${ }^{1}$ ${ }^{1}$ Univ.- Klinik f. Kinder- u. Jugendheilkunde, Klin. Abt. für Pädiatrische Kardiologie, Medizinische Universität Graz, ${ }^{2}$ Univ.- Klinik für Innere Medizin, Klin. Abt. für Kardiologie, Medizinische Universität Graz

Hintergrund. Die Schwangerschaft (Schw.) bei Pat. mit pulmonaler Hypertension (PHT) aufgrund angeborener Herzfehler ist mit hoher Mortalität verbunden. Erfahrungen über therapeutische Möglichkeiten während und nach SS sind begrenzt.

Fall. Eine $24 \mathrm{~J}$. alte schwarzafrikanische Patientin ohne kardiale Anamnese präsentiert sich in der 22. SSW erstmals in unserer EMAH-Ambulanz, nachdem ein Herzgeräusch aufgefallen war. Keine Zyanose $\left(\mathrm{S}_{\mathrm{a}} \mathrm{O}_{2} 94 \%\right)$, 3/6 Syst., NYHA II. Im Echo großer VSD mit bidirektionalem Shunt. Nach problemlosem Schw.-Verlauf und Sectio in PDA (37. SSW) Geburt einer gesunden Tochter. Postpartal Prostazyklin i.v. über 5 Tage, $\mathrm{O}_{2}$-Th. und Heparinisierung. 3 Monate p.p. Dyspnoe (NYHA III), der HK zeigt nahezu Systemdruck in der PA (PAP/SAP: 0,72), hoher RPI $\left(15 \mathrm{Uxm}^{2}\right)$. Unter $\mathrm{O}_{2}$ und NO Zunahme des L/R Shunts (QP/ QS von 1,5:1 auf 4:1) und Reduktion des RPI (3,3 Uxm²). Beginn einer Bosentan-Therapie, der 6MWT verbessert sich im Vgl. von 503 m (Kollaps) auf $560 \mathrm{~m}$. Eine erneute HK-Testung zeigt unter Bosentan einen niedrigeren RPI $\left(5,9 \mathrm{Uxm}^{2}\right)$ bei erhaltener Vasoreagibilität unter $\mathrm{O}_{2}$ (RPI $1 \mathrm{Uxm}^{2}$ ), der PA-Druck bleibt hoch (PAP/SAP: o,76). Entscheidung für operativen VSD-Teilverschluss mit $6 \mathrm{~mm}$-Lochpatch; der postop. Verlauf ist problemlos. Bosentan-Therapie für weitere $12 \mathrm{Mo}-$ nate, der 6 MWT verbessert sich auf $682 \mathrm{~m}$, die Pat. ist belastbarer (NYHA II). Eine HK-Testung unter Bosentan (12 Monate postop.) zeigt einen weiter abfallenden RPI $\left(4,4 \mathrm{Uxm}^{2}\right.$ in Ruhe, $2,9 \mathrm{Uxm}^{2}$ unter $\left.\mathrm{O}_{2}\right)$ bei niedrigerem PA Druck (PAP/SAP: o,4). 6 Monate nach Absetzen des Bosentan ist eine Gesichtsakne deutlich gebessert, Kopfschmerzen sind seltener und der $6 \mathrm{MWT}$ verlängert auf $721 \mathrm{~m}$.

Diskussion. Erwachsene mit PHT bei großem VSD ohne Eisenmenger-Physiologie können trotz nahezu Systemdruck eine gute Vasoreagibiltät ihrer Pulmonalgefäße haben. Dies kann eine unkomplizierte Schw. ermöglichen und mit Unterstützung eines Endothelin-Rezeptorantagonisten einen operativen VSD-Teilverschluss erlauben. 
1.13 Arrhythmien nach Fontanoperation: intrakardialer lateraler Tunnel vs. extrakardiales Conduit

T. Rehak' ${ }^{1}$, N. Zimmermann ${ }^{1}$, M. Köstenberger ${ }^{1}$, B. Heinzl ${ }^{1}$, P. Fritsch', B. Nagel', C. Wolf ${ }^{2}$, A. Gamillscheg'

'Univ.-Klinik f. Kinder- u. Jugendheilkunde, Klin. Abt. für Pädiatrische Kardiologie, Medizinische Universität Graz, ${ }^{2}$ Kinderabteilung, LKH Villach

Einleitung. Bei univentrikulären Herzfehlern ermöglicht die Fontanoperation als "definitive Palliation“ die Trennung des System- und Pulmonalkreislaufs. Früh postoperativ als auch im Langzeitverlauf stellen Arrhythmien eine wichtige Komplikation dar. Diese Studie sollte zeigen, ob die seit etwa 15 Jahren eingeführte Modifikation des extrakardialen Conduits (EC) eine Reduktion der Arrhythmieinzidenz im Vergleich zum früher durchgeführten intrakardialen lateralen Tunnels (ILT) erbracht hat.

Methoden. Retrospektiv wurden alle an unserer Abteilung in Langzeitbetreuung stehenden Fontan-Pat. $(\mathrm{n}=57)$ hinsichtlich Arrhythmien ausgewertet: 37 ILT-Pat., 20 EC-Pat. Das Alter der Pat. bei Fontankomplettierung betrug im Mittel 4,68 $\pm 3,77$ Jahre (ILT 4,60 $\pm 3,96$ Jahre, EC 4,84 $\pm 3,48$ Jahre; $p>0,8)$, die Nachbeobachtungszeit betrug im Mittel

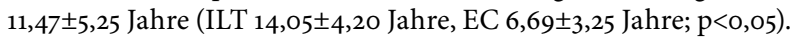

Ergebnisse. In der frühen postoperativen Phase $(<30$ Tage nach Fontan-Op) ergab sich kein signifikanter Unterschied zwischen der ILTund der EC-Gruppe, während sich im Langzeitverlauf in der ILTGruppe signifikant häufiger therapiebedürftige Arrhythmien zeigten (11/37 vs. $1 / 20 ; p<0,05)$. Von 7 Pat., die mit einem Schrittmacher versorgt werden mussten, stammt nur 1 Pat. aus der EC-Gruppe. Die Hämodynamik bei der postoperativen Herzkatheteruntersuchung (Druck im Tunnel, pulmonaler Gefäßwiderstand, Ventrikelfunktion) zeigte dagegen keinen signifikanten Unterschied zwischen den beiden Gruppen.

Zusammenfassung: Trotz des unterschiedlichen Nachbeobachtungszeitraums scheint die Einführung des EC eine Reduktion der Inzidenz relevanter Arrhythmien im Langzeitverlauf nach Fontan-Operationen zu bringen. Da sich die postoperative Hämodynamik zwischen den beiden Gruppen nicht unterscheidet, dürfte dieser Unterschied auf die ausgedehnte Vorhofchirurgie bei der ILT-Prozedur zurückzuführen zu sein.

\subsection{Der 6-Minuten-Gehtest bei gesunden Kindern und Jugend- lichen: Vergleichstest mit und ohne Laufmessrad}

J. Schneider ${ }^{1}$, R. Geiger ${ }^{1}$, V. Colleselli², M. Ruepp ${ }^{2}$, M. Rauchenzauner ${ }^{3}$, J. Stein 1

${ }^{1}$ Universitätsklinik für Kinder und Jugendliche - Kardiologie, Innsbruck, Österreich, ${ }^{2}$ Medizinische Universität Innsbruck, Innsbruck, Österreich, ${ }^{3}$ Neuropädiatrie, Schön Klinik Vogtareuth, Vogtareuth, Deutschland

Hintergrund. Zur Durchführung des 6-Minuten-Gehtests (6MWT) bei Kindern und Jugendlichen wurden bisher unterschiedliche Methoden angewendet. Diese prospektive Studie untersuchte potentielle Unterschiede in der 6-Minuten-Gehstrecke (6MWD) bei Verwendung eines Laufmessrades. Zusätzlich sollte die Bedeutung verschiedener Motivationsfaktoren durch Vergleiche zwischen Sport- und NichtSportschülern erfasst werden.

Methodik. Es wurden 317 (145 Mädchen, 172 Buben) gesunde Kinder und Jugendliche aus Tirol zwischen 6 und 15 Jahren aus regulären Schulen sowie aus Schulen mit Schwerpunkt Sport getestet. Diese führten den 6MWT randomisiert entweder mit oder ohne Laufmessrad durch. Zudem wurden die Resultate der Sport- und Nicht-Sportschüler miteinander verglichen, um potentielle Unterschiede zu erfassen.

Ergebnisse. Insgesamt war die 6MWD mit Laufmessrad signifikant höher als ohne $(690 \pm 78 \mathrm{~m}$ vs. $652 \pm 72 \mathrm{~m}, \mathrm{p}<0,001)$. Sportschüler erreichten im Mittel wesentlich bessere Resultate als Nicht-Sportschüler ( $727 \pm 62 \mathrm{~m}$ vs. $672 \pm 62 \mathrm{~m} ; \mathrm{p}<0,001)$. Wichtige Korrelationsfaktoren für die 6MWD waren, wie auch in anderen vergleichbaren Studien, Körperlänge und Nachtest-Herzfrequenz.
Schlussfolgerung. Die Verwendung eines Laufmessrades beeinflusst die $6 \mathrm{MWD}$ wesentlich. Dies ist erklärbar zum einen durch die präzisere Dokumentation der tatsächlich zurückgelegten Strecke und zum anderen durch die zusätzliche Motivation. Der Vergleich verschiedener 6MWT-Ergebnisse im Langzeitverlauf ist nur dann verlässlich, wenn durchgehend dieselbe Methodik angewendet wird.

\section{Dermatologie}

\subsection{Timolol - ein nicht selektiver Betablocker für die topische Behandlung des oberflächlichen, unkomplizierten infantilen Hämangioms}

E. Frey ${ }^{1}$, C. Mädel ${ }^{1}$, E. Moser ${ }^{2}$

${ }^{1}$ St. Anna Kinderspital, Wien, ${ }^{2}$ Universitätsklinik für Augenheilkunde, Wien

Die Behandlung des infantilen Hämangiom (IH) hat sich seit der Einführung des nicht selektiven Betablockers Propranolol sehr verändert. Die Indikationsstellung hat sich erweitert, es kamen jene hinzu, von denen ein rasches Wachstum, oder die Lokalisation ein deutliches Residuum erwarten lassen. Wie vielfach beschrieben, können auch wir diese äußerst positive Erfahrung unterstreichen: Wir haben eine 100\%ig Ansprechrate beobachtet, Nebenwirkungen traten selten auf und waren gut beherrschbar. Es bleiben aber eine Reihe von IH übrig, welche an weniger auffälligen Lokalisationen sind, bei sehr jungen Säuglingen gerade im Entstehen, und solche bei denen die Relation $\mathrm{zu}$ einer systemischen Therapie grenzwertig ist. Nachdem eine Kasuistik über die topische Applikation von Timolol publiziert wurde (Arch Ophtalmol 2010; 128:255-6), waren wir sehr interessiert dieses bei einer größeren Serie anzuwenden. Wir behandelten 38 Kinder ( $m: w$ 19:19) mit oberflächlichen IH mit topischen Timolol (Dispatim-Augengel) $0,1 \%$, welches primär zur Glaukomtherapie verwendet wird. Das Durchschnittsalter bei Therapiestart war $5 \mathrm{LM}$, bei 2 Pat. unmittelbar nach der Geburt. 16 Pat. hatten ein singuläres IH, 13 Patienten multiple Läsionen. Lokalisationen: 48\% Kopf/Hals Bereich, 38\% Stammbereich, 8\% obere Extremität und 6\% untere Extremität. 97\% der Pat. zeigten ein Ansprechen: bei $63 \%$ kam es bereits nach 1 bis 3 Wochen zu deutlichen Involutionszeichen, bei $34 \%$ zu einem Wachstumsstopp, was bei dieser Art von IH ein ausreichender Therapieerfolg ist. Es traten keine systemischen Nebenwirkungen auf, bei 2 Patienten beobachteten wir eine livide Verfärbung der umgebenden Haut. Timolol, ein nicht selektiver Betablocker, für die topische Anwendung, stellt in unserer Serie, übereinstimmend mit den Einzelberichten der Literatur, eine Behandlungsoption für oberflächliche, unkomplizierte IH dar. Die Indikationskriterien für eine systemische Therapie komplizierter Hämangiome werden dadurch nicht verändert.

\section{Endokrinologie und Diabetes}

\subsection{Transienter Pseudohypoaldosteronismus im Rahmen eines Harnwegsinfektes}

C. Diakos ${ }^{1}$, S. Riedl', E. Pracher ${ }^{1}$

${ }^{1}$ St. Anna Kinderspital, UKKJ, MUW, Wien, Österreich

Eine erhöhte Plasma-Aldosteron-Konzentration könnte das Ergebnis einer Renaltubulären-Aldosteron-Resistenz sein und kann sich als ein transienter Typ 1 Pseudohypoaldosteronismus mit Hyperkaliämie, Hyponatriämie und metabolische Azidose manifestieren.

Wir berichten über den Fall eines 8 Monate alten Säuglings, der eine Hyponatriämie und Hyperkaliämie im Rahmen einer akuten Harnwegsinfektion entwickelte. Das Kind wurde, in erster Linie aufgrund, inadäquater psychomotorischer Entwicklung schlechtem Allgemeinzustand und mangelnder Gewichtszunahme aufgrund einer monatelangen problematische Ernährungssituation mit Fehlernährung 
und inadäquate Kalorien Zufuhr ins Krankenhaus eingewiesen. Das Mädchen präsentierte sich in stark reduziertem Allgemeinzustand, Dystroph mit Ödemen an den Extremitäten aufgrund unzureichender Nahrungsaufnahme mit Appetitlosigkeit, Lethargie und Hypotonie.

Die Laborbefunde ergaben eine akute Harnwegsinfektion und eine Elektrolytentgleisung (schwere Hyponatriämie und Hyperkaliämie) in Verbindung mit einer ausgeprägten Hyperaldosteronemie. Die Elektrolytentgleisung wurde mit entsprechend adaptierter parenteraler Flüssigkeitszufuhr korrigiert. Die Harnwegsinfektion wurde mit Amoxicillin mit Clavulannsäure behandelt. Der pathologisch erhöhte AldosteronSpiegel war im Laufe der Behandlung rückläufig und der Hypoaldosteronismus erwies sich als transient. Der Nahrungsaufbau wurde, Initial auch über eine Magensonde mit Pregomin durchgeführt. Die MCU Untersuchung ergab eine Dilatation des Nierenbeckens mit einen Megaureter links und einem vesikoureteralem Reflux dritten Grades. Ein transienter Typ 1 Pseudohypoaldosteronismus sollte als mögliche Differenzialdiagnose in Betracht gezogen werden, wenn sich im Rahmen eines Harnwegsinfektes ausgeprägte Elektrolytstörungen nachgewiesen werden.. Besondere Aufmerksamkeit ist geboten, weil klinische Anzeichen zunächst unspezifisch sein können, wie es der Fall bei unserer Patientin war.

\subsection{Pitfalls in der Diagnostik des MODY Diabetes 2}

\section{Fritsch', G. Berger ${ }^{2}$, T. Hörtenhuber ${ }^{3}$, B. Rami ${ }^{3}$, E. Schober ${ }^{3}$}

${ }^{1}$ Abteilung für Neonat, Abteilung für Pädiatrische Pulmologie, Allergologie und Endokrinologie, Universitätsklinik für Kinder- und Jugendheilkunde, Wien, ${ }^{2}$ Abteilung für Pädiatrische Pulmologie, Allergologie und Endokrinologie, Universitätsklinik für Kinder- und Jugendheilkunde, Wien, ${ }^{3}$ Abteilung für Neonatologie, Pädiatrische IntensivAbteilung für Pädiatrische Pulmologie, Allergologie und Endokrinologie, Universitätsklink für Kinder- und Jugendheilkunde, Wien

Hintergrund. „Maturity-onset diabetes of the young“ (MODY) ist eine monogenetische Form von familiärem frühmanifestierendem Diabetes, der auf Mutationen in einem von zumindest 7 verschiedenen Genen basiert. Viele MODY-Fälle werden initial inkorrekt als Typ1- oder Typ-2-Diabetes diagnostiziert. Wir berichten über 2 Fälle mit „Hindernissen“ in der Diagnostik.

Fall 1. Die Patientin wurde im Alter von 1 Jahr bei wiederholt erhöhtem BZ (bis $290 \mathrm{mg} \%$ ), Gewichtsabnahme, Polyurie und Polydipsie unter dem Verdacht auf Typ-1-Diabetes (T1DM) auf Insulin eingestellt. Bei negativen Inselzell-AK und autosomal dominant erscheinendem Erbgang für Diabetes wurde eine Diagnostik auf MODY 2/3 eingeleitet. Auf Grund einer initial als Mutation beschrieben Veränderung des HNF1a Gens wurde die Diagnose MODY 3 gestellt und die Therapie von Insulin auf Sulfonylharnstoff umgestellt. Eine neuerliche molekulargenetische Untersuchung zeigte eine neu entdeckte Mutation des GCK Gens (MODY 2), die ursprünglich beschriebene Veränderung im HNF1a-Gen erwies sich als Polymorphismus ohne Krankheitswert. Die Therapie mit Sulfonylharnstoff konnte ohne Auswirkung auf den $\mathrm{HbA1C}(<6,5 \%)$ beendet werden.

Fall 2. Bei der Abklärung von Kopfschmerzen zeigte sich bei dem 10-jährigen Patienten ein Zufallsbefund mit BZ > 200 mg \%. In der Familienanamnese fand sich bei Mutter und Schwester ein insulinpflichtiger TDiM. Initial erfolgte eine Einstellung auf Insulin. Die InselzellAK waren negativ und es bestand eine hohe Insulinrestsekretion. Die molekulargenetische Untersuchung zeigte sich bei allen 3 eine Mutation im HNF1a-Gen (MODY 3). Der Patient wurde erfolgreich auf eine Therapie mit Sulfonylharnstoffen umgestellt.

Konklusion. Bei positiver Familienanamnese, nicht nachweisbaren Inselzell-AK, aber auch bei unüblich milder Diabetesmanifestation sollte das Vorliegen eines MODY erwogen werden, da die richtige Diagnose sowohl für die Vorhersage des klinischen Verlaufs als auch für die geeignete Therapie essenziell ist.

\subsection{Normalisierung der Thromboseneigung von übergewichti- gen Kindern nach "lifestyle intervention"}

P. Fritsch ${ }^{1}$, M. Fritsch' ${ }^{1}$, B.Heinzl ${ }^{1}$, M. Köstenberger ${ }^{1}$, B. Nagel ${ }^{1}$, T. Rehak ${ }^{1}$, A. Gamillschec' ${ }^{1}$ W. Muntean' ${ }^{1}$, T. Reinehr ${ }^{2}$

${ }^{1}$ Klinische Abteilung für päd. Kardiologie, Universitätsklinik für Kinderund Jugendheilkunde, Medizinische Universität Graz, ${ }^{2}$ Vestisches Krankenhaus für Kinder- und Jugendheilkunde, Universität Witten/Herdecke

Einleitung. Übergewicht bei Erwachsenen ist mit einem erhöhten Thromboserisiko und dadurch mit einem erhöhtem Risiko für kardiovaskuläre Erkrankungen assoziiert.

Methoden. Wir untersuchten daher prospektiv 27 übergewichtige Kinder. Es wurden der SDS-BMI, Fibrinogen, endogenem Thrombinpotenzial (ETP) zu Beginn der Studie und nach einem Jahr , lifestyle intervention" mittels Ernährungsberatung, Bewegungstherapie und psychologischer Unterstützung bestimmt (mittleres Alter: 11,9 $\pm 2,4$ Jahre, $45 \% \mathrm{w}$, Median BMI 27,5 $\pm 5,6 \mathrm{~kg} / \mathrm{m}^{2}$, Medain SDS-BMI 2,31 $\pm 0,48$ ) Weiters wurden eine Kontrollgruppe von 50 gesunden Kindern untersucht. Ergebnis. Die übergewichtigen Kinder zeigten signifikant erhöhtes Fibrinogen und ETP im Vergleich zu gesunden Kindern. Nach signifikanter Gewichtsreduktion der übergewichtigen Kinder $(-0,45 \pm 0,22$ SDS-BMI) zeigten sich auch eine Normalisierung der erhobenen Gerinnungsparameter (Reduktion von Fibrinogen und ETP).

Schlussfolgerung. Bei übergewichtigen Kindern besteht eine signifikant erhöhte Thromboseneigung. Diese Veränderungen normalisieren sich nach Gewichtsverlust durch „lifestyle intervention“.

\subsection{Neurokognitive Leistung und strukturelles zerebrales MRT bei Kindern und Jugendlichen mit Diabetes mellitus Typ 1}

T. Giner', S. Pixner', M. Starke2, S. Zotter', D. Meraner', K. Egger², M. Scho$\mathrm{cke}^{2}$, L. Kaufmann ${ }^{3}, \mathrm{~S}$. Hofer ${ }^{1}$

${ }^{1}$ Medizinische Universität Innsbruck, Abteilung für Kinder- und Jugendheilkunde, ${ }^{2}$ Medizinische Universität Innsbruck, Abteilung für Radiologie, ${ }^{3}$ UMIT Hall in Tirol

Fragestellung. Neurokognitive Leistungen bei Kindern und Jugendlichen mit Diabetes mellitus Typ 1 (DM1) können durch schwere Hypoglykämien beeinträchtigt werden. Unsere Hypothese ist es, dass auch chronische Hyperglykämien bei Diabetes mellitus zu Veränderungen der neurokognitiven Leistungen und zerebralen Struktur führt.

Methoden. An 30 Kindern und Jugendlichen mit DM1 (mittleres Alter 14,3/SD 3,9) und 19 gesunden Kontrollkindern (mittleres Alter 13,0 Jahre/SD 3,2) wurden PC-gesteuerte Testverfahren zur Erfassung (prä-) frontaler (Arbeitsgedächtnis/Aufmerksamkeit, kognitive Flexibilität) und temporaler (Merkfähigkeit) Funktionsbereiche und ein zerebrales strukturelles MRT ("voxel-based morphometry" und "diffusion tensor imaging") durchgeführt. Die Patienten mit DM1 wurden in 2 Gruppen (Gruppe 1: HbA1c $\leq 7,9 \%$ und Gruppe 2: HbAic $\geq 8$,0\%) eingeteilt und untereinander sowie mit der gesunden Kontrollgruppe verglichen.

Ergebnisse. 1. Behaviorale Daten: Es zeigten sich signifikante Gruppenunterschiede bezüglich der Bearbeitungsgenauigkeit bei einer Marker-Aufgabe zur Erfassung des räumlichen Arbeitsgedächtnisses. Die Gruppenunterschiede waren unabhängig von Alter und Bearbeitungsgeschwindigkeit. 2. Strukturelle Daten: Signifikante Gruppenunterschiede zeigten sich bei der strukturellen Bildgebung, die Kontrollgruppe wies ein höheres Totalvolumen der grauen und weißen Hirnsubstanz auf. 56\% der neurokognitiven Leistungsvarianz waren erklärbar durch Erkrankungsdauer, Alter bei Diagnose und Volumen der weißen Hirnsubstanz im Uncus.

Schlussfolgerung. Diese Daten stärken die Hypothese, dass chronische Hyperglykämie bei Kindern und Jugendlichen mit Diabetes zu neurokognitiven Dysfunktionen und strukturellen zerebralen Veränderungen führen. Vor allem mediale Strukturen im Temporallappen (Uncus) spielen eine wichtige Rolle bei der Prädiktion der neurokognitiven Leistungsvarianz. 


\subsection{Auftreten von pathologischer Nervenleitgeschwindigkeit bei Kindern und Jugendlichen mit Diabetes mellitus Typ I}

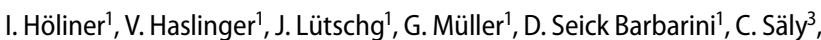
J. Fußenegger ${ }^{2}$, U. Zanier ${ }^{2}$, B. Simma'

${ }^{1}$ Abteilung für Kinder- und Jugendheilkunde, Akademisches Lehrkrankenhaus, Feldkirch, ${ }^{2}$ Abteilung für Kinder- und Jugendheilkunde, Krankenhaus der Stadt Dornbirn, ${ }^{3}$ Abteilung für Innere Medizin, Akademisches Lehrkrankenhaus, Feldkirch

Hintergrund. Diabetes mellitus (DM) ist eine der weltweit häufigsten und weitest verbreiteten Krankheiten. Eine der Langzeitfolgen der Erkrankung stellt die diabetische Neuropathie (DNP) dar, wobei es bei Kindern und Jugendlichen keine genauen Zahlen über deren Prävalenz gibt. Die Werte divergieren sehr stark und belaufen sich auf Angaben zwischen 5 und $100 \%$. Für diabetische Folgeerkrankungen bei Kindern und Jugendlichen gibt es klare Richtlinien über die Art und Häufigkeit der Untersuchung im Rahmen von jährlichen Kontrollen, festgehalten in den ISPAD (International Society for Pediatric and Adolescent Diabetes) Clinical Practice Consensus Guidelines. Für die DNP gibt es keine nationalen und internationalen Vorgaben; weder für die geeignete Untersuchungsmethode, den Untersuchungsbeginn, noch die zeitlichen Intervalle zwischen den Untersuchungen.

Ziel. Ziel dieser Studie ist es, mittels Messung der Nervenleitgeschwindigkeit (NLG) zu untersuchen, wie viele der Kinder und Jugendlichen mit Diabetes mellitus Typ I an einer DNP leiden und wie die Ergebnisse mit dem neurologischen Status, der Blutzuckereinstellung (HbA1c), und anderen Folgeerkrankungen (Retinopathie und Nephropathie) korrelieren.

Ergebnisse. Wir fanden bei 15 der 39 Patienten (38\%) eine pathologische NLG als Hinweis auf eine DNP. Nur 4 dieser 15 Patienten (27\%) zeigten einen auffälligen neurologischen Status. Eine Korrelation zu mittlerem HbA1c, Diabetesdauer, Alter der Patienten und Retinopathie bzw. Nephropathie fanden wir nicht.

Schlussfolgerung. Die vorliegenden Befunde zeigen, dass die DNP bereits im Kindes und Jugendalter eine hohe Prävalenz aufweist. Auch bei fehlenden Symptomen und unauffälligem neurologischem Status kann letztendlich nur durch die Untersuchung der NLG eine DNP erfasst werden.

\subsection{Diabetes im 4. Lebensmonat - ein seltener Fall von perma- nenten neonatalem Diabetes Mellitus}

T. Hörtenhuber ${ }^{1}$, M. Fritsch', G. Berger', S. E. Flanagan², S. Ellard³ , E. Schober ${ }^{1}$

${ }^{1}$ Medizinische Universität Wien, Universitätsklinik für Kinder- und Jugendheilkunde, ${ }^{2}$ Peninsula College of Medicine and Dentistry, Institute of Biomedical and Clinical Science, Exeter, UK, ${ }^{3}$ Royal Devon \& Exeter NHS Hospital, Department of Molecular Genetics, Exeter, UK

Hintergrund. Der permanente neonatale Diabetes mellitus (PNDM) ist eine selten Erkrankung mit einer geschätzten Inzidenz von 1 auf 215.000-500.000 Geburten. Meist beruht der PNDM auf einer $\mathrm{Mu}-$ tation innerhalb eines von drei Genloci: in den Genen KCNJ11 (ca. $30-50 \%$ aller Fälle) und ABCC8 (in ca. 10-15\%), die für Kir6.2 bzw. SUR1-Untereinheiten des ATP-sensitiven K+-Kanals kodieren, sowie im Insulin-kodierenden Gen INS in rund 15-20\% der PNDM-Fälle.

Kasuistik. Bei einem 4 Monate alten, männlichen Säugling wurden im Rahmen einer Pneumokokkenimpfung nach einer Verschlechterung des Allgemeinzustands, eine ausgeprägte Glukosurie und ein Blutzucker von über $300 \mathrm{mg} / \mathrm{dl}$ festgestellt. Mit der Verdachtsdiagnose eines neumanifestierten Typ-1-Diabetes mellitus, wurde der Patient an der Diabetes-Ambulanz vorstellig, der HbAic-Spiegel betrug 8,9\%. In der Familienanamnese zeigte sich, dass auch der Vater seit seinem 3. Lebensmonat als Typ-1-Diabetiker mit Insulin behandelt wird. Diese Konstellation bzw. das Manifestationsalter machten eine monogenetische Form bzw. einen PNDM wahrscheinlich und es wurde eine genetische Abklärung eingeleitet (Univ. Exeter). Kind und Vater zeig- ten sich heterozygot für eine neue Missense-Mutation des INS Gens (p.Y5oC), welche zu einem Funktionsverlust des endogenen Insulins durch falsche Faltung des Proteins führt. Diese Form des PNDM ist insulinpflichtig und es wurde daher mit einer sensorunterstütze Insulinpumpentherapie begonnen, bei einem Insulinbedarf von rund o,6 IE/ $\mathrm{kg}$, darunter kam es zu einer zufriedenstellenden Blutzuckereinstellung bei stabilem Allgemeinzustand und guter Gewichtszunahme.

Schlussfolgerung. Nach Empfehlung der ISPAD sollte bei einem Auftreten von Diabetes mellitus innerhalb der ersten 6 Lebensmonate eine monogenetische Diabetes-Form in Betracht gezogen und eine molekulargenetische Abklärung angestrebt werden, da im Falle einer $\mathrm{Mu}$ tation des KCNJ11 Gens ein Wechsel von Insulin auf Sulfonylharnstoff versucht werden kann.

\subsection{Reverse hybridization test strips for detection of common CYP21A2 mutations in dried blood spots from newborns with elevated 17-OH progesterone}

S. Riedl1', S. Nemeth ${ }^{1}$, G.Kriegshäuser ${ }^{2}$, S. Baumgartner-Parzer ${ }^{3}$, F. Waldhauser $^{1}$, C. Oberkanins ${ }^{2}$

${ }^{1}$ Universitätsklinik für Kinder- und Jugendheilkunde, Medizinische Universität Wien, ${ }^{2}$ ViennaLab Diagnostics $\mathrm{GmbH}$, Wien, ${ }^{3}$ Universitätsklinik für Innere Medizin III, Abteilung für Endokrinologie und Stoffwechsel, Medizinische Universität Wien

The average incidence of classical CAH is about 1 in 15,00o births worldwide, and more than $90 \%$ are caused by mutations in the $\mathrm{CYP}_{21} \mathrm{~A}_{2}$ gene encoding steroid 21-hydroxylase. In the majority, low/abolished residual enzymatic activity leads to a severe clinical phenotype (salt-wasting $\mathrm{CAH}$ ) due to aldosterone deficiency. Newborn screening programs based on 17-hydroxyprogesterone (17-OHP) levels have been introduced in various countries to identify affected babies prior to developing life-threatening salt-wasting crisis. Since neonatal 17-OHP screening has a considerable false positive recall rate, causing a substantial economical burden and emotional stress for parents, concurrent genetic testing for $\mathrm{CYP}_{21} \mathrm{~A}_{2}$ defects to corroborate or exclude $\mathrm{CAH}$ diagnosis would be desireable. We have therefore developed a reverse-hybridization assay for rapid and simultaneous analysis of common CYP21 A2 mutations from dried blood spots. The StripAssay, applicable for use in dried blood spots, works as follows: The entire CYP21 $\mathrm{A}_{2}$ gene is amplified in two overlapping fragments using PCR primers that will not co-amplify the highly homologous pseudogene. Biotinylated amplicons are hybridized under exactly defined stringency to a teststrip presenting a parallel array of allele-specific oligonucleotide probes for the following 11 mutations: $\mathrm{P}_{3} \mathrm{OL}$, IVS-2 A/ $\mathrm{C}>\mathrm{G}, 8$ bp del (exon 3), I172N, I236N/V237E/M239K (,cluster"), V281L, F306 insT, Q318X, R356W, P453S and R483 P. Specifically bound PCR products are detected using enzymatic colour reaction. The entire procedure from DNA extraction to the interpretation of results takes less than 6 hours.

The new CAH StripAssay was validated in a series of DNA samples from known CYP21A2 genotypes. Automated instrumentation and use of a scanner-based software tool (StripAssay Evaluator) for recording and interpreting results may further contribute to making the StripAssay a useful tool in CAH newborn screening programs.

\subsection{Severe virilization of a 46,XX newborn and her mother du- ring pregnancy: a novel case of aromatase deficiency}

S. Riedl ${ }^{1}$, A. Springer ${ }^{2}$, J.Huber ${ }^{3}$

${ }^{1}$ Universitätsklinik für Kinder- und Jugendheilkunde, Medizinische Universität Wien, ${ }^{2}$ Universitätsklinik für Chirurgie, Abteilung für Kinderchirurgie, Medizinische Universität Wien, ${ }^{3}$ Universitätsklinik für Frauenheilkunde, Abteilung für Gynäkologische Endokrinologie und Reproduktionsmedizin, Medizinische Universität Wien

A female newborn, $3^{\text {rd }}$ child from Turkish consanguineous parents, presented with Prader stage 4-virilized external genitalia. Starting 
from the second trimester, the mother had developed progressive hirsutism, acne, and deepening of her voice. Two weeks after birth, the mother's LH and FSH were suppressed whereas testosterone, androstendione, 17-hydroxy progesterone, and estradiol were extremely high, declining rapidly to approximately $1 / 10$ of their initial level a week later. Sonography revealed markedly enlarged ovaries with PCOS morphology. An adrenal/ovarian virlilizing tumour was ruled out by MRI. The baby had a 46,XX karyotype and was negative for SRY. A normal uterus could be visualized on sonography. Biochemically, the girl showed constantly elevated LH and FSH without measurable estradiol at 3, 5, and 7 weeks. Initial testosterone was $0.37 \mathrm{ng} / \mathrm{ml}$ and anti mullerian hormone undetectable. Cortisol rise following $125 \mu \mathrm{g}$ of synacthen was normal. The urinary steroid profile showed normal excretion of $\mathrm{C}_{21}$ and $\mathrm{C} 17$ metabolites. Molecular genetics revealed a homozygous Glu210Lys mutation in exon 5 of the CYP19A1 gene (chromosome 15q21). In conclusion, this is the $12^{\text {th }}$ case of aromatase deficiency in a $46, \mathrm{XX}$ individual reported so far. Excess of fetal androgens and estrogen deficiency due to a lack of placental aromatization led to the combination of virilized external genitalia in the baby (Prader 4) and acne, hirsutism, and voice deepening in the mother. Interestingly, the mother's ovaries were enlarged showing PCOS morphology and produced high amounts of androgens even some weeks after birth. We propose that increased fetal LHRH, driven by estrogen deficiency, may have crossed the placenta and stimulated maternal gonadotrophins, eventually leading to PCOS associated with autonomous overproduction of androgens that decreased with time. To our knowledge, the changes observed in the mother during the first weeks after birth have not been documented yet.

\section{Ernährung}

\subsection{Frühkindliche Gedeihstörung: organische oder nichtorgani- sche Ursachen?}

A. Käfer, G. Zoder, H. Fürnkranz, A. Göttling, E. Bauer-Wais, A. Lischka

Kinderklinik Glanzing, Wilhelminenspital der Stadt Wien

Im Alter von 8,5 Wochen wird Lukas wegen „Nahrungsverweigerung“ zugewiesen. Er ist zu diesem Zeitpunkt in Krisenpflege, da „der Patient bei der Mutter nicht trinkt“ (JA). Die Trinkmengen werden mit 10 bis $40 \mathrm{ml} / \mathrm{MZ}$ (Beba HA Pre) von der Pflegemutter angegeben. Es besteht ein Gewichtsstillstand über 4 Wochen bzw. ein Perzentilensprung um 2, also eine frühkindliche Gedeihstörung. Das Gewicht bei Aufnahme beträgt $3295 \mathrm{~g}(<3 . \%), \mathrm{I}=51,5 \mathrm{~cm}, \mathrm{KU}=36 \mathrm{~cm}$; im Vgl. das GG $2660 \mathrm{~g}$ (25.\%), I= $48 \mathrm{~cm}$ (25.-50.\%), KU=34 cm (50.-75.\%); FG 35+5. SSW

Der Patient zeigt ein sehr auffälliges Trinkverhalten (beim Trinken kommt es zum Zurückfließen von Milch aus dem Mund) sowie einen in- und exspiratorischen Stridor, die durchgeführten Untersuchungen bleiben jedoch ohne pathologischen Befund. Die Ernährungsregime wird (mehrmals), optimiert und Lukas kann nach 12 Tagen mit einem Gewicht von 3555 g zurück zur Pflegemutter.

Eine Woche später (mit 11 Wochen) wegen ausbleibender Gewichtszunahme neuerliche stationäre Aufnahme (3555 g). Bei V. a. Kuhmilchunverträglichkeit wird auf Pregomin umgestellt. Da Lukas nun auch noch erbricht und sich beim Füttern opisthoton überstreckt, wird das Regime wieder geändert (8 MZ, Rückkehr zu Beba HA Pre). Weitere Untersuchungen inkl. EEG folgen. Ein intercurrenter Atemwegsinfekt verschlechtert die Situation zusätzlich, so dass eine Woche nach Aufnahme die Nahrung fast ausschließlich sondiert wird.

Bei V. a. NOFT (nichtorganischen Gedeihstörung, infantile Anorexie) wird die Verlegung auf unsere Säuglingspsychosomatik geplant. Nun folgt eine rasch progrediente Verschlechterung der Atmung (Stridor, Einziehungen) und der Ernährungssituation, weshalb der Pat. An eine kinderchirurgische Abteilung zur Bronchoskopie transferiert wird. Dort findet man eine den Larynx einengende Zungengrundzyste, die entfernt wird.
Der postoperative Nahrungsaufbau gelingt problemlos, 3 Wochen nach der Operation kann Lukas mit einem Gewicht von $4470 \mathrm{~g}$ gemeinsam mit seiner Mutter das Spital verlassen.

\subsection{Ernährung des Säuglings und Kleinkindes in den ersten zwei Lebensjahren in Tirol}

D. Karall' ${ }^{1}$ A. Heichlinger ${ }^{2}$, U. Kiechl-Kohlendorfer ${ }^{1}$, S. Baumgartner Sigl ${ }^{1}$, K. Hof ${ }^{1}$, M. Huber ${ }^{1}$, S. Wimmer ${ }^{1}$, B. Wild ${ }^{3}$, S. Scholl-Bürgi ${ }^{1}$

${ }^{1}$ Medizinische Universität Innsbruck, Department für Kinder- und Jugendheilkunde, Univ.-Klinik für Pädiatrie IV, Neonatologie, Neuropädiatrie und angeborene Stoffwechselstörungen, Innsbruck, ${ }^{2}$ Fachhochschule für Gesundheit, Bachelorstudiengang Hebamme, Zentrum für Gesundheitsberufe Tirol GmbH, Innsbruck, ${ }^{3}$ UMIT (Private Universität für Gesundheitswissenschaften, Medizinische Informatik und Technik, Hall in Tirol

Einleitung. Zur Ernährung des Säuglings und Kleinkindes liegen in Tirol nur wenig Daten vor. Im Hinblick auf präventivmedizinische Aspekte (z. B. Allergien, Übergewicht, metabolisches Syndrom) wurden Daten zur Evaluierung der Umsetzung der bestehenden Empfehlungen erhoben.

Ergebnisse. Von Juni und Dez 2009 wurden 555 Mutter-Kind-Paare aus 8/9 geburtshilflichen Abteilungen in Tirol eingeschlossen. Erhoben wurden Daten nach dem Erstkontakt im Krankenhaus in regelmäßigen Abständen per telefonischem Interview (im Alter von $0,5,1,5,3,6$, 12, 18 und 24 Monaten). 66,9\% der Mütter waren 26-35 Jahre alt, 96,2\% in Partnerschaft lebend. Der initiale Stillbeginn betrug 89,6\%, die mittlere Stilldauer 4,7 Monate (o-15 Monate). Mit 6 Monaten wurden 10,5\% der Kinder ausschließlich gestillt. Der mittlere Beikostbeginn war bei 5,5 Monaten (3-8 Monate). In den ersten Tagen wurden 58,6\% der Neugeborenen zugefüttert. Die häufigsten dafür angegebenen Gründe waren zu wenig Muttermilch (20,5\%), unruhiges Kind (11,6\%), medizinische Probleme des Neugeborenen (9,8\%). Es gab keine Unterschiede zwischen den BFHI („baby friendly hospital initiative“) zertifizierten Krankenhäusern und denen ohne Zertifizierung.

Konklusion. Die aktuellen Empfehlungen, die ausschließliches Stillen in den ersten (vier bis) sechs Lebensmonaten mit anschließendem „teilweise stillen“ bis über das erste Lebensjahr hinaus empfehlen, werden in Tirol nicht vollständig umgesetzt - trotz hoher initialer Stillprävalenz. Insgesamt sind die Stillfrequenzen in Tirol denen im mitteleuropäischen Raum vergleichbar. Eine Steigerung der Stillrate in den letzten 15 Jahren ist nicht erkennbar. Auffällig ist die hohe Zufütterungsrate in den ersten Tagen, die nicht der empfohlenen medizinisch notwendigen Indikation entspricht. Frühes Zufüttern wirkt sich signifikant auf die Stilldauer aus, daher ist ein Überdenken der Routine in diesem Bereich angezeigt. Es erstaunt, dass sich keine Unterschiede zwischen BFHI und Nicht-BFHI-Abteilungen zeigen. Der Beikostbeginn entspricht großteils den aktuellen Empfehlungen.

\subsection{Preliminary Results. the effects of a soy protein dietary regime in pediatric patients affected by heterozygous familial hypercholesterolemia}

A. KreißI, M. Fritsch, G. Skacel, E. Aldover-Macasaet, K. Widhalm

Klinik für Kinder- und Jugendheilkunde, Medizinische Universität Wien

Background. Over the last 30 years, several studies have demonstrated that soy protein is effective in reducing increased total cholesterol (TC) and LDL cholesterol (LDL-C) levels in hypercholesterolaemic patients. This pilot study investigated the effects of a soy substituted diet on serum lipid levels in children and adolescents with heterozygous familial hypercholesterolemia (heFH).

Subjects/Methods. The results show a sample of 9 patients (6 male, 3 female) who were affected with familial hypercholesterolemia, with a mean age of $8.78 \pm 4.15$ years and a mean BMI $16.27 \pm 3.15 \mathrm{~kg} / \mathrm{m}^{2}$. The dietary intervention was based on a low-fat-modified dietary regime and additionally the patients started with a soy protein substitution of 
$0.38 \pm 0.29 \mathrm{~g}$ soy protein $/ \mathrm{kg}$ BW/d. To improve long-term compliance, commonly available soy drinks and desserts of the same brand were used for 13 weeks. Adherence to the soy intervention strategy was assessed by measuring the urinary isoflavone excretion via plasma and urine samples and by keeping self-reported soy intake logbooks, and dietary food records, over 7 consecutive days, including 1 weekend day. Data analysis was performed with a paired sample T-test and was evaluated with the SPSS, version 16.o.

Preliminary Results. This soy-substituted diet significantly decreased TC by $-17 \mathrm{mg} / \mathrm{dl}(\mathrm{p}<0.001)$ and LDL-C by $-14 \mathrm{mg} / \mathrm{dl}(\mathrm{p}=0.004)$ after 3 months, respectively. During soy treatment, in 5 out of 9 patients, LDL cholesterol dropped down under the cut-off level, which is considered to be the borderline for the introduction of drug treatment $(160 \mathrm{mg} / \mathrm{dl})$.

\subsection{Stabiles DOWN des Körpergewichtes und ein steigendes UP der Lebensqualität}

\section{A. Maria Radinger ${ }^{1}$, E. Hecher ${ }^{2}$ \\ ${ }^{1}$ Klinikum Klagenfurt am Wörthersee, Abteilung für Kinder- und Jugend- heilkunde, ${ }^{2}$ Verein OMEGA, Bereich Psychologische Betreuung bei Jugendlichen}

Wie Studien bisher belegen, hängt Adipositas von mehreren Faktoren ab, wie genetische Disposition oder falsche Essgewohnheiten. Die Folgen können sich zeigen durch ein vermindertes Selbstwertgefühl und ein negatives Körperbild, was eine verminderte Lebensqualität zur Folge haben kann. Einige Ergebnisse weisen auch darauf hin, dass die Emotionsregulation beim Essverhalten eine Rolle spielt. Das Ziel dieser Intervention ist es in erster Linie die Lebensqualität in unterschiedlichen Lebensbereichen wie Körperwahrnehmung, Essgewohnheiten, soziale Kontakte und Leistungsfähigkeit zu erhöhen. Ein schulbegleitendes Interventionsprogramm mit Inhalten wie Bewegungsmotivation, Psychologische Betreuung und Ernährungsberatung wurde innerhalb 6 Monaten bei adipösen Kinder und Jugendlichen im Alter zwischen 7 und 16 Jahren in Graz angeboten. Eine Datenerhebung zu Beginn und am Ende der Intervention wurde in Bereichen der sportphysiologischen Leistung und klinisch-psychologischen Skalen zu Adipositas (AD-EVA), sowie der Lebensqualität (ILK) und der selbstwahrgenommenen sozialen Kompetenzen (K-FSK) durchgeführt, als auch eine ärztliche Untersuchung mit der Erhebung des BMI und der Blutfettwerte. Die Ergebnisse weisen darauf hin, dass die Lebenszufriedenheit tendenziell gesteigert werden konnte sowie die selbstwahrgenommenen sozialen Kompetenzen signifikant zunahmen als auch tendenziell das Selbstwertgefühl. Eine Abnahme des BMI konnte nicht erzielt werden. Auch die Eltern konnten von der Intervention erkennbar an der angegebenen Lebensqualität profitieren. Schulstress und mangelnde Zeitressourcen waren vermutlich hemmende Faktoren für den Erfolg der Intervention. Defizite bei Emotionsregulationsstrategien bezüglich Stressfaktoren sind anhand der Daten anzunehme

\section{5 Überdosierung von Vitamin D - Eine seltene Form der Gedeihstörung}

W. Schacherer, O. Brunner, J. Schwarz - Gerö, M. Hauptmann, A Lischka Kinderklinik Glanzing, Wilhelminenspital der Stadt Wien

Als Gedeihstörung wird eine Verzögerung der körperlichen Entwicklung des Kindes bezeichnet, die häufig mit Auffälligkeiten in der motorischen und psychosozialen Entwicklung verbunden ist. Dabei werden die Perzentilen für Körpergewicht und Länger unterschritten. Es handelt sich dabei um die Folge unterschiedlichster Krankheitsbilder. Wir berichten über den Fall eines 8 Monate alten Mädchens welches nach Kontrollen an unserer Frühgeborenenambulanz wegen Gedeihstörung zur Durchuntersuchung stationär aufgenommen wurde. Bezüglich Größe und Gewicht lag das King deutlich unter der 3. Perzentile. Es zeigte sich grob neurologisch unauffällig, jedoch bestanden sowohl ein gestörtes Essverhalten als auch eine Interaktionsstörung. Im Rahmen der Durchuntersuchung wurde unter anderem auch eine Abdomensonographie durchgeführt. Hier zeigte sich eine Nephrokalzinose Typ 2a beidseits. Auffällig waren initial erhöhte Kalziumwerte im Serum sowie rezidivierende Fieberzacken und ein geblähtes Abdomen. Anamnestisch konnte eine deutliche Überdosierung von Vitamin-D-Tropfen über mehrere Monate erhoben werden. Eine Hypervitaminosis D wurde durch die Bestimmung des Vitamin-D-Spiegels sowie der relevanten Co-Parameter (PTH, Calcitonin) bestätigt.

Bei der weiteren Diagnostik auf der Abteilung für Säuglingspsychosomatik zeigte sich auch ein teils altersinadäquater Umgang seitens der Mutter mit zeitweise dysregulierter Nahrungszufuhr. Nach Absetzen der Vitamin D-Tropfen kam es zu einer Normalisierung der Laborwerte. Das Kind nahm im weiteren Verlauf regelmäßig und aufholend an Gewicht zu. Von Seiten der Säuglingspsychosomatik wurden unter anderem verhaltenstherapeutische Maßnahmen und Handlingberatung durchgeführt.

Gedeihstörungen können vielfältige Ursachen haben. Neben organischen Gründen müssen mögliche extrinsische Ursachen abgeklärt werden. Die vorliegende Kasuistik zeigt, dass neben Fütterungsstörungen auch die Fehldosierung eines gängigen prophylaktischen Medikamentes eine solche zumindest mitverursachen kann.

\section{Gastroenterologie}

\subsection{Heterozygote Mutation im MDR3 - sowie heterozygoter Polymorphismus im BSEP - Transporter als Ursache einer Hepa- topathie}

A. Deutschmann, E. Heitzer, J. Jahnel, K. M. Hoffmann, C. Hauer Almuthe Universitätsklinik für Kinder- und Jugendheilkunde, Klinische Abteilung für allgemeiene Pädiatrie, Graz

Kasuistik. Ein 8-jähriges Mädchen zeigte bei einer Routine-Blutabnahme erhöhte Leberwerte: AST $117 \mathrm{U} / 1$ (-43), ALT $160 \mathrm{U} / 1$ (-35), $\gamma$-GT 240 U/l (-38), AP 274 U/l (-160). Bilirubin, Albumin, PTT, Virologie, Coeruloplasmin, a-1-Antitrypsin, AIH-Screening, IgA, Transglutaminase, Gallensäuren waren unauffällig, Medikamentenanamnese leer, sonografisch keine Auffälligkeiten. Eine Leberbiopsie zeigte in einem Portalfeld eine diskrete periduktale Fibrosierung und der Verdacht auf eine PSC wurde ausgesprochen. Eine MRCP zeigte keine Veränderungen an den Gallengängen. Auf die Gabe von Ursodeoxycholsäure (UDCA) sank die Leberfunktion fast auf Normalwerte. Nach sieben Jahren erfolgte ein Auslassversuch von UDCA, rasch kam es zu einem Wiederansteigen von AST, ALT und $\gamma$-GT und zu einem erneuten Abfall derselben bei Wiedereinführen der Medikation. Die MRCP war wiederholt unauffällig. Die Diagnostik wurde um eine genetische Untersuchung der hepatozellulären Transportproteine MDR3 und BSEP erweitert. Es fand sich eine bisher nicht beschriebene heterozygote Mutation im $\mathrm{MDR}_{3}$-Transporter (c.1732-39A $>\mathrm{G}$ ) sowie heterozygot der häufig vorliegende Polymorphismus c.1331T >C (p.V444A) im BSEPTransporter.

Diskussion. Die Aufnahme und Exkretion von Gallebestandteilen am Hepatozyten wird durch hepatozelluläre Transportproteine gewährleistet. Mutationen im $\mathrm{MDR}_{3}$-Transporter führen zu einer schweren Form der Cholestase, der PFIC 3, sind aber auch mit der Schwangerschaftscholestase (SSC) und medikamentös induzierter Cholestase (DILI, „drug induced liver injury“) assoziiert. Der Polymorphismus im BSEP-Transporter hat eine Frequenz von $>0,5 \%$ und wird ebenfalls im Zusammenhang mit SSC und DILI beschrieben. Die bei unserer Patientin vorliegenden genetischen Veränderungen könnten für die Hepatopathie verantwortlich sein.

Konklusion. Bei unklarer Hepatopathie sollte die Diagnostik um eine Genetik der hepatozellulären Transportproteine erweitert werden. 


\section{2 (Inadäquate) Stressantwort bei Zöliakie am In-vitro-Zellkul- turmodell}

\section{R. Lüftinger, B.Bidmon-Fliegenschnee, C.Aufricht}

Medizinische Universität Wien, Universitätsklinik für Kinder- und Jugendheilkunde

Hintergrund. Bei Zöliakie kommt es zu einer Schädigung der Darmmukosazellen, welche durch die bestehende Gliadinunverträglichkeit einem hohen zellulären Stress unterliegen. Zellen erleiden unter Stress Schaden. Gleichzeitig kommt es in Stresssituationen zu einer Hochregulation von zytoprotektiven Mechanismen. Unsere Arbeitsgruppe konnte im Modell der Peritonealdialyse zeigen, dass HSP-Expression als bester Marker für diese Stressantwort zeichnet; diese Stressantwort kann allerdings bei atypischen Stressoren inadäquat sein. In dieser Studie wird die inadäquate Stressantwort anhand eines etablierten Invitro-Modells der Zöliakie mit Caco2/IEC-Zelllinien untersucht und so ein möglicher Teilaspekt der Zellschädigung bei Zöliakie durch unzureichenden HSP-Schutz evaluiert.

Methodik. Immortalisierte Zelllinien (Caco2, IEC) wurden für 2 beziehungsweise 3 Stunden mit unterschiedlich aufbereitetem Gliadin einerseits und mit Hitze und Gliadin andererseits behandelt und anschließend für 24 Stunden zur Erholung in physiologischem Nährmedium inkubiert. Bestimmt werden die Zellvitalität (LDH, Trypanblaufärbung) und die Expression von HSP 70 und HSP 27 (Western Blot).

Resultate. Sowohl Gliadinexposition als auch Hitzestress resultieren in einer signifikanten Upregulation der HSP-Expression noch bevor es zu einer deutlichen Zunahme der zellulären Letalität (LDH-Release) kommt. Die Kombination beider Stressoren war expositionsabhängig und bedarf noch weiterer Analysen.

Schlussfolgerung. Im Krankheitsmodell der Zöliakie zeigt sich ana$\log \mathrm{zu}$ anderen Modellen eine Hochregulation der Stressantwort, die zwischen Gliadinexposition, Hitze und deren Kombination unterschiedlich ausgeprägt ist. Weitere Untersuchungen mit klinisch relevanteren Stresskombinationen (Osmolarität, Azidose) sind geplant.

\subsection{Mechanischer Ileus durch Fremdkörperingestion bei einem 11-jährigen Knaben}

C. Pontasch, K. Lingitz, H. Kenzian, C. Liechtenstein, F. Ertle, R. Birnbacher Abteilung für Kinder- und Jugendheilkunde, LKH Villach

Anamnese. Ambulante Vorstellung eines 11-jährigen Knaben mit kurz bestehender heftiger kolikartiger abdomineller Beschwerdesymptomatik, Übelkeit und Erbrechen, unauffälliges Stuhlverhalten, afebril. Keine Infekt- und Traumaanamnese, keine relevanten Vorerkrankungen erhebbar. Aufnahmestatus: reduzierter AZ bei gutem EZ, Abd.: diffus druckdolent, BD gespannt, keine typ. Appendizitszeichen fassbar, übriger somatischer Status unauffällig.

Diagnostik. Aufnahmelabor und Kontrolle nach 12 Stunden: BB, Leber-, Pankreas-, Nieren- und Gerinnungsparameter, CRP, BSG im Normbereich, neutrophilie 83\%. In der Abdominalsonographie anfänglich massive Gastroenteritiszeichen mit hypoperistaltisch bis aperistaltisch dilatiert flüssigkeitsgefüllten Darmschlingen. In der neuerlichen Ultraschallkontrolle das Bild eines Subileus mit flüssigkeitsgefüllten, dilatierten, distendierten und aperistaltischen Darmschlingen v.a. im Unterbauch keine freie Flüssigkeit, keine appendizitsverdächtige Struktur, keine Invaginationskonkarde darstellbar. Im CT-Abdomen kommt ein mechanischer Dünndarmileus mit bis zu über $3 \mathrm{~cm}$ im Durchmesser haltenden flüssigkeitsgefüllten dilatierten Darmschlingen zur Darstellungen. Ursache des mechanischen Ileus ist offensichtlich eine Strangulation aufgrund eines metalldichten Fremdkörpers im Bereich des rechten Mittelbauches. Um diesen Fremdkörper sind die Dünndarmschlingen teilweise volvolusartig aufgerollt, weiters lässt sich ein Kalibersprung im Bereich des rechten Unterbauches respektive terminalem Ileums darstellen. Nach mehreren Gesprächskontakten mit dem Patienten gibt dieser nach durchgeführter Diagnostik eine Ingestion einer Schraube und eines kleinen magnetischen Fremdkörper an.
Therapie. Dünndarmresektion: Bei der Exploration zeigen sich im Bereich zweier Dünndarmschlingen aneinander haftende Darmwände. Ursache dafür zwei Fremdkörper, wobei einer davon magnetisch ist. Postoperativ erfolgte eine analgetische- und antibotische Therapie sowie psychotherapeutische Unterstützungsmassnahmen, da die Ingestion im Zusammenhang mit einer familiären Belastungssituation erfolgte.

Zusammenfassung. Mögliche Auslöser eines mechanischen Ileus im Schulkind- und Jugendalter sind wie in unserem Fall Fremdkörperingestion, Volvulus aufgrund von Rotationsanomalien und entzündliche Stenosen bedingt im Rahmen einer CED seltenere Ursachen sind Invaginationen, Pankreas anulare, Darmduplikaturen oder inkarzerierte Hernien

5.4 Von der Appendizitis bis zur Sigmaperforation - die ungeK. Wagner ${ }^{1}$, C. Bittermann ${ }^{2}$, Flora Berger ${ }^{3}$, Doris Ehringer-Schetitska ${ }^{1}$ ${ }^{1}$ Kinderabteilung LK Wr. Neustadt, ${ }^{2}$ Chirurgie LK Wr. Neustadt, ${ }^{3}$ Radiologie LK Neunkirchen

Hintergrund. Wir übernahmen einen 14-Jährigen von einer auswärtigen chirurgischen Abteilung zur weiteren Behandlung. Nach erfolgter Appendektomie und unauffälliger Coloskopie wegen Hämatochezie hatte sich im MRT der Verdacht auf Sigmadivertikulitis ergeben.

Methoden. Wir führten die Antibiotikatherapie zunächst fort. Im MR-Enteroklysma zeigte sich eine gedeckte Perforation mit Schlingenabszess und Fistelbildung im Unterbauch links. Der Abszess wurde CT-gezielt drainiert, die Drainage nach 7 Tagen entfernt und der Patient drei Tage später entlassen. Zwei Tage darauf kam er erneut mit zunehmenden Bauchschmerzen zur Aufnahme. Ein Abdomen-CT ergab Luft- und Flüssigkeitsansammlung in der Abszesshöhle. Es erfolgte eine Sigmateilresektion und Kolostomie-Anlage bei Bauchdeckenabszess und massiver Entzündung mit Perforationen, Schlingenabszessen und Peritonitis.

Ergebnisse. Bis auf eine kleine Wunddehiszenz war der postoperative Verlauf sehr zufriedenstellend. Die Diagnose Sigmadivertikulitis wurde histologisch bestätigt. Die Entlassung erfolgte am 14. postoperativen Tag. Die Rückoperation ist nach ca. 3 Monaten geplant.

Diskussion. Fälle von Kindern mit akuter Sigmadivertikulitis waren in unserer Literaturrecherche extrem selten zu finden, und fast immer mit einer Grunderkrankung assoziiert (Williams Beuren, Marfan, Ehlers Danlos, Hyper-IgE-Syndrom). Den Ausschluss einer solchen Erkrankung mittels Genetik haben wir veranlasst. In der Literatur findet sich eine anhaltend kontrovers geführte Diskussion über einen etwaigen ,virulenten“ Verlauf von Divertikulitiden bei jungen Patienten.

\section{Genetik}

\subsection{Ist ein Subtelomerscreening in der Syndromologie (noch) sinnvoll?}

O. Rittinger, G. Kronberger, G. Sander, I. Vlasak

UK f. Kinder- und Jugendheilkunde, Paracelsus Medizinische Privatuniversität Salzburg

Hintergrund. Kinder mit kognitiver Beeinträchtigung bleiben auch heute noch oftmals ohne definitive Diagnose. Die vor über 10 a etablierte Untersuchung auf Rearrangements im Subtelomerbereich (SR) hat mehrfach über einen auffallenden Aspekt des Gesichts (Monosomie 1p36) oder des Verhaltens (Mikrodeletion 22q13) zur Diagnose geführt. Seit etwa 5 a ist eine molekulare Karyotypisierung (MK) auch in Österreich für die Routine verfügbar. damit stellt sich die Frage nach der Berechtigung des SR-Screenings. Wir vergleichen dazu unsere Ergebnisse samt Phänotypen aus beiden Untersuchungen in den letzten 5 a. 
Patienten und Methoden. 146 Pat mit unklarer MR, normalem Karyotyp und neg. Syndromzuordnung wurden mittels FISH und MLPA Technik im Zeitraum V/o6-V/11 untersucht. Im selben Zeitraum wurden 37 Pat. mittels MK (array CGH, HG Graz) untersucht und der Befund soweit möglich, durch Elternuntersuchung überprüft.

Ergebnisse. SR ergab in 7,5\% (11/146) einen gesichert pathologischen Befund. Mittels MK konnte in 16\% (6/37) eine zytogenetische Ursache gefunden werden. Nur 1/37 MK wäre retrospektiv die Diagnose mittels SR möglich gewesen (22q13-Deletion). In 1/37 MK ergab sich ein Angelman-Syndrom, das auch ohne MK mittels MS-PCR nachweisbar gewesen wäre.

Schlussfolgerung. Die Untersuchung auf SR ist bei einer Diagnoserate von 7,5\% bei kritischer Indikationsstellung weiterhin sinnvoll, kostengünstig (etwa ein Drittel des MK), und im Zweifel auch für einen „second look“ eines vermeintlich unauffälligen Karyogramms wertvoll. Die mittels MK gefundenen Aberrationen lagen mit einer Ausnahme nicht im Subtelomerbereich und hatten ausnahmslos keinen klinisch erkennbaren Phänotyp. Demnach ist das SR solange sinnvoll, als Array-Techniken aus Kapazitäts- und Kostengründen nicht primär eingesetzt werden können. Eine gute Ergänzung des SR ist das gleichfalls MLPA-gestützte Screening auf wiederkehrende Mikroaberrationen, da letzteres auch die mittels Array-Verfahren neu erfassten Mikrodeletionen berücksichtigt.

\subsection{A rare case of photosensitive trichothiodystrophy with com- plex cerebral abnormalities}

H. Schober ${ }^{1}$, I. Höliner ${ }^{1,3}$, S. Dertinger ${ }^{2}$, J. Lütschg ${ }^{1}$, F. Offner ${ }^{2}$, B. Simma ${ }^{1}$

${ }^{1}$ Department of Pediatrics, Academic Teaching Hospital, Feldkirch, Austria, ${ }^{2}$ Department of Pathology, Academic Teaching Hospital, Feldkirch, Austria, ${ }^{3}$ University of Human Sciences, Triesen, Principality of Liechtenstein

Background. Trichothiodystrophy (TTD) is a rare ectodermal disorder with congenital hair dysplasia and autosomal recessive inheritance. Tigerstripe pattern under polarized light and low sulfur content of hair plus trichoschisis are pathognomic for this disorder. Most mutations are found in the ERCC2/XPD and ERCC/XPB gene in the long arm of chromosome 19. In the case of photosensitivity, the disease is typically associated with additional DNA repair defects which can be classified by distinct mutations.

Case report. The $5^{\text {th }}$ male baby of non consanguineous parents from Chechenian showed severe congenital dystrophy and microcephaly (birth weight $1900 \mathrm{~g} 500 \mathrm{~g}<\mathrm{P} 10$, head circumference $27 \mathrm{~cm} 4.5 \mathrm{~cm}<\mathrm{P} 10$, length $36 \mathrm{~cm} 9 \mathrm{~cm}<\mathrm{P} 10$ ) ichthyosiforme erythrodermia (collodion baby), cataract, puffy cheeks, typical sparse and brittle hair as well as onychodystrophy which led to clinical diagnosis of TTD. The diagnosis was confirmed by the tiger-stripe pattern and reduced sulfur content of hair. At the age of 5 weeks, the child died after recurrent apnoe and aspiration leading to bilateral pneumonia. Autopsy was performed and showed cerebral abnormalities with pachygyria, hypoplasia of corpus callosum, cerebellum, vermis and showed histologically a cortical migration disorder. An index child also died in 2004 at the age of 3 month (no autopsy) presenting with an identical phenotype.

Results. Hair analysis and autopsy findings revealed the diagnosis of trichothiodystrophy with complex cerebral abnormalities. The karyotype was normal $(46, \mathrm{XY})$. Molecular analysis is pending.

Conclusions. TTD is a rare ectodermal disorder. A new classification scheme has been developed in 2009 focusing on two distinct different entities concerning in vitro photosensitivity and additional genetic mutations in DNA repair mechanisms.

\section{Hämatoonkologie}

\subsection{Omenn-Syndrom verursacht durch eine Mutation im RAG2- Gen mit eosinophiler granulomatöser Hepatitis}

H. Boztug', G. Fritsch', S. Matthes-Martin', G. Mann¹

${ }^{1}$ St. Anna Kinderspital, UKKJ, MUW, Wien, Österreich, ${ }^{2}$ St. Anna Kinderkrebsforschung, Wien, Österreich

Wir berichten über einen Säugling mit Omenn-Syndrom und hepatischer Beteiligung. Kurz nach Geburt fiel eine sich rasch ausbreitende generalisierte Erythrodermie, sowie stark erhöhtes IgE und Eosinophile bei normaler Anzahl von Granulozyten und Lymphozyten auf. Unter dem Verdacht eines Omenn-Syndroms wurde der Patient am 4. Lebenstag auf die Stammzelltransplantationsstation des St. Anna Kinderspital verlegt.

Unsere Untersuchungen bestätigten einen schweren angeborenen Immundefekt verursacht durch eine homozygote Mutation im RAG2 Gen. Die Durchflusszytometrie zeigte ein Fehlen von reifen B-Zellen und B-Vorläuferzellen. Eine Analyse der T-Zell-Subtypen ergab typischerweise nur aktivierte T-Zellen ( $\mathrm{RO}+, \mathrm{CD} 25+$ ), keine naiven T-Zellen. TRECS waren nicht nachweisbar.

Unter einer cortisonhaltigen Salbe besserte sich die Erythrodermie. Ein 10/10 HLA kompatibler Fremdspender wurde gefunden. Kurz vor Beginn der Konditionierung fiel ein rasch steigendes Bilirubin (max. $16 \mathrm{mg} / \mathrm{dl}$ ) bei ansonsten normalen Leberfunktionsparametern auf. Eine Leberbiopsie zeigte eine granulomatöse Hepatitis mit eosinophiler Infiltration. Unter der Annahme, dass die Inflammation ein autoimmunes Phänomen beim Omenn-Syndrom widerspiegelt, wurde eine systemische Cortisontherapie gestartet. Hierunter normalisierte sich das Bilirubin rasch. Nach einer Konditionierung mit Fludarabin und Thiotepa konnte der Patient komplikationslos transplantiert werden. Am Tag +40 ist er in einem guten Allgemeinzustand und zeigt ein vollständiges Engraftment.

Autoreaktive und allergische Inflammationen sind ein Hauptkennzeichen des Omenn Syndroms. Eine gestörte zentrale Toleranz, eine verminderte Anzahl an regulatorischen T-Zellen sowie vermehrte Anzahl an Th2-T-Zellen tragen zur Hyperinflammation bei. Vor allem Lymphknoten, Leber und Haut sind beteiligt. Histologisch zeigt sich meist eine Infiltration mit $\mathrm{CD}_{3}+-\mathrm{T}-Z$ Zellen. Bisher wurde in der Literatur noch keine eosinophile Infiltration wie bei unserem Patienten beschrieben.

\subsection{Aplastisches Prodrom einer akuten lymphoblastischen Leuk- ämie bei einem 4,5-jährigen Mädchen}

G. Dobrovoljski, O. Tunstall, M. Cummins, J. Cargill, J. Hancock, P. Virgo, J. Moppett

University Hospital Bristol

Ein 4,5-jähriges Mädchen wurde im Oktober 2010 mit Fieber und Abgeschlagenheit seit 7 Tagen, Rhinorrhoe, makulopapulösem Ausschlag, zervikaler Lymphadenopathie und Hepatomegalie an unserer Abteilung vorgestellt. Das Blutbild war panzytopenisch mit einem

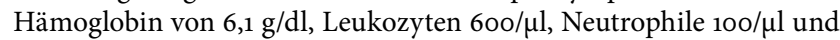
Thrombozyten $24.000 / \mu$ l. In der Blutkultur fanden sich Streptokokken der Gruppe A und ein positiver Betaglucantest und Aspergillusantigen erhärteten den Verdacht auf eine nasopharyngeale Mykose.

Das Knochenmark war zu diesem Zeitpunkt hypoplastisch, ohne Nachweis von Blasten sowohl im Ausstrich, als auch in der Biopsie. Allerdings zeigte die FACS Analyse $3 \% \mathrm{CD} 19+, \mathrm{CD}_{20}+, \mathrm{CD} 10+, \mathrm{TDT}+$ CD45wk+, CD 38wk+, CD58+ Zellen. Zytogenetisch konnten keine Translokationen nachgewiesen werden.

Die Patientin wurde antibiotisch und antimykotisch behandelt und das Blutbild normalisierte sich innerhalb von 2 Wochen. Der weitere Verlauf wurde kompliziert durch das Auftreten einer Coombs positiven hämolytischen Anämie und durch eine anaphylaktische Reaktion 
auf Tazonam. Eine Kontroll Knochenmarkpunktion 4 Wochen später zeigte ein regeneriertes Knochenmark, ohne Nachweis von Blasten, mit vermehrtem Retikulingehalt. In der Flowanalyse fand sich die vorher gefundene Blastenpopulation in einem Anteil von $<1 \%$, weitere 4 Wochen später in einem Anteil von 2,2\%. Die MRD Level waren $10^{-2} /$ $10^{-4}$ und $10^{-1} \mathrm{zu}$ den 3 oben genannten Zeitpunkten.

Im März dieses Jahres präsentierte sich die Patientin neuerlich mit Fieber, Zytopenie, und nun zeigte sich ein Knochenmarkinfiltrat mit $>95 \%$ Precursor B Lymphoblasten CD19+, CD10+, CD79a+, TDT+, zytogenetisch TEL/AML positiv. Eine Therapie nach UKALL 2003 Protokoll wurde eingeleitet und die Patientin zeigte ein rasches Ansprechen und befindet sich derzeit in anhaltender 1. kompletter Remission.

Transiente Panzytopenie wird bei $1-3 \%$ aller ALL Patienten im Kindesalter beobachtet. Innerhalb von Tagen bis Wochen kommt es meist zu einer Spontanremission. Vor allem Mädchen sind betroffen und die Latenzzeit bis zur Diagnose der Leukämie beträgt im Schnitt 6 Monate. Diese Art der Präsentation hat keinen Einfluss auf die Prognose. Ob die Ursache in der Bildung von wachstumsinhibierenden Faktoren durch die Lymphoblasten liegt, oder ob Infektionen und wenn ja welche, eine Remission der Leukämie induzieren können, ist zum jetzigen Zeitpunkt unklar, ebenso wie die Frage, ob die heutigen sensitiveren Nachweismethoden unser therapeutisches Management ändern sollten.

\subsection{Neuroblastom mit Tumorthrombus der Vena renalis, Vena cava inferior und des rechten Vorhofs mit anschließender Thrombektomie -ein Fallbericht}

G. Engstler ${ }^{1}$, M. Kronberger-Vollnhofer ${ }^{1}$, E. Horcher ${ }^{2}$, D. Zimpfer ${ }^{3}$, R. Ladenstein', G. Mann' ${ }^{1}$. M. Dworzak ${ }^{1}$

${ }^{1}$ St. Anna Kinderspital, UKKJ, MUW, Wien, Österreich, ${ }^{2}$ Klinische Abteilung für Kinderchirurgie, Universitätsklinik für Chirurgie, MUW, AKH - Wien, Österreich, ${ }^{3}$ Klinische Abteilung für Herzchirurgie; Universitätsklinik für Chirurgie; MUW, AKH - Wien, Österreich

Einleitung. Wir möchten einen zum Diagnosezeitpunkt 2,5-jährigen Knaben mit einer ungewöhnlicher Präsentation eines Neuroblastoms vorstellen. In der initialen Schnittbildgebung zeigte sich eine große Raumforderung im Bereich der linken Niere mit einem großen Tumorthrombus welcher sich von der linken Nierenvene über die V. cava inferior bis in den rechten Vorhof zog. Dieser war subtotal ausgefüllt.

Befunde. Echosonographie: Tumorthrombus welcher den rechten Vorhof subtotal ausfüllt. Eine FS von 25\%, ein kleiner Perikarderguss, eine mäßige Trikuspidalinsuffizienz, sowie ein gering hämodynamisch wirksamer VSD. Gerinnung: PZ 46\%, eine PTT 27 s, Fibrinogen von $226 \mathrm{mg} / \mathrm{dl}$, AT III von 56\%, D-Dimere bei 10,86 mg/l. Protein S, Protein C und APCR unauffällig; Tumormarker: NSE $165 \mu \mathrm{g} / \mathrm{l}$, Vanillinmandelsäure 206,5 $\mu \mathrm{g} / \mathrm{mg}$ Kreatinin, Homovanillinsäure $228 \mu \mathrm{g} / \mathrm{ml}$, Dopamin 0,41 $\mu \mathrm{g} / \mathrm{mg}$ Kreatinin.

In einer auswärtigen Klinik wurde eine Chemotherapie gegen ein $\mathrm{Ne}$ phroblastom gemäß SIOP 2001/GPOH begonnen. Auf Grund schlechten Therapieansprechens erfolgte die Transferierung an unsere Klinik. Hier erhielt der Knabe 2 Blöcke Carboplatin/VP 16. Anschließend wurde in gleichzeitiger Sterniotomie und Laparotomie eine Nephrektomie/Tumorexstirpation sowie eine Thrombektomie aus Vena renalis, Vena cava inferior und des rechten Vorhofs an der Herz-Lungen-Maschine in Hypothermie durchgeführt. Aus dem operativ gewonnenen Tumormaterial konnte die Diagnose eines Neuroblastoms gestellt werden. Postoperativ musste einmalig, bei drohender Perikardtamponade, eine Perikarddrainage durchgeführt werden.

Anschließend wurde die Chemotherapie nach dem HR-NBL 1/ESIOP Protokoll, Abschnitt Rapid Cojec fortgesetzt. Nach Gewinnung von peripheren Stammzellen erfolgte die Hochdosischemotherapie und autologe Stammzellreinfusion. Nach Regeneration soll eine Erhaltungstherapie angeschlossen werden. Der initial schwer kranke Patient hat gut auf die erfolgte Therapie angesprochen und ist klinisch derzeit in gutem Allgemeinzustand.

\subsection{Erstdiagnose Hämophilie bei Pseudotumor der linken Wange - ein Fallbericht}

W. Friesenbichler ${ }^{1}$, M. Kronberger-Vollnhofer ${ }^{1}$, C. Male ${ }^{2}$, M. Dworzak ${ }^{1}$ ${ }^{1}$ St. Anna Kinderspital, UKKJ, MUW, Wien, Österreich, ${ }^{2}$ Univ. Klinik für Kinder- und Jugendheilkunde - AKH Wien, Österreich

Hintergrund. Hämophile Pseudotumoren im Kindesalter sind eine seltene Diagnose. Wiederholte intramuskuläre/intraossäre Blutungen können zum Auftreten eines Pseudotumors führen.

Anamnese und Klinik. Am Vorstellungstag fiel der Mutter des 8 Monate alten Säuglings eine schmerzlose Schwellung der linken Gesichtshälfte auf. Palpatorisch fand sich eine derbe, nichtverschiebliche, ca. $2 \times 2 \mathrm{~cm}$ große Raumforderung im Bereich der linken Schläfe/Maxilla. Verlauf und Therapie. Anhand der bildgebenden Befunde wurde ein tumoröser Prozess vermutet, sodass eine Biopsie der Raumforderung beschlossen wurde. Das gewonnene Gewebe zeigte keine Tumorzellen. Die aufgrund einer Nachblutung durchgeführte erweiterte Gerinnungsdiagnostik führte zur Diagnose einer schweren Hämophilie A. Konsekutiv wurde eine Substitutionstherapie mit rekombinantem Faktor VIII (ADVATE ${ }^{\circledR}$ ) etabliert. Die über 14 Tage durchgeführte hochfrequente Substitutionstherapie führte zu einer sukzessiven Rückbildung des Pseudotumors. In der laufenden Erhaltungstherapie erhält der Patient dreimal wöchentlich eine Faktor-VIII-Substitution und ist darunter klinisch unauffällig.

Schlussfolgerung. Der Bericht zeigt einen in der Literatur nur vereinzelt beschriebenen Fall, in dem aufgrund eines Tumorverdachtes die Erstdiagnose Hämophilie gestellt wurde. Selten aber doch kann die Ursache einer unklaren rasch wachsenden Raumforderung auch ein „hämophiler Pseudotumor“ sein und sollte dann differentialdiagnostisch berücksichtigt werden.

\subsection{All-trans-Retinsäure (ATRA) induzierte Hyperkalzämie bei einer Patientin mit akuter Promyelozytenleukämie}

K. Großauer, H. Lackner, V. Strenger, W. Schwinger, M. Benesch, P. Sovinz, C. Urban

Klinische Abteilung für Pädiatrische Hämato/-Onkologie, Universitätsklinik für Kinder- und Jugendheilkunde, Medizinische Universität Graz

Einleitung. All-trans-Retinsäure (ATRA) wird erfolgreich bei der Behandlung der akuten Promyelozytenleukämie eingesetzt. Neben den bekannten Nebenwirkungen wurden auch einzelne Fälle von Hyperkalzämie unter ATRA-Therapie beschrieben.

Kasuistik. Wir berichten über eine 18-jährige Patientin mit der Diagnose AML FAB M3v und initialer Chemotherapie nach AML BFM 2004. Aufgrund einer Hirnmassenblutung wurde am 5. Tag der Induktionschemotherapie (AIE) auf eine Monotherapie mit Arsentrioxid (ATO) umgestellt. Nach 36 Tagen wurde eine komplette hämatologische und molekularbiologische Remission erreicht. Aufgrund wieder aufgetretener Positivität im molekularbiologischen Monitoring des Fusionsgens PML/RAR a erfolgte eine Intervallverkürzung der ATO Therapie sowie bei weiterhin bestehenden Nachweis eine Erweiterung der Therapie um ATRA ( $25 \mathrm{mg} / \mathrm{m} 2 /$ Tag p.o. für 2 Wochen, dann 2 Wochen Pause). Kurz nach Beginn des 5 . Zyklus mit ATRA klagte unsere Patientin über Kopfschmerzen, Knochenschmerzen und Müdigkeit. Im Labor zeigte sich eine Hyperkalzämie $(\mathrm{Ca}++3.37 \mathrm{mmol} / \mathrm{l})$. Trotz forcierter Diurese stiegen die Kalziumwerte weiter an $(\mathrm{Ca}++4,13 \mathrm{mmol} / \mathrm{l})$. Parathormon zeigte einen Wert von 7,2 pg/ml (normal 15-65 pg/ml). Der Osteoklasten-Marker b-crosslaps war mit 2,26 ng/ml deutlich erhöht. Aufgrund der ansteigenden Kalziumwerte sowie erhöhter Kreatininwerte $(1,37 \mathrm{mg} / \mathrm{dl})$ wurde die Therapie mit ATRA abgesetzt. Die ausgeprägten Knochenschmerzen wurden mit Bisphosphonat (Zoledronsäure) therapiert. Die Laborwerte normalisierten sich innerhalb von 6 Tagen nach Absetzen von ATRA. Die Knochenschmerzen besserten sich innerhalb von 1 Tag nach Gabe von Zoledronsäure.

Schlussfolgerung. Hyperkalzämie ist eine seltene Nebenwirkung von ATRA. Nach Absetzen von ATRA und Gabe von Bisphosphonaten 
bessert sich das Krankheitsbild schnell. Ob das Wiederansetzen von ATRA oder die Applikation von ATO eine Option für die Fortführung der antileukämischen Therapie darstellen, muss noch geklärt werden.

\subsection{Predicting severity of hereditary spherocytosis (HS)}

\section{H. Herbrüggen, M. Minkov}

St. Anna Kinderspital

Background. HS is the most common inherited haemolytic anaemia in individuals of Northern and Central European ancestry. The cardinal signs of HS are anaemia, jaundice and splenomegaly. Cholelithiasis, haemolytic episodes and aplastic crisis due to Parvovirus B19 infection occur in the majority of the patients. The clinical course of HS is very heterogeneous and varies from asymptomatic carriage through compensated haemolysis to severe transfusion-dependent anaemia. We searched for a simple predictive system and an optimal point in time for predicting the severity of the clinical course with respect to the need for transfusions and splenectomy.

Patients and methods. The clinical records of $37 \mathrm{HS}$ patients (21 males and 16 females), diagnosed and treated between 1984 and 2010 were retrospectively analysed. Based on the haemoglobin level the cohort was classified into four different degrees of severity: 11-15, 8-11, 6-8, and $<6 \mathrm{~g} / \mathrm{dl}$ were defined as mild, moderate, severe and very severe HS. The assessment of severity was performed at first referral, at initial steadystate presentation (no concurrent disease and no preceding transfusion for 2 months), as well as on the basis of the calculated average steadystate values.

Results. At first referral, 9, 20, 5 and 3 pts. had mild, moderate, severe and very severe HS, respectively. In these groups, $44 \%, 75 \%, 100 \%$ and $100 \%$ required transfusions and $22 \%, 40 \%, 40 \%$ and $67 \%$ had splenectomy. At initial steady-state assessment 12, 19 and 6 pts had mild, moderate and severe HS. In these groups, $17 \%$ of the pts received a median of 2 (range 1-2), 100\% 3 (range 1-23) and 100\% 12 (range 2-31) transfusions. $17 \%, 42 \%$ and $50 \%$ of the pts had splenectomy, respectively. At average steady-state assessment the distribution of the patients among the severity categories was quite similar.

Conclusion. The assessment of severity based on haemoglobin at initial steady-state presentation permits a reliable estimation of the further clinical course.

\subsection{Uveitis as side effect of cidofovir therapy in a 12-year-old girl with acute myeloid leukaemia}

H. Hubmann', V. Strenger', M. Benesch'1, P. Sovinz' ${ }^{1}$, W. Schwinger ${ }^{1}$, H. Lackner ${ }^{1}$, S. Schmidt ${ }^{1}$, K. Weiss ${ }^{2}$ and C. Urban ${ }^{1}$

${ }^{1}$ Klinische Abteilung für Pädiatrische Hämatologie/Onkologie; Univ.-Klinik für Kinder und Jugendheilkunde; Medizinische Universität Graz, ${ }^{2}$ Abteilung für Augenheilkunde und Optometrie; LKH Klagenfurt

Background. Uveitis is a rare complication observed after treatment with cidofovir.

Case report. Bilateral uveitis occurred in a 12-year-old girl with AMLFAB M5 who received intravenous cidofovir therapy repeatedly due to recurrent CMV infection. Maintenance chemotherapy had to be stopped because of haemophagocytosis with CMV as possible trigger. At last $1.3 \times 10^{\wedge} 3 \mathrm{cop} / \mathrm{ml}$ of CMV were verified in saliva fluid. Four days after the $17^{\text {th }}$ dose of cidofovir severe photophobia, dull pain, reduced visual acuity and hyperaemic uveal injection occured. Topical ophthalmologic therapy with prednisolon every hour and cyclopentolat three times per day for therapeutic mydriasis of the left eye was initiated. Subsequently topical atropin was given instead of cyclopentolat because of persistent posterior synechias. Inflammatory involvement of the vitreous body with intravitreal cells did also occur. There was no retinal detachment, but macular oedema and retinal swelling as well as ocular hypotension bilaterally. Intraocular pressure decreased to $2 \mathrm{mmHg}$ in both eyes despite continuing topical glucocorticoid thera- py. Since there was no increase of intraocular pressure especially of the left eye intravitreous application of prednisolon was indicated.

Conclusion. Secondary uveitis may be a severe complication after repeated doses of intravenous antiviral therapy with cidofovir.

\subsection{Stammzelltransplantation bei Kindern mit Parvovirus B19 ausgelöster SAA oder MDS}

H. Lackner, P. Sovinz, W. Schwinger, M. Benesch, V. Strenger, S. Schmidt, C. Urban

Klinische Abteilung für Pädiatrische Hämatologie/Onkologie; Univ.-Klinik für Kinder- und Jugendheilkunde; Medizinische Universität Graz

Einleitung. Parvovirus B19 (PVB19) als Ursache einer schweren aplastischen Anämie (SAA) oder eines myelodysplastischen Syndroms (MDS) ist bisher erst selten beschrieben. Es existieren auch kaum Berichte über Stammzell-Transplantationen (SCT) bei diesen Krankheitsbildern.

Patienten und Methoden. Bei 6 Patienten mit SAA $(n=4)$ oder MDS $(n=2)$ wurde bei Diagnosestellung eine frische Infektion mit PVB19 mittels positivem Nachweis von $\operatorname{IgM}, \operatorname{IgG}(n=6)$ und PCR $(n=5)$ nachgewiesen. Alle Patienten erhielten eine SCT unter dem Schutz repetitiver intravenöser Immunglobulin (IVIG)-Gaben. Das virologische Monitoring mittels PCR erfolgte in 5 von 6 Fällen in der Akutphase wöchentlich, danach monatlich bis zur hämatologischen Rekonstitution.

Resultate. Die 4 Patienten mit SAA erhielten Knochenmark eines HLA-identen Geschwister-Spenders $(\mathrm{n}=3)$ oder HLA-idente hochgereinigte, periphere Stammzellen eines unverwandten Spenders $(n=1)$. Ein Patient entwickelte nach SCT eine chronische hypoplastische Anämie, die bis zur vollständigen Blutbild-Regeneration am Tag 186 andauerte. Der Posttransplantations-Verlauf der übrigen 3 Patienten war komplikationslos mit einem Leukozyten-Engraftment nach 8-31 Tagen und einer hämatologischen Rekonstitution nach 36-112 Tagen. Die 2 Patienten mit MDS wurden nach Konditionierung mit Thiotepa, Fludarabin und ATG einer SCT mit unverwandten Spendern (1-mal Knochenmark, 1-mal periphere hochgereinigte Stammzellen) unterzogen. Nach zögerlichem Leukozyten-Engraftment dauerte es 126o bzw. 119 Tage bis zur Blutbildnormalisierung, PVB19 wurde in der PCR bis zum Tag 686 bzw. 139 nachgewiesen.

Diskussion und Schlussfolgerungen. Eine erfolgreiche SCT bei diesen Patienten ist möglich, sofern eine engmaschige Monitorisierung der PVB19-PCR und eine konsequente repetitive IVIG-Therapie erfolgen. Der Transplantationsverlauf kann durch ein zögerliches Engraftment und eine prolongierte „poor graft function“ kompliziert werden.

7.9 Add-on-Therapie mit dem monoklonalen anti-VEGF-Antikörper Bevacizumab (Avastin ${ }^{\circledast}$ ) bei prognostisch ungünstigen soliden Tumoren im Kindes- und Jugendalter außerhalb des ZNS

J. Pansy' ${ }^{1}$, P. Fritsch², P. Sovinz ${ }^{1}$, H. Lackner', W. Schwinger ${ }^{1}$, C. Urban' ${ }^{1}$, M. Benesch ${ }^{1}$

${ }^{1}$ Klinische Abteilung für Pädiatrische Hämatologie/Onkologie, ${ }^{2} \mathrm{Klinische}$ Abteilung für Pädiatrische Kardiologie; Univ.-Klinik für Kinder und Jugendheilkunde; Medizinische Universität Graz

Hintergrund. Trotz multimodaler Behandlung kann bei Patienten mit metastasierten oder refraktären soliden Tumoren meist keine Langzeitremission erzielt werden. Neue Therapiemodalitäten müssen daher vor allem hinsichtlich des Sicherheits- und Toxizitätsprofils untersucht werden. Ziel dieser Studie ist die Beschreibung von Nebenwirkungen und Wirksamkeit einer Add-on-Therapie mit Bevacizumab.

Patienten und Methode. Sieben Patienten im Alter von 4,5-19 Jahren (weiblich, $n=5)$ mit rezidivierten $(\mathrm{n}=3)$ oder primär metastasierten $(n=4)$ soliden Tumoren erhielten zusätzlich zur multimodalen onkologischen Chemo- und Radiotherapie Bevacizumab (5-10 mg/kg KG) in einem Abstand von 2-3 Wochen. Neben einer regelmäßigen klini- 
schen Evaluierung wurden kardiale Funktion, Schilddrüsenparameter, Harnbefund und Ansprechen des Tumors in 3-monatigen Abständen überprüft.

Resultate. Im Median wurden 16 Dosen (10-38) über einen Zeitraum von 10 (5-17) Monaten verabreicht. Bei einem Patienten kam es zur Abnahme der Shortening Fraction (FS) von $42 \%$ auf $30 \%$, während bei allen übrigen Patienten die kardiologischen Untersuchungen unauffällig waren. Weiters wurden eine Erhöhung des basalen TSH $(n=4)$, eine milde Proteinurie/Hämaturie $(n=7)$, intermittierend hypertone RR-Werte $(n=2)$, eine therapiebedürftige Hypertonie $(n=3)$ und Epistaxis $(n=2)$ beobachtet. Bei 2 Patienten wurde die Therapie aufgrund von Nebenwirkungen (Hypertonie, $n=1$, Abnahme der FS, $n=1$ ) beendet. Bei einer medianen Nachbeobachtungszeit von 17 (13-30) Monaten befinden sich 3 Patienten in anhaltender Remission (17, 23, 23 Monate). Vier Patienten entwickelten nach 7-25 Monaten ein Rezidiv, 1 Patientin verstarb.

Schlussfolgerung. Die Nebenwirkungen von Bevacizumab entsprachen den in der Erwachsenenliteratur beschriebenen und waren meist nur geringgradig ausgeprägt. Besonderes Augenmerk muss auf die kardiale Funktion gelegt werden. Ob die Zugabe von Bevacizumab die Prognose dieser Patienten verbessert, kann nur in einer randomisierten Studie beantwortet werden.

\subsection{Erstaunliche Rekonvaleszenz eines apallischen Zustands- bilds im Rahmen einer genetisch verifizierten, aktivierten EBV - assoziierter Lymphoproliferation mit ausgeprägter ZNS-Be- teiligung}

M. Preisel, V. Witt, H. Pichler, M. Kronberger, B. Neophytou, B. Keck, A. Zimprich, G. Mann, M. Dworzak

\section{St. Anna Kinderspital, UKKJ, MUW, Wien}

Hintergrund. Das apallische Syndrom ist bei Kindern insgesamt mit einer schlechten Prognose behaftet. Hier beschreiben wir die überraschende neurologische Genesung eines 6,5-jährigen Knabens mit EBVassoziierter hämophagozytischer Lymphohistiozytose (HLH) mit ausgeprägter ZNS-Beteiligung.

Anamnese und Klinik: 6,5-jähriger Knabe mit St. p. Burkitt-Lymphom, der im Rahmen der Nachsorge an einer EBV-Infektion fulminant erkrankt. Aufgrund des schweren Verlaufs wird eine „X-linked lymphoproliferative (XLP) disease" genetisch detektiert.

Verlauf und Therapie. Klinisch entwickelt der Knabe im Rahmen der EBV-Infektion eine typische hämophagozytische Lymphoproliferation, die nach dem HLH-2004 Protokoll behandelt wird. (Dexamethason, Etoposid, Cyclosporin A, intrathekales Methotrexat und Prednisolon). Schließlich kam es zu einer rapiden klinischen Verschlechterung mit prolongiertem, zerebralem Krampfgeschehen. Wiederholte zerebrale Bildgebungen zeigten einen trotz intensiver Therapie zunehmenden Befall mehrerer Gehirnregionen (Basalganglien, Marklager, Kleinhirn). Unter Intensivierung der Therapie (Cyclophosphamid, Rituximab intravenös und intrathekal, tripple Intrathekaltherapie) und interdisziplinärem Support (Pflege, Physiotherapie, Ergotherapie, Logopädie und Musiktherapie) gelang es den Prozess aufzuhalten. Nach knapp 2 Monaten im vegetativen Zustandsbild konnte sich der Patient wieder mit zufriedenstellender motorischer, sprachlicher und psychosozialer Interaktion in den Alltag integrieren. Schlussfolgerung. Der Bericht zeigt die eindrucksvolle Rekonvaleszenz eines Knaben mit apallischem Zustandsbild und unterstreicht abermals das unsichere und unterschiedliche Outcome von schwer hirngeschädigten Intensivpatienten.

\subsection{Familiärer Morbus Hodgkin}

S. Schmidt, V. Strenger, M. Benesch, P. Sovinz, W. Schwinger, H. Lackner, H. Hubmann, C. Urban

Klinische Abteilung für Pädiatrische Hämatologie/Onkologie; Univ.-Klinik für Kinder und Jugendheilkunde; Medizinische Universität Graz

Einleitung. Bei etwa 5\% der malignen Erkrankungen im Kindesalter handelt es sich um einen Morbus Hodgkin (Mb.H.). Ein familiäres Auftreten wird gelegentlich beobachtet.

Fallbeispiele. Wir berichten über 4 Patienten aus 2 Familien mit Mb.H. In der ersten Familie erkrankte Patientin 1 (Mutter) 1981 mit 23 Jahren an einem Mischtyp eines Mb.H. IA; als primäre Therapie wurden eine Splenektomie sowie eine Mantelfeldbestrahlung durchgeführt. Sieben Jahre später kam es zu einem Rezidiv vom nodulär-sklerosierenden Typ IIA, welches mit 6 Zyklen MOPP behandelt wurde. Patientin 2 (Tochter) erkrankte im Alter von 17 Jahren 2011 an einem nodulär-sklerosierenden $\mathrm{Mb}$.H.II $\mathrm{E}$ B und erhält derzeit eine Chemotherapie nach der Therapieoptimierungsstudie EuroNet-PHL-C1 TG3. Die zweite Familie umfasst ein Geschwisterpaar, wobei Patient 3 (Bruder) 1992 im Alter von 13 Jahren an einem nodulär-sklerosierenden Mb.H., Stadium IIA erkrankte. Er wurde nach dem DAL-HD-9o-Protokoll + Radiotherapie behandelt und ist bis zum heutigen Tag rezidivfrei. Bei Patientin 4 (Schwester) wurde 1999 mit 16 Jahren die Diagnose eines nodulär-sklerosierenden $\mathrm{Mb}$.H. $\mathrm{II}_{\mathrm{E}} \mathrm{A}$ gestellt. Sie erhielt primär eine Chemotherapie entsprechend GPOH-HD-95(TG2) und bei Tumorprogredienz eine Bestrahlung und Salvage-Chemotherapie mit IEP, CWS96-Rezidivprotokoll und 3 Mini-Beam-Blöcke, verstarb jedoch 2 Jahre nach Erstdiagnose an therapierefraktärer Tumorprogression.

Diskussion. Die exakte Ätiopathogenese des Mb.H. ist nicht bekannt, jedoch haben Verwandte 1. Grades eines Patienten ein 5-6\% erhöhtes Risiko ebenfalls an einem Mb.H. zu erkranken. Betroffene Familien und Patienten müssen diesbezüglich aufgeklärt werden, regelmäßige Kontrollen sollten auch das erhöhte Sekundärmalignom-Risiko berücksichtigen.

7.12 Erste Erfahrungen mit dem Einsatz von Rapamycin bei pädiatrischen Patienten außerhalb der Transplantationsmedizin

P. Sovinz, H. Lackner, W. Schwinger, M. Benesch, V. Strenger, S. Schmidt, C. Urban

Klinische Abteilung für Pädiatrische Hämatologie/Onkologie; Univ.-Klinik für Kinder- und Jugendheilkunde; Medizinische Universität Graz

Einleitung. Der mTOR-Inhibitor Rapamycin (Sirolimus) wird im Rahmen von Calcineurin-freien Immunsuppressions-Regimes nach solider Organtransplantation eingesetzt. Wegen seiner antiproliferativen, antiangiogenetischen und antineoplastischen Wirkung wurde Rapamycin off-label bei verschiedenen Erkrankungen wie dem autoimmunproliferativen Syndrom (ALPS), komplexen vaskulären Anomalien, tuberöser Sklerose und Neoplasien wie dem Kaposi-Sarkom in kleinen Fallserien angewendet. Wir berichten über eigene Erfahrungen mit 4 Patienten, die seit 2010 mit Rapamycin behandelt wurden.

Patienten, Methoden, Resultate. Bei 2 Patienten wurde im Alter von 3 bzw. 10 Monaten eine vaskuläre Malformation der Orbita \pm der Gesichtweichteile diagnostiziert, die den Visus bedrohte. Vorhergehende Behandlungsversuche umfassten Prednisolon, Interferon, eine OK432 Instillation bzw. Propranolol und eine Teilresektion. Durch Rapamycin wurde in einem Fall eine deutliche Regression erreicht, sodass nach 5,5 Monaten eine vollständige Resektion möglich war; im anderen Fall kam es zu einer geringen Größenabnahme und Stabilisierung. Ein Neugeborenes mit Kaposiformem Hämangioendotheliom des Rückens wurde unter dem Bild eines lebensbedrohlichen KasabachMerritt Syndroms mit Prednisolon, Propranolol, Vincristin und Cyclophosphamid behandelt. Erst nach Einführung von Rapamycin erlosch die DIC-Aktivität, die Thrombozyten stiegen binnen 5 Wochen in den Normbereich an; bei klinisch weitgehender Tumorrückbildung wird Rapamycin derzeit nach 5 Monaten ausgeschlichen. Bei einer Pa- 
tientin mit ALPS führte Rapamune zu einem deutlichen Rückgang der Splenomegalie/Lymphadenopathie und zu Blutbild-Normalisierung. Unter spiegeladaptierter Dosierung und antimikrobieller Prophylaxe traten keine schwerwiegenden Nebenwirkungen auf

Schlussfolgerung. Rapamune ist eine potentielle neue Therapieoption auch für intensiv vorbehandelte Patienten mit ausgewählten Krankheitsentitäten wie dem ALPS und komplexen vaskulären Anomalien.

\subsection{Haemophagocytic lymphohistiocytosis (HLH) and acute monoblastic leukemia with $\mathrm{t}(9 ; 11)($ p22; q23) in a 12-year-old patient - a coincidental finding?}

V. Strenger, V. Hubmann, M. Benesch, P. Sovinz, W. Schwinger, H. Lackner, S. Schmidt, C. Urban

Klinische Abteilung für Pädiatrische Hämatologie/Onkologie; Univ.-Klinik für Kinder- und Jugendheilkunde; Medizinische Universität Graz

Background. Haemophagocytic lymphohistiocytosis (HLH) is a severe disorder characterized by overactivation of macrophages. Beside genetic, autoimmune and viral diseases, T-cell lymphoma, Hodgkin lymphoma and natural-killer cell leukemia/lymphoma are known to be associated with HLH.

Case report. We report the case a 12-year-old girl with acute myeloic leukemia (AML) FAB-M5 with $\mathrm{t}(9 ; 11)(\mathrm{p} 22 ; \mathrm{q} 23) / \mathrm{MLL} \mathrm{T}_{3}$-MLL. Treatment according to AML-BFM 2004 study with cytarabin, daunorubicin and VP-16 was initiated. On day 12 of therapy, maculopapular exanthema appeared and several splenic infarcts were detected in sonography for the first time. Despite broad-spectrum antibiotic and antimycotic therapy temperature rose up to $40^{\circ} \mathrm{C}$ and $\mathrm{HLH}$ parameters increased (fibrinogen $717 \mathrm{mg} / \mathrm{dl}$, sIL2R $44.150 \mathrm{U} / \mathrm{ml}$, ferritin $9597 \mathrm{ng} /$ $\mathrm{ml}$ ). After initiation of dexamethason therapy, adaption of antiinfectious treatment and supplementation of immunoglobulins, symptoms and laboratory results stabilized. Due to repeated CMV detection by PCR in blood, urine and saliva, virustatic treatment with cidofovir was initiated. During further AML therapy, $\mathrm{HLH}$ was active at different degrees. Maintenance chemotherapy with thioguanin and cytarabin had to be discontinued due to recurrent fever and increasing HLH parameters. After 1-year follow-up the patient is in complete remission without clinical signs of HLH. Prophylactic immunoglobulin treatment is given in regular intervals in order to prevent EBV infection.

Discussion. To our knowledge, this is the $3^{\text {rd }}$ report of AML associated with HLH. The translocation $\mathrm{t}(9 ; 11)$ (p22; q23) observed in our patient has also been observed in one hitherto reported case, in which HLH preceded the development of AML-M5 for 5 months.

Conclusion. In addition to known risk factors, AML and $t(9 ; 11)\left(\mathrm{p}_{22}\right.$; q23) might also be associated with HLH, making treatment even more difficult.

\subsection{Nicht jede renale Neoplasie beim Kind und Jugendlichen ist ein Wilmstumor - Fallbericht eines Nierenzellkarzinoms bei einer 16-jährigen Patientin}

\section{Tamesberger, R. Steiner, K. Jilka, G. Ebetsberger-Dachs}

Linzer Frauen- und Kinderklinik

Hintergrund. Mehr als 90\% aller kindlichen Nierentumore sind Wilmstumore (Nephroblastome), die Therapie erfolgt nach den Studienprotokollen von SIOP/GPOH. Neben Nephroblastomen finden sich Klarzellensarkom, Rhabdoidtumor der Niere, mesoblastisches Nephrom, Nierenzellkarzinom und verschiedene Raritäten.

Fallbericht. Aufgrund einer Synkope und Unterbauchschmerzen rechts wird bei einer knapp 16-jährigen Patientin eine Abdomensonographie und anschließend eine Magnetresonanztomographie (MRT) durchgeführt, die eine inhomogene, $5 \mathrm{~cm}$ große Raumforderung im unteren Nierendrittel rechts und vergrößerte lokale Lymphknoten zeigen. Da Alter der Patientin und Bildgebung nicht für einen Wilmstumor sprechen, erfolgt primär eine Nephrektomie rechts mit Lymph- knotenexstirpation. Die Histologie ergibt ein Nierenzellkarzinom (Xp11.2-Translokationstumor), der die Nierenkapsel durchbricht, aber komplett entfernt ist. Die Lymphknoten sind tumorfrei. CT Thorax, MR Cerebrum und Knochenzintigraphie sind unauffällig. Bei lokalisierten Tumoren liegt das Überleben bei 90\%, eine weitere Therapie ist bei fehlender Radio- und Chemotherapiesensitivität nicht indiziert. Leider finden sich bei unserer Patientin 6 Monate nach Erstdiagnose inoperalble Lymphknotenmetastasen mediastinal und hilär. Eine Therapie mit dem oralen Multi-Tyrosinkinaseinhibitor Sunitinib wird eingeleitet. Die Nebenwirkungen der Therapie schränken die Lebensqualität der Patientin ein. Die erste bildgebende Kontrolle ist nach 3 Monaten vorgesehen. Der weitere Verlauf wird dargestellt.

Schlussfolgerung. Nierenzellkarzinome machen $2-6 \%$ aller kindlichen Nierentumore aus. Die Operation ist die Therapie der Wahl. Im lokalisierten Stadium ist die Prognose sehr gut. Bei Metastasen werden aufgrund der fehlenden Radio- und Chemotherapiesensitivität antiangiogenetische Medikamente wie Tyrosinkinaseinhibitoren eingesetzt, die eine Progressionsfreiheit und bei einem Teil der Patienten sogar eine Regression der Tumore bedingen können.

\subsection{Multifocal osseous involvement in a patient with Hodgkin lymphoma}

M. Tappauf, H. Lackner, P. Sovinz, W. Schwinger, M. Benesch, V. Strenger, S. Schmidt, C. Urban

Klinische Abteilung für Pädiatrische Hämatologie/Onkologie; Univ.-Klinik für Kinder und Jugendheilkunde; Medizinische Universität Graz

Background. We would like to report a patient with Hodgkin lymphoma initially presenting as bone tumor with multiple skeletal involvement.

Case report. A 16-year-old male was referred with a 3-week history of painful swelling in the region of the left shoulder without preceding trauma, suspicious for a bone tumor. The x-ray of the shoulder showed signal intensity changes of $6 \times 1.5 \mathrm{~cm}$ at the spine of the scapula. Magnetic resonance imaging (MRI) showed a mass, infiltrating the deltoid muscle with perifocal edema, originating from the spine of the scapula and the acromion. A biopsy of the lesion in the scapular region was performed showing necrosis, tumor cells and Reed- Sternberg cells, consistent with Hodgkin lymphoma. Bone scan, MRI of the whole spine as well as thoracal and abdominal CT scan showed multifocal osseous involvement (left scapula, right clavicle, T2, T4, T12, L2 vertebrae, both hips, sacrum, left tibia and left femur). Hodgkin lymphoma with multifocal osseous involvement was diagnosed, and chemotherapy according to the GPOH-HD protocol followed by involved field irradiation ( $20 \mathrm{~Gy})$ to all skeletal sites was given. More than 7 years after the end of therapy, the patient is in continuous complete remission.

Discussion and conclusion. Hodgkin lymphoma rarely presents as a bone tumor, and the scapular region is an even more uncommon location since only one case of a 37 -year-old woman with osseous involvement of the scapula is reported in literature. However though rare, Hodgkin lymphoma should be also considered in the differential diagnosis of solitary bone lesions in young patients presenting with painful swelling. 
7.16 JMML (juvenile myelomonocytic leukemia) with platelet derived growth factor-receptor beta (PDGFR $\beta$ ) gene rearrangement - treatment with imatinib followed by hematopoietic stem cell transplantation (HSCT)

R. Ulreich ${ }^{1}$, M. Dworzak ${ }^{2}$, H. Lackner ${ }^{1}$, W. Schwinger ${ }^{1}$, M. Benesch', P. Sovinz ${ }^{1}$, V. Strenger ${ }^{1}$, C. Urban ${ }^{1}$

${ }^{1}$ Klinische Abteilung für Pädiatrische Hämatologie/Onkologie; Univ.-Klinik für Kinder- und Jugendheilkunde; Medizinische Universität Graz, ${ }^{2}$ St. Anna Kinderspital; Medizinische Universität Wien

A previously healthy boy presented at the age of 18 months with fatigue, loss of appetite and reddish skin lesions. Peripheral white blood count was $87,000 / \mu$ with $20 \%$ monocytes, $10 \%$ myelocytes, and $1 \%$ blasts. Bone marrow revealed $6 \%$ blasts, immunologically mainly of myeloic and monocytic differentiation. BCR/ABL was ruled out by PCR, monosomy 7 by FISH analysis. Cytogenetic analysis showed translocation $(5 ; 17)$ with PDGFR $\beta$ rearrangement in 5933 . HbF was $23 \%$. Neither GM-CSF hypersensitivity of progenitors nor KRAS, NRAS, PTPN11, cCBL mutations nor splenomegaly were present. JMML was confirmed by the EWOG-MDS study center. Initial cytoreduction was achieved by administering 1 cycle of azacytidine followed by daily imatinib. Subsequent bone marrow analysis showed complete hematologic and cytogenetic remission and skin lesions disappeared. However 7.5 month later hematologic and cytogenetic relapse was diagnosed despite normal imatinib plasma trough level. Although cytoreduction was again achieved by nilotinib treatment, an increasing lymphatic blast crisis of B-cell precursor differentiation containing the specific rearrangement (5; 17) was diagnosed 21 days later and treated with vincristine, daunorubicin and prednisolone. Meanwhile a matched unrelated donor (MUD) could be identified. 11 month after initial diagnosis MUD bone marrow transplantation was performed successfully.

JMML has a poor prognosis without HSCT.This is the first published pediatric case with JMML and $t(5 ; 17)$ which involves the PDGFR $\beta$ gene. It illustrates that tyrosine kinase inhibitors may be a useful bridging-therapy until a suitable donor is identified.

\subsection{Alternative donor hematopoietic stem cell transplantation (HSCT) in refractory severe aplastic anemia (SAA). The impact of conditioning and graft manipulation for prevention of graft rejection and graft vs. host disease (GVHD)}

R. Ulreich, W. Schwinger, H. Lackner, M. Benesch, P. Sovinz, V. Strenger, C. Urban

Klinische Abteilung für Pädiatrische Hämatologie/Onkologie; Univ.-Klinik für Kinder- und Jugendheilkunde; Medizinische Universität Graz

Background. HSCT from a matched sibling donor (MSD) is the treatment of choice for children with SAA, however available in only $25 \%$. Alternative treatment is immunosuppressive therapy (IST) with the disadvantage of high treatment failures.

Patients and methods. Six patients with SAA ( 5 of them refractory to IST), median age 11.5 years ( $7-16)$, median interval from diagnosis to HSCT 39, 6 months (3-155) and median number of transfusions before HSCT 49 (19-116) underwent alternative HSCT. Donors were matched unrelated (MUD; $\mathrm{n}=4$ ), mismatched unrelated $(\mathrm{n}=1)$ and haploidentical $(n=1)$. 6/6 conditioning regimens contained either muromonab$\mathrm{CD}_{3}$ or anti-thymocyte globulin (ATG) and cyclophosphamide, 4/6 fludarabine (FLU), 2/6 total lymphoid irradiation and 5/6 thiotepa (THT). Grafts were either CD 34+ selected and/ or CD 3/ 19 depleted, using the Miltenyi CliniMACS device for manipulation. Mean yield of purified CD $34+$ cells was $11.99 \times 10$ E6/kg (8.14-24.3) and median CD $3+$ number was $5.27 \times 10 \mathrm{E}_{4} / \mathrm{kg}(0.84-10)$.

Results. All patients engrafted median on day 10 (8-12). There was no GVHD prophylaxis in 2 patients and either cyclosporine-A or mycophenolate mofetil up to day +60 in 4 patients. 1 MUD-HSCT recipient developed GVHD (grade I-II) on day +125 . All children are alive with a median follow-up of 65.5 months (7-139) with stable complete engraftment.

Conclusion. Long interval to transplant, multiple transfusion support and long term immunosuppression before HSCT are associated with poor alternative donor HSCT- outcomes in SAA. Cyclophosphamide conditioning including FLU, THT and ATG, high doses of purified $34+$ cells and/or $\mathrm{CD}_{3} / 19$ depletion may facilitate rapid engraftment and prevent GVHD.

7.18 „Pure red-cell aplasia“ (PRCA) als ungewöhnliche Erstmanifestation einer akuten lymphatischen Leukämie vom B-Vorläufer-Typ

U. Wanz, H. Lackner, P. Sovinz, W. Schwinger, M. Benesch, V. Strenger, C. Urban

Klinische Abteilung für Pädiatrische Hämatologie/Onkologie; Univ.-Klinik für Kinder- und Jugendheilkunde; Medizinische Universität Graz

Einleitung. Die akute lymphatische Leukämie (ALL) ist eine klonale hämatologische Erkrankung, die sich durch inadäquate Hämatopoese als Folge exzessiver Proliferation von Blasten auszeichnet. Entsprechend manifestiert sich diese Erkrankung mit Symptomen, die Ausdruck eines Knochenmarkversagens sind. Eine reine Störung der Erythropoese ist für ALL-Patienten sehr ungewöhnlich und bisher nach unserem Wissen für den B-Vorläufer-Typ erst einmal beschrieben worden.

Fallbericht. Ein 15-jähriger Junge wird wegen Müdigkeit, Belastungsdyspnoe und rezidivierender Bauchschmerzen beim Hausarzt vorstellig. Von dort erfolgt eine Zuweisung wegen massiver Anämie zur Abklärung. Bei der klinischen Untersuchung fallen ein reduzierter Allgemeinzustand und eine blasse Haut auf. Blutbild: $\mathrm{Hb} 7 \mathrm{~g} / \mathrm{dl}$, Ery 2,o ml/ $\mu \mathrm{l}, \mathrm{MCV} 104 \mathrm{fl}$, Retikulozyten $2 \%$, Leukozyten $487 \mathrm{o} / \mu \mathrm{l}$, Thrombozyten $251.000 / \mu l$. Der periphere Blutausstrich ist unauffällig. Die unter der Verdachtsdiagnose PRCA durchgeführte Knochenmarkpunktion ergibt ein völliges Fehlen der Erythropoese und lymphatische Blasten (82\%) vom L1-Typ nach der FAB-Klassifikation. Die Immunophänotypisierung bestätigt die Diagnose einer B-Vorläufer-ALL. Weitere laborchemische Untersuchungen ergaben einen erhöhten Erythropoetinspiegel $(>2800 \mathrm{mU} / \mathrm{ml})$. Ein serovirologischer Befund zeigt keine frische Infektion mit Parovirus B19 oder Epstein-Barr-Virus. Die Therapie erfolgte gemäß dem AIEOP-BFM ALL Protokoll mit Prednison, MTX intrathekal, Vincristin, Daunorubicin. Am Tag 15 ergibt die Knochenmarkspunktion eine prominente stark linksverschobene Erythropoese bei einer Blastenreduktion auf 1\%.

Schlussfolgerung. Der Mechanismus des alleinigen Fehlens einer Erythropoese als Erstsymptom einer ALL ist derzeit noch ungeklärt. Ähnliche Fallberichte gibt es nur für T-ALL und chronisch lymphatische Leukämien.

\subsection{Hämophagozytäre Lymphohistiozytose}

S. Wurm, A. Biebl, G. Ebetsberger-Dachs, K. Jilka, K. Schmitt Kinderklinik Linz

Definition. Überschießende, ineffektive Immunantwort mit Aktivierung von Lymphozyten und Histiozyten mit Hyperzytokinämie und Hämophagozytose

Fallbeispiel. Der 4-jährige Dion wurde im Januar 2011 mit rezidivierendem Fieber bis $40^{\circ} \mathrm{C}$ seit einer Woche und unklaren abdominalen Beschwerden bei palpatorisch vergrößerter Leber und Milz zur weiteren Abklärung aufgenommen. Auffallend hohe Leberwerte, eine Panzytopenie und positive EBV-Serologie wiesen in Richtung des äußerst seltenen Krankheitsbildes. Nach HLH-Kriterien wurde die Diagnose gestellt und die Therapie nach HLH-Schema unverzüglich eingeleitet. Prinzipiell wird zwischen einer familiären und einer erworbenen Verlaufsform unterschieden. Die familiäre Form tritt vorrangig im Säuglingsalter mit einer Inzidenz von 1:50.0oo auf; Knaben und Mädchen 
sind gleich häufig betroffen. Bereits mehrere Gendefekte wurden isoliert. Die erworbene Form tritt eher bei Kleinkindern auf. Die Inzidenz liegt höher als bei der familiären Form inkl. Dunkelziffer; als Auslöser kommen sowohl Viren, Bakterien, Parasiten, Pilze, als auch unter anderem Autoimmunerkrankungen und rheumatische Erkrankungen in Frage. $\mathrm{Zu} 74 \%$ ist eine EBV-Assoziation nachweisbar. Die Diagnose basiert auf der Klinik und erweiterter Labordiagnostik und wird nach den HLH Kriterien gestellt.

Schlussfolgerung. Bei 5 von 9 zutreffenden Kriterien sollte unverzüglich eine Therapie nach HLH-Schema eingeleitet werden. Die Letalität liegt unter eingeleiteter Therapie mit Vepesid, Dexamethason und Sandimmun noch bei $50 \%$.

\subsection{Sichelzellkrankheit: ein zunehmendes Problem in Österreich}

\section{Minkov, P. Zoubek}

\section{St. Anna Kinderspital, Wien}

Einleitung. Die Sichelzellkrankheit (SSD) ist die Folge einer genetisch bedingten Bildung von pathologischem Hämoglobin (HbS) mit verminderter Löslichkeit. Daraus resultieren eine chronische Hämolyse, akute Gefäßverschlussereignisse, sowie eine Vaskulopathie mit chronischen Organschäden. In Österreich gilt diese Krankheit als exotisch und dementsprechend werden die notwendigen Kenntnisse während des Medizinstudiums nicht vermittelt. Ziel dieses Beitrags ist es, Pädiater/Innen über die steigende PatientInnenzahl in Österreich und den daraus folgenden Problemen zu informieren.

Patienten und Methoden. Retrospektive Analyse von 51 Fällen von SSD, diagnostiziert bzw. betreut im St. Anna Kinderspital, Wien seit 1983 . Ergebnisse. Neuerkrankungen zwischen 1988 und 2002 wurden nur sporadisch beobachtet (insgesamt 12 Patienten). Seit 2003 wurden 39 Patienten diagnostiziert, seit 2007 betrug die Anzahl der Neudiagnosen etwa 5-7 pro Jahr. Die PatientInnen stammen aus Nigeria (52\%), Ghana (8\%), Türkei (8\%), Guinea, Angola und Togo mit jeweils 4\%, und selten aus anderen Endemiegebieten. 41 Patienten (80\%) waren homozygot für $\mathrm{HbS}$, und 10 (20\%) doppelheterozygot für $\mathrm{HbS}$ und ein anderes Hämoglobinvariant ( $\mathrm{HbC}, \mathrm{HbD}$ und Beta-Thalassämie). Die beobachteten akuten Ereignisse während der letzen 5 Jahre waren: unzählige Schmerzkrisen, mehrere septische Episoden, Milzsequestrationen, akutes Thoraxsyndrom, paralytischer Ileus, rezidivierende Priapismen, Glaskörperblutung, Hörverlust und 1 Todesfall. Seit 2007 wurden bei den PatientInnen mit SSD jährlich 230-296 ambulante, 6-47 tagesklinische und 358-380 stationäre Tage registriert.

Schlussfolgerung. Mit 5-10 Neudiagnosen pro Jahr ist die SSD nicht mehr als exotisch zu betrachten. Der Betreuungsaufwand ist beträchtlich. Für eine adäquate Versorgung der SSD-PatientInnen gilt es pädiatrische Kompetenzzentren zu etablieren, internationale Behandlungsstandards zu implementieren, sowie eine geregelte Betreuung nach Erreichen des Erwachsenenalters zu sichern.

\subsection{Busulphan-melphalan is the superior myeloablative thera- py (MAT) for high-risk neuroblastoma: results from the HR-NBL1/ SIOPEN Trial}

R. Ladenstein 1 , U. Pötschger ${ }^{1}$, R. Luksch², P. Brock ${ }^{3}$, V. Castel ${ }^{4}$, I. Yaniv ${ }^{5}$, C. Papadakis $^{6}$, G. Laureys ${ }^{7}$, D. Valteau-Couanet ${ }^{8}$

${ }^{1}$ St. Anna Kinderspital \& St. Anna Kinderkrebsforschung, ${ }^{2}$ Instituto nazionale Tumori di Milano, ${ }^{3}$ Great Ormond Street Hospital, ${ }^{4} \mathrm{Hospital}$ La Fee, ${ }^{5}$ Schneider Children's Hospital, Medical Center of Israel, ${ }^{6}$ Athens General Peadiatric Hospital, ${ }^{7}$ University Hospital Genf, ${ }^{8}$ Institut Gustave Roussy

Aims. The HR-NBL1 trial of the European SIOP Neuroblastoma Group randomised 2 MAT regimens with the primary aim to demonstrate superiority based on event free survival (EFS).

Patients and methods. At randomisation closure, 1577 high risk neuroblastoma patients (944 males) had been included since 2002; with INSS stage 4 disease (1369 pts) >1 year, infants (65 pts) and stage 2 und 3
(143 pts) of any age with MYCN amplification. Response eligibility criteria prior to randomisation after Rapid COJEC Induction (J Clin Oncol, 2010) \pm 2 courses of TVD (Cancer, 2003) included complete bone marrow remission and $\leq_{3}$, but improved, mIBG positive spots. The MAT regimens were BuMel (oral busulfan till 2006, $4 \times 150 \mathrm{mg} / \mathrm{m}^{2}$ in 4 equal doses, or after 2006 intravenous use according to body weight and melphalan $140 \mathrm{mg} / \mathrm{m}^{2} /$ day) and CEM (carboplatin ctn. infusion (4×AUC $4.1 \mathrm{mg} / \mathrm{ml} \mathrm{min/day),} \mathrm{etoposide} \mathrm{ctn.} \mathrm{infusion}\left(4 \times 338 \mathrm{mg} / \mathrm{m}^{2}\right.$ day or $4 \times 200 \mathrm{mg} / \mathrm{m}^{2} /$ day $\left.^{*}\right)$, melphalan $\left(3 \times 70 \mathrm{mg} / \mathrm{m}^{2} /\right.$ day or $3 \times 60 \mathrm{mg} /$ $\mathrm{m}^{2} /$ day $^{*}$. ${ }^{*}$ reduced if GFR $<100 \mathrm{ml} / \mathrm{min} / 1.73 \mathrm{~m}^{2}$ ). A minimum of $3 \times 10 \mathrm{E} 6$ $\mathrm{CD}_{34} / \mathrm{kgBW}$ PBSC were requested. VOD prophylaxis included ursadiol, but not prophylactic defibrotide. Local control included surgery and radiotherapy of $21 \mathrm{~Gy}$. A total of 598 patients were randomised (296 BuMel, $302 \mathrm{CEM})$. The median age at randomisation was 3 years (1-17.2) with a median follow-up of 3 years.

Results. At the last analysis, the Peto rule of $\mathrm{p}<0.001$ was met. A significant difference in EFS in favour of BuMel (3-years EFS $49 \%$ vs. $33 \%$ ) was observed as well as for overall survival (3-years OS $60 \%$ vs. $48 \%$, $\mathrm{p}=0.004)$. This difference was mainly related to the relapse and progression incidence, which was significantly $(\mathrm{p}<0.001)$ lower with BuMel ( $48 \%$ vs. $60 \%$ ). The severe toxicity rate up to day 100 (ICU and toxic deaths) was below $10 \%$, but was significantly higher for CEM ( $p=0.014)$. The acute toxic death rate was $3 \%$ for BuMel and $5 \%$ for CEM (NS). The acute MAT toxicity profile favours the BuMel regimen in spite of a total VOD incidence of $18 \%$ (grade $3.5 \%$ ). Based on these results and following advice from the DMC, the randomisation was closed early.

Conclusions. BuMel was demonstrated to be superior to CEM and hence is recommended as standard treatment.

7.22 The prognostic value of semi-quantitative I-123 mibg scintigraphy at diagnosis in high risk neuroblastoma: validation of the SIOPEN score method

R. Ladenstein', U. Pötschger', A. Boubaker ${ }^{2}$, Z. Bar-Sever ${ }^{3}$, A. Staudenherz ${ }^{4}$, M. R. Castellani ${ }^{5}$, B. Lambert ${ }^{6}$, D. Calteau-Couanet ${ }^{7}$, V. Lewington ${ }^{8}$

${ }^{1}$ St. Anna Kinderspital \& St. Anna Kinderkrebsforschung, ${ }^{2}$ Centre Hospitalier Universitaire Caudois, ${ }^{3}$ Schneider Children's Hospital, Medical Center of Israel, ${ }^{4}$ Vienna General Hospital, ${ }^{5}$ Istituto Nazionale Tumori di Milano, ${ }^{6}$ Ghent University Hospital, ${ }^{7}$ Institut Gustace Roussy, ${ }^{8}$ Guy's and St. Thoma's NHS Foundation, Trust, Guy's Hospital

Background. A semi quantitative reporting method developed by an international expert panel (1) was used to evaluate the role of 1-123 meta-lodoBenzylGuanidine [1231 mIBG] imaging in high risk neuroblastoma [HRN].

Methods. Patterns of skeletal $1231 \mathrm{mlBG}$ uptake were assigned numerical scores (Mscore) ranging from o (no metastasis) to 72 (diffuse metastases) within 12 body areas as described previously (1). 271 anonymised, paired image data sets acquired at diagnosis and on completion of Rapid COJEC induction chemotherapy were reviewed, constituting a representative sample of 1602 children treated prospectively within the HR-NBL 1/ SIOPEN trial. Pre-and posttreatment Mscores were compared with bone marrow cytology (BM) and 3 year event free survival (EFS).

Results. 224/271 patients showed skeletal MIBG-uptake at diagnosis and were evaluable for MIBG-response. Complete response (CR) on MIBG to Rapid COJEC induction was achieved by $66 \%, 34 \%$ and $15 \%$ of patients who had pretreatment Mscores of $<18(n=65,29 \%), 18-44(n=95,42 \%)$ and $45(\mathrm{n}=64,28.5 \%)$ respectively (chi squared test $\mathrm{p}<0.0001)$. Mscore at diagnosis and on completion of Rapid COJEC correlated strongly with $\mathrm{BM}$ involvement $(\mathrm{p}<\mathrm{o} .0001)$. The correlation of pre score with post scores and response was highly significant $(\mathrm{p}<0.001)$. Most importantly, the 3 -year EFS in 47 children with Mscore o at diagnosis was 0.68 ( \pm 0.07$)$, by comparison with $0.42( \pm 0.06), 0.35( \pm 0.05)$ and $0.25( \pm 0.06)$ for patients in pre-treatment score groups $<18,18-44$ and 45 , respectively $(\mathrm{p}<0.001)$. An Mscore threshold of 45 at diagnosis was associated with significantly worse outcome by comparison with all other Mscore groups $(\mathrm{p}=0.029)$. The 3-year EFS of $0.53( \pm 0.07)$ of patients in metastatic CR (mIBG and 
$\mathrm{BM})$ after Rapid Cojec ( $33 \%)$ is clearly superior to patients not achieving metastatic CR (0.24 ( $\pm 0.04 ; \mathrm{p}=0.005)$.

Conclusions. SIOPEN scoring of $1231 \mathrm{mlBG}$ imaging has been shown to predict response to induction chemotherapy and outcome at diagnosis in children with HRN.

Lewington $V$ et al (2009) Development of a semi-quantitative I-123 mIBG reporting method in HRN. J Nucl Med 50:1379

\section{Immunologie}

\subsection{Prospektiver Einsatz des molekularen Ansprechens zur Risikostratifizierung von Kindern und Jugendlichen mit akuter lymphoblastischer Leukämie - Ergebnisse der AIEOP-BFM ALL 2000 Studie in Österreich}

A. Attarbaschi', R. Panzer-Grümayer ${ }^{2}$, C. Urban ${ }^{3}$, B. Meister ${ }^{4}$, G. Ebetsberger $^{5}$, N. Jones ${ }^{6}$, B. Ausserer ${ }^{7}$, R. Kerbl ${ }^{8}$, W. Kaulfersch ${ }^{9}$, M. Dworzak $^{1}$, O. Haas $^{1}$, H. Gadner', G. Mann ${ }^{1}$

${ }^{1}$ St. Anna Kinderspital, UKKJ, MUW, Wien, ${ }^{2}$ St. Anna Kinderkrebsforschung, Wien, ${ }^{3}$ Univ. Klinik für Kinder- und Jugendheilkunde Graz, ${ }^{4}$ Univ. Klinik für Kinder- und Jugendheilkunde Innsbruck, ${ }^{5}$ Landesfrauen und -Kinderklinik Linz, ${ }^{6}$ Landeskrankenhaus Salzburg, ${ }^{7}$ Landeskrankenhaus Dornbirn, ${ }^{8}$ Landeskrankenhaus Leoben, ${ }^{9}$ Landeskrankenhaus Klagenfurt

Die zwischen Juni 1999 und Dezember 2009 in Österreich durchgeführte multizentrische Studie AIEOP-BFM ALL 2000 zur Behandlung von 591 Kindern und Jugendlichen mit akuter lymphoblastischer Leukämie (ALL) hat erstmalig die quantitative Erfassung der minimalen Resterkrankung (MRD) an 2 Zeitpunkten während der Therapie (Tag 33 und Tag 78) zur prospektiven Risikostratifizierung der Patienten verwendet. Patienten mit nicht mehr messbaren leukämiespezifischen Markern (mit einer Sensitivität von mindestens $10^{-4}$ ) zu beiden Zeitpunkten wurden dem Standardrisikoarm (SRG) zugeordnet. Patienten mit einer hohen MRD von $\geq 10^{-3}$ am Tag 78 qualifizierten sich für den Hochrisikoarm (HRG), während die übrigen Patienten im mittleren Risikoarm (MRG) behandelt wurden. MRD-Standardrisiko-Patienten umfassten 30\% der Studienpopulation und hatten ein Ereignisfreies Überleben (EFS) nach 6 Jahren von $90 \%$. 60\% der Kinder wurden als MRD-Mittelrisiko-Patienten identifiziert mit einem 6-Jahres-EFS von $80 \%$ und $10 \%$ als MRDHochrisiko-Patienten mit einem 6-Jahres-EFS von 65\%. Das Gesamt-EFS lag bei $80 \%$. Detaillierte Analysen ergaben, dass die MRD in praktisch allen klinisch relevanten Subgruppen (Alter, Geschlecht, Leukozytenzahl bei Diagnose, NCI-Kriterien, Immunphänotyp, Genotyp und Prednisone Response) in der Lage war, Patienten mit einer sehr guten und sehr ungünstigen Prognose zu identifizieren. Wir konnten auch zeigen, dass insbesondere bei Kindern mit B-Zellvorläufer ALL die Kombination von beiden MRD-Zeitpunkten prognostisch bedeutsam ist, da zum Beispiel Patienten mit einer MRD von $\geq 10^{-3}$ am Tag 33 und jeglichem positivem Signal am Tag 78 ein schlechtes Ergebnis vorwiesen. Hingegen erscheint bei Kindern mit T-Zellvorläufer ALL die MRD zum Tag 78 allein ausreichend, um das Rezidivrisiko festzustellen. Auf Grund der dargestellten Ergebnisse wird die im Dezember 2010 gestartete AIEOP-BFM ALL 2009 Studie die MRD in verfeinerter Form weiterhin als vorrangigen Faktor zur Risikostratifizierung verwenden.

\subsection{The Austrian registry of patients with primary immunodefi- ciencies - two years experience of a national subnetwork of the European Society of Immunodeficiencies (ESID)}

N. Haninger ${ }^{1}$, W. Schwinger ${ }^{2}$, G. Ebetsberger-Dachs ${ }^{3}$, E. Förster-Waldl' ${ }^{1}$, M. G. Seidel ${ }^{2}$

${ }^{1}$ Univ. Klinik für Kinder- und Jugendheilkunde, Abt. f. Neonatologie, Pädiatrische Intensivmedizin und Neuropädiatrie, Medizinische Universität Wien, ${ }^{2}$ Univ. Klinik für Kinder- und Jugendheilkunde, Abt. f. Pädiatrische Hämato-Onkologie, Medizinische Universität Graz, ${ }^{3}$ Landes-Frauen- und
Kinderklinik Linz, Abt. f. Pädiatrische Hämato-Onkologie, Landes-Frauenund Kinderklinik Linz

Die European Society of Immunodeficiencies (ESID) ist eine Non-Profit-Organisation die 1983 gegründet wurde. Ziel der ESID-Datenbank ist ein Informationsaustausch zum Nutzen für Patienten mit primären Immundefekten (PID), und somit die Erforschung von Ursache, Mechanismus und Behandlung dieser Erkrankungen voran zu treiben, sowie eine Standardisierung in Diagnostik, Therapie und Forschung $\mathrm{zu}$ erreichen. Es ist eine komplett pseudonymisierte, strukturierte $\mathrm{Da}-$ tenbank für eine Vielzahl von Parametern über Klinik, Laborwerte, Molekulargenetik und Therapie der PID.

Bereits über 13.00o Patienten sind europaweit registriert, Länder wie Deutschland, Italien, Frankreich, Großbritanien, Spanien und die Türkei sind maßgeblich am Wachstum der Datenbank beteiligt. Während es in einigen Ländern Nationale Dokumentationszentren mit Subzentren für einzelen Kliniken gibt, stehen auch einzelne Kliniken selbständig im ESID-Register angeführt. Bisher sind 7o Patienten in Österreich registriert, davon ein Großteil aus dem St. Anna Kinderspital. Dass knapp 90\% der österreichischen Patienten im St. Anna Kinderspital registriert wurden entspricht nicht der Epidemiologie, sondern zeigt dass viele österreichische Zentren noch nicht begonnen haben, Patienten mit primären Immundefekten in dieses Register einzutragen.

Die österreichische Teilnahme am ESID-Register durch die Arbeitsgruppe für Pädiatrische Immunologie der ÖGKJ (AGPI) ist zum einen wichtig für die Vernetzung der österreichischen pädiatrischen Immunologen, andererseits bietet sie direkte Vorteile für die Qualität im Bereich der Patientenbetreuung und ermöglicht durch internationale Kontakte ein akkordiertes, modernes Vorgehen in den Bereichen Diagnose und Therapie. Zudem ermöglicht sie die Partizipation an multinationalen Forschungsprojekten in den Bereichen „basic and clinical research", was speziell im Bereich von seltenen Erkrankungen wie den primären Immundefekten von äußerster Bedeutung für den Fortschritt der Medizin ist.

\subsection{Morbus Kikuch-Fujimoto in a 7-year-old boy: a case report}

\section{Rhomako, F. Eitelberger}

Klinikum Wels-Grieskirchen, Kinderabteilung

In this report the course of Kikuchi-Fujimoto disease (KFD) in a seven year old boy who was admitted due to fever of unknown origin is described. The fever had already lasted for more than two weeks. The administered antibiotic therapy - as tonsillitis was suspected initially - had been without effect. While the blood work showed anaemia and leucopenia, LDH- and transaminases, as well as the erythrocyte sedimentation rate and the C-reactive protein levels were elevated. Clinically the child presented with intermittent abdominal pain, frequent fever spikes, night sweats, loss of weight and a cervical lymphadenopathy.

We diagnosed the boy with KFD by the clinical features and the histological findings, a necrotizing histocytic lymphadenitis. As he additionally developed a pseudoporphyria triggered by proxen, we started him on prednisolone. The fever subsided promptly and the skin lesions healed.

KFD is an idiopathic rare and self-limiting condition. As there are few paediatric reports, we find it crucial to include this disease early in the differential diagnosis of lymphadenopathy in children to avoid unnecessary diagnostic procedures and distinguish the disease from severe conditions as lymphoma or systemic lupus erythematosus. 
8.4 Evaluation of toll-like receptor agonists as potential adjuvants - in vitro studies on neonatal antigen presenting cells

S. Schüller ${ }^{1}$, E. A. Gindl' ${ }^{1}$ K. Sadeghi' ${ }^{1}$, A. Spittler ${ }^{2}$, H. Helmer ${ }^{3}$, P. Husslein ${ }^{3}$, A. Berger ${ }^{1}$, A. Pollak ${ }^{1}$, E. Förster-Wald ${ }^{1}$

${ }^{1}$ Dept. of Pediatrics and Adolescent Medicine, Medical University of Vienna, Vienna, Austria, ${ }^{2}$ Dept. of Surgery, Medical University of Vienna, Vienna, Austria, ${ }^{3}$ Dept. of Obstetrics and Gynecology, Medical University of Vienna, Vienna, Austria.

Introduction. Human newborns, particularly preterm newborns display functional immunodeficiencies of the innate and the adaptive immune system resulting in impaired responses against vaccines. Early and efficient vaccination strategies in preterm neonates could help to avoid severe infections with long term sequelae, improving the individual clinical outcome and reducing health care costs. Next to alum, the most commonly used adjuvant worldwide, new adjuvants directly targeting mechanisms of innate immunity, namely Toll like receptor (TLR) pathways such as CpG ODN2006, a TLR9 agonist and R848, a TLR7/8 agonist, are currently investigated in preclinical settings in adults. We aim to analyze the immunostimulatory mode of vaccine adjuvants, being in clinical/preclinical use, on human leucocytes from preterm neonates by measuring activation and maturation makers on antigen presenting cells (APC) upon adjuvants stimulation.

Materials and methods. We investigated APC, namely monocytes and $\mathrm{B}$-cells from term and preterm neonates (CBMC) in comparison to APC from healthy adults (PBMC) by specific surface staining and flow cytometric analysis. CBMC and PBMC were stimulated with alum, ODN2006, R848 and LPS. After 24 hours of adjuvants exposure, a four-color staining was performed in order to quantify maturation and activation markers on the cell surface of monocytes and B-cells.

Results. Preliminary data indicate that the substance R848 increases CD14, CD8o and HLA-DR-expression on monocytes from CBMC while ODN20o6 appears to upregulate CD40, CD86 and HLA-DR, an effect being most prominent on cells from preterm neonates. Our results indicate that R848, as well as ODN2006 have the potential to activate monocytes and $\mathrm{B}$-cells from neonates in a differential manner , showing distinct differences to the traditional adjuvant alum.

Conclusion. R848 and ODN2006, two TLR agonists, have the potential to induce maturation and activation markers on monocytes and $\mathrm{B}$ cells from term and preterm neonates, and thus might be interesting candidates for future vaccine adjuvant development for this age group.

\subsection{Newborn screening for lymphopenia and severe combined immunodeficiencies (SCID) - current state and proposal for an Austrian initiative to reduce morbidity and mortality from congenital risk of severe infections}

M. Seidel' ${ }^{1}$, D. Kasper ${ }^{2}$, G. Fischer ${ }^{3}$, U. Wintergerst ${ }^{4}$, W. Schwinger ${ }^{5}$, G. Mann $^{6}$, A. Pollak ${ }^{2}$, E. Förster-Waldl2 ${ }^{2}$ J. Brunner ${ }^{6}$

${ }^{1}$ Medizinische Universität Graz, Häm.-Onk.-Immunol. Amb, ${ }^{2}$ Univ. Klinik für Kinder- und Jugendheilkunde, Wien, ${ }^{3}$ Univ. Klinik für Transfusionsmedizin Wien, ${ }^{4}$ LKH Brauau, ${ }^{5}$ Universitätsklinik für Kinder- und Jugendheilkunde Graz, ${ }^{6}$ Universitätsklinik für Kinder- und Jugendheilkunde Innsbruck

Severe combined immunodeficiencies (SCID) are rare inborn errors which may be asymptomatic at birth but fatal with occurrence of a first infection, or causing organ damage severely compromising future health. Moreover, interventions such as vaccinations have to be adapted in SCID patients because live vaccines may cause systemic infection with the vaccination agent. In fact, severe courses of rotavirus-vaccine infections have been reported in patients identified to have SCID [1] later on. A major proportion of SCID patients are estimated to die undiagnosed, and early diagnosis may reduce mortality by approximately two thirds [2][3]. Thus, the diagnosis of SCID is regarded as emergency.
The incidence of SCID is estimated 1:30,000-1:66,000 and higher than that of many conditions defined by the American College of Medical Genetics as "core" targets of newborn screening [4][5]. Considering the availability of confirmatory laboratory tests and potential cure by early treatment, i.e. hematopoietic stem cell transplantation, the criteria for implementation of a newborn screening are fulfilled [4][6]. Identification of SCID upon screening for severe T-cell reduction is feasible. Molecular detection of T-cell receptor excision circles (related to T-cell numbers) in DNA isolated from dried blood spots (Guthrie cards) [7] [8] is associated with relatively low costs and already led to the implementation of newborn screening for SCID/severe T-cell lymphopenia in several US states [9][10]. Pilot projects in European countries are ongoing. Taken together, these facts and developments suggest that the feasibility and effectiveness of a newborn screening in Austria for SCID and T-cell lymphopenia should be explored.

\section{Referenzen}

1. Bakare N, Menschik D, Tiernan R, Hua W, Martin D (2010) Severe combined immunodeficiency (SCID) and rotavirus vaccination: reports to the Vaccine Adverse Events Reporting System (VAERS). Vaccine 28(40):6609-6612

2. Chan A, Scalchunes C, Boyle M, Puck JM (2010) Early vs. delayed diagnosis of severe combined immunodeficiency: A family perspective survey. Clin Immunol

3. Brown L, Xu-Bayford J, Allwood Z, Slatter M, Cant A, Davies EG et al (2011) Neonatal diagnosis of severe combined immunodeficiency leads to significantly improved survival outcome: the case for newborn screening. Blood 117(11):3243-3246

4. Newborn screening: toward a uniform screening panel and system--executive summary. Pediatrics. 2006;117(5 Pt 2):S296-307

5. Calonge N, Green NS, Rinaldo P, Lloyd-Puryear M, Dougherty D, Boyle C et al (2010) Committee report: method for evaluating conditions nominated for population-based screening of newborns and children. Genet Med 12(3):153-159

6. Lindegren ML, Kobrynski L, Rasmussen SA, Moore CA, Grosse SD, Vanderford $M L$ et al (2004) Applying public health strategies to primary immunodeficiency diseases: a potential approach to genetic disorders. MMWR Recomm Rep 53(RR-1):1-29

7. Baker MW, Grossman WJ, Laessig RH, Hoffman GL, Brokopp CD, Kurtycz DF et al (2009) Development of a routine newborn screening protocol for severe combined immunodeficiency. The Journal of allergy and clinical immunology 124(3):522-527.

8. Chan K, Puck JM (2005) Development of population-based newborn screening for severe combined immunodeficiency. The Journal of allergy and clinical immunology 115(2):391-398

9. Hale JE, Bonilla FA, Pai SY, Gerstel-Thompson JL, Notarangelo LD, Eaton RB et al (2010) Identification of an infant with severe combined immunodeficiency by newborn screening. The Journal of allergy and clinical immunology 126(5):1073-1074

10. Routes JM, Grossman WJ, Verbsky J, Laessig RH, Hoffman GL, Brokopp CD et al (2009) Statewide newborn screening for severe T-cell lymphopenia. JAMA. 302(22):2465-2470

\subsection{SCID - Klink und Diagnose bei einem 4 Monate alten Mädchen}

M. Szkwarek' ${ }^{1}$ H. Wolf ${ }^{2}$, A. Lischka' ${ }^{1}$, H. Boztug ${ }^{3}$, S. Matthes-Martin ${ }^{3}$

${ }^{1}$ Kinderklinik Glanzing, Wilhelminenspital der Stadt Wien, ${ }^{2}$ Immunologische Tagesklinik, Wien, ${ }^{3}$ St. Anna Kinderspital, Wien

Severe Combined Immunodeficiency (SCID) ist eine heterogene Gruppe von angeborenen, genetisch bedingten Erkrankungen des Immunsystems. Sie ist charakterisiert durch das Fehlen von funktionstüchtigen T-Zellen. Dies führt zu einer Störung der zellulären Immunantwort. Je nach SCID Form fehlen unter Umständen ebenfalls die NK-Zellen, wobei immer die Funktion, manchmal auch die Anzahl der B-Lymphozyten und somit die humorale Immunität beeinträchtigt ist. Die klinische Manifestation ist eine erhöhte Anfälligkeit 
für schwere, rezidivierende Infektionen, Diarrhoe und Gedeihstörung. Unbehandelt versterben betroffene Kinder zumeist im ersten Lebensjahr. Die einzige kurative Therapie besteht in der allogenen Stammzelltransplantation. Die Diagnose wird meist nach rezidivierenden, oft schweren Infektionen gestellt.

Wir berichten über ein 4 Monate altes Mädchen, das mit persistierendem Husten und Sauerstoffbedarf an unserer Notfallambulanz vorstellig wurde. Nach frustranen Therapieversuchen bei V. a. obstruktive, sauerstoffbedürftige Bronchitis und antibiotischer Kombinationstherapie bei V. a. Pneumonie, wurde die klinisch immunologische Abklärung durchgeführt. Diese zeigte massiv reduzierte bis fast fehlende T-Zellpopulation und CD4-Subset, NK-Zellen im Normbereich und nicht nachweisbare B-Zellen. Der Befund bestätigte die Diagnose T-BNK+SCID z. B. im Sinne einer RAG-Mutation. Aufgrund der Diagnose wurde eine sofortige Transferierung an das St. Anna Kinderspital zur Stammzellentransplantation durchgeführt. Dort konnte sie haploident von ihrer Mutter transplantiert werden.

SCID erfüllt die Kriterien für ein Neugeborenen-Screening (asymptomatisch bei Geburt, ernste bzw. tödliche Folgen ohne Therapie, gutes Outcome bei früher Diagnose und Therapie), welches im Rahmen des NBSProgramms mittels Trockenblutkärtchen in einigen amerikanischen Bundesstaaten bereits erfolgreich als Pilotprojekt durchgeführt wurde.

\subsection{Thymektomie im Kindesalter: Rückgang der CD4+-T-Zellen und verzögerte Immunantwort nach Impfung}

M. Zlamy' ', C. Gögele', R. Würzner², R.Geiger³ , L. B. Zimmerhackl'1, M. Prelog 1,4

'Department Pädiatrie I, Medizinische Universität Innsbruck, Österreich, ${ }^{2}$ Department für Hygiene, Mikrobiologie und Sozialmedizin, Medizinische Universität Innsbruck, Österreich, ${ }^{3}$ Department Pädiatrie III, Medizinische Universität Innsbruck, Österreich, ${ }^{4}$ Universitätskinderklinik, Universität Würzburg, Deutschland

Fragestellung. Ein Ziel unserer Studie war es den Einfluss der Thymektomie im frühen Kindesalter auf die naiven T-Zell-Subpopulationen, die T Cell Receptor Excision Circles (TRECs) und die Ki67Expression (als Marker für die Thymusfunktion und die periphere Replikationsrate der T-Zellen) in thymektomierten Kindern (TP) und gesunden altersentsprechenden Kontrollen (HC) zu vergleichen. Ein zweites Ziel unserer Studie war es die Immunantwort auf ein NeoAntigen (FSME Impfung) bei TP und HC zu vergleichen.

Methoden. Naive T-Zellen $\left(\mathrm{CD}_{4}+\mathrm{CD}_{45} \mathrm{RA}+\mathrm{CD} 62 \mathrm{~L}+\right)$ und Gedächtnis T-Zellen $(\mathrm{CD} 28+\mathrm{CD} 45 \mathrm{RO}+)$ von $101 \mathrm{TP}$ und $81 \mathrm{HD}$ wurden mittels Durchflusszytometrie charakterisiert. 44 TP und 56 HC wurden folgend dem österreichischen Impfplan gegen das Frühsommermeningoencephalitis (FSME) Virus, mittels 3 Teilimpfungen (Tag o, Woche 4 und Woche 48) geimpft (FSME Immun junior, Baxter, Vienna, Austria). Die IgG Titer and IgG spezifischen Aviditäten wurden 4 Wochen nach der zweiten und dritten Teilimpfung sowie 2 Jahre nach der dritten Teilimpfung mittels eines kommerziellen ELISAS (Euroimmun, Lübeck, Germany) bestimmt.

Resultate. TP zeigten erniedrigte Werte an naiven T-Zellen ( $\mathrm{p}<\mathrm{o}, \mathrm{oo1})$ und TRECs $(\mathrm{p}<0,001)$ verglichen mit HC. Die Anzahl der TRECs korrelierte signifikant mit der Zeit nach Thymektomie ( $<<0,001)$. In TP wurde ein höherer Prozentsatz an Ki67 expremierenden naiven TZellen gefunden im Vergleich zu HC ( $\mathrm{p}<0,01)$. Vier Wochen nach der zweiten FSME Teilimpfung zeigten TP 2,2-fach niedrigere IgG Titer als $\mathrm{HD}(\mathrm{p}=0,03)$. Zwei Jahre nach der dritten Teilimpfung zeigten TP und HC vergleichbare IgG Titer und Aviditätsindixes.

Konklusion. Unsere Daten der T-Zell-Subpopulationen in TP sind vergleichbar mit Werten von Probanden nach stattgefundener Thymusinvolution. Die periphere T-Zell-Homöostase in TP ist geprägt durch eine extrathymische Autoproliferation peripherer naiver T-Zellen. TP zeigten eine verzögerte Immunantwort auf die FSME Impfung bei erhaltener Gedächtnis Funktion des Immunsystems. Der Langzeitverlauf wird zeigen ob TP auf Grund dieser Veränderungen ein erhöhtes
Mortalitätsrisiko auf Grund von Infektionen mit Neo-Antigenen im späteren Leben aufweisen.

\section{Infektiologie}

\subsection{Floride Endokarditis bei iatrogenem Cushing-Syndrom}

P. Fritsch' ${ }^{1}$, M. Koestenberger ${ }^{1}$, A. Fandl ${ }^{1}$, K. Finding ${ }^{1}$, B. Heinzl ${ }^{1}$, B. Nagel ${ }^{1}$, G. Zobel', A. Gamilscheg' $^{1}$

${ }^{1}$ Klinische Abteilung für päd. Kardiologie, Universitätsklinik für Kinder- und Jugendheilkunde, Medizinische Universität Graz, ${ }^{2}$ Allgemeine Einrichtungen, päd. Intensivstation, Universitätsklinik für Kinder- und Jugendheilkunde, Medizinische Universität Graz

Das Risiko von Immunsuppremierten an infektiöser Endokarditis zu erkranken ist signifikant erhöht. Das therapuetische Vorgehen bei infektiöser Endokarditis ist in den Richtlinien von 2009 klar geregelt. Nicht immer lässt der Zustand der Patienten ein Vorgehen nach Schema zu.

Ein 10 Monate alter Säugling mit Trisomie 21 in stark reduziertem Allgemeinzustand, der aufgrund eines therapieresistenten Westsyndroms eine Hochdosissteroid-Therapie erhielt und ein ausgeprägtes CushingSyndrom zeigte, wurde mit einer bakteriellen Endokaridits an unserer Intensivstation aufgenommen. Der Patient zeigte Auflagerungen an der Aorten- und Pulmonalklappe bis zu 1,7 cm. Trotz der Operationsindikation entsprechend der Richtlinien entschieden wir uns aufgrund des reduzierten Allgemeinzustandes und der Grundkrankheiten für eine konservative Therapie und Absetzen der Steroidtherapie. Nach anfänglicher Besserung zeigte der Patient nach einem Monat Therapie zusätzlich eine bakterielle Spondylodiszitis. Nach Erweiterung der antibiotischen Therapie kam es zu einer raschen Besserung. Die Auflagerung an der Aortenklappe zeigte sich vollständig aufgelöst, die Auflagerung an der Pulmonalklappe war regredient. Der Patient konnte nach acht Wochen antibiotischer Therapie in gutem Allgemeinzustand und ohne Anfälle nach Hause entlassen. Der Patient 10 Monate nach Beendigung der Therapie immer noch beschwerdefrei.

Trotz kompliziertem Verlauf einer bakteriellen Endokarditis mit embolischem Geschehen und trotz Kontraindikation zur Operation bei multimorbidem Allgemeinzustand des Patienten konnte unser Patient nach acht Wochen antibiotischer Therapie in bestem Allgemeinzustand entlassen werden.

\subsection{Evaluation des Österreichischen Risikoscores zur Prophylaxe schwerer RSV-Infektionen bei Frühgeborenen SSW 33-35}

N. Haninger, A. Oberleitner, J. Straub, J. Böhm, F. Cardona, A. Berger Medizinische Universität Wien

Hintergrund. Frühgeborene (FG) der Schwangerschaftswochen 33-35 werden zunehmend als Risikopopulation für einen schweren Verlauf einer Infektion mit Respiratory Syncytial Viren (RSV) erkannt. Eine generelle Prophylaxe dieser Patientengruppe mit Palivizumab ist aus ökonomischen Gründen nicht durchführbar, weshalb unterschiedliche Risikoscores entwickelt wurden mit dem Ziel, Kinder mit dem höchsten Risiko für Hospitalisierung zu identifizieren und so die Prophylaxe gezielt einsetzen zu können.

Ziel. Ziel dieser Studie war die Evaluation des 2008 eingeführten Österreichischen Risikoscores für die RSV-Prophylaxe von FG der SSW 33-35. Methoden. Prospektiver Einschluss aller zwischen 1.8.2010 und 31.3.2011 an der Universitätsfrauenklinik Wien geborenen Kinder der SSW 33-35. Zweiwöchentliche Telefoninterviews zu Gesundheitszustand, stationären Aufenthalten, Arztbesuchen und Datum/ Dosierung der Palivizumabgaben über die RSV-Saison.

Ergebnisse. Von 116 im Studienzeitraum geborenen Kindern wurden 114 in die Studie eingeschlossen. 11 Patienten erreichten 4 Punkte anhand des Österreichischen Risikoscores (10\%), insgesamt 17 Patienten 
erhielten eine medikamentöse RSV Prophylaxe (15\%). Eine Rehospitalisierung aufgrund respiratorischer Probleme war bei 6 Patienten notwendig (5,3\%). Davon lag bei 5 Patienten eine Infektion mit RSV vor $(4,4 \%)$, ein Patient hatte eine Infektion mit Pertussis. Alle Patienten mit RSV-Infektion wurden an eine neonatologische Intensiv- oder Intermediate-Care-Station aufgenommen, ein Patient musste maschinell beatmet werden. Alle hospitalisierten Patienten waren in der Gruppe ohne Palivizumabprophylaxe.

Konklusion. Unter Einsatz des Österreichischen Risikoscores sowie Einzelfallindikationsstellung wurden 15\% der studierten Kohorte einer Palivizumabprophylaxe zugeführt. Die RSV-Rehospitalisierungsrate lag bei $4,4 \%$ und betraf ausschließlich Kinder ohne Palivizumabprophylaxe.

\subsection{Treatment of chickenpox-caused amaurosis}

\section{J. Hruby, R. Seidl}

\section{AKH Wien Kinderklinik}

We report a very rare case of Varicella infection (chickenpox) leading to bilateral amaurosis a few days after onset in an immunocompetent child. A previously healthy girl with the age of six presented with Varicella-Infection and acute amaurosis on both eyes. The fundoscopy showed an optic neuritis and retinitis with haemorrhage and oedema, but no necrotic areas were detected.

This is the second reported case of optic retinitis/neuritis due to Varicella infection in an immunocompetent child. Severe forms with necrotizing retinopathy and optic neuritis are normally only seen in immunocompromised individuals, like HIV-positive patients. Aim of this report is to recommend the right timing of treatment. Cortison therapy was initially postponed until the viral infection was controlled and supported the immune system with antiviral-treatment throughout steroidtreatment, including immunoglobulins. Due to these interventions the danger of a systemic infection and subsequent meningitis or encephalitis was minimized and we were able to treat the optic neuritis with high-dose methylprednisolone. Initially diminished visually evoked potentials showed a marked improvement within days of treatment.

\subsection{Präpartale HIV-Infektion einer Frühgeburt (29+6 SSW)}

N. Memaran, D. Endress, P. Haidl, S. Schacherl, A. Ramasani, A. Weiss, R.Ollerieth

Kinderklinik Glanzing, Wilhelminenspital der Stadt Wien

Case report. Das Hauptrisiko für die vertikale Ansteckung mit HIV besteht peri- und postpartal. Sehr wenige Fälle von präpartaler Anstekkung wurden publiziert. Wir berichten über einen Fall von gesicherter präpartaler Infektion bei einer Frühgeburt in der 29+6 SSW. Bei der Kindsmutter wurde die HIV- und HBV-Infektion zum Zeitpunkt der Geburt diagnostiziert. Antenataltransport an das Geburtszentrum, Sectio, Apgar 8/9/9,GG 1480 g, KL 40,5 cm, Ku 28 cm. Nach Diagnosestellung bei der Mutter Etablierung der antiretroviralen Kombinationstherapie mit Lamivudin, Zidovudin, Nevirapin, sowie Aktiv-/Passiv- Immunisierung gegen HBV. Die initiale Virenlast war mit 121.600 copies/ml beweisend für die intrauterine Infektion, im Immunstatus CD4+ Zellen mit 11\% (1299/ $\mu$ abs.) deutlich reduziert. Die Resistenzbestimmung ergab bereits Mutationen.

Primär bestand keine Therapieindikation der CMV-Infektion wegen fehlender Organbeteiligung. Pneumocysts carinii-Prophylaxe mit Cotrimoxazol, antimykotische Prophylaxe mit Fluconazol; supportiv erfolgten Immunglobulingaben. Atemunterstützung mittels nasalem CPAP anfänglich, danach erhöhter Sauerstoffbedarf bis zu 38 SSW. Im weiteren Verlauf manifestierte sich die CMV-Infektion als Chorioretinitis des rechten Auges. Unter sechswöchiger parenteraler Gancyclovir-Therapie kam es zur Ausheilung der Läsion.

Unter der hochwirksamen antiretroviralen Kombinationstherapie kam es zur sukzessiven Reduktion der Viruslast bis unter die Nach- weisgrenze, sowie zu einer Normalisierung der T- und B-Subpopulationen. Als Nebenwirkung traten neben der Erhöhung der Tranaminasen, eine Thrombopenie sowie eine zunehmende Anämisierung auf. Eine Dosisreduktion war zu keinem Zeitpunkt erforderlich. Sonographisch zeigte sich lediglich eine IVH I ${ }^{\circ}$ bds., entwicklungsneurologisch war eine dem Gestationsalter entsprechende psychomotorische Entwicklung zu beobachten.

\subsection{Lebensbedrohliche bakterielle Infektionen ausgehend von Varizellen-Hautläsionen - 2 Fallberichte}

E. Resch, V. Haslinger, T. Wagner, U. Ihm, H. Kurz SMZ Ost, Wien

Hintergrund. Varizellen sind nicht immer eine harmlose Erkrankung, auch bei immunkompetenten Kindern können schwere Komplikationen auftreten. Die häufigsten sind bakterielle Superinfektionen der Haut, hervorgerufen meist durch Streptokokken der Gruppe A oder Staphylokokken.

Fall 1. Ein 2-jähriges Mädchen wurde am 5 . Tag der Varizellen Infektion im Rahmen eines septischen Schocks intensivpflichtig. Die Patientin erlitt ein Multiorganversagen und großflächige Nekrosen der Cutis und Subcutis am Stamm. Nach 4 Wochen intensivmedizinischer Maßnahmen und plastischer Deckung der Hautdefekte sind bis auf die großflächigen Narben keine schweren Spätfolgen verblieben.

Fall 2. Ein knapp 1-jähriges Mädchen entwickelte, ausgehend von einer Varicellenläsion durch eine Superinfektion mit Streptokokken der Gruppe A eine Orbitalphlegmone links mit tiefreichenden Nekrosen. Das septische Zustandsbild besserte sich erst nach chirurgischer Sanierung. Die beträchtlichen Substanzdefekte im Bereich der Orbita machen eine plastische Rekonstruktion des Oberlides erforderlich.

Diskussion. Unter den Komplikationen bei Varizellen werden ca. ein Drittel Haut-Superinfektionen beschrieben, über Verläufe mit lebensbedrohlichen Hautinfektionen bzw. Septitiden existieren nur einzelne Kasuistiken. Ob engmaschige Inspektion der Varizellenläsionen, damit frühzeitiges Erkennen von Superinfektionen und frühzeitige Therapie solche Verläufe verhindern könnten, bleibt offen. Sicher bewiesen ist eine Reduktion von Varizellen-Komplikationen nach Einführung der Varizellen-Impfung.

Konklusion. Lebensbedrohliche und potenziell entstellende Komplikationen von Varizellen durch bakterielle Superinfektionen lassen sich nur durch den interdisziplinären Einsatz von intensivmedizinischen, chirurgischen und plastisch chirurgischen Maßnahmen beherrschen und Spätschäden minimieren. Das derzeitige österreichische Impfprogamm ist zu überdenken.

\subsection{Zytische Echinokokkose der Leber bei einem Migrantenkind}

\section{T. Rojacher}

LKH Villach Pädiatrie

Anamnese und Status. Wir berichten über einen 9-jährigen Knaben mit Migrationshintergrund der wegen unspezifischen Oberbauchbeschwerden an unsere Abteilung transferiert wird. Eine auswärts durchgeführte Abdomensonographie zeigt eine zystische Struktur im rechten Oberbauch. Anamnestisch keine relevanten Vorerkrankungen, Familienanamnese negativ. Im Aufnahmestatus auffällig ein Druck- und Spontanschmerz im rechten Oberbauch, der übrige internistische und neurologische Status unauffällige Diagnostik I: Aufnahmelabor: unauff. Blutbild, im Diff.-BB zeigt sich eine Eosinophilie mit 23\%, eine Erhöhung der GPT sowie der Cholestaseparameter Normwerte für CHE, Pankreasenzyme, Parameter des Zellzerfalls, CK, CRP und Gerinnungsparameter. Infektserologie: Hepatitis A, B, C und HIV negativ. Echinokokkose-Serologie: Nachweis von spezif. Ig G-AK. Das Western Blot-Ergebnis bestätigt eine E. granulosus-Infektion.

Diagnostik II. Oberbauch-Sonographie: $10 \mathrm{~cm}$ große Zyste in Segment IV der Leber mit teilweise verdickter Wand. Im Segment II eine 
irreguläre RF mit ca. $5 \mathrm{~cm}$ DM mit soliden und zystischen Anteilen. Weiters eine umschriebene zystische RF im Segment VIII. MRT-Oberbauch: Bis zu max. 9,2 cm haltende, glatt berandete Zyste im Leberdom. 4,6 cm große, polyzystische RF im Lebersegment II . Die Zyste im Segment VIII zeigt die größte Ausdehnung. MRT-Gehirnschädel: unauff. Röntgen-Thorax: unauff.

Therapie. Präoperative Behandlung mit Albendazol. Nachfolgende perkutane sterilisierende Zystenpunktion im VIII. Lebersegment und schließlich operative Entfernung der bekannten Zysten.

Diskussion. Die zystische Echinokokkose ist weltweit verbreitet und betrifft alle Altersgruppen. Die Gefahr besteht in einer spontanen oder traumatischen Zystenruptur mit akuter allergischer Reaktion und der Sekundärechinokokkose. Als Therapieoptionen stehen neben der chirurgischen Sanierung medikamentöse und perkutan sterilisierende Therapieverfahren zur Verfügung.

\subsection{Augenärztliches Management bei konnataler Toxoplasmose}

E. Stifter ${ }^{1,2}$, D. Endress ${ }^{2}$, T. Neumayer ${ }^{1}$, A. Prusa ${ }^{3}$, M. Hayde ${ }^{3}$, E. Moser ${ }^{1}$, A. Lischka ${ }^{2}$

${ }^{1}$ Universitätsklinik für Augenheilkunde und Optometrie, Medizinische Universität Wien, Wien, ${ }^{2}$ Abteilung für Kinder- und Jugendheilkunde, Kinderklinik Glanzing, Wilhelminenspital, Wien, ${ }^{3}$ Universitätsklinik für Kinder- und Jugendheilkunde, Medizinische Universität Wien, Wien.

Bei konnataler Toxoplasma Infektion ist die interdisziplinäre Zusammenarbeit von Labor, Gynäkologen, Kinderärzten und Augenärzten für eine adäquate Versorgung von entscheidender Bedeutung. In Österreich besteht ein nationales systematisches serologisches Toxoplasmose-Screening für schwangere Frauen im Rahmen der Mutter-Kind-Pass-Untersuchungen. Dieses präventive Programm erkennt Schwangere mit akuter Infektion, um diese einer antiparasitären Therapie zuzuführen. Unerkannte und damit unbehandelte bzw. zu spät behandelte Infektionen während der Schwangerschaft können zu einer schwerwiegenden konnatalen Toxoplasmose des Kindes mit okulären und cerebralen Komplikationen führen. Neben der Problematik einer Retinochoroiditis mit funktioneller Beeinträchtigung besteht auch ein Risiko für okuläre Sekundärkomplikationen und Reaktivierungen bzw. Rezidiven der retinochoroidalen Entzündung auch noch nach Jahren.

Anhand von Bespielfällen wird die Bedeutung der augenärztlichen Diagnose für die Gesamtprognose der betroffenen Kinder, das gesamte Spektrum der ophthalmologischen Therapieoptionen und der Nachbehandlungskonzepte zur Optimierung des funktionellen Endergebnisses präsentiert.

\subsection{Multiplex Pathogen-PCR zur Sepsisdiagnose bei Früh- geborenen}

J. Straub, J. Böhm, K. R. Herkner, A. Pollak, D. C. Kasper, A. Berger Universitätsklinik für Kinder- und Jugendheilkunde, Medizinische Universität Wien, Österreich

Hintergrund. Frühgeborene sind aufgrund der Unreife ihrer Immunabwehr besonders anfällig für schwerwiegende Infektionen und erleiden in ca. $25 \%$ der Fälle zumindest eine Infektion im Rahmen ihres Krankenhausaufenthaltes. Diagnostischer „Goldstandard" ist eine positive Blutkultur, allerdings bleibt diese häufig negativ und ist frühestens nach 2-3 Tagen verfügbar. Moderne molekulargenetische PCR-Analysen sind diagnostische Werkzeuge zur schnellen, sensitiven und spezifischen Analysen von Pathogenen in der Blutbahn Erwachsener. In einer Pilotstudie konnten wir zeigen, dass durch Modifikation der Probenaufbereitung ein Einsatz des Roche Septifast-Systems bei Frühgeborenen mit einem geringen Blutvolumen von minimal $100 \mu \mathrm{lmöglich}$ ist.

Ziele. Ziel der Studie war die prospektive Evaluation des diagnostischen und klinischen Nutzens des Roche Septifast PCR-Systems zur Anwendung in der Neonatologie.
Ergebnisse. In dieser Studie wurden 90 Proben von 78 Patienten (mittleres Geburtsgewicht 1259 g, mittleres Gestationsalter 29+1 Schwangerschaftswochen) ausgewertet. In 24 Fällen einer Blutkultur-positiven Sepsis wurden alle Isolate auch vom PCR-System korrekt detektiert. In 6 der 23 Fälle wurde in der PCR Bakterien-DNA detektiert, welche auf eine Infektion mit mehreren Keimen schließen ließ. 50 Episoden zeigten keine Infektion (negative Blutkultur und keine Antibiotika oder Absetzen der Antibiotika nach maximal 72 h). In 39 dieser Fälle lieferte auch das PCR-System ein negatives Ergebnis, in weiteren 11 Fällen ergab sich ein falsch positiver Wert mittels des Septifast-Systems. Weitere 16 Fälle wurden als klinische Sepsis eingestuft (negative Blutkultur, laborchemisch und klinisch Infektion, Antibiotikum für mindestens 5 d). Bei 12 dieser Episoden zeigte sich ein positiver Keimnachweis mittels des Pathogen PCR Systems.

Konklusion. Die Ergebnisse zeigen eine hohe Sensitivität und Spezifität des PCR-Systems für die Detektion von Keimen im Rahmen der Neugeborenensepsis unter Einsatz eines minimalen Blutvolumens von $100 \mu \mathrm{l}$.

\subsection{ESBL-Keime auf der NICU/PICU: aktuelle Problematik, Trans- mission, Dauerausscheider, klinisches Management}

V. Strenger ${ }^{1}$, A. Grisold², G. Zarfel2 , G. Feierl'2, L. Masoud ${ }^{2}$, B. Resch ${ }^{1,3}$, W. Müller ${ }^{1}$, B. Urlesberger ${ }^{1}$

${ }^{1}$ Universitätsklinik für Kinder- und Jugendheilkunde, Medizinische Universität Graz, ${ }^{2}$ Institut für Hygiene, Mikrobiologie und Umweltmedizin, Medizinische Universität Graz, ${ }^{3}$ Forschungseinheit für neonatale Infektionserkrankungen und Epidemiologie, Medizinische Universität Graz

Extended-Spectrum beta-Lactamasen (ESBL) sind eine Gruppe zahlreicher, molekularbiologisch unterschiedlicher Enzyme, welche bei gram-negativen Stäbchen (i.e.L. bei Enterobakterien) gefunden werden und Resistenzen gegenüber beinahe aller beta-Lactam Antibioti$\mathrm{ka}(\mathrm{AB})$ verursachen. Sie sind plasmid-kodiert und können daher von Bakterium zu Bakterium übertragen werden. Häufig werden weitere Resistenzmechanismen gegenüber anderer $\mathrm{AB}-\mathrm{Kl}$ lassen beobachtet, was die therapeutischen Möglichkeiten weiter einschränkt. International wie auch national kommt es - sowohl in - wie auch außerhalb von Gesundheitseinrichtungen - zu einer starken Zunahme von ESBL bildenden Enterobakterien (ESBL-E). Auch in pädiatrischen und neonatologischen Intensivstationen (PICU/NICU) wird zunehmend teils ausbruchartig - das Auftreten von ESBL-E Kolonisationen und Infektionen beobachtet. Eine Assoziation zwischen ESBL-E Kolonisation und dem Auftreten von Nekrotisierender Enterocolitis (NEC) wurde beobachtet. Früh- und Neugeborene erscheinen besonders empfänglich und können nach Besiedlung in der Neonatalperiode bis zu 1 Jahr ESBL-E-Ausscheider bleiben und die entsprechenden Keime auf Familienangehörige übertragen. Während die Dekolonisation der betroffenen Patienten nicht sinnvoll (weil meist nicht erfolgreich) ist, ist das Intensivieren der Hygienemaßnahmen und ein routinemäßiges Screening empfehlenswert, um Ausbrüche erkennen und die entsprechenden Maßnahmen ergreifen zu können. Dabei ist die Isolation bzw. Kohortierung der besiedelten (und evtl. infizierten) Patienten und das Modifizieren des empirischen antibiotischen Regimes essenziell. Bei möglicher Infektion mit ESBL-E stellen Carbapeneme das Mittel der Wahl dar. Genetische Analysen der ESBL-E helfen einen Ausbruch (durch Patient-zu-Patient-Übertragung) von einem zufällig gehäuften Auftreten zu unterscheiden und sind bei der Analyse möglicher Übertragungswege hilfreich. 
9.10 Auswirkung der Einführung der Rotavirusimpfung auf Hospitalisierungsraten und Hopsitalisierungsdauer an der Kinderklinik Innsbruck

M. Zlamy' ${ }^{1}$ S. Kofler', M. Prelog',

'Department für Pädiatrie, Univ.-Klinik für Kinder- und Jugenheilkunde I; Medizinische Universität Innsbruck, Österreich, ${ }^{2}$ Universitätskinderklinik, Universität Würzburg, Deutschland

Hintergrund. Im Juli 2007 wurde die Rotavirus(RV)-Impfung ins staatlich finanzierte österreichische Impfprogramm aufgenommen. Fragestellung. Ziel unserer retrospektiven Studie war, die Auswirkungen der Routine Impfung auf die RV-bedingten Hospitalisierungsraten und die Hospitalisierungsdauer am Department für Pädiatrie, Medizinische Universität Innsbruck, zu evaluieren.

Methoden. Im Zeitraum von 1. Januar 2002 bis 31. Dezember 2009 wurden 1532 RV Gastroenteritis(GE)-Fälle mittels spezifischer Testsysteme (Pathfinder Direct Antigen Detection System, CerTestRota Card) ermittelt.

Resultate. Im Studienzeitraum konnte ein Rückgang der stationär behandelten RV-GE-Fälle nach Einführung der Routine Impfung beobachtet werden (vor Impfung: 1367 Fälle; nach Impfung: 165 Fälle; $\mathrm{p}=0,041)$. Nach Einführung der Impfung konnte eine signifikante Reduktion der Hospitalisierungsdauer $(\mathrm{p}<\mathrm{0}, \mathrm{Oo1})$ festgestellt werden (mittlere Aufenthaltsdauer vor Impfung: 4,9 $\pm 4,0$ Tage; mittlere Aufenthaltsdauer nach Impfung: $3,9 \pm 3,8$ Tage). Insbesondere in der Altersgruppe der 6-24 Monate alten Kinder wurde ein signifikanter Rückgang der Hospitalisierungsdauer beobachtet (mittlere Aufenthaltsdauer vor Impfung: 4,2 $\pm 3,1$ Tage; mittlere Aufenthaltsdauer nach Impfung: 3,5 $\pm 1,9$ Tage; $\mathrm{p}=0,013)$. Nach Einführung der Impfung war ein 6,4-facher Rückgang nosokomial erworbener RV-GE-Fälle zu beobachten.

Konklusion. Zusammenfassend lässt sich festhalten, dass die ersten 2,5 Jahre nach Einführung der Impfung zu einem signifikanten Rückgang der Hospitalisierungsraten, der nosokomialen RV-GE-Fälle und damit verbundener Komplikationen, wie beispielsweise sekundärer Bakteriämien, führte.

\section{Intensivmedizin}

\subsection{Extrakorporale Membranoxygenierung als Rescueverfah- ren bei hämodynamischem oder respiratorischem Versagen im Kindesalter}

G. Cortina, R. Geiger, U. Schweigmann, E. Schermer, N. Neu, M. Frühwith Department für Kinder und Jugendheilkunde. Medizinische Universität Innsbruck

Einleitung. Extrakorporale Membranoxygenierung (ECMO) ist ein invasives Unterstützungsverfahren, das bei potentiell reversiblem Lungen- und/oder Herzversagen nach Ausschöpfung der konventionellen Therapieoptionen zum Einsatz kommt. Wir berichten alle pädiatrischen ECMO-Fälle die von 1996 bis heute an unserer Pädiatrischen Intensivstation (PICU) behandelt wurden.

Methoden. Insgesamt 31 Kinder (14 Mädchen, 17 Jungen) mit einem mittleren Alter von 7a 10m \pm 7 a 5 m (2d-24a10m) haben von 1996 bis 2011 an der PICU Innsbruck eine ECMO erhalten. Die Patienten wurden in eine kardiale $(58,6 \%)$, eine onkologische $(17,2 \%)$ sowie in eine dritte, heterogene Gruppe $(24,1 \%)$ eingeteilt. Die ECMO-Indikation stellte entweder Kreislauf $(58,6 \%)$ oder Lungenversagen $(41,6 \%)$ dar. Bei 5 Patienten wurde unter Reanimation die ECMO eingebaut.

Ergebnisse. 17 Kinder erhielten eine venoarterielle, 14 eine venovenöse ECMO. Die ECMO Dauer war signifikant höher bei Kinder mit respiratorischem Versagen $(9,3 \pm 6,3 \mathrm{~d})$ als bei hämodynamischem Versagen $(3,6 \pm 3 d)$ und am höchsten bei onkologischen Patienten mit ARDS $(11,9 \pm 5,2 \mathrm{~d})$. Blutungskomplikationen waren mit $51,7 \%$ die häufigste Komplikation, gefolgt vom Bedarf an Nierenersatztherapie mit 48,3\% und Oxygenatorversagen mit 34,5\%. Der Bedarf an Nierenersatztherapie und Blutungen waren mit einer signifikant erhöhten Mortalität assoziiert. Das Gesamtüberleben lag bei $59 \%$, wobei es am mit $70,6 \%$ am höchsten bei Patienten mit kardiologischer Grunderkrankung und mit 40\% am schlechtesten bei onkologischen Patienten war. 3/5 der Patienten bei denen die ECMO unter Reanimation eingebaut wurde überlebten, 2 mit normalem neurologischen Outcome.

Schlussfolgerung. Das Gesamtüberleben von $59 \%$ entspricht den Angaben in der internationalen Literatur. Die ECMO Behandlung kann somit eine lebensrettende Maßnahme darstellen und kann als Rescueverfahren entsprechend der ERC Guidelines von 2010 auch bei therapierefraktärer CPR bei ausgewählten Patienten in Betracht gezogen werden.

\subsection{Stellt die Nah-Infrarot-Spektroskopiemessung eine Belas- tung für das Neugeborene dar}

E. Ziehenberger, G. Pichler, M. Pocivalnik, A. Brandner, C. Binder, W. Müller, B. Urlesberger

LKH - Universitätsklinikum Graz

Hintergrund. Nahinfrarotspektroskopie (NIRS) ermöglicht die nicht invasive Messung der regionalen Oxygenierung/Hämodynamik im Gewebe. Trotz der Nicht-Invasivität von NIRS, die dem Ziel des bei Neugeborenen zunehmend angestrebten „minimal handlings“ entspricht, sind zerebrale und vor allem peripher-muskuläre Messungen mit Manipulationen verbunden.

Fragestellung. Stellen die bei zerebralen und peripher-muskulären NIRS Messungen durchgeführten Manipulationen eine Belastung für das Neugeborene dar.

Patienten. Reife Neugeborene und Frühgeborene ohne respiratorischer und/oder kardiozirkulatorischer Unterstützung, bei denen eine zerebrale NIRS-Messung und eine peripher muskuläre NIRS-Messung in Kombination mit venösen Okklusionen durchgeführt wurden.

Methode. Zu vier Zeitpunkten (1: unmittelbar vor der ersten Manipulation; 2: nach Anlegen der NIRS Optode, Blutdruckmanschette und Pulsoximetrie; 3: vor der ersten venösen Okklusion; 4: nach Beendigung der Messung venöser Okklusionen) wurden Herzfrequenz, Atmung, der Blutdruck, arterielle Sauerstoffsättigung, Temperatur, periphere und zerebrale regionale Sättigung und der Schmerzscore nach KUSS aufgezeichnet. Neben diesen Vitalparametern wurde die Zeit der Manipulation notiert und die Hautbelastung beurteilt.

Ergebnisse. Insgesamt wurden 25 Neugeborene mit einem Gestationsalter von 35,6 Wochen, Tagesgewicht $2735 \mathrm{~g}$ und Alter von $2 \mathrm{Ta}$ gen bisher in die Studie eingeschlossen. Es zeigten sich keine signifikanten Unterschiede in Herzfrequenz, Atmung, Blutdruck, arterieller Sauerstoffsättigung, Temperatur, peripherer und zerebraler regionale Sättigung und Schmerzscore zwischen den vier Messzeitpunkten: vor der ersten Manipulation, nach Anlegen der NIRS Optoden, Blutdruckmanschette und Pulsoximetrie, vor der ersten venösen Okklusion und nach Beendigung der Messung. Die durchschnittliche Manipulationsdauer betrug 53 Minuten. Bei 8 Neugeborenen trat eine leichte Hautrötungen an der muskulären Fixationsstelle auf.

Schlussfolgerung. Die zerebralen und peripheren NIRS-Messungen stellen bei reifen Neugeborenen und Frühgeborenen keine messbare Belastung dar. 


\section{Jugendmedizin}

\subsection{Bedeutung kardiovaskulärer Erkrankungs(CVD)-Risikore- duktion bereits im Kindes- und Adoleszentenalter unter beson- derer Berücksichtigung der Lipidanomalien als meist sensitive und spezifische Risikofaktoren für frühe CVD}

R. Eyermann

Kinder- und Jugendmedizin, Kinderkardiologie, Sportmedizin, München

Atherosklerose, der pathophysiologische Prozess, der CVD zugrunde liegt, beginnt in der Kindheit und akzeleriert während der Adoleszenz. Diese Progression verläuft so oder so ob ein Individuum eine genetische Prädisposition für frühe CVD hat oder nicht. Bei Personen mit genetischen Abnormalitäten die sie für Atherosklerose prädisponieren - etwa eine familiäre Hypercholesteriolämie (FH), die bestcharakterisierte genetische Form der Atherosklerose - ist die Adoleszentenperiode kritischer. $15 \%$ der Teenager mit FH haben bei der ärztlichen Untersuchung periphere Lipiddepositionen in Form von Haut- oder Augenläsionen, sog. Xanthome bzw. Cornealarcus. 50\% der FH-Patienten haben periphere Lipiddepositionen in ihren zoigern und ca. eine Dekade später manifeste CVD. Die Pathobiological Determinants of Atherosclerosis in Youth (PDAY) und Bogalusa Heart Studien haben gezeigt, dass atherosklerotische Läsionen bei Adoleszenten mit evidenzbasierten Risikofaktoren wie erhöhtem LDL-C, erniedrigtem HDL-C, Hypertension, Tabakrauchen und Adipositas korreliert sind. Da die Hälfte aller ersten Herzereignisse fatal sind, ist Prävention essenziell, um Morbidität, Mortalität und Gesundheitskosten durch CVD zu reduzieren. Kindheit und Adoleszenz sind das Schlüsselalter, in dem mit der atherosklerotischen Lastreduktion begonnen werden muss.

Lipidanomalien: Erhöhte LDL-C, niedrige HDL-C und hohe Triglyceride sind die am meisten sensitiven und spezifischen Risikofaktoren für frühe CVD. Diese Abnomalitäten sind in vielen Formen präsent und können generell klassifiziert werden als: 1) Familiäre Hypercholesterolämie (FH), 2) Familiäre kombinierte Hyperlipidämie (FCH), 3) Mixed environmental Hyperlipidemia, 4) Metabolisches Syndrom. Diät und therapeutische Lifestyleänderungen (TLC) sind die Säulen in der Prävention und Behandlung von Hyperlipidämien. Additiv sind bei manchen Adoleszenten Pharmaka hilfreich. Diät: Um die Serumlipidparamter zu verbessern und das CVD-Risiko zu reduzieren sollten Personen mit Hyperlipidämie eine Diät essen, die reduziert ist an Fett, Cholesterol und gesättigtem Fett, aber suffizient an Kalorien, um Wachstum und Entwicklung der Kinder zu fördern (NECP Step One und ggf. nach 3 Monaten Step Two Diet). NECP, AHA Scientific Statement on Cardiovascular Health in Childhood, AAP Committee on Nutrions's „Cholestrol in Childhood” statement empfehlen 2 Strategien: 1) eine populationsbasierte Strategie aller Kinder $>2$ Jahre zur Förderung herzgesunder Ernährung, 2) ein individualisierte Strategie für Kinder mit positiver Familienanamnese (FA) für frühe CVD, elterliche Hypercholesterolämie oder Kinder mit anderen CVD-Risikofaktoren. Eine Pharmakotherapie sollte reserviert bleiben für Adoleszente, die trotz TLC die Lipidzielwerte in der CVD-Prävention LDL-C $<130 \mathrm{mg} /$ $\mathrm{dl}$ und $\mathrm{TG}<150 \mathrm{mg} / \mathrm{dl}$ nicht erreichen. Neue AAP-Guidelines empfehlen eine Intervention ab 8 Jahren bei LDL-C $\mathrm{ab} 190 \mathrm{mg} / \mathrm{dl}$, bei positiver FA oder 2 additiven Risikofaktoren ab $160 \mathrm{mg} / \mathrm{dl}$ bzw. ab $130 \mathrm{mg} / \mathrm{dl}$ bei Diabetes mellitus. Zur LDL-C-Senkung sind nach FDA einige Statine $(>12$ Jahre) und Harze (nicht alle $<18$ Jahre) zugelassen. Niacin, Fibrate und Ezetimibe sind nach FDA nicht $<18$ Jahre zugelassen.

Konklusion. Kindheit und Adoleszenz sind das Schlüsselalter, in dem mit der atherosklerotischen Lastreduktion begonnen werden muss. Lipidanomalien, wie erhöhte LDL-C, niedrige HDL-C und hohe Triglyceride sind die am meisten sensitiven und spezifischen Risikofaktoren für frühe CVD.
11.2 Achsenfehlstellung der distalen Extremitäten bei morbid adipösen Kindern und Jugendlichen

G. Huber ${ }^{1}$, F. Landauer ${ }^{2}$, D. Weghuber ${ }^{1}$

${ }^{1}$ Universitätsklinik für Kinder- und Jugendheilkunde, Paracelsus Medizinische Privatuniversität, Salzburg, ${ }^{2}$ Abteilung für Orthopädie, Paracelsus Medizinische Privatuniversität, Salzburg

Einführung. Durch die rapide Zunahme von Adipositas bei Kindern und Jugendlichen steigen auch die damit verbundenen medizinischen Komplikationen. Neben metabolischen, psychischen und kardiovaskulären Probelem treten auch orthopädische Komplikationen speziell in den distalen Extremitäten vermehrt auf. Aus diesem Grund untersuchten wir die Häufigkeit von genu varum (GVR) und genu valgum (GVL) bei adipösen Kindern und Jugendlichen.

Methoden. 31 übergewichtige und adipöse Kinder (16 männliche,

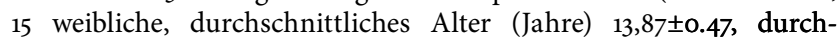
schnittliche Größe (cm) 162,29 $\pm 2,72$, durchschnittliches Gewicht (kg) 90,62 $\pm 4,97$, durchschnittlicher Body Mass Index $\left(B M I=\mathrm{kg} / \mathrm{m}^{2}\right)$ $33,82 \pm 1,23$ ) wurden mithilfe der Mikuliczline klinisch untersucht, um die Verteilung des auf das Knie einwirkende Gewichts festzustellen. Bei 21 Teilnehmern wurde wegen unklarer klinischer Präsentation oder wegen einer Abweichung der Mikuliczline von der Kniemitte eine Röntgenganzbeinaufnahme durchgeführt.

Ergebnis. 14/62 (22,58\%) untersuchten Beinen zeigten eine Valgusstellung des Knies. 1 Bein (1,16\%) zeigte ein Genu-varum-Fehlstellung und 47 (75,81\%) zeigten keine Fehlstellung des Kniegelenks. Bei der Minderheit der Genu-valgum-Fehlstellungen konnte der Femur als Zentrum der Achsenabweichung festgestellt werden (8/14; 57,14\%). Bei 1/14 (7,14\%) Teilnehmern war die Tibia das Zentrum der Achsenabweichung und 5/14 (35,71\%) waren nicht klassifizierbar. 12/47 (25,53\%) Teilnehmer ohne Fehlstellung im Kniegelenk zeigten eine Abduktionsstellung des Beines, $2 / 47$ (4,25\%) zeigten eine Adduktionsstellung des Beines.

Conclusion. GVR und GVL Fehlstellungen der distalen Extremitäten können bei übergewichtigen und adipösen Kindern und Jugendlichen festgestellt werden, wobei eine GVL-Fehlstellung eine höhere Prävalenz aufweist. Es ist daher wichtig, übergewichtige und adipöse Kinder auf diese Fehlstellungen vor Schließung der Epiphysenfuge zu screenen. Weiters ist es sinnvoll, die Tibia oder den Femur als Zentrum der Achsenabweichung festzustellen, da dies direkte Auswirkungen auf die Therapie hat (Epiphyseodese).

\subsection{Geschlechtsspezifische Unterschiede in einer universitären pädiatrischen Notfallambulanz}

C. Koslowski' ${ }^{1}$ D. Koller ${ }^{1}$, E. Schuster ${ }^{2}$, U.Salzer-Muhar ${ }^{1}$

${ }^{1}$ Medizinische Universität Wien, Univ.-Klinik für Kinder- und Jugendheilkunde, ${ }^{2}$ Zentrum für Medizinische Statistik, Informatik und Intelligente Systeme

Ziel. Ziel dieser Diplomarbeit war die Analyse geschlechtsspezifischer Aspekte in Bezug auf PatientInnen, Altersspektrum, Symptome und Diagnosen einer urbanen universitären pädiatrischen Notfallambulanz.

PatientInnen und Methodik. Analysiert wurden die Daten einer Kohorte von 3732 Kindern und Jugendlichen, die im Zeitraum Juli 2006 bis März 2007 und zwar jeweils nur an den Wochenenden in der NFA der Univ.-Klinik für Kinder- und Jugendheilkunde vorstellig waren. Die Daten waren prospektiv im Rahmen einer ärztlichen Bedarfserhebung erstellt worden Die Auswertung erfolgte durch SPSS 17 und Microsoft Excel, die Analyse wurde großteils deskriptiv durchgeführt. Ein p-Wert von $<0,05$ wurde als signifikant definiert.

Ergebnisse. Von den 3732 untersuchten Kindern waren 2032 (54,4\%) Knaben. Das mediane Alter bei Vorstellung lag bei Knaben bei 3 Jahren , bei Mädchen bei 4 Jahren. Bei der Analyse der häufigsten Symptome (6) und Diagnosen (26) zeigte sich, dass bei Atemwegserkrankungen ( $\mathrm{n}=875)$ im Allgemeinen (55\% Knaben vs. $45 \%$ Mädchen) und 
obstruktiver Bronchitis im Speziellen ( $\mathrm{n}=109 ; 71,6 \%$ vs. $28,4 \%$ ) eine Knabenwendigkeit vorlag, betroffene Knaben waren signifikant jünger als betroffene Mädchen. Bei Harnwegsinfekten $(n=98)$ lag eine Mädchenwendigkeit vor (18,4\% vs. 81,6\%), sie waren älter (Medianwert für Knaben 1 Jahr, für Mädchen 4 Jahre) aber wurden im Vergleich zu betroffenen Knaben seltener stationär aufgenommen. Das Symptom Bauchschmerzen $(n=42)$ war bei Mädchen signifikant häufiger Vorstellungsgrund als bei Knaben (23,8\% vs. $76,2 \%)$ Bei gastrointestinalen Erkrankungen im Allgemeinen und Gastroenteritis waren Knaben und Mädchen gleichermaßen betroffen.

Die Analyse bestätigt geschlechtsspezifische Unterschiede in Bezug auf PatientInnen, die zur Vorstellung führenden Symptome und die gestellten Diagnosen in einer pädiatrischen NFA. Knaben wurden häufiger vorgestellt, dies mag daraus resultieren, dass sie von den sehr häufigen Atemwegserkrankungen mehr betroffen sind. Inwieweit neben der tatsächlich höheren geschlechtsspezifischen Morbidität einzelner Krankheiten auch Genderaspekte eine Rolle spielen, muss offen gelassen werden.

\subsection{Frühkindliche, gesundheitliche Bildung zur vorausschauen- den Patientenedukation in der Allgemeinpädiatrie}

\section{S. Mottl-Link}

Stadt Mannheim, Fachbereich Gesundheit, Kinder- und Jugendärztlicher Dienst

Hintergrund. Frühkindliche Bildung im Bereich der Gesundheitserziehung beschränkt sich bisher auf die Themen Bewegung, Ernährung und Zahngesundheit. Das Thema „Handlungsstrategien bei pädiatrischer Akutsymptomatik“ wurde bisher nicht berücksichtigt. Ziel war die Entwicklung eines Mediums, das potentiellen Patienten nicht nur Verhaltensleitlinien für die häufigsten Symptome vermittelt, sondern bei der pädiatrischen Zielgruppe Akzeptanz findet.

Material und Methode. Aus präventiven Ratgeberinhalten wurden Verhaltensstrategien bei den häufigsten allgemeinpädiatrischen Beschwerden wie Durchfall, Erbrechen, Husten, Schnupfen, Fieber, Ohrenschmerzen usw. ausgewählt. Als Motivationsmotoren zur Beschäftigung mit komplexen Lerninhalten insbesondere zur frühkindlichen Bildung wurden „Spaß“ und „Spannung“ gewählt. Als Methodik dienten das „Clown-Prinzip“ und der „mythischen Heldenkreis“.

Ergebnisse. Aus der Kombination von ernsthaften, präventiven Themen und lustiger und spannender Aufbereitung resultierten die zwölf Vorlesegeschichten „Frau Doktor hat einen Vogel“ für Kinder ab 4 Jahren, die inklusive Hausmittelrezepten und Arztnotizen im Bildungsverlag eins erscheinen. Erste Lesungen vor Kindergarten- und Grundschulkindern zeigten, dass die Texte von den Kindern als „lustig und spaßig“ empfunden werden, woraus eine enorme Lern-Motivation resultiert. Eine Nachhaltigkeit wurde durch Erlernen eingängiger Reime und Basteln von „Gesundmach-Kisten" (Kinderhausmittelapotheken) erreicht.

Schlussfolgerung. Der Wissenstransfer aus Bildungseinrichtungen in die Familien hat das Potential, wesentlich zur Stärkung der gesundheitlichen Selbstsicherheit unabhängig von Alter oder sozialer Schicht und damit zur gesundheitlichen Chancengleichheit beizutragen. Eine Verringerung des Aufsuchens pädiatrischer Notaufnahmen bzw. ärztlicher Bereitschaftsdienste bei Bagatellsymptomatik und ein Anstieg der adäquaten Inanspruchnahme bei lebensbedrohlichen Situationen könnten die wünschenswerten Folgen sein.

\subsection{Paradigmenwechsel in der Jugendmedizin unter den Aspekten der Wirtschaft und Gesundheitserhaltung}

P. Schmidt

Györ, Ungarn

Der Autor betont die Wichtigkeit der Prävention unter dem Aspekt der Jugendmedizin. Die Gesundheitserhaltung und Gesundheitserziehung spielen in der Gesundheitsversorgung eine sehr wichtige Rolle, denn die materiellen Aufwendungen für die Prävention können dazu betragen, dass im Laufe der Jahrzehnten in der Zukunft unter anderem die Zahl der Krebserkrankungen, der medikamentösen Behandlung, sowie die Menge der verordneten Antibiotika bedeutend reduziert werden. Laut der Forschung des Autors in Ungarn ist die medizinische Versorgung lediglich in $15 \%$ für den Gesundheitszustand der Bevölkerung verantwortlich, während die Betonung einzelner Faktoren der Lebensweise wie die gesunde Ernährung, Sport, regelmäßige Vorsorgeuntersuchungen - für die junge Generation relevant ist. Die Prävention sollte bereits im Kindergarten begonnen werden - Die Schulung der Prävention gegen Rauchen, Alkohol und Drogen verlangt enge Zusammenarbeit durch die aufklärende Arbeit der Kindergärtnerinnen, Fachleuten der Gesundheitserziehung, Kinderbetreuerinnen, Ärzte und Pädagogen. Auf Grundlage einer Analyse demographischer Daten unter wirtschaftlichen Aspekten betont der Autor die Wichtigkeit des in Ungarn einzuführenden Volksgesundheitsprogramms, wo das wichtigste Ziel ist, die Zahl der chronischen Erkrankungen infolge der Globalisation (wie Diabetes, Asthma, allergische Erkrankungen usw.) zu reduzieren. Der Autor formuliert zugleich Empfehlungen zur qualitativen Entwicklung und Priorisierung der Indikatoren der Jugendmedizin.

\subsection{Zwischen Faszination, Gewalt und Abhängigkeit: Wie sich Video- und Computerspiele auf Kinder und Jugendliche aus- wirken}

F. Rehbein

Kriminologisches Forschungsinstitut Niedersachsen (KFN)

In dem praxisorientierten Fachvortrag soll der aktuelle Forschungsstand zu den Auswirkungen von Computerspielnutzung auf Schulleistung, Sozialverhalten und die psychische Gesundheit anschaulich vermittelt werden. Dabei wird aufgezeigt, dass Kinder nicht nur vor problematischen (entwicklungsbeeinträchtigenden) Spielinhalten geschützt werden müssen, sondern eine immer wichtigere Verantwortung auch darin besteht, einer zeitlich ausufernden (exzessiven) Mediennutzung junger Menschen entgegenzuwirken. Aktuelle Computerspiele wie das Onlinerollenspiel World Of Warcraft sind auf eine Weise gestaltet, dass Kinder sich monate- oder auch jahrelang für diese virtuellen Welten begeistern können und eine sehr große Zeit mit dem Spielen verbringen. Immer mehr droht damit eine Verlagerung kindlicher Sozialisation in den Cyberspace und schließlich eine Computerspielabhängigkeit. Wie eine drohende oder bereits bestehende Computerspielabhängigkeit erkannt werden kann und wie diese mit anderen Risikofaktoren in Zusammenhang steht soll ebenfalls dargestellt werden. Aus den Daten sollen konkrete Handlungsempfehlungen für die pädiatrische Praxis abgeleitet und diskutiert werden.

\section{Neonatologie}

\subsection{Der Einfluss des Duktus arteriosus auf die zerebrale und periphere Gewebssättigung bei Neugeborenen 15 min nach Geburt}

C. Binder, G. Pichler, A. Brandner, M. Pocivalnik, E. Ziehenberger, H.Zotter, W. Müller, B. Urlesberger

LKH Univ.-Klinikum Graz, Universitätsklinik für Kinder- und Jugendheilkunde, Abteilung für Neonatologie

Hintergrund. Bei der Geburt finden komplexe kardiozirkulatorische Umstellungsprozesse statt. Der Schluss der Duktus arteriosus (DA) spielt dabei eine zentrale Rolle.

Fragestellung. Ziel der Studie war es, 15 min nach Geburt, den Einfluss des DA (offen vs. geschlossen) auf zerebrale und periphere präduktale/postduktale Gewebssättigungen, welche mittels Nah-Infrarotspektroskopie (NIRS) gemessenen wurden, zu untersuchen. 
Patienten. Reife Neugeborene nach Entbindung mittels elektiver Sectio caesarea mit unauffälliger Adaptation.

Methodik. In einer prospektiven Beobachtungsstudie wurde mit NIRS nach 15 Min die zerebrale ( $\mathrm{CrSO}_{2}$; links frontal), die präduktale (prä-rSO $\mathrm{SO}_{2}$; rechter Unterarm) und die postduktale (post-rSO $\mathrm{S}_{2}$; linker Unterschenkel) Gewebssättigung mit NIRS gemessen. Es wurden fünf Reapplikationen der NIRS Sensoren jeweils an den einzelnen Messstellen durchgeführt, um die Messgenauigkeit durch Mittelung der Werte zu erhöhen. Arterielle Sauerstoffsättigung und Herzfrequenz wurden präduktal (rechte Hand) und postduktal (linker Fuß) mit Pulsoximetrie gemessen. Unmittelbar nach den NIRS-Messungen wurde der Blutdruck nichtinvasiv oszillometrisch erhoben und eine Echokardiographie durchgeführt, um den DA (offen/geschlossen) zu beurteilen.

Ergebnisse. Bisher wurden 44 Neugeborene inkludiert (Gestationsalter:39,1 $\pm 0,9$ SSW; Geburtsgewicht: $3433 \pm 482 \mathrm{~g}$ ) wobei 22 einen offenen DA hatten und 22 einen geschlossenen DA. $\mathrm{CrSO}_{2}$ war bei den Neugeborenen mit offenem DA $(82,5 \pm 8,6 \%)$ signifikant höher als bei den Neugeborenen mit geschlossenem DA $(76,4 \pm 6,5 \%)$. Neugeborene mit offenem und geschlossenem DA hatten keine signifikant unterschiedlichen prä- $\mathrm{rSO}_{2}(69,7 \pm 9,8 \%$ vs. $73,1 \pm 11,4 \%)$ und post-rSO $2(73,6 \pm 15,2 \%$ vs. $71,7 \pm 10,7 \%)$ Werte. Die Herzfrequenz war bei Neugebornen mit offenem DA signifikant niedriger $(143 \pm 8)$ als bei Neugeborenen mit

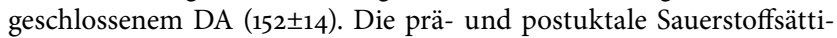
gung zeigte keinen signifikanten Unterschied zwischen den beiden Gruppen.

Schlussfolgerung. Reife Neugeborene mit offenem DA haben nach klinisch unauffälliger Adaptation eine höhere zerebrale Gewebssättigung. Ein noch offener DA 15 min nach Geburt könnte somit als Vorteil in der Adaptationsphase angesehen werden.

\subsection{Contaminated breast milk - source of infection? The transmission of Escherichia coli ESBL to preterm infants through breast milk}

\section{Binder, A. Repa, A. Berger, A. Pollak, N. Haiden}

Department for Paediatrics and Adolescent Medicine, Division of Paediatric Neonatology, Intensive Care and Neuropaediatry; Medical University Vienna

Introduction. Significant benefits of breast milk compared to formula feeding could be observed in a lot of studies. A lower rate of necrotizing enterocolitis as well as neonatal sepsis is described. Breast milk is a determinant for the healthy development of the gastrointestinal flora and for the prevention of allergies. Contaminated breast milk with certain bacterial pathogens, such as methicillin-resistant Staphylococcus aureus (MRSA), Streptococcus B or Escherichia coli extended-spectrum Beta lactamases (ESBL) could be a potential source of infection and responsible for neonatal sepsis. Case reports about contaminated breast milk hence neonatal sepsis are described in the literature and illustrated the potential risk of contaminated breast milk for preterm infants. Case report. We report the case of dichoreal gemini: spontaneous delivery, week of pregnancy 25+4. Child 1: birthweight $850 \mathrm{~g}$, APGAR 4/5/9. Child 2: birthweight 767 g, APGAR 5/8/9. Child 1: After uncomplicated primary care and an initial unstable phase, the child was stable with the infant flow. No signs of infection were noticed. Child 2: The cardiorespiratory adaption was easily and the child was stable with the infant flow. Also no signs of infection were noticed.

44 days postpartum worsened the condition of child 1 and the blood culture (peripheral) was positive for Escherichia coli ESBL. Therapy with optinem was started. After cardiorespiratory stabilisation, 11 days after the positive blood culture the antibiotic therapy could be discharged. At the time of sepsis the twins were spatially separated and were at various stations; Child 1: neonatal intensive care unit (NICU) and Child 2: Intermediate Care Unit (IMC).

54 days postpartum an aggravation at Child 2 was noticed and the blood culture was also positive for Escherichia coli ESBL. At this point of time the preterm was at the IMC, without any peripheral or central line and no other cases of Escherichia coli ESBL was observed at both station.

For that reason the breast milk was a hypothetical source of this infection and a microbiological screening was performed. The breast milk was positiv for Escherichia coli ESBL. Therefore contaminated breast milk is certainly the source of infection and for that reason the breast milk was pasteurized until negative pathogens in the breast milk could be noticed.

\subsection{Einfluss der Behandlung eines persistierenden Ductus arteriosus Botalli mit Cyclooxygenasehemmern auf das Hirnblu- tungsrisiko von Frühgeborenen - retrospektive Analyse}

B. Brunner ${ }^{1}$, M. Höck' ${ }^{1}$, W. Streif ${ }^{2}$, U. Kiechl-Kohlendorfer ${ }^{1}$

${ }^{1}$ Universitätsklinik für Pädiatrie IV, Abteilung für Neonatologie, Medizinische Universität Innsbruck, ${ }^{2}$ Universitätsklinik für Pädiatrie II, Hämostasiologie, Medizinische Universität Innsbruck

Frühgeborene haben ein erhöhtes Risiko für das Ausbleiben des Verschlusses des Ductus arteriosus Botalli postnatal. Ein persistierender Ductus arteriosus ist mit erhöhter Morbidität infolge bronchopulmonaler Dysplasie, nekrotisierender Enterokolitis, intrazerebraler Blutung und periventrikulärer Leukomalazie assoziiert. Zur Verbesserung des Outcomes von Frühgeborenen hat sich die frühe medikamentöse Therapie des persistierenden Ductus arteriosus mit Cyclooxygenasehemmern bewährt.

Die Fragestellung unserer Studie war, ob die Cyclooxygenasehemmer Ibuprofen und Indomethacin unabhängige Risikofaktoren für Hirnblutungen bei Frühgeborenen sind.

Es wurden retrospektiv Daten von Frühgeborenen mit einem Gestationsalter $<32$ SSW sowie einem Geburtsgewicht $<1500$ g, die in Innsbruck in der Zeit von 2003 bis 2009 geboren und behandelt wurden $(n=354)$, erhoben. Neben Angaben zur Diagnose eines persistierenden Ductus arteriosus (PDA) innerhalb der ersten Lebenswoche $(n=164)$ und dessen medikamentöser Therapie (Ibuprofen $n=138$, Indomethacin $n=10$, Gesamt $n=148$ ) wurden die Co-Faktoren für eine intracerebrale Blutung erhoben (Gestationsalter, Geburtsgewicht, antenatale Steroidtherapie, NsApH, 5 min APGAR, Beatmung/Surfactanttherapie, primäre/sekundäre Infektionen, arterielle Hypotonie/Katecholamintherapie in der ersten Lebenswoche).

Der Anteil der Patienten, die eine intrazerebrale Blutung erlitten war 20,5\% (71 von 346). In der multivariaten Analyse blieb die Diagnose eines PDA als unabhängiger Risikofaktor für eine intracerebrale Blutung signifikant $(\mathrm{p}<0,05)$, während die Therapie mit Ibuprofen oder Indomethacin kein unabhängiger Risikofaktor war. Dieses Ergebnis weist darauf hin, dass ein medikamentöser Verschluss des Ductus arteriosus das Hirnblutungsrisiko von Frühgeborenen nicht signifikant erhöht, obwohl Cycloxygenasehemmer über eine Hemmung der Thrombozytenfunktion blutungsfördernd wirken.

\subsection{Kolonstenosen als Frühkomplikation nach unkomplizierter nekrotisierender Enterokolitis}

E. Griesmaier1, K. Wegleiter ${ }^{2}$, K. Maurer ${ }^{2}$, K. Unsinn², U. Kiechl-Kohlendorfer $^{1}$, J. Hager ${ }^{3}$

${ }^{1}$ Univ. Klinik Innsbruck, Pädiatrie IV, ${ }^{2}$ Univ.-Klinik für Radiodiagnostik, Kinderradiologie, ${ }^{3}$ Univ. Klinik für Visceral-, Transplantaticns und Thoraxchirurgie, Kinderchirurgie

Hintergrund. Die nekrotisierende Enterokolitis (NEC) ist eine schwere Erkrankung des Neugeborenen. Die Frühgeburtlichkeit per se gilt als einziger sicher nachgewiesener ätiologischer Faktor. Zur Senkung der Morbidität steht die Früherkennung und konsequente Behandlung sekundärer Komplikationen an erster Stelle.

Kasuistik. Wir berichten über ein reifes Neugeborenes, das im Alter von 2 Tagen mit der Diagnose NEC an unsere Abteilung aufgenommen wurde. Es erfolgte die konservative Therapie (Nahrungskarenz und 
antibiotische Therapie). Der klinische Zustand stabilisierte sich rasch und der nach 8 Tagen wiedereingeleitete Nahrungsaufbau war unproblematisch. Klinisch zeigte unser Patient ein an Größe wechselndes, ausladendes Abdomen, insbesondere nach den Mahlzeiten, ohne Hinweis für Stuhlentleerungsprobleme oder Ileus Symptomatik. Im Alter von 2 Wochen wurde eine Irrigographie durchgeführt, in welcher sich zwei Kolonstenosen darstellten. Nach 11 Tagen wurde zur Reevaluation der Stenosierungstendenz neuerlich eine Irrigographie durchgeführt. Die klinische Symptomatik des Patienten war weiterhin gering ausgeprägt, dieser voll oral ernährt und es zeigte sich eine gute Gewichtszunahme. Die Irrigographie ergab eine deutliche Verschlechterung des Befundes mit Passagehindernis des Kontrastmittels. Es erfolgte nach explorativer Laparotomie die linksseitige Hemikolektomie und Anlage einer endständigen, doppelläufigen Kolostomie. Histopathologisch zeigten sich floride Entzündungsreste und Granulationsgewebsbildung.

Diskussion. Der vorliegende Fallbericht beschreibt das frühzeitige Auftreten von Kolonstenosen als Komplikation einer NEC bei einem Termingeborenen. Dies ist die häufigste Komplikation nach NEC und tritt zumeist nach konservativer Behandlung auf. Die Diagnose wird zumeist im Zeitraum von 4 Wochen bis 20 Monaten nach NEC gestellt. Die Durchführung einer Irrigographie ist nach konservativer Therapie der NEC in jedem Fall frühzeitig zu erwägen.

\subsection{Beeinflussung des aEEG durch postnatale Analgosedierung und Surfactantgabe}

E. Griesmaier', M. Bachmann'1, V. Neubauer', U. Kiechl-Kohlendorfer', M. Keller ${ }^{1,2}$

${ }^{1}$ Department für Kinder- und Jugendheilkunde, Pädiatrie IV, (Neonatologie, Neuropädiatrie, angeborene Stoffwechselerkrankungen), Medizinische Universität Innsbruck, Österreich, ${ }^{2}$ Pädiatrie I, Neonatologie, Universitätsklinikum Essen, Deutschland

Hintergrund. Das amplitudenintegrierte EEG (aEEG) bietet die Möglichkeit der kontinuierlichen Überwachung der elektrokortikalen Aktivität im Langzeitverlauf. Das aEEG wird durch verschiedenste exogene Faktoren beeinflusst. Ziel dieser Studie war es Einflüsse auf das aEEG in den ersten 72 Stunden und vier Wochen nach Geburt durch postnatale Analgosedierung und Surfactantapplikation zu untersuchen.

Methodik. Frühgeborene (FG) mit einem Gestationsalter (GA) von 28-32 SSW wurden in diese Studie eingeschlossen. Die Analyse des aEEG erfolgte durch visuelle Beurteilung des Hintergrundmuster und der Schlaf-Wach-Zyklen, Quantifizierung der Amplituden, sowie Kalkulation des Burdjalov Scores (Pediatrics 2003). Die statistische Auswertung erfolgte mit SPSS 18 für Windows.

Ergebnisse. Es wurden 41 Frühgeborene (20 Kontrollen, 21 Sedierte) in die Studie eingeschlossen. Die aEEG Parameter zeigten einen signifikanten Unterschied zur Kontrolle in den ersten 24 bis 36 Stunden postnatal (Summenscore, sowie Einzelparameter nach Burdjalov, minimale Amplitude). Das Auftreten von Schlaf-Wach-Zyklen war in der Gruppe der sedierten Kinder signifikant verzögert. In den weiteren Untersuchungszeitpunkten zeigt sich keine Beeinflussung des aEEG.

Konklusion. Bei der Beurteilung des aEEGs ist es wichtig Einflüsse durch Medikamente zu beachten. Eine aussagekräftige Beurteilung des aEEG ist erst nach Inbetrachtnahme einer Beeinflussung durch Medikamente und ggf. nach Beendigung derselben möglich.

\subsection{Arterial-ventricular coupling in preterms with patent ductus arteriosus}

V. Jeitler', S. Baumgartner' ${ }^{2}$, M. Wald ${ }^{2}$, T. Waldhör ${ }^{3}$, U. Salzer-Muhar ${ }^{4}$

${ }^{1}$ Medizinische Universitätsklinik Wien, ${ }^{2}$ Medizinische Universitätsklinik

Wien, Abteilung Neonatologie, ${ }^{3}$ Medizinische Universitätsklinik Wien,

Abteilung Epidemiologie, ${ }^{4}$ Medizinische Universitätsklinik Wien,

Abteilung Kardiologie

Aim of the study. To analyze arterial-ventricular coupling (AV-C) in a cohort of preterms before and after ductal closure.
Patients and methods. Inclusion criteria: Gestational age $<33+0$, normal intracardiac anatomy, no coarctation, minimum stay in the NICU from day 1 to day 3 of life in the period from 11/2009-11/2010. Further criteria were complete M-mode (left atrium, left ventricle) and Doppler recordings (left pulmonary artery, descending aorta and PDA), Patients were stratified into 3 subgroups according to GA. PDA flow patterns were classified according to Skinner (PDA type 1-6). As a measure for $\mathrm{AV}-\mathrm{C}$ the ratio of effective arterial elastance to left-ventricular endsystolic elastance $\left(\mathrm{E}_{\mathrm{A}} / \mathrm{E}_{\mathrm{LV}}\right)$ was calculated based on $\mathrm{M}$-mode derived volumes.

Results. The study cohort comprised of 38 patients [subgroup 1 $\left(\mathrm{GA}_{23}+0-25+6\right) \mathrm{n}=14$, subgroup 2 (GA $\left.26+0-27+6\right) \mathrm{n}=16$, subgroup 3 $(\mathrm{GA} 28+0-33+0) \mathrm{n}=8$ ]. PDA types 5 and 6 were found in $57 \%, 25 \%$ and $25 \%$ of patients in subgroups 1,2 , and 3 respectively. 34 patients with a PDA received ibuprofen, in 8 of them ductal clipping was required. Calculation of $\mathrm{E}_{\mathrm{A}} / \mathrm{E}_{\mathrm{LV}}$ before and after ductal closure revealed the following ratios: subgroup 1: 0.28 vs. 0.36 , subgroup 2: 0.36 vs.0.41 and subgroup 3: 0.49 vs.0.45.

Conclusion. Our preliminary data indicate that the effect of ductal closure on either $\mathrm{E}_{\mathrm{A}}$ or $\mathrm{E}_{\mathrm{LV}}$ or both depends on gestational age.

12.7 Die Therapie des neonatalen Abstinenzsyndroms mit Morphin und Homöopathie - "quo vadis?"

A. Käfer, C. Hartlieb, A. Göttling, G. Zoder, M. Bejaoui, A. Lischka

Kinderklinik Glanzing, Wilhelminenspital der Stadt Wien

Der Terminus „NAS“ (neonatales Abstinenzsyndrom) beschreibt die postpartum auftretende Entzugssymptomatik von Neugeborenen, die während ihres inrauterinen Lebens suchterzeugende Noxen (Opiaten + Beikonsum wie Benzodiazepinen, Kokain, Cannabis, AD, Neuroleptika, Analgetika, Barbiturate, u. v. m.) exponiert gewesen sind. Das NAS ist ein Hyperexcitationssyndrom, charakterisiert durch schrilles Schreien, Zittrigkeit, Tremor, Myoklonien, Krampfanfälle, muskulärem Hypertonus. Hinzu kommen Diarrhoen, Fütterungs- und Gedeihstörungen, exzessives Schwitzen und ein gestörtes Schlafverhalten.

Das Ausmaß der Störung dieser Kinder durch den maternalen Drogenkonsum geht jedoch weit über die klinisch-neurologischen Symptome hinaus und betrifft sowohl die psychisch-emotionale wie auch die psychozosiale Gesundheit und Entwicklung der Patienten. Demzufolge sollte auch der Therapieansatz ganzheitlich sein und auf alle diese Ebenen einwirken.

Die medikamentöse Therapie besteht aus Morphinhydrochlorid bis zu einer Dosierung vn $6 \times 0,15 \mathrm{mg} / \mathrm{kgKG} /$ Tag; adjuvant Clonidin, Chloralhydrat, Benzodiazepine, etc. Seit Jänner 2010 bekommen unsere Patienten auch eine spezifische homöopatische Therapie, die entsprechend dem homöopatischen Prinzip der Ähnlichkeitsregel verordnet wird. Dabei steht die Individualität des Patienten im Vordergrund.

Die Möglichkeit, zusätzlich zum medikamentösen Drogenentzug noch homöopatische Arzneimittel zu verordnen, ist ein wertvolles Instrument, um die extrem angespannte Betreuungssituationen zu erleichtern. Wir hoffen in Zukunft auch zeigen zu können, dass wir dadurch Psychopharmaka einsparen und die Aufenthaltsdauer der Patienten reduzieren können.

Die stationäre Betreuung beinhaltet weitere Therapieformen, wie Craniosacraltherapie, Ergotherapie und Musuktherapie. Mithilfe von Psychologen und Sozialarbeitern versuchen wir, durch Veränderungen im emotionalen und sozialen Umfeld der Patienten eine bessere Mutter/ Eltern-Kind-Bindung zu erreichen. 


\subsection{Metabolomics: Möglichkeiten der Biomarkerentwicklung bei Frühgeborenen}

M. Keller ${ }^{1}$, D. Enot' ${ }^{1,2}$, M. Urban ${ }^{3}$, U. Felderhoff-Müser ${ }^{1}$, U. Kiechl-Köhlendorfer $^{2}$, H.-P. Deigner ${ }^{3}$, E. Griesmaier ${ }^{2}$

${ }^{1}$ Pädiatrie I, Neonatologie, Universitätsklinikum Essen, Deutschland, ${ }^{2} \mathrm{De}-$ partment für Kinder- und Jugendheilkunde, Pädiatrie IV, (Neonatologie, Neuropädiatrie, angeborene Stoffwechselerkrankungen), Medizinische Universität Innsbruck, Österreich, ${ }^{3}$ BIOCRATES life Sciences AG , Innsbruck, Österreich;

Hintergrund. Im Gegensatz zu Untersuchungen bei Erwachsenen gibt es bei Frühgeborenen bisher nur wenige Studien, die den Gehalt von Metaboliten insbesondere in Zusammenhang mit diversen Pathologien beschreiben. Ziel dieser Pilotstudie war 1.) die Evaluation der Einsetzbarkeit von Metabolomics bei Frühgeborenen im klinischen Setting und 2.) die Definition von Normwerten mit Untersuchung der Dynamik dieser Metabolite, sowie Beeinflussung derselben durch populationsbezogene Effekte (Geschlecht, Gestationsalter, etc.).

Methoden. Blutproben von 41 FG (28-32 SSW) wurden bei Geburt, sowie im Alter von 24 h, 72 h, 1 und 2 Wochen gesammelt. Die Quantifizierung der Metabolite erfolgte mittels hochsensitiver LC-MS (Massenspektroskopie). Diese ermöglicht die multiparametrische, simultane Quantifizierung endogener Spaltprodukte (Aminosäuren, biogene Amine, Acylkarnitine, Oxysterole, etc.).

Ergebnisse. In den ersten Tagen nach Geburt zeigt sich eine hohe Varianz der untersuchten Metabolitkonzentrationen. Es ist diese jedoch in der Klasse der Lipide und Acylkarnitine, im Gegensatz zu biogenen Aminen und Prostaglandinen gering ausgeprägt. Von 215 Metaboliten, zeigten zwischen $116(\mathrm{q}<0,001)$ und $185(\mathrm{q}<0,1)$ eine differenzierte Regulation in den ersten 2 Lebenswochen. Bei 9 Patienten in unserer Kohorte wurde eine Hirnschädigung im MRT nachgewiesen. Diese Patienten zeigten im Vergleich zu gesunden Kontrollen einen signifikanten Unterschied bestimmter Metabolitkonzentrationen (ADMA/ SDMA, $\mathrm{q}<\mathrm{o}, \mathrm{o1})$.

Konklusion. Metabolomics können bei Frühgeborenen effizient und valide untersucht werden. Insbesondere der Zeitpunkt der Probengewinnung, sowie die Verarbeitungsdauer sind wichtig. Die Quantifizierung dieser Metabolite bietet uns die Möglichkeit Umgebungsfaktoren und deren Einfluss auf das Frühgeborene zu untersuchen. Insbesondere ADMA könnte bereits unmittelbar nach Geburt ein potentieller Biomarker der perinatalen Hirnschädigung des Frühgeborenen sein.

\subsection{Homozygoter Surfactant-Protein-B(SFTPB)-Mangel - ein Fallbericht}

S. Kurath ${ }^{1}$, R. Kraschl' ${ }^{2}$ B. Resch ${ }^{3}$, W. Kaulfersch ${ }^{2}$

${ }^{1}$ Krankenhaus Waiern, Diakonie De La Tour, Kärnten, ${ }^{2}$ Abteilung für Kinderund Jugendheilkunde, Klinikum Klagenfurt am Wörthersee, ${ }^{3}$ Klinische Abteilung für Neonatologie, Univ. Klinik für Kinder- und Jugendheilkunde, Medizinische Universität Graz

Hintergrund. SFTPB-Mangel ist eine seltene (1:1 Mio.) aber schwerwiegende Erkrankung, welche meist bei Reifgeborenen auftritt und zu einer letalen respiratorischen Insuffizienz während der ersten sechs Lebensmonate führt. Lungentransplantation und Gen-Therapie, derzeit noch Gegenstand der Forschung, stellen Therapieoptionen zur Verlängerung der Überlebenszeit dar.

Fallbericht. Wir berichten über ein männliches Reifgeborenes einer 41-jährigen Mutter. Die Schwangerschaft verlief unauffällig. Post partum präsentierte sich das Kind mit schwachem Schreien, oberflächlicher Atmung, niedrigem Muskeltonus und peripherer Zyanose. Maskenbeatmung und Nasen-CPAP führten zu einer prompten Adaptation. APGAR 7/10/10. Während der ersten Lebensstunden verschlechterte sich die respiratorische Situation und das Kind wurde auf die NICU überstellt und eine mechanische Beatmung begonnen. Ein Röntgen zeigte diffuse Infiltrationen beider Lungen und ein im Ver- lauf vermindertes Lungenvolumen, sowie retikuläre Infiltrationen und ein positives Pneumobronchogramm. Surfactant Gabe führte zu einer akuten, aber temporären Verbesserung der Oxygenierung. Antibiotika und Methylprednisolon zeigten keinen Effekt. Im Weiteren wurde mit HFOV unter NO Zugabe begonnen, wodurch wiederum eine temporäre Verbesserung erreicht werden konnte. Die respiratorische Problematik persistierte über die 2. LW hinaus. Aufgrund der Klinik und der radiologischen Befunde wurde ein SFTPB-Mangel vermutet und eine Surfactant Protein-Gen Analyse durchgeführt. Es konnte ein homozygoter SFTPB-Mangel, bedingt durch die C248X Mutation an Exon 7 des SFTPB-Gens welche zur Synthese eines inkompletten Genprodukts führt, nachgewiesen werden. Während der folgenden Wochen verschlechterte sich die klinische Situation zusehends, und der Junge verstarb am 92. LT.

Schlussfolgerung. Trotz der Rarität sollte bei Kindern mit therapieresistenter respiratorischer Insuffizienz differentialdiagnostisch an einen SFTP-B-Mangel gedacht werden.

\subsection{Chronic intestinal pseudo-obstruction sydrome (CIPO) - ein Fallbericht}

S. Kurath ${ }^{1}$, R. Kraschl' ${ }^{2}$ B. Resch ${ }^{3}$, W. Kaulfersch ${ }^{2}$

${ }^{1}$ Krankenhaus Waiern, Diakonie De La Tour, Kärnten, ${ }^{2}$ Abteilung für Kinderund Jugendheilkunde, Klinikum Klagenfurt am Wörthersee, ${ }^{3}$ Klinische Abteilung für Neonatologie, Univ. Klinik für Kinder- und Jugendheilkunde, Medizinische Universität Graz

Hintergrund. CIPO ist eine sehr seltene Erkrankung des Verdauungstraktes charakterisiert durch eine zur Obstruktion führende Störung der Darmmotilität ohne nachweisbaren obstruktiven Prozess. Es gibt idiopathische sowie sekundäre Formen und sowohl Morbidität und Mortalität sind hoch. Es werden AD wie AR wie auch ein X-chromosomaler Erbgang beschrieben und die Klassifikation unterscheidet myopathische, mesenchymale oder neuropathische CIPO. Die Diagnostik stützt sich vorwiegend auf das klinische Bild und radiologische Charakteristika. Therapeutisch kommen vorwiegend supportive Therapien und in sehr speziellen Fällen Operationen in Frage. Das Langzeit-Outcome ist in den meisten Fällen schlecht.

Fallbericht. Wir berichten über ein Reifgeborenes, welches nach der Geburt mit Tachypnoe an unsere NICU überstellt wurde. Bei Aufnahme war der Bauch des Kindes gebläht aber weich. Abdomen-Leer-Aufnahmen und eine Irrigoskopie zeigten erweiterte Darmschlingen und einen geblähten Magen. Der Bub begann gallig zu erbrechen und Stuhl konnte nur nach mehrfachen rektalen Spülungen mobilisiert werden. Ende der ersten Woche wurde mit oraler Ernährung begonnen und das Kind in der dritten Woche nach Hause entlassen. Während der nächsten Monate wurde der Bub mehrfach aufgrund rezidivierenden galligen Erbrechens und Stuhlentleerungsproblemen stationär aufgenommen. Untersuchungen zeigten persistierend erweiterte Darmschlingen ohne Hinweis auf einen obstruktiven Prozess. Anhand einer Rektoskopie mit Biopsien konnten andere Ursachen ausgeschlossen und CIPO diagnostiziert werden. Während des 5,5-jährigen Follow-ups wurde eine zweimal wöchentliche parenterale Ernährung sowie Darmspülungen begonnen. Derzeit ist eine weitere Biopsie mit Versand des Probenmaterials nach London zur Diagnosesicherung und Klassifizierung geplant.

Schlussfolgerung. Trotz der Seltenheit und diagnostischen Schwierigkeiten sollte bei der genannten Symptomatik an ein CIPO differenzialdiagnostisch gedacht werden. 


\subsection{Zerebrales MRI ohne Sedierung bei Frühgeborenen am errechneten Geburtstermin}

V. Neubauer ${ }^{1}$, E. Griesmaier ${ }^{1}$, K. Baumgartner ${ }^{1}$, A. Mallouhi ${ }^{2}$, M. Keller ${ }^{1}$, U. Kiechl-Kohlendorfer ${ }^{1}$

${ }^{1}$ Univ.- Klinik für Kinder- und Jugendheilkunde IV, Abteilung für Neonatologie, Neuropädiatrie und Stoffwechselerkrankungen, Innsbruck, ${ }^{2}$ Univ.Klinik, Abteilung für Radiologie, Innsbruck

Hintergrund. Zerebrales MRI als bildgebendes Instrument zur Beurteilung von Hirnschädigung und vor allem Hirnentwicklung von Frühgeborenen nimmt an Bedeutung zu. Ziel dieser Studie war es, die Durchführbarkeit von MRI bei nichtsedierten Frühgeborenen am errechneten Geburtstermin (EGT) zu evaluieren. Der Fokus wurde dabei auf die notwendigen zeitlichen und personellen Ressourcen gelegt.

Methoden. 89 Kinder $<32$ Schwangerschaftswochen wurden in ihrer 1. Lebenswoche rekrutiert. An ihrem EGT erhielten die Kinder ein zerebrales MRT ohne Sedierung. Die Dauer der Untersuchung, der notwendigen Unterbrechungen bzw. Wiederholungen wegen Bewegungsartefakten wurde gemessen und dokumentiert.

Ergebnisse. 56 (63\%) von den 89 Kindern wurden mittels MRT am EGT untersucht. Drei Personen waren während der gesamten Vorbereitungszeit und Untersuchungsdauer anwesend (Assistenzärztin/arzt der Pädiatrie, RTA, StudentIn). Um ggf. Sequenzen wiederholen zu können, war ein Radiologe zur Beurteilung der Bildqualität vor Ende der Untersuchung verfügbar. Die Untersuchungen von Patienten, die zu diesem Zeitpunkt bereits nach Hause entlassen waren, konnten schneller abgewickelt werden als von Patienten, die am EGT noch stationär behandelt wurden ( $32 \pm 12$ Minuten vs. $54 \pm 10$ Minuten; $\mathrm{p}<0,01$ ). Von den 56 Kindern konnten 39 (69,6\%) ohne Unterbrechung untersucht werden. Nur 4 von 56 Untersuchungen $(7,2 \%)$ waren aufgrund starker Bewegungsartefakte nicht verwertbar. Die durchschnittliche Dauer aller Untersuchungen betrug $36 \pm 14$ Minuten.

Konklusion. Es hat sich gezeigt, dass ein engagiertes Team mit ausreichendem zeitlichen Spielraum die Grundvoraussetzung für hochwertige Bilder und somit unabdingbar für deren Befundung und entsprechende prognostische Schlussfolgerungen ist. Aus unseren Erfahrungen haben wir einen Leitfaden zusammengestellt, um den reibungslosen Ablauf von MRT-Untersuchungen ohne Sedierung bei stabilen Neugeborenen zu gewährleisten.

\subsection{Hat die orale Applikation von Gastrografin einen Ein- fluss auf die Mekoniumentleerung beim sehr unreifen Früh- geborenen?}

F. Norooz ${ }^{1}$, A. Repa ${ }^{2}$, K. Klebermaß-Schrehof ${ }^{2}$, A. Horak, A. Pollak ${ }^{2}$, N. Haiden $^{2}$

${ }^{1}$ AKH Wien, ${ }^{2}$ Univ.-Klinik für Kinder- und Jugendheilkunde, Wien

Hintergrund. Frühgeborene haben durch die Unreife des Gastrointestinaltraktes eine verzögerte Mekoniumausscheidung. Die Obstruktion tiefer Darmabschnitten durch Mekonium führt zu Rückstau der Nahrung und einer verlängerten Nahrungspassage. Der orale Nahrungsaufbau wird protrahiert, die Infektionsgefahr steigt durch venöse Zugänge und der stationäre Aufenthalt verlängert sich. Gastrografin ist ein osmotisch wirksames Kontrastmittel, das zu einem Wassereinstrom in das Darmlumen führt und die Magen-Darmpassage beschleunigt.

Ziel und Fragestellung. Ziel der Studie war es, den Einfluss von Gastrografin auf die Mekoniumentleerung zu evaluieren und die Auswirkung auf den enteralen Nahrungsaufbau zu untersuchen.

Material und Methode. Im Rahmen der prospektiven, randomisierten Doppelblindstudie wurden Frühgeborene (Geburtsgewicht $<1500$ g, Gestationsalter $<32$ SSW) untersucht. Die Interventionsgruppe erhielt einmalig in den ersten 24 Lebensstunden eine Dosis Gastrografin via Magensonde ( $3 \mathrm{ml} / \mathrm{kg}$ Körpergewicht 1:3 mit Aqua verdünnt);die Kontrollgruppe ein Placebo.
Ergebnisse und Diskussion. In die PP Analyse wurden 39 Kinder je Gruppe eingeschlossen. Das Gestationsalter betrug in beiden Gruppen 188 Tage, das Geburtsgewicht in der Kontrollgruppe 795 g (=Median, Range:934) in der Gastrografingruppe 87og (=Median, Range: 950; n.s.). Die vollständige Mekoniumpassage dauerte in der Kontrollgruppe 8 Tage (=Median, Range: 23 ) in der Gastrografingruppe 7 Tage (=Median, Range 16; n.s). Der enterale Nahrungsaufbaus betrug in der Gastrografingruppe 19 Tage, in der Kontrollgruppe 26 Tage ( $\mathrm{p}=0,05)$. Die Gesamtaufenthaltsdauer war mit 57 Tagen in der Gastrografingruppe vs 78 Tage in der Kontrollgruppe kürzer $(\mathrm{p}=0,02)$.

Schlussfolgerungen. Die orale Applikation von Gastrografin verkürzt die Mekoniumentleerung nicht signifikant. Der enterale Nahrungsaufbau ist aber rascher - möglicherweise begünstigt durch eine höhere Stuhlfrequenz.

\subsection{Messung von visuell evozierten Potenzialen (VEP) bei Frühgeborenen <29 SSW: eine Querschnittsstudie zur Erstellung von Referenzwerten in dieser Patientengruppe - Präsentation erster Ergebnisse}

E. Obwegeser, Z. Rona, B. Hengl, V. Giordano, C. Czaba, M. Olischar, M. Weninger, K.Klebermaß-Schrehof

Abteilung für Neonatologie und Neuropädiatrie, Univ. Klinik für Kinderund Jugendheilkunde, AKH Wien, Währinger Gürtel 18-20, 1090 Wien

Einleitung. Laufende Verbesserungen der letzten Jahrzehnte im Bereich Neonatologie und Geburtshilfe haben zu einer zunehmenden Überlebensrate von sehr kleinen Frühgeborenen geführt. Ziel ist nun nicht mehr das reine Überleben dieser Kinder, sondern vor allem der Erhalt einer guten Lebensqualität und Langzeitprognose. Umso wichtiger ist heute eine geeignete frühzeitige Überwachung der neuronalen Funktion und Entwicklung. Ein weiteres Verfahren zum Neuromonitoring (neben etwa amplitudenintegriertem EEG oder zerebralem Ultraschall) können visuell evozierte Potentiale sein, die mittels BlitzlichtStimulus (flash-VEP) auch bereits bei sehr kleinen Kindern eingesetzt werden können. VEP sind bei Frühgeborenen auch deshalb relevant, weil die Sehbahn in der periventrikulären Region verläuft, die bei diesen Kindern zu den vulnerabelsten zählt und bei Hirnblutungen häufig beeinträchtigt ist. Um eine Aussage über den Entwicklungsstand und Veränderungen des visuellen Systems bei Frühgeborenen mittels VEP treffen zu können, müssen jedoch Kenntnisse über die normale Entwicklung gewonnen werden. Da es bisher für Frühgeborene unter 29 Schwangerschaftswochen noch keine Daten diesbezüglich gibt, ist das Ziel dieser Studie das Erstellen einer Basis für Referenzwerte von VEP bei Frühgeborenen unter 29 Schwangerschaftswochen.

Methodik. VEP sollen innerhalb der ersten 2 Lebenswochen bei Kindern zwischen $23+0$ und 28+6 Schwangerschaftswochen gemessen werden. Nur Messungen von Kindern mit normaler Entwicklung (unauffällige Schädelsonographie, Fundoskopie sowie normaler Bayley Scale of Infant Development im Alter von 24 Monaten) sollen später in die Berechnung der Referenzwerte einbezogen werden.

Erste Ergebnisse. Es konnten bisher ${ }_{13}$ Patienten eingeschlossen werden $(24+1$ bis $28+6 \mathrm{SSW})$. In jeder Messung wurden die Latenzen N2, $\mathrm{P}_{2}$ und $\mathrm{N}_{3}$ ermittelt und deren Mittelwert mit Standardabweichung als Referenz für die jeweilige Schwangerschaftswoche berechnet. (siehe Tab. 1)

Konklusion. Aus den ersten Ergebnissen konnten Referenzwerte berechnet werden, welche als Basis für Normwerte von visuell evozierten Potentialen bei Frühgeborenen auch unter 29 Schwangerschaftswochen gesehen werden können. Damit soll die normale Entwicklung und Reifung des visuellen Systems bereits bei sehr kleinen Frühgeborenen überwacht und eventuelle Defizite (z. B. durch eine intraventrikuläre Blutung oder posthämorrhagischem Hydrozephalus) bereits früh erkannt werden. 


\begin{tabular}{|llll|}
\hline Tab.1 & & & \\
& SSW 23-24 & SSW 25-26 & SSW 27-28 \\
& $\mathrm{n}=4$ & $\mathrm{n}=4$ & $\mathrm{n}=4$ \\
\hline N2 & $344(25)$ & $331(18)$ & $\mathbf{3 0 9}(20)$ \\
\hline P2 & $507(30)$ & $560(73)$ & $474(26)$ \\
N3 & $591(38)$ & $705(104)$ & 564 (29) \\
\hline
\end{tabular}

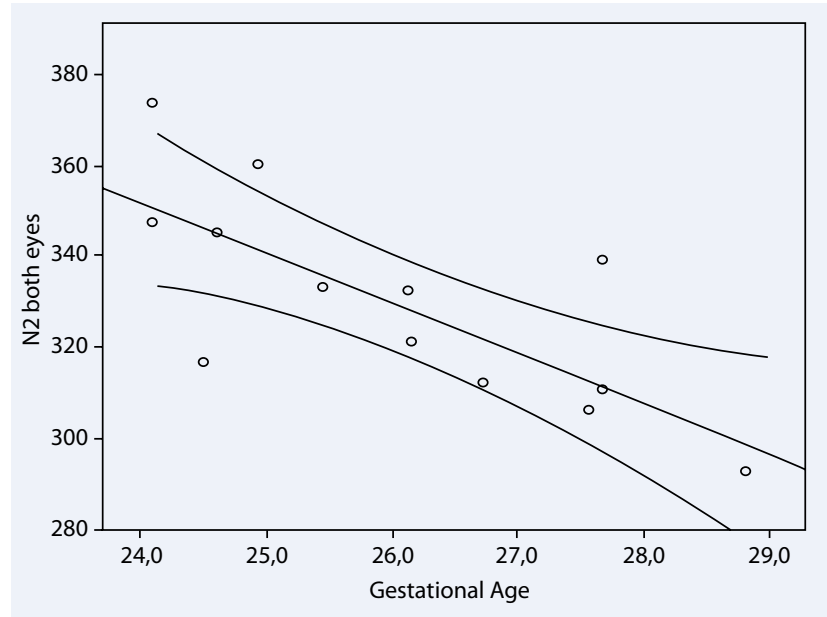

Abb. 1 ॥ Negative Korrelation der Latenz N2 mit dem Gestationsalter

\subsection{Geburt und mütterliche Stressverarbeitung}

E. Pichler-Stachl' ${ }^{1}$, G. Pichler ${ }^{1}$, J. Wasserbauer', S. Gramm², W. Müller', B. Urlesberger'

${ }^{1}$ Univ.-Klinik für Kinder- und Jugendheilkunde, Abteilung Neonatologie, Graz, ${ }^{2}$ Univ.-Klinik für Kinder- und Jugendheilkunde, Abteilung Geburtshilfe, Graz

Fragestellung. In der vorliegenden Studie wurde untersucht, ob sich Mütter von Frühgeborenen und Mütter von Reifgeborenen in ihrer Art der Stressbewältigung nach der Geburt unterscheiden.

Methode. Innerhalb der ersten drei Tage nach Entbindung wurden bei Mütter Frühgeborener $(\geq 28+0$ SSW $<33+0)$ und bei Mütter Reifgeborener $(>37$ SSW) die individuelle Stressverarbeitung anhand des Stressverarbeitungsfragebogens SVF12o (Janke, Erdmann, Kallus und Boucsein, 1997) bestimmt. Mittels SVF120 können positive (Abwertung/ Abwehr, Ablenkung, Kontrolle des Stressors) und negative Strategien zur Stressbewältigung, das Bedürfnis nach sozialer Unterstützung, das Vermeiden von Stressoren, sowie aggressives Verhalten in Stresssituationen erhoben werden.

Ergebnisse. Bisher nahmen 23 Mütter (Alter: 29.9 \pm 5.1$)$ von Frühgeborenen (Gestationsalter: $32.6 \pm 2.8$ SSW, Geburtsgewicht: $1911 \pm 558 \mathrm{~g}$ ) und 23 Mütter (Alter: 30,2 \pm 5,1) Reifgeborener (Gestationsalter: 40,1 $\pm 0,9$ SSW, Geburtsgewicht: $3464 \pm 347$ g) an der Studie teil. Mütter Frühgeborener zeigten eine signifikant geringere Stressverarbeitung mittels negativer Stressbewältigungsstrategien (Flucht, soziale Abkapselung, gedankliche Weiterbeschäftigung, Resignation, Selbstbemitleidung, Selbstbeschuldigung; $\mathrm{p}<0,05)$, sowie ein signifikant geringeres aggressives Verhalten $(\mathrm{p}<0,05)$ in Stresssituationen als Mütter Reifgeborener. In der Stressbewältigung mittels positiver Strategien, dem Bedürfnis nach sozialer Unterstützung sowie dem Vermeiden von Stressoren unterscheiden sich die Mütter Früh- bzw. Reifgeborener nicht signifikant.

Schlussfolgerung. Mittels den bisher vorliegenden Daten konnte erstmals gezeigt werden, dass die mütterliche Stressverarbeitung abhängig vom Gestationsalter des Neugeborenen ist. Diese Ergebnisse sind in der Betreuung und Unterstützung von Müttern Früh- und Reifgeborener in Hinblick auf die Mutter-Kind-Interaktion in Betracht zu ziehen.
12.15 Rehospitalisation von Frühgeborenen $<32$ Schwangerschaftswochen in ihren ersten 2 Lebensjahren

E. Ralser', W. Müller ${ }^{2}$, C. Haberland ${ }^{3}$, F. Fink ${ }^{4}$, Karl, H. Gutenberger ${ }^{5}$, R. Strobl ${ }^{6}$, U. Kiechl-Kohlendorfer ${ }^{1}$

${ }^{1}$ Department für Pädiatrie IV; Abteilung für Neonatologie, Neropädiatrie und metabolische Stoffwechselerkrankungen, Universitätsklinik Innsbruck, ${ }^{2}$ Kinderstation, Landeskrankenhaus Reutte, ${ }^{3}$ Kinderstation, Landeskrankenhaus Kufstein, ${ }^{4}$ Kinderstation, Landeskrankenhaus St. Johann, ${ }^{5}$ Kinderstation, Landeskrankenhaus St. Vincent's Landeck, ${ }^{6}$ Kinderstation, Landeskrankenhaus Lienz

Ziel. Ziel dieser Studie war es, die Häufigkeit von und die beeinflussenden Faktoren für eine Rehospitalisierung kleiner Frühgeborenen in den ersten 2 Lebensjahren zu untersuchen.

Methodik. Alle Kinder, die zwischen Jänner 2003 und Juli 2008 vor vollendeten 32 Schwangerschaftswochen in Innsbruck geboren wurden und deren Eltern in Nordtriol leben, wurden in diese Studie eingeschlossen. Von dieser Kohorte wurden sämtliche stationären Krankenhausaufenthalte an allen Kinderstationen Nordtirols geprüft. Hieraus wurde eine Assoziation zwischen Risikofaktoren und Wiederaufnahmen mit Hilfe von logistischen Regressionsanalysen berechnet (SPSS). Resultate. Von 377 Kindern wurden 151 und 93 (40.1\% und 24.7\%) in den ersten beiden Jahren aufgenommen. Die häufigste Ursache waren respiratorische Infekte (42.1\% und 47.4\%). Chronische Lungenerkrankung, das männliche Geschlecht und Rauchen während der Schwangerschaft waren unabhängige Risikofaktoren für stationäre Aufenthalte im ersten Jahr. Im zweiten Lebensjahr zeigte sich lediglich die Chronische Lungenerkrankung als nahezu signifikant.

Schlussfolgerung. Frühgeborene mit einem Gestationsalter $<32$ SSW bei Geburt haben ein hohes Risiko einer stationären Wiederaufnahme, besonders durch respiratorische Infekte. Dies zeigt erneut wie wichtig Verbesserungen bezüglich pulmonaler Entwicklung und Therapie für Frühgeborene sind und soll zu weiterer Forschung in diesem Bereich animieren. Ebenso sind eine gute Nachbetreuung von Frühgeborenen und das Bewusstsein über die Vulnerabilität ihrer Lunge in der Versorgung von großer Bedeutung.

\subsection{Eingeschränkte periphere Oxygenierung und Zirkulation in Abhängigkeit von der Schwere einer peripartalen Asphyxie}

N. Tax, G. Pichler, C. Binder, M. Pocivalnik, E. Ziehenberger, H. Zotter, E. Pichler-Stachl, W. Müller, B. Urlesberger

Univ.-Klinik für Kinder- und Jugendheilkunde, Graz

Fragestellung. Ziel dieser prospektiven Beobachtungsstudie war es einen mit Nahinfrarot-Spektroskopie (NIRS) messbaren Zusammenhang zwischen peripherer Oxygenierung und Zirkulation und der Schwere einer peripartalen Asphyxie festzustellen.

Methodik. Bei Neugeborenen mit peripartaler Asphyxie (NapH $\leq 7,15$ und Apgar $5<7$ ) wurden innerhalb der ersten 48 Lebensstunden in Ruhe NIRS-Messungen am Unterschenkel durchgeführt. Mit Hilfe von NIRS in Kombination mit venösen Okklusionen konnten "Gesamthämoglobin“ (HbT), Oxygen delivery“ (DO2), „Oxygen consumption“ $\left(\mathrm{VO}_{2}\right)$, „Tissue oxygenation index“ (TOI), venöse Sättigung $\left(\mathrm{S}_{\mathrm{v}} \mathrm{O}_{2}\right)$ und „Fractional oxygen extraction“ (FOE) gemessen und berechnet werden. Anschließend wurde der $\mathrm{NapH}$ mit $\mathrm{HbT}, \mathrm{DO}_{2}, \mathrm{VO}_{2}$, TOI, $\mathrm{S}_{\mathrm{v}} \mathrm{O}_{2}$ und FOE korreliert.

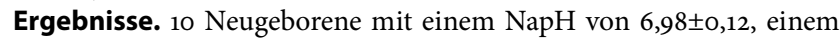

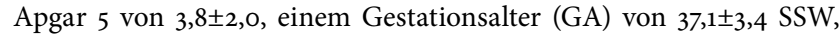
einem postnatalem Alter (PA) von 23,0 \pm 15 , o Stunden und einem Geburtsgewicht $(\mathrm{GG})$ von $3095 \pm 830 \mathrm{~g}$ wurden in die Studie eingeschlossen. $\mathrm{HbT}$ und $\mathrm{VO}_{2}$ zeigten eine signifikante Korrelation mit $\mathrm{NapH}$ $(\mathrm{r}=0,63$ bzw. 0,67; $\mathrm{p}<0,05)$. Bei $\mathrm{DO}_{2}$ bestand ein Trend zur positiven Korrelation mit NapH $(r=0,62, p=0,057)$. Für TOI, $\mathrm{S}_{\mathrm{v}} \mathrm{O}_{2}$ und FOE konnten keine signifikanten Korrelationen mit $\mathrm{NapH}$ nachgewiesen werden. 
Schlussfolgerung. Diese Studie zeigt, dass mit sinkendem NapH bei peripartaler Asphyxie der periphere Hämoglobinfluss (Hbflow) und die periphere Sauerstoffextraktion vor allem in den ersten beiden Lebenstagen erniedrigt sind. Dies ist in erster Linie als Ausdruck einer (Mikro-)Zirkulationsstörung zu interpretieren.

\subsection{Erstversorgung ab SSW 23+0: Surfactantgabe bei sponta- ner Atmung am CPAP mit konstant hohem PEEP}

M. Wald, K. Klebermass, J. Schwindt, N. Haiden, A. Messerschmidt, M. Hayde, A. Berger, A. Pollak

Klinische Abteilung für Neonatologie, Pädiatrische Intensivmedizin und Neuropädiatrie, Universitätsklinik für Kinder- und Jugendheilkunde, Medizinische Universität Wien

Einleitung. Seit 2009 wird an der Medizinischen Universität Wien Surfactant ab der SSW 23+o am CPAP verabreicht (Methode nach Angela Kribs, Universität Köln). Der CPAP wird über ein Flow reguliertes Benveniste-Ventil (Jet-CPAP) aufgebaut. Der Flow von 20 l/ min erzeugt 25 mbar PEEP während der gesamten Erstversorgung (40-6o min). Unsere Studie hat den Einfluss dieser Form von Erstversorgung ohne Beatmung auf Mortalität und Morbidität untersucht.

Methode. Retrospektive Datenanalyse der Vermont Oxford Network Daten (VON) unseres Zentrums (2009 und 2010) im Vergleich mit den VON-Daten aller Level C NICU's sowie der 1-Jahres-Outcome-Daten (Bayley Scales) aus 2009. Inkludiert wurden alle Frühgeborenen bis SSW 29+3.

Ergebnisse. 272 Kinder (Geb.-Gew. 904 \pm 282 g) wurden versorgt (VON n=11.833, Geb.-Gew. $934 \mathrm{~g}$; p>0,05), 82,7\% überlebten (VON $80 \% ; p=0,305$ ), 80,1\% erhielten Surfactant (VON 8o,4\%; $p=0,963$ ), 10,1\% hatten einen Pneumothorax (VON 6,4\%; $\mathrm{p}=0,020$ ), 54,5\% wurden im Verlauf maschinell beatmet (VON 84,9\%; $\mathrm{p}<0,001$ ), 16,9\% entwickelten eine bronchopulmonale Dysplasie (VON 39,2\%; p<0,001). Eine Hirnblutungen (IVH) Grad 1-2 zeigten 20,4\% (VON 20,0\%; $\mathrm{p}=0,931$ ); 9,4\% eine IVH 3-4 (VON 13,9\%; p=o,041). Wegen einer Retinopathie (ROP) wurden 10,2\% gelasert (VON 7,1\%; $\mathrm{p}<0,001$ ) ein Kind (o,004\%) zeigte danach eine Progredienz (ROP 4; VON o,5\%; p<0,oo1). Von den mit 1 Jahr nachuntersuchten FG zeigten $14,7 \%$ schwere (MDI/PDI $<70$ ), $27,9 \%$ mittlere bis leichte und 57,4\% keine neurologische Beeinträchtigungen (=MDI/PDI $>85$ ).

Schlussfolgerung. In der Literatur werden CPAP-Drücke um 25 mbar während der Erstversorgung von Frühgeborenen als kurze Blähmanöver beschrieben. Diese gelten als sicher und effektiv für das primäre Recruitment der Lungen. Die Ergebnisse unserer Untersuchung sprechen dafür, dass die Surfactantapplikation unter kontinuierlich hohem PEEP während der gesamten Erstversorgung sicher ist und dieses Vorgehen keinen negativen Einfluss auf Mortalität und Outcome hat.

\subsection{Konnatale CMV-Infektion bei frühgeborenen Zwillingen - CMV-assoziierte Enterokolitis bei extremer Dystrophie}

K. Wegleitner', B. Brunner², K. Maurer ${ }^{3}$, R. Trawöger', U. Kiechl-Kohlendorfer $^{1}$

${ }^{1}$ Department für Kinder- und Jugendheilkunde, Pädiatrie IV, Innsbruck, ${ }^{2}$ Department für Kinder- und Jugendheilkunde, Innsbruck, ${ }^{3}$ Univ.-Klinik für Radiologie, Innsbruck

Hintergrund. Die kongenitale Cytomegalie-Virus(CMV)-Infektion stellt die häufigste konnatale Infektion des Menschen dar. Eine primäre CMV Infektion findet bei $2 \%$ aller schwangeren Frauen statt und verläuft bei mehr als $95 \%$ asymptomatisch. Vor allem Frühgeborene mit einem niedrigen Geburtsgewicht haben ein höheres Risiko einer klinischen Manifestation.

Kasuistik. Wir berichten über weibliche monochoriale diamniote Zwillingsfrühgeborene, mit $31 \mathrm{o} / 7$ Schwangerschaftswochen geboren. Neben der Symptomatik der Frühgeburtlichkeit, zeigte der II. Zwilling eine Dystrophie mit einem Geburtsgewicht von 560 g. Der routinemä-
Big durchgeführte Erregernachweis im Harn beider Kinder war positiv, die mütterliche CMV Serologie ergab einen IgG positiven und IgM negativen Befund. Während sich ein asymptomatischer Verlauf beim I. Zwilling zeigte, kam es im Alter von 3 Monaten beim II. Zwilling zu einer schweren nekrotisierenden Enterokolitis, welche sich unter Antibiotikatherapie und Nahrungskarenz nicht besserte. CMV konnte in Blut, Harn und Stuhl als zugrundeliegendem Erreger nachgewiesen werden. Die CMV-Analyse im Trockenblut, welches 48 h nach Geburt gewonnen wurde, erbrachte die Diagnose einer konnatalen CMV-Infektion. Die antivirale Therapie mit CMV Gammaglobulin und Ganciclovir brachte schnell klinischen Erfolg. Die Entlassung war mit dem Alter von 47 o/7 SSW möglich. Beide Patientinnen zeigten bei Entlassung einen altersentsprechenden neurologischen Status und einen unauffälligen audiologischen Befund.

Diskussion. Der Fallbericht beschreibt eine konntatale CMV-Infektion eines frühgeborenen Zwillingspärchens und illustriert die Variabilität der klinischen Ausprägung, welche in diesem Fall mit einem niedrigen Geburtsgewicht korrelierte. Ein asymtpomatischer Verlauf schließt eine konnatale CMV-Infektion nicht aus. Auch bei verzögertem Beginn der Symptomatik ist eine Diagnosestellung durch den Nachweis in der Trockenblutkarte möglich und kann daher zur richtigen Diagnose beitragen.

\subsection{Prophylaktische vs. „early rescue“-Surfactanttherapie bei VLBW-Frühgeborenen}

M. Weissensteiner ${ }^{1}$, O. Wagner ${ }^{1}$, G. Wiesinger-Eidenberger ${ }^{1}$, E. Lechner ${ }^{1}$, M.Eibisberger ${ }^{2}$, N. Hofer ${ }^{2}$, B. Resch ${ }^{2}$

${ }^{1}$ Abteilung für Neonatologie, Landes- Frauen- und Kinderklinik Linz, ${ }^{2}$ Klinische Abteilung für Neonatologie, Univ. Klinik für Kinder- und Jugendheilkunde Graz

Es konnte gezeigt werden, dass eine prophylaktische Verabreichung von Surfactant an Frühgeborene unter 30 SSW mit geringer antenataler Steroidtherapie im Vergleich zu einer Rescue-Therapie die Mortalität, die Frequenz und Schwere eines RDS und die Pneumothoraxhäufigkeit reduziert und das kombinierte Outcome BPD und Tod verbessert [1].

Die zunehmende antenatale Steroidtherapie und der frühe Einsatz von nCPAP reduzieren den Benefit einer prophylaktischen Surfactanttherapie. Die European Consensus Guidelines 2010 [2] empfehlen eine prophylaktische Surfactanttherapie für nahezu alle Frühgeborene unter 26 SSW.

Drei rezente Multizenterstudien konnten jedoch zeigen, dass es für Frühgeborene ab der SSW 25/o [3][4] bzw. 24/o [5] nicht von Nachtteil war, wenn sie keine prophylaktische Surfactanttherapie erhielten. Die Indikation zur prophylaktischen Surfactanttherapie bleibt somit in Diskussion.

\section{Literatur}

1. Surfactant-Replacement Therapy for Respiratory Distress in the Preterm and Term Neonate W. Engle, Pediatrics 2008

2. European Consensus Guidelines on the Management of Neonatal Respiratory Distress Syndrome in Preterm Infants - 2010 Update, Sweet et al.

3. Nasal CPAP or Intubation at Birth for Very Preterm Infants Morley et al., New England Journal of Medicine Feb 2008 4Prophylactic or Early Selective Surfactant Combined With nCPAP in Very Preterm Infants Sandri et al., Pediatrics Mai 2010 5Early CPAP vs. Surfactant in Extremely Preterm Infants Finer et al., New England Journal of Medicine, Mai 2010 
12.20 Zusammenhang zwischen reduzierter Verarbeitungsgeschwindigkeit und motorischen bzw. kognitiven Defiziten bei ehemaligen Frühgeborenen im Alter von 5 Jahren

S. Zotter, B. Fussenegger, N. Walser, K. Rostasy, U. Pupp-Peglow, U. KiechlKohlendorfer

Medizinische Universität Innsbruck, Universitätsklinik für Pädiatrie IV (Neonatologie, Neuropädiatrie, angeborene Stoffwechselerkrankungen)

Hintergrund. Ehemalige Frühgeborene haben ein erhöhtes Risiko für die Entwicklung von motorischen sowie kognitiven Defiziten [Lernstörungen, reduziertes intellektuelles Leistungsniveau, Aufmerksamkeitsstörungen, (visuo-)motorische Störungen]. Weiters wird in der Literatur von einer reduzierten Verarbeitungsgeschwindigkeit berichtet. Es stellt sich die Frage inwieweit sich eine reduzierte Verarbeitungsgeschwindigkeit durch motorische Defizite erklären lässt bzw. ob ein Zusammenhang mit kognitiven Defiziten besteht.

Material und Methoden. Im Rahmen der Frühgeborenennachsorge der Universitätsklinik Innsbruck wurden innerhalb von 2 Jahren 100 ehemalige Frühgeborene im Alter von 5 Jahren entwicklungspsychologisch untersucht (kognitives Leistungsprofil: HAWIVA; Verarbeitungsgeschwindigkeit: HAWIVA; numerisch-rechnerische Vorläuferfertigkeiten: TEDI-MATH; Benenngeschwindigkeit: BISC; feinmotorische Koordinationsleistung: Grooved Pegboard; Arbeitsgedächtnis: Zahlenspanne, Corsi-Blockspanne).

Ergebnisse. Bei $26 \%$ der untersuchten Frühgeborenen zeigt sich eine reduzierte Verarbeitungsgeschwindigkeit. Diese lässt sich nur teilweise durch Defizite im motorischen Bereich erklären. Darüber hinaus besteht ein signifikanter Zusammenhang zwischen Verarbeitungsgeschwindigkeit und Benenngeschwindigkeit sowie zwischen Verarbeitungsgeschwindigkeit und Exekutivfunktionen (Arbeitsgedächtnis; Inhibition).

Schlussfolgerungen. Die reduzierte Verarbeitungsgeschwindigkeit ist zum einen auf motorische Defizite und zum anderen auf kognitive Defizite zurückführen. Studien belegen, dass die Benenngeschwindigkeit im Vorschulalter einen guten Prädiktor für spätere Lernstörungen darstellt. Daher stellt die Erfassung der unterschiedlichen Facetten von Verarbeitungsgeschwindigkeit (visuomotorische Anforderungen, Benenngeschwindigkeit) einen wichtigen Bestandteil fundierter Diagnostik dar, um mit adäquaten Therapiemaßnahmen den vorliegenden Defiziten adäquat entgegenzuwirken.

12.21 Improved weight gain in VLBW infants after the introduction of a computer-based plan for individualized parenteral nutrition

M. Gnigler' ${ }^{1}$ S. Navarro-Psihas' ${ }^{1}$, B. Schlenz ${ }^{1}$, U. Kiechl-Kohlendorfer ${ }^{1}$,M. Rüdiger ${ }^{2}$

'Department of Neonatology, University Hospital of Innsbruck, ${ }^{2}$ Department of Neonatology, Carl Gustav Carus University Hospital of Dresden

Background. Although only $10 \%$ of very low birth weight infants (VLBW) have a birth weight under the 1oth percentile, almost all of them are under this percentile at 36 weeks of gestation. This extrauterine growth retardation is mainly caused by inadequate supplementation of nutrients in the first weeks of life and has been associated with higher morbidity in these patients [1][2][3].

Aim. We compared somatometric weight data of VLBW-infants before and after introduction of a standardized, computer-based plan for parenteral nutrition in our hospital in 2003.

Methods. In this retrospective, comparative study, somatometric data and the composition of parenteral nutrition were compared in two periods of time (group A in 2001-2002; group B in 2004-2005). In the first period 56 patients were treated with individualized plans for parenteral nutrition, whereas in the second period a computer based individual nutrition plan designed at the University Hospital of Innsbruck was used for 59 patients.
Results. Although the number of infants with a birth weight over the 1oth percentile (AGA) did not differ ( $71 \%$ group A vs. $70 \%$ group B), group $B$ had a higher percentage of AGA-infants at the time of hospital discharge (group B $44 \%$ vs. group A $14 \%, \mathrm{p}<0.01$ ). In group B, more protein was administered in the first 5 days of life (group B $7.3 \mathrm{~g}$ vs. group A $4.5 \mathrm{~g}, \mathrm{p}<0.01$ ) and also the administration of parenteral fat was higher in the first 10 days of life (day 6-10: group B $11.3 \mathrm{~g}$ vs. group A $8.9 \mathrm{~g}, \mathrm{p}<0.01)$. Moreover, infants in group $\mathrm{B}$ had a shorter duration of total parenteral nutrition (group B 16 vs. group A 24 days, $\mathrm{p}<0.01$ ).

Conclusion. The introduction of a computer based plan for parenteral nutrition was associated with better weight gain and higher administration of protein and fat in VLBW-infants in the first days of life. This is probably due to a more precise and easier calculation of nutrition components.

\section{Literatur}

1. Ehrenkranz RA,Younes N,Lemons JA et al (1999) Longitudinal growth of hospitalized very low birth weight infants. Pediatrics 104(2 Pt 1):280-9.

2. Clark RH, Thomas P, Peabody J (2003) Extrauterine growth restriction remains a serious problem in prematurely born neonates. Pediatrics $111(5$ Pt 1):986-90.

3. Ziegler E (1991) Malnutrition in the preterm infant. Acta Paediatr. Scand Suppl. 374:58-66

\section{Nephrologie}

\subsection{Fibromuskuläre Dysplasie mit Multiorganbeteiligung}

\section{Cimenti' ${ }^{1}$ C. J. Mache ${ }^{1}$, R. H. Portugaller ${ }^{2}$, A. Pilhatsch², E. Ring ${ }^{1}$}

${ }^{1}$ Universitätsklinik für Kinder- und Jugendheilkunde Graz, ${ }^{2}$ Klinische Abteilung für vaskuläre und interventionelle Radiologie, Universitätsklinik für Radiologie, Graz

Die fibromuskuläre Dysplasie (FMD) ist eine nicht-atherosklerotische, nicht-inflammatorische Gefäßerkrankung, die zu Stenosen, Aneurysmen, Dissektionen und Verschlüssen führen kann (Jeffrey W et al., J Vasc Surg 2011; 53:826-36). Am häufigsten befallen sind Nierenarterien und Carotiden, wobei jedoch jede Arterie betroffen sein kann.

Bei einem 17-jährigen Patienten wurde bei einer schulärztlichen Untersuchung ein arterieller Hypertonus festgestellt. Eine 24-StundenBlutdruckmessung ergab durchschnittliche Tageswerte von 167/103 mmHg und Nachtwerte von $159 / 93 \mathrm{mmHg}$. Laborchemisch zeigten sich keinerlei Entzündungszeichen. Das Serumkreatinin war 1,03 mg/ $\mathrm{dl}$ (errechnete GFR $122 \mathrm{ml} / \mathrm{min} / 1,73 \mathrm{~m}^{2} \mathrm{KO}$ ), im Harn bestand eine asymptomatische Proteinurie (Eiweiß $186 \mathrm{mg} / \mathrm{g}$ Kreatinin). Das ReninAngiotensin-Aldosteron-System war aktiviert.

In der Bildgebung fanden sich multiple perlschnurartig angeordnete Aneurysmen der rechten Nierenarterie, das größte Aneursyma hilusnah gelegen mit einer Ausdehnung von $2 \times 1 \times 1,7 \mathrm{~cm}$. Zusätzlich multiple hiläre und intrarenale Aneurysmen beidseits bis maximal 1,3 cm, links mehr als rechts. Eine 99m-Tc-DMSA Nierenszintigraphie zeigte vaskulär bedingte Parenchymläsionen beidseits mit Funktionseinschränkung der linken Niere (Partialfunktion 44\%). Die Durchuntersuchung ergab zusätzlich eine Mitbeteiligung folgender Gefäße: Ein 4,2×1,4 cm großes Aneurysma im extrakraniellen Abschnitt der A. carotis int. dext., Kaliberunregelmäßigkeiten mit Ektasien an der A. vertebralis sin., eine fokale Ausweitung der A. brachialis dext. und perlschnurartige Kaliberschwankungen eines Asts der A. mesenterica sup. Zusammenfassend besteht in Anbetracht des Alters, der fehlenden Entzündungszeichen und der Lokalisation der Gefäßveränderungen das klassische Bild einer FMD. Die in dieser Kasuistik beschriebene ausgeprägte Multiorganbeteiligung unterstreicht die Wichtigkeit einer systematischen Durchuntersuchung bei Auftreten von Nierenarterienstenosen oder -aneurysmen. 


\subsection{Rezidivierende tubulointersititielle Nephritis mit Uveitis (TINU)}

C. Cimenti' ${ }^{1}$ C. J. Mache' ${ }^{1}$, B. Langner-Wegscheider ${ }^{2}$, M. Ratschek ${ }^{3}$, E. Ring ${ }^{1}$ ${ }^{1}$ Universitätsklinik für Kinder- und Jugendheilkunde Graz, ${ }^{2}$ Universität Augenklinik Graz, ${ }^{3}$ Institut für Pathologie, Medizinische Universität Graz

Die akute tubulointerstitielle Nephritis (TIN) ist eine häufige Ursache des akuten Nierenversagens im Kindes- und Jugendalter mit oft ungeklärter Ätiologie und im Allgemeinen guter Prognose. In seltenen Fällen kommt es auch zeitlich unabhängig zu einer Uveitis (TINU).

Bei einer 16-jährigen Patientin bestanden seit 6 Wochen Flankenschmerzen, intermittierendes Fieber, Gewichtsabnahme ( $-4 \mathrm{~kg})$, zunehmendes Durstgefühl und Nykturie. Laborchemisch zeigten sich eine Anämie ( $\mathrm{Hb} 10,5 \mathrm{~g} / \mathrm{dl})$, eine Erhöhung des CRP (99,5 mg/L) und der BSG (6o mm/Stunde). Das Serumkreatinin lag bei $1,43 \mathrm{mg} / \mathrm{dl}$, der Harnstoff war normal $(26 \mathrm{mg} / \mathrm{dl})$. Die Harnbefunde zeigten eine Glucosurie (100 mg/dl) sowie eine tubuläre Proteinurie ( $\beta-2$ Mikroglobulin $19.300 \mu \mathrm{g} / \mathrm{l}$, normal <300). Weiterführende Untersuchungen ergaben keine Ursache für die TIN, auch eine Augenuntersuchung war unauffällig. Eine Steroidtherapie (Prednisolon $75 \mathrm{mg} /$ Tag für 4 Wochen) führte zu kompletter Remission. Zwei Monate nach Absetzen der Steroidtherapie kam es erneut zu Flankenschmerzen und Fieber im Rahmen eines TIN-Rezidivs mit steigendem Serumkreatinin $(1,25 \mathrm{mg} / \mathrm{dl})$ bei weiterhin unauffälligem Augenbefund. Es erfolgte eine erneute Steroidtherapie (Prednisolon $75 \mathrm{mg} /$ Tag für 1 Woche, innerhalb von 2 Wochen Reduktion auf 7,5 mg/Tag), gleichzeitig wurde eine immunsuppressive Basistherapie mit Mycophenolat mofetil (MMF; $2 \mathrm{~g} / \mathrm{Tag}$ ) eingeleitet. Unter dieser Erhaltungstherapie kam es nach etwa 3 Wochen zu einem zweiten Rezidiv, wobei sich erstmals eine Uveitis (TINU) zeigte. Eine Nierenbiopsie bestätigte die TIN mit minimaler interstitieller Fibrose und vorwiegender T-Zell-Infiltration, daraufhin erfolgten eine Erhöhung der Steroidtherapie und die zusätzliche Gabe von Tacrolimus.

Derzeit existieren keine evidenzbasierten Empfehlungen zur Therapie einer TIN (Jahnukainen T et al, Pediatr Nephrol 2011, 26:291-299). Die Behandlung mit MMF konnte im gezeigten Fall das Auftreten eines Rezidivs mit Uveitis nicht verhindern.

\subsection{Schwerer, multisystemischer Verlauf eines Lupus erythe- matodes}

S. Dufek, D. Csaicsich, S. Fodor, T. Müller-Schacherer, C. Aufricht, K. Arbeiter Universitätsklinik für Kinder- und Jugendheilkunde, Abteilung für pädiatrische Neophrologie und Gastroenterologie

Mädchen, geb. 1998, wurde im Kleinkindalter zunächst wegen juveniler Polyarthritis behandelt. Aufgrund massiver Gelenksbeschwerden Therapie mit Steroiden, Methotrexat und weiters mit Azathioprim und Resochin. Wegen zunehmender Hämaturie und Proteinurie folgte 07/2006 eine Nierenbiopsie, in der sich eine Lupusnephritis Grad IIIb nach WHO zeigte. Aufgrund der arthritischen Beschwerden wurde 01/2007 eine Kombinationstherapie aus Enbrel und Cellcept begonnen. ANA waren erstmalig Anfang 2008 positiv.

Weiters entwickelte sich eine behandlungsbedürftige Hypertonie sowie tendenziell steigende Entzündungsparameter. Im Rahmen der Abklärung wurde eine Nierenarterienstenose (NAST) links diagnostiziert. Wegen eines neu aufgetretenen nephrotischen Syndroms wurde 04/2009 neuerlich eine Nierenbiopsie durchgeführt. Nach Diagnose einer Lupusnephritis Grad IV wurde eine Urbasonstoßtherapie in Kombination mit Endoxan verabreicht und zur Erhaltungstherapie Cellcept beibehalten. Ein operativer Korrekturversuch der NAST 09/2009 blieb erfolglos, es kam zu einem kompletten Verschluss des Gefäßes.

$\mathrm{Ab}$ 10/2009 zunehmende Bauchschmerzen, welche ursprünglich auf eine Laktoseintoleranz zurückgeführt wurden. 12/2010 fiel im Herzultraschall eine Verengung der Aorta abdominalis auf, in der darauffolgenden MR-Angiographie zeigten sich ein Verschluss des Truncus coeliacus und der Art. mesenterica sup., eine Verengungen der Art. mesenterica inf. sowie eine neue NAST rechts. ANA, dsDNA sowie die BSG waren durchwegs leicht erhöht, jedoch ohne Proteinurie und Hämaturie. Zunächst wurde Cortison erhöht, womit ein Rückgang der Entzündungsparameter erreicht wurde. Zur Cortisonreduktion wurde Rituximab verabreicht. Ein Kontrolle MRI 03/2011 zeigte kein Fortschreiten der Gefäßbeteiligung.

Hier zeigt sich ein schwerer Verlauf eines SLE der sich zunächst monosymptomatisch mit Gelenkserkrankung, dann mit Nierenbeteiligung und trotz intensiver immunsuppressiver Therapie mit schwerer Gefäßbeteiligung präsentierte.

\subsection{Das chronische Nierenversagen in der Pädiatrie: Verände- rungen des Zustandes der Kinder zum Zeitpunkt der Erstvor- stellung und zum Zeitpunkt des Einsetzens der Nierenersatz- therapie an der Kinderdialyse Wien 1978-2007}

K. Gruber, M. Böhm, C. Aufricht, K. Arbeiter, T. Müller, D. Csaicsich Univ.-Klinik für Kinder- und Jugendheilkunde der Medizinischen Universität Wien, Pädiatrische Nephrologie und Gastroenterologie

Die Qualität und die Möglichkeiten der Betreuung des chronischen Nierenversagens im Kindesalter haben sich seit Gründung der Kinderdialyse Wien im Jahr 1978 in mehrerer Hinsicht verändert. Das Ziel der vorliegenden Studie war die retrospektive Evaluierung der Veränderungen von Erkrankungsschwere und Behandlungsintensität sowie der möglichen therapeutischen Verbesserungsoptionen. Wir untersuchten demographische, diagnostische und therapeutische Parameter von 161 Kindern zu jeweils zwei Zeitpunkten: zum Zeitpunkt der Erstvorstellung (EV) und zum Zeitpunkt der ersten Nierenersatztherapie (NET) an der Kinderdialyse Wien. Die Kinder wurden nach dem Datum der EV in Dekade A (1978 bis 1988), Dekade B (1989 bis 1998) und Dekade C (1999 bis 2007) eingeteilt und verglichen.

Die 161 Kinder (47,8\% Mädchen) hatten bei EV im Median ein Alter von 7,8 Jahre. Der Anteil der Altersgruppe von o bis 3 Jahren stieg von Dekade A bis C kontinuierlich an (A: 6,9\%, B: $27,7 \%$, C: $36,8 \%$ ). Bei EV konnte eine Abnahme von Azidose und Anämie von Dekade A auf C, und eine signifikant öfter verabreichte antihypertensive Therapie, Vitamin D Substitution, Eisen- und Erythropoietintherapie erhoben werden. Ebenso wurden die Kinder mit zunehmend steigender GFR zur EV überwiesen (A: 13,25; B: 15,50; C: 18,60 ml/min/1,73 $\mathrm{m}^{2}$ Körperoberfläche). Zum Zeitpunkt der NET stiegen EPO-Therapie (A: 6,7\%, C: $75 \%$ ) und Eisen-Substitution (A: 17,8\%, C: 71,9\%) deutlich an, Hämoglobin konnte dadurch signifikant verbessert werden (Hb: A: 7,9; B: 9,4; C: 10,3 g/dl). Die präemptive Nierentransplantation stieg von $22,4 \%$ in A auf $35,1 \%$ in C, die präemptive Lebendnierenspende von $14 \%$ auf $33,3 \%$. Die Chance auf eine Lebendnierenspende korrelierte mit einer frühen EV am Zentrum.

Wir konnten deutliche Verbesserungen hinsichtlich diagnostischer und therapeutischer Parameter seit Beginn der Kinderdialyse Wien feststellen. Einzelne Parameter wie z. B. Wachstum und GH-Indikation bedürfen noch genauerer Untersuchungen in weiteren Studien.

\subsection{Peritonealdialyseflüssigkeiten beeinflussen die Protein- Glykosylierung humaner Mesothelzellen}

R. Herzog, K. Kratochwill, C. Aufricht

Medizinische Universität Wien, Universitätsklinik für Kinder- und Jugendheilkunde, Kinderdialyse

In der Peritonealdialyse (PD) führt die Zusammensetzung der verwendeten Flüssigkeiten (PDF) mit hohem Glukosegehalt zur Schädigung der Mesothelzellen (MZ) des Peritoneums. Folge dieses negativen Einflusses ist die Fibrosierung des Peritoneums und der damit verbundene zunehmende Funktionsverlust der Peritonealmembran. Zum Teil lassen sich die schädlichen Effekte der PDF durch unzureichenden Schutz der Zellen durch Hitzeschockproteine erklären. Kürzlich wurde im 
in-vitro Modell der experimentellen PD gezeigt, dass die Zugabe von Alanylglutamin (AG) die Stressantwort der Mesothelzellen verbessert. Ziel dieser Studie ist es, die Mechanismen der O-Glykosylierung in der inadäquaten Stressantwort von MZ und deren Verbesserung durch AG zu untersuchen.

MZ wurden aus PD-Effluaten von Kindern gewonnen, kultiviert und bei Konfluenz mit einem Gemisch aus Nährmedium und PDF behandelt. Untersucht wurden die Unterschiede der Stressantwort und der Glykosylierungsmuster nach Inkubation mit unterschiedlichen PDFs oder nach Zugabe von Alanylglutamin. Mit Hilfe spezifischer Antikörper gegen glykosylierte Proteine wurde der Einfluss auf die Glykosylierungsmuster in Gesamtprotein-Extrakten und subzellulären Fraktionen untersucht.

Die Einwirkung von PDF auf MZ führt zu Veränderungen der Proteinmodifikationen als Form der Stressantwort. Die enthaltene Glukose und ihre Degradationsprodukte können dabei besonders die Glykosylierung und damit verbundene regulatorische Funktionen aus ihrem physiologischen Gleichgewicht bringen. Die Einwirkung von AG auf spezifische Enzyme der Glykosylierungskaskade stellt möglicherweise einen attraktiven therapeutischen Ansatzpunkt zur Beeinflussung der Stressantwort von MZ nach PDF Exposition dar.

\subsection{Antibodies against complement factor $\mathrm{H}$ in aHUS: 1-year follow-up data from the international Innsbruck HUS-Net aHUS registry}

J. Hofer ${ }^{1}$, M. Riedl' ${ }^{1}$, T. Giner ${ }^{1}$, A. Rosales' ${ }^{1}$, V. Jeller ${ }^{1}$, R. Würzner², T. Jungraithmayr ${ }^{1}$

${ }^{1}$ Universitätskinderklinik Innsbruck, Pädiatrie, ${ }^{2}$ Department für Hygiene, Mikrobiologie und Sozialmedizin, Medizinische Universität Innsbruck

Introduction. Antibodies against complement factor $\mathrm{H}(\mathrm{FH} \mathrm{Ab})$ have been reported in aHUS patients. The role of $\mathrm{FH} \mathrm{Ab}$ in disease onset, progression and treatment is of critical interest for physicians and patients dealing with this unsolved problem. At present, evidence based therapy recommendations are missing.

Methods. We comment on 16 patients with FH Ab associated aHUS from the Innsbruck HUS-Net registry (www.hus-online.at). Patients were followed from the beginning of the acute phase, with recording on patient's therapy and clinical progression over a period of 1 year.

Results. Patients show a median age at disease onset of 7 years. All patients presented with hemolytic anemia (mean hemoglobin: $5,8 \mathrm{~g} / \mathrm{l}$ ), thrombocytopenia (mean platelet count: $33,2 \times 10^{9} / \mu \mathrm{l}$ ) and elevated creatinine levels (mean: $458 \mu \mathrm{mol} / \mathrm{l}$ ). Only $37 \%$ of the patients showed decreased $\mathrm{C}_{3}$ levels and $15 \%$ showed decreased Factor $\mathrm{H}$ levels. Within the follow up period of 1 year $25 \%$ of the patients developed renal insufficiency, $33 \%$ showed ESRD, and $67 \%$ showed at least one disease recurrence. Using supportive therapy without plasmatherapy or immunosuppression $2 / 2$ patients showed disease recurrence, $6 / 7$ patients recurred under plasmatherapy without additional immunosuppression and only $2 / 7$ patients with plasmatherapy followed by immunosuppression developed recurrences.

Conclusion. $\mathrm{CFH}$ Ab positivity is a distinct pathogenetic aHUS subgroup mainly of pediatric patients. Testing for $\mathrm{CFH} \mathrm{Ab}$ as soon as possible is mandatory, as in positive cases this has important impact on prognosis and the recommended therapy. Following our results and the literature a recommendation for the use of plasmatherapy as induction therapy followed by a maintenance therapy using immunosuppressive agents can be given. Nevertheless, treatment responses are heterogeneous and the different alternative immunosuppressive agents, the used dosages and the timing of initiation and withdrawal are still a matter of speculation.

\subsection{Living related renal transplantation in a 14-year-old boy with factor $\mathrm{H}$ antibody associated aHUS}

J. Hofer' ${ }^{1}$, T. Giner' ${ }^{1}$, M. Riedl', A. Rosales' , G. Cortina' ', R. Trojer' ${ }^{1}$, R. Würzner², W. Mark ${ }^{3}$, T. Jungraithmayr ${ }^{1}$

${ }^{1}$ Universitätskinderklinik Innsbruck, Pädiatrie I, ${ }^{2}$ Institut für Hygiene, Mikrobiologie und Sozialmedizin, Medizinische Universität Innsbruck, ${ }^{3}$ Operative Medizin, Medizinische Universität Innsbruck

Objectives. A 12-year-old boy was admitted to hospital on April 2007. Laboratory examination showed hemolytic anemia, thrombocytopenia and acute renal failure. The patient was diagnosed with Factor $\mathrm{H}$ antibody (FH-Ab) associated aHUS. The initial FH-Ab level was high $(1600 \mathrm{AU} / \mathrm{ml})$ and even increased during the following months (180o AU/ml). Under HD the titer dropped to $800 \mathrm{AU} / \mathrm{ml}$. However, renal function did not recover and the patient required chronic dialysis, thus renal transplantation from a living donor (father) was planned. To reduce $\mathrm{FH}-\mathrm{Ab}$ titers prior to kidney transplantation plasma exchange and a single infusion of i.v. IgG on the day before transplantation were planned. In 11/2009 the living related renal transplant was done. Induction therapy with ATG and continuous immunosuppression with ATG, Tacrolimus, MMF and Steroids was done. 1.5 years after transplantation complement levels $\left(\mathrm{C}_{3}\right.$, terminal complement complex) are still normal, the FH-Ab titers always stayed in the low range $(<200 \mathrm{AU} / \mathrm{ml})$.

Conclusions. At present, evidence based therapy recommendations for $\mathrm{FH}-\mathrm{Ab}$ aHUS are missing. In this case report antibody titers dropped during frequent $\mathrm{HD}$, but stayed clearly positive over a 2 -year period. In our successfully transplanted patient FH-Ab titers dropped below 100 $\mathrm{AU} / \mathrm{ml}$ under the combination of i.v. IgG and maintenance immunosuppression and complement system remained normal for the follow up period over 1.5 years.

\subsection{Acute manifestation and 1-year follow-up of a big cohort of patients with atypical heamolytic uremic syndrome}

J. Hofer ${ }^{1}$, M. Riedl' ${ }^{1}$, T. Giner ${ }^{1}$, A. Rosales ${ }^{1}$, V. Jeller ${ }^{1}$, R. Würzner ${ }^{2}$, L. Bernd Zimmerhackl ${ }^{1}$, T. Jungraithmayr ${ }^{1}$, HUS study group GNP ${ }^{3}$

'Universitätskinderklinik Innsbruck, Pädiatrie I, ${ }^{2}$ Institut für Hygiene, Mikrobiologie und Sozialmedizin, Medizinische Universität Innsbruck, ${ }^{3} \mathrm{GPN}$

Objectives. The atypical HUS is a form of thrombotic microangiopathy. Dysfunctions of complement proteins are associated with the pathogenesis of the disease. Long-term prognosis is poor.

Methods. Since 2002 the HUSnet Registry investigates the role of complement in aHUS and collects clinical data on long-term outcome. Here we present data of 116 aHUS patients at diagnosis and the 1-year follow-up of 72 patients.

Results. During acute phase the hemoglobin value dropped to $6.03 \pm 1.4 \mathrm{mg} / \mathrm{dl}$, the platelet count to $51.3 \pm 43.8 \times 109$ and mean creatinine was elevated to 4.8 [plusmn] $3.5 \mathrm{mg} / \mathrm{dl}$. Oliguria/anuria was seen in $59 \%$ (mean duration: $13 \pm 15$ days) of patients. Dialysis was performed in $66 \%$ (mean duration: $26 \pm 44$ days) of patients, of which $30 \%$ required chronic dialysis. Arterial hypertension was seen in $79 \%$. Other organ involvement was reported as follows: GI (44\%), CNS (28\%), cardiac (12\%) and pancreas (8\%). Treatment of first episode included plasma infusions (PI, $42 \%$ ) and plasma exchange (PE, 50\%). PT was initiated in patients with a higher rate of CNS involvement $\left(\mathrm{p}<0.05, \chi^{2}\right)$ and a tendency towards an increased need for dialysis $\left(\mathrm{p}=0.057, \chi^{2}\right)$.HUS recurrences were reported in $68 \%$ (mean $2.6 \pm 2.2$ ) of the patients. The first recurrence occurred in median after 4.5 months (range 1-26 months). One year after diagnosis arterial hypertension was seen in $65 \%$, dialysis in $33 \%$ and chronic renal insufficiency in $13 \%$ of patients. $51 \%$ of the patients had a normal renal function. Two patients died within the first year, due to cardiopulmonary insufficiency. CNS sequel was reported in 1 patient. Patients treated with plasma therapy (PT) showed comparable outcomes to patients without PT after 1 year as measured by the incidence of hypertension, kidney function, CNS sequel and recurrences. 
Conclusion. In the acute phase aHUS presents as a multisystem disorder, but in the long term impaired renal function is the main concern. $\mathrm{PT}$ is considered as first line treatment, it was especially used in severe cases. Outcome after 1 year was comparable between patients with vs. without PT.

\subsection{Einfluss unterschiedlicher Peritonealdialyseflüssigkeiten auf die Phagozytosekapazität von Makrophagen}

L. Kuster ${ }^{1}$, M. Böhm', K. Kratochwill ${ }^{2}$, A. Spittler ${ }^{3}$, C. Aufricht ${ }^{1}$

${ }^{1}$ Medizinische Universität Wien, Universitätsklinik für Kinder- und Jugendheilkunde, Kinderdialyse, ${ }^{2}$ Zytroprotec $\mathrm{GmbH},{ }^{3}$ Medizinische Universität Wien, Universitätsklinik für Chirurgie \& Core Facility Flow Cytometry

Hintergrund. Ein großer, klinisch relevanter Bestandteil der peritonealen Zellpopulation sind peritoneale Makrophagen (MØ). Diese haben für das peritoneale Abwehrsystem eine entscheidende Bedeutung, da sie u. a. exogen eingedrungene Erreger phagozytieren und damit abwehren können. Bei der Peritonealdialyse (PD) wird diese Funktion der MØ durch die toxische Zusammensetzung der Peritonealdialyseflüssigkeiten (PDF) negativ beeinflusst. Ziel dieser Studie war es, unterschiedliche PDF in Hinblick auf ihren Einfluss auf die Phagozytosekapazität von $\mathrm{M} \varnothing$ zu untersuchen.

Methoden. Humane immortalisierte makrophagenähnliche U937Zellen werden für $4 \mathrm{~h}$ in einer 1:1-Mischung aus Kulturmedium und unterschiedlichen PDF geschädigt, mit opsonisierten und fluoreszenzmarkierten E. coli inkubiert und mittels Durchflusszytometrie ihre Phagozytosekapazität bestimmt. Weiters werden auch $M \emptyset$, die aus Peritonealdialyseeffluaten (PDE) isoliert wurden, bezüglich ihrer Phagozytosekapazität untersucht.

Resultate. Vorläufige Ergebnisse zeigen, dass die Phagozytosekapazität von U937-Zellen von konventionellen PDF unterschiedlich stark negativ beeinflusst wird. Ähnlich sind auch die Ergebnisse in den Vorversuchen mit peritonealen MØ aus PDE von Patienten, die mit unterschiedlichen PDF dialysiert wurden. Die Dauer, die der einzelne Patient schon an der Dialyse war, zeigte einen zusätzlichen Einfluss.

Schlussfolgerung. Diese Daten zeigen, dass sich die unterschiedlich zusammengesetzten PDF verschieden stark auf die Phagozytosekapazität von $M \emptyset$ auswirken. Weiters wurde auch deutlich, dass nicht nur die toxische Zusammensetzung der PDF, sondern auch die Dauer der Peritonealdialyse einen entscheidenden Einfluss auf den Zustand und die Phagozytosekapazität hat. In bereits angelaufenen Folgestudien werden nun weitere PDF untersucht und weiters auch der Einfluss von zytoprotektiven Additiva zu PDF auf Zustand und Funktion der M $\varnothing$ getestet.

\subsection{In-vivo proteomics of the mesothelial stress response in an experimental peritoneal dialysis setup}

A. Michael Lichtenauer' ${ }^{1}$ K. Kratochwill', M. Böhm¹' R. Herzog ${ }^{2}$, C. Aufricht ${ }^{1}$ ${ }^{1}$ Medizinische Universität Wien, Universitätsklinik für Kinder- und Jugendheilkunde, Abteilung für Pädiatrische Nephrologie, ${ }^{2}$ Zytoprotec $\mathrm{GmbH}$

Peritoneal dialysis (PD) is a simple patient-performed renal replacement therapy, using the peritoneum as membrane for removal of uremic toxins and excessive water. However, the PD fluid (PDF) has cytotoxic effects on the mesothelial cells (MC) lining the peritoneal cavity. Most animal and clinical studies so far only rely on functional outcome parameters whereas for biocompatibility testing of PDF and the examination of cellular mechanisms mainly in-vitro models are used.

The objective of the study is the examination of cellular stress response mechanisms in-situ. Proteomics is a powerful tool for analysing global expression levels of proteins as the effectors of these mechanisms. By combining molecular biological methods and well-established animal models of experimental PD, it is possible to characterise cellular processes during PDF-exposure in-vivo. Protein expression patterns of PD-effluent fractions of rat and mouse were generated by using special extraction methods and 2D-DIGE followed by MALDI-TOF MS protein identification.

Our results show that residual plasma including detached MC as well as leucocytes and residual peritoneal MC can be separated by increasing detergent concentration during sample extraction. With the aid of depletion methods for plasma proteins, $2 \mathrm{D}$-DIGE and dedicated software and database tools it is possible to distinguish between the fractions and characterise the involved cellular mechanisms. With this method the proteome of peritoneal MC following PD-exposure can be analysed in-vivo in an animal model.

To test the relevance of the results obtained in the animal model, an examination of human PD effluent utilising the established workflow, is part of current studies.

\subsection{Dent's Disease als Ursache einer Proteinurie}

\section{A. Mang, S. Ribeiro, I. Vlasak, O. Rittinger, W. Radauer} Gemeinnützige Salzburger Landeskliniken BetriebsgmbH

Hintergrund. Das Eponym-Dent steht für eine X-chromosomal vererbte Form einer proximalen Tubulopathie, gekennzeichnet durch LMW(„low molecular weight")-Proteinurie, Mikrohämaturie, Hyperkalziurie, Nephrokalzinose, evt. anderen Zeichen eines partiellen Fanconisyndroms sowie progredientem Nierenversagen. Männer sind obligat, aber in variablem Ausmaß symptomatisch, auch heterozygote Frauen können Symptome entwickeln. Der überwiegende Typ (Dent 1) beruht auf einer inaktivierenden Mutation $\mathrm{CLCN}_{5}$ des proximalen Tubulussystems, Dent 2 auf einer Mutation im OCRL1-Gen (allelisch zu Lowe-Syndrom).

Patienten. Wir berichten von 2 nichtverwandten, klinisch unauffälligen Knaben, die in Routineharnkontrollen durch persistierende Proteinurie auffielen. Neben der Ausscheidung von LMW-Proteinen zeigten sich jeweils Hypercalciurie und Mikrohämaturie mit normaler Nierenfunktion, mäßige unselektive glomeruläre Proteinurie, kein Anhalt für Nephrocalcinose oder Rachitis. In Familie 1 ergab sich eine positive FA hinsichtlich Urolithiasis.

Genetische Befunde. Mutation im $\mathrm{CLCN}_{5}-\mathrm{Gen}$ (Dent 1) in Familie 1, OCRL1-Mutation (Dent 2) in Familie 2; in beiden Fällen Mütter heterozygot (Befund: Dr. M. Nagel, Weisswasser). Das X-Inaktivierungs (XI)-Screening ergab eine ausgeprägte XI bei der Mutter aus Familie 1. Schlussfolgerung. Dent's Disease ist eine seltene Tubulopathie, die unbehandelt bei männlichen Patienten in $2 / 3$ der Fälle bereits in der 4 . Lebensdekade zum terminalen Nierenversagen führt. Eine frühe Diagnose und Therapie mit ausreichend Flüssigkeit (mind. 2 1/m² KOF/ Tag), ACE-Hemmer, Thiazid-Diuretika und evt. Citrat ist essenziell. Jeder männliche Patient mit persistierender Proteinurie (Harnteststreifen) sollte auf LMW-Proteinurie im Spontanharn untersucht werden. Das ausgeprägte XI-Muster bei Dent 1 kann wegweisend für die weitere Diagnostik sein.

\subsection{Inadäquate Hitzeschockprotein-Antwort in Mesothelzel- len nach Behandlung mit Peritonealdialyseflüssigkeit}

K. Rusai, B. Bidmon, R. Herzog, L. Kuster, K. Kratochwill, C. Aufricht Medizinische Universität Wien, Universitätsklinik für Kinder- und Jugendheilkunde

Hintergrund. Peritonealdialyseflüssigkeiten (PDF) schädigen Mesothelzellen durch ihre toxische Eigenschaften und führen dadurch zum zunehmenden Verlust der Ultrafiltrationskapazität des Peritoneums. Hitzeschockproteine (HSPs) können gegen diese Schädigung schützen. Unlängst wurde bei längeren PDF Behandlungszeiten eine abfallende HSP-Produktion beobachtet. Ziel dieser Studie ist die Untersuchung dieser inadäquaten Stressantwort auf dem Niveau der Regulationsmechanismen.

Methoden. In dieser Studie wurden Met5a-Mesothelzellen mit der PD Lösung „Dianeal“ (PDF) für unterschiedliche Zeiträume (ab o,5 bis 
4 Stunden) behandelt. Als Positivkontrolle für Hitzeschock Antwort wurden die Zellen erhöhter Temperatur ausgesetzt. Die Stressantwort der PDF behandelten Zellen (HSP-72, HSF-1, sowie p38 MAP-KinaseProduktion und Aktivierung) wurde mittels Western Blot und „electrophoretic mobility shift assay” im Vergleich zu hitzeausgesetzten Zellen untersucht.

Resultate. PDF-Behandlungszeiten für länger als 1 Stunde verursachte neben erhöhten LDH Werten eine abfallende HSP-72 Produktion; bei 4 Stunden war HSP-72 nicht mehr nachweisbar. Hitzebehandelte Zellen zeigten eine erhöhte HSP-72 Produktion, die durch die Zugabe von PDF blockiert werden konnte. Aktivierung der HSF-1 war nur in hitzebehandelten Zellen signifikant erhöht. p38 MAP-Kinase-Aktivierung war in PDF und in PDF und Hitze behandelten Zellen komplett inhibiert. Mit Normalisierung des $\mathrm{pH}$ der PDF wurden diese Effekte auf HSP-72, HSF-1 und p38 weitestgehend reduziert.

Schlussfolgerung. Unsere Resultate zeigen dass die bei längeren PD Inkubationen beobachtete inadäquate Stressantwort eine Folge einer Azidose bedingten Blockierung der $\mathrm{p} 38$ MAPK-HSF-1-Axis sein könnte. Die Normalisierung des niedrigen $\mathrm{pH}$ Werts der PDF, repräsentiert dadurch auch aus der Sicht der zellulären Stressantwort ein potenziales Therapietarget dar, um das Überleben von Mesothelzellen während einer PD Behandlung zu verbessern.

\subsection{Kontroverse Verläufe der neonatalen Nierenvenenthrom- bose}

R. Trojer'1, W. Streif', A. Dettmar', K. Maurer², K. Unsinn², G. Mikuz ${ }^{3}$, U. Kiechl-Kohlendorfer ${ }^{1}$, B. Brunner ${ }^{1}$, R. Trawöger ${ }^{1}$, Th. Jungraithmayr $^{1}$ ${ }^{1}$ Department für Pädiatrie Medizinische Universität Innsbruck, ${ }^{2}$ Department für Radiologie Medizinische Universität Innsbruck, ${ }^{3}$ Department für Pathologie, Medizinische Universität Innsbruck

Die neonatale Nierenvenenthrombose (NNVT) hat eine Inzidenz von 2,2 auf 100.000 Lebendgeburten. Sie ist gekennzeichnet durch eine Trias aus vergrößerten Nieren (42,1\%), Makrohämaturie $(55,4 \%)$ und Thrombozytopenie (49\%). 50\% aller NNVT sind sonographisch nachweisbar. Das Krankheitsbild ist mit einer erheblichen Morbidität verknüpft. Eine irreversible Schädigung der Nieren tritt in $75 \%$ aller Fälle auf. Obwohl die NNVT zu den häufigsten thromboembolischen Komplikationen des Neugeborenen zählt, fehlen bisher einheitliche und allgemein anerkannte Richtlinien zur Diagnose, Behandlung und Langzeitbetreuung.

Am Department für Pädiatrie der MUI wurden zwischen 2001-2009 1,5 NNVT pro Jahr diagnostiziert. Wir präsentieren drei Fälle, die jeweils unterschiedliche diagnostische und therapeutische Herausforderungen darstellten.

Patient 1 (P1) konnte die NNVT sonographisch nicht nachgewiesen werden. Es zeigten sich sonographisch lediglich echodichte Nieren, welche histomorphologisch durch eine abgelaufenen NNVT erklärt werden konnten. Grund dafür könnte eine in utero bereits abgelaufene NNVT gewesen sein. P1 erhielt bis zum 4. Lebensjahr eine symptomatische Therapie, musste jedoch 2006 aufgrund einer terminalen Niereninsuffizienz transplantiert werden. Bei P2 wurde die NNVT als Zufallsbefund entdeckt. Unter Antikoagulation konnte eine Restitutio ad integrum erreicht werden. $\mathrm{P}_{3}$ zeigte als Hauptursache der NNVT eine Thrombophilie durch ein dysfunktionelles Antithrombin. Eine partielle Nierenfunktionseinschränkung wurde beobachtet, die in einem Verlauf von 2 Jahren bisher noch keine Behandlungsbedürftigkeit verursachte. Gemeinsames Merkmal war bei $\mathrm{P}_{1}-\mathrm{P}_{3}$ das männliche Geschlecht, sowie bei $\mathrm{P}_{1}$ und $\mathrm{P}_{3}$ die Frühgeburtlichkeit.

Zusammenfassend können verschiedene Ursachen eine NNVT bewirken. Eine frühzeitige Diagnosestellung und eine der Ausprägung und Symptomatik angepasste Therapie sind für die Langzeitbehandlung wichtig.

\subsection{Chronic hepatitis $C$ infection (type lb) associated with nephrotic syndrome in a 14-year-old boy}

\section{R. Trojer ${ }^{1}$, T. Müller ${ }^{1}$, W. Vogl ${ }^{2}$, T. Jungraithmayr ${ }^{1}$}

'Department of Paediatrics, Medical University of Innsbruck, Austria, ${ }^{2}$ Department of Internal Medicine II, Medical University of Innsbruck, Austria;

Background. Chronic Hepatitis C infection is known to be related with extra hepatic manifestations, including the kidney (38\%). Membranoproliferative Glomerulonephritis or Membranous Glomerulonephritis with or without cryoglobulinemia is such a known manifestation of renal involvement. In the pathogenesis immune complexes are playing an important role. The immune complexes deposit in the kidney, leading to renal injury. Because of the permanent viral replications and development of new immuncomplexes the prognosis without therapy is worse, leading to impairment of the renal function, in up to $50 \%$ in adult patients. A combination therapy PegIFNa and Ribavirin is the first choice for patients with chronic hepatitis $\mathrm{C}$ infections. Whether responders to this combination therapy will also benefit with respect to renal improvement is controversial. Since extrahepatic manifestatations are rarely seen in children with chronic hepatitis $\mathrm{C}$ infection, it is unknown whether antiviral therapy has an efficacy of the improvement of extrahepatic manifestations of chronic hepatitis $\mathrm{C}$ infection.

Case report. In April 2010 the 14-year-old boy was assigned to the Department of paediatrics because of oedema of the lids and the lower legs. The patient's history showed a viral infection of hepatitis $\mathrm{C}$ probably transmitted by a single administration of human albumin in Croatia 2002. Chronic hepatitis $\mathrm{C}$ infection (genotype $\mathrm{Ib}$ ) was already diagnosed in 2006. Routine laboratory tests confirmed a diagnosis of nephrotic syndrome with hyperlipidemia, hyopalbuminemia and gross proteinuria. He was successfully treated with prednisolon $60 \mathrm{mg} / \mathrm{m} 2 /$ day and tapered accordingly. In September 2010 he experienced his first relapse. Steady proteinuria and increasing load of viral DNA $(20,000,000 \mathrm{IU} / \mathrm{ml})$ lead to the final decision to introduce antiviral treatment with pegIFNa - $(1,5 \mu \mathrm{g} / \mathrm{kg} /$ week s.c.) Ribavirin (10oo mg). After 12 weeks of antiviral therapy neither Hepatitis C RNA nor proteinuria was detectable.

Conclusion. Further follow-up of this patient will show whether sustained viral response will be achieved and paralleled by disappearance of the hepatitis $\mathrm{C}$ related glomerulonephritis.

\subsection{Postinfektiöse Glomerulonephritis aber keine Normalisie- rung von C3? Eine Falldarstellung}

V. Zaller ${ }^{1}$, K. Rusai', Á. Szilágyi ${ }^{2}$, K. Arbeiter ${ }^{1}$, D. Csaicsich ${ }^{1}$, T. Müller ${ }^{1}$, Z. Prohászka ${ }^{2}$, C. Aufricht ${ }^{1}$

${ }^{1}$ Universitätsklinik für Kinder- und Jugendheilkunde, Medizinische Universität Wien, ${ }^{2} 3$. Innere Abteilung, Forschungslabor, Semmelweis Universität Budapest

Hintergrund. Postinfektiöse Glomerulonephritiden (PIGN) treten 1 bis 3 Wochen nach Infekten auf. Man vermutet, dass es durch Immunkomplexe zu einer Aktivierung des Komplementsystems und $\mathrm{zu}$ einer Ablagerung von $\mathrm{C}_{3}$ in den glomerulären Kapillaren kommt. Im Rahmen von PIGN kommt es zu einer passageren Serum-C3-Verminderung, die sich meist nach 6 Wochen normalisiert.

Fallbericht. Wir berichten von einer Patientin, bei der im Alter von 1o Jahren nach Tonsillitis eine Mikrohämaturie mit $\mathrm{C}_{3}$-Erniedrigung auffallen und die Verdachtsdiagnose einer PIGN gestellt wird. In den Nachkontrollen findet sich weiterhin eine Mikrohämaturie mit konstant erniedrigtem $\mathrm{C}_{3}$. Drei Jahre später tritt eine Makrohämaturie auf. Bei persistierender Mikrohämaturie und Proteinurie kommt es 4- bis 5-mal jährlich zu makrohämaturischen Episoden. Es wird eine Nierenbiopsie durchgeführt, die den Befund einer PIGN mit immunhistologischem Nachweis von mesangialen $\mathrm{C}_{3}$-Ablagerungen ergibt.

Aufgrund des verminderten Serum- $C_{35}$ wird eine detaillierte Komplementanalyse durchgeführt. Unter den untersuchten Komplementfaktoren lässt sich kein Faktor-H (Negativregulator des Komplement- 
systems) nachweisen, bei fehlenden Faktor-H-Antikörpern (AK). Laut Fachliteratur kann ursächlich eine genetische Mutation von Faktor-H und somit eine fehlende Blockierung des alternativen Komplementweges zugrunde liegen, die durch Aktivierung der Komplementkaskade zur Entstehung einer GN führen kann.

Conclusio. Bei Verdacht auf PIGN und Persistenz der Symptome bei fehlender $\mathrm{C}_{3}$-Normalisierung sollten Patienten weiter abgeklärt werden. Durch die Möglichkeit, einzelne Komplementfaktoren sowie möglicherweise vorliegende $\mathrm{AK}$ zu bestimmen, kann einerseits die $\mathrm{Pa}-$ thophysiologie besser verstanden werden, andererseits können therapeutische Konsequenzen - wie möglicherweise eine Komplementfaktor-Substitution durch Plasmagabe - gezogen werden. Im vorliegenden Fall steht eine genetische Sequenzierung bei fraglicher Faktor-H-Mutation vorerst noch aus.

\section{Neuropädiatrie}

\subsection{Anti-N-methyl-D-aspartate-Rezeptor-Enzephalitis: Diskus- sion der Phänotypen anhand zweier Fallbeispiele}

M. Brunner-Krainz'1 , U. Gruber-Sedlmayr ${ }^{1}$, K. Pfurtscheller', E. Sorantin ${ }^{2}$, T. $\mathrm{Kröpfl}^{3}$, B. Plecko

${ }^{1}$ Universitätsklinikum für Kinder- und Jugendheilkunde, ${ }^{2}$ Universitätsklinikum für Radiologie, Kinderradiologie, ${ }^{3}$ Klinik für Kinder- und Jugendpsychiatrie

Die Anti-NMDA-Rezeptor Enzephalitis ist eine autoimmunologische Erkrankung des ZNS mit Autoantikörpern gegen die NRı Untereinheit des NMDA-Rezeptors. Die Erkrankung wurde primär bei jungen Frauen mit Ovarialtumoren beschrieben. Typischerweise dominieren anfangs psychiatrische Symptome, im Verlauf eine dyskinetische Bewegungsstörung, epileptische Anfälle und autonome Dysfunktion. Neben einer immunsuppressiven Therapie sollte eine Abklärung auf Neoplasien erfolgen.

Fallberichte. Ein 21 Monate alter Knabe wurde mit Verhaltensänderungen, Nahrungsverweigerung, Verlust der aktiven Sprache und motorischer Regression vorgestellt. Wenige Tage später kam es zu einer rechtsbetonten choreatischen Bewegungsstörung die zur Ateminsuffizienz führte. Eine entzündliche oder infektiöse Ursache konnte weder im Serum noch im Liquor gefunden werden. Lediglich die anti-NMDAR Antikörper waren im Liquor und Serum positiv. Da die Immunsuppression mit Cortison und intravenöser Immunglobulingabe keinen Erfolg zeigte, wurde eine Plasmapherese durchgeführt und anschließend die Therapie mit Mycophenolatmofetil erweitert. Unter dieser Therapie zeigte sich eine langsame Besserung der Symptomatik. Freies Gehen war nach 6 Monaten wieder möglich, erste Worte wurden 10 Monate nach Krankheitsbeginn gesprochen, das Verhalten ist weiterhin autistisch. Die Diagnose bei unserer 2. Patientin, einem 17-jährigen Mädchen wurde retrospektiv gestellt. Die Erstvorstellung erfolgte wegen Verhaltensänderung und Gedächtnisproblemen. In weiterer Folge kam es zu einer dyskinetischen Bewegungsstörung und epileptischen Anfällen. Im Liquor fand sich eine Pleocytose ohne Erregernachweis. Unter symptomatischer Therapie erholte sie sich innerhalb von 5 Monaten. Es besteht eine komplette retrograde Amnesie.

Schlussfolgerungen. Bei plötzlich auftretenden Verhaltensänderungen mit dyskinetisch gestörtem Bewegungsmuster muss eine NMDAR-Enzephalitis in Betracht gezogen werden. Das phänotypische Spektrum erscheint breiter als ursprünglich definiert.

Acknowledgement: NMDAR Ak „Neurosciences Group“ Oxford.
14.2 Febrile infection-related epileptic synrome - ein Fallbericht M. Brunner-Krainz ${ }^{1}$, K. Pfurtscheller ${ }^{1}$, C. Ebner ${ }^{2}$, S. Rödl ${ }^{1}$, U. Gruber-Sedlmayr $^{1}$, A.Kortschak ${ }^{1}$, G. Zobel' ${ }^{1}$, M. Edlinger ${ }^{3}$, B. Plecko ${ }^{1}$

${ }^{1}$ Universitätsklinik für Kinder- und Jugendheilkunde, ${ }^{2}$ Universitätsklinik für Psychiatrie, ${ }^{3}$ Kinderabteilung Klinikum Klagenfurt

Hintergrund. Unter FIRES („febrile infection related epileptic syndrome“) versteht man ein Krankheitsbild mit fieberinduziertem, therapieresistentem Status epilepticus bei zuvor gesunden Kindern. Der Erkrankungsgipfel liegt im Schulalter, die Ätiologie blieb bei allen bislang publizierten Fällen unklar. Wir berichten über den Therapieverlauf eines 11-jährigen Patienten mit über 3 Monate anhaltendem FIRES. Fallbericht. Der 11-jährige, zuvor gesunde Knabe entwickelte 3 Tage nach einem banalen Infekt einen generalisierten konvulsiven Status epilepticus. Liquordiagnostik auf infektiöse Ursachen sowie Schrankenstörung und autoimmunmediierte Enzephalitis negativ. cMRI bis auf diskrete Schwellung der Basalganglienregion unauffällig. Screening auf Aminound Organoacidopathien, biochemische Untersuchung der mitochondrialen Atmungskette im frischen Muskelgewebe sowie Vitamin-B6-Versuch unauffällig. Rocephin- und Zoviraxtherapie iv. Bei mangelndem Therapieeffekt nach Aufsättigung von Levetiracetam Phenobarbital, Midazolam, Phenytoin und Propofol, Beginn einer Thiopentalnarkose. Im weiteren völlige Therapieresistenz auf Valproinsäure, Lacosamid, Ketamin, Topiramat und Lidocain. Ab Tag 3 bis Tag 28 hochdosierte Cortisontherapie, Immunglobulingabe und Plasmapherese - sämtliche ohne Effekt. Am Tag 36 Einleiten einer ketogenen Diät, welche wegen massiven Anstiegs der Triglyceride und Lebertransaminasen abgebrochen werden musste. Ab Tag 54 bis 63 elektrokonvulsive Behandlung in ansteigender Dosis ohne Effekt. Anlegen einer Jejunalsonde am Tag 13. Anlegen eines Tracheostomas und suprapubischen Katheters am Tag 34. Ab Tag 55-115 Inhalationsnarkose mit Isofluran, antikonvulsive Therapie mit Zonisamid, Levetiracetam, Vigabatrin und K-Bromid. Bei Reduktion der Narkose im EEG weiterhin bioelektrischer Status. Die molekulargenetische Analyse von $\mathrm{SCN}_{1} \mathrm{~A}, \mathrm{SCN}_{2} \mathrm{~A}$ und $\mathrm{SCN}_{2} \mathrm{~B}$ ist derzeit noch ausständig. Schlussfolgerungen. Trotz weitreichender Diagnostik blieb auch bei diesem Patienten die Ätiologie des FIRES bislang unklar. Die Prognose ist bei Dauer des SE über 3-4 Wochen zumeist infaust.

\subsection{DRESS-Syndrome - „drug rash with eosinophilia and syste- mic symptoms"}

M. Eichberger, A. Biebl, R. Schwarz, U. Rossegg, V. Tschemmernegg, K. Schmitt

LFKK - Linz

Das DRESS-Syndrom ist eine schwere Arzneimittelreaktion auf die Einnahme eines bestimmten Medikamentes die typischerweise ein bis acht Wochen nach Beginn einer medikamentösen Therapie auftritt. $\mathrm{Zu}$ den häufigsten Auslösern zählen unter anderem aromatische Antikonvulsiva (Phenytoin, Carbamazepin, Phenobarbital). Die vermutete Inzidenz für ein DRESS-Syndrom unter der Therapie mit Phenytoin, Carbamazepin oder Phenobarbital liegt bei 1:500o bis 1:10.00o behandelten Patienten. Der Verlauf ist rasch progredient, die Gesamtmortalität liegt bei 10\%. Typische Symptome sind ein Beginn mit Fieber und Myalgien, gefolgt von einem makulopapulösen Exanthem. Typisch ist auch das Auftreten eines Ödems mit periorbitaler Betonung, sowie eine anschließende Beteiligung innerer Organe (Hepatitis, Nephritis, Myocarditis, Thyreoiditis, Pneumonie). Laborchemisch ist eine hohe Eosinophilie charakteristisch, eine Thrombopenie ist ebenfalls möglich, sowie das Auftreten von mononukleoseähnlichen Lymphozyten.

Therapeutisch werden nach Absetzten des auslösenden Medikamentes systemische Kortikosteroide in mittelhoher Dosierung eingesetzt, wodurch sich eine rasche Limitierung des Systemprozesses erzielen lässt. Anhand der Kasuistik eines 6-jährigen Knaben mit bekannter Epilepsie und neu begonnener Carbamazepintherapie werden Anamnese, Diagnostik, Therapie und Verlauf des DRESS-Syndroms anschaulich dargestellt. 
14.4 Die Behandlung des ausgeprägten Brachy-Plagiocephalus erfolgt an unserer Abteilung mittels Kopforthese

U. Frühwald, C. Blecher, Ch. Liechtenstein, K. Kaltenbrunner, R. Brinbacher

LKH Villach

Lagebedingte Schädeldeformitäten die nicht durch eine prämature Nahtsynostose entstanden sind, nehmen im ersten Lebensjahr stetig zu. Wahrscheinlich führt eine intrauterine Enge, ein Hydramnion, zu frühe Rotation oder Mehrlingsschwangerschaften zu einer Asymmetrie der Halsmuskulatur die postpartal zu einer einseitigen Lagerung führt. Die streng empfohlene Rückenlagerung zur SIDS Prävention trägt das übrige zur Entstehung eines Brachy- bzw. Plagiocephalus bei. Ein ausgeprägter Brachy-Plagiocephalus hat häufig auch eine Verschiebung der Schädelbasis zur Folge. Das führt später zu einem ungleichen Wachstum von Kiefer- und Gesichtsknochen. In diesen Fällen ist eine Behandlung mittels Kopforthese dringend indiziert um später Fehlbisse oder Gesichtsasymmetrien zu vermeiden.

Die Therapie wird nach erfolglosen physiotherapeutischen Maßnahmen ab dem 4. Lebensmonat eingesetzt. Nach geprüfter medizinischer Indikation und $3 \mathrm{D}$ Vermessung wird ein individueller sehr leichter Kunststoffhelm angepasst. Dieser liegt den promineneten Arealen des Kopfes an und lässt an den abgeflachten Stellen Platz. Das eigene Wachstum des Köpfchens wird so ausgenutzt um den Brachy- Plagiocephalus auszugleichen. Das Kopfwachstum insgesamt wird dabei nicht eingeschränkt sondern erfolgt stets perzentilengerecht. Wird der Kunststoffhelm $23 \mathrm{~h}$ am Tag für 8 Wochen bis 8 Monaten getragen, können lebenslang stabile Ergebnisse erzielt werden.

\subsection{Transiente globale Amnesie (TGA) bei körperlicher Belas- tung im Kindesalter: ein Fallbericht eines 14-jährigen Knaben}

G. Grangl' ${ }^{1}$ M. Tappauf ${ }^{1}$, E. Sorantin ${ }^{2}$, W. Muntean ${ }^{1}$, S. Gallist| ${ }^{1}$

${ }^{1}$ Universitätsklinik für Kinder- und Jugendheilkunde, Abteilung für allgemeine Pädiatrie, Graz, ${ }^{2}$ Universitätsklinik für Radiologie, Abteilung für Kinderradiologie, Graz

Wir beschreiben den Fall eines 14-jährigen Knaben, der aufgrund einer akut beginnenden Amnesie, die während körperlicher Belastung im Rahmen eines Fußballspiels auftrat, an unserer Abteilung aufgenommen wurde. Zum Aufnahmezeitpunkt war der Patient zeitlich und örtlich vollkommen desorientiert, Angaben zur Person konnte er jedoch problemlos machen. Auffallend war das ständige Wiederholen derselben Fragen (verbale Perservationen), die Ausdruck seiner Ratlosigkeit waren; andererseits waren zu jeder Zeit komplexe Handlungsabläufe wie z. B. Schreiben möglich.

Die Symptomatik klang spontan nach ca. 6 Stunden allmählich ab und bildete sich vollständig zurück. Ein Trauma (Commotio cerebri) konnte ausgeschlossen werden, auch war Migräne als Vorerkrankung nicht eruierbar. Psychische Belastungsfaktoren zur Diagnosestellung einer dissoziativen Fugue waren ebenfalls nicht zu erheben. Bei leerer Medikamentenanamnese konnten Nebenwirkungen bzw. Überdosierungen außer Acht gelassen werden. Der Untersuchungsstatus war intern und neurologisch vollkommen unauffällig.

Folgende Untersuchungen ergaben unauffällige Befunde: CT Schädel, MRT Schädel mit intrazerebraler Angiographie mit besonderer Berücksichtigung der Mesiotemporalregion, EEG. Eine Stoffwechselstörung konnte laborchemisch ausgeschlossen werden. Im Serum zeigte sich eine normale S-10o-Protein-Konzentration. Eine Harnuntersuchung auf Drogen brachte einen unauffälligen Befund.

Zusammenfassend ließen uns Anamnese, Symptome, Verlauf und Diagnostik die Diagnose Transiente globale Amnesie stellen. Die für diese im Erwachsenenalter relativ bekannte Symptomatik infrage kommenden Ursachen konnten ausgeschlossen werden. Ursächlich war bei unserem Patienten nur die körperliche Belastung zu finden. In der pädiatrischen Literatur findet man hierzu erst spärlich Einträge.

\subsection{Arrhythmie und Myopathie im Kindesalter}

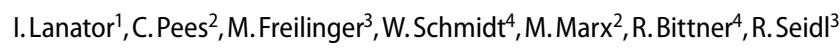
${ }^{1}$ Medizinische Universität Wien, ${ }^{2}$ Univ- Klinik für Kinder- und Jugendheilkunde, Abteilung für Pädiatrische Kardiologie, Medizinische Universität Wien, ${ }^{3}$ Univ-Klinik für Kinder- und Jugendheilkunde, Klinische Abteilung für Pädiatrische Pulmologie, Allergologie und Endokrinologie, Medizinische Universität Wien, ${ }^{4}$ Zentrum für Anatomie und Zellbiologie, Abteilung für angewandte Anatomie, Medizinische Universität Wien

Die kardiale Komorbidität bei neuromuskulären Erkrankungen im Kindesalter ist ein häufig klinisch und prognostisch dominierendes Symptom. Neben der ventrikulären Dysfunktion sind maligne Arrhythmien für plötzliche Todesfälle und Mortalität verantwortlich.

Die Gruppe der kongenitalen, generalisierten Lipodystrophien (CGL) sind charakterisiert durch beinahe komplettes Fehlen von Körperfett, Prädisposition zu Insulinresistenz, Diabetes, Hypertriglyzeridämie und Steatosis hepatis. Patienten mit Mutationen im PTRF („polymerase I and transcript release factor", PTRF) präsentieren sich mit Myopathie und CGL.

Wir untersuchten eine jugendliche Patientin, bei der nach plötzlichem Tod ihrer 15 jährigen Schwester aufgrund einer fatalen Arrhythmie die Diagnose einer congenital generalized lipodystrophy (CGL4) und PTRF-CAVIN Mutation gestellt wurde. Klinisch wegweisende Symptome - Lipodystrophie, „muscle rippling“ und „smooth-muscle hypertrophy“ - sowie die bislang therapieresistente Arrhythmie trotz ICD (,implantable cardioverter-defibrillator“) werden dargestellt.

Auf Basis dieses Falles einer seltenen Erkrankung werden weitere neuromuskuläre Erkrankungen im Kindesalter mit klinisch relevanten Arrhythmien dargestellt und damit auf diese diagnostisch wie prognostisch bedeutsame Assoziation aufmerksam gemacht.

\subsection{Fulminante akute Multiple-Sklerose-Erstmanifestation bei akuter Hemisymptomatik}

\section{Liechtenstein, U. Frühwald, R. Birnbacher, A. Pötsch \\ Kinderabteilung u. Röntgenabteilung, LKH Villach, Kärnten}

Eine fast 16-jährige Jugendliche wird wegen akuter und über Stunden zunehmender sensomotorischer Hemisymptomatik links aufgenommen, bereits nur gestützt geh- und stehfähig und ausgeprägt hemiplegisch, mit beginnender Sprach- und Hirnnervenbeteiligung links.

Breites Akutlabor u.CCT waren unauffällig, ein Akut-MRT zeigt zunächst das Bild einer frischen Ischämie, also Infarktverdacht, im rechten Cerebrum (Zentrum semiovale bis Stammganglien). Ohne Lysetherapie wurde symptomatisch behandelt, Diagnostik eingeleitet und intensivüberwacht. Die Hemiplegie verschlechterte sich weiter und das nächste MRT am nächsten Tag zeigt ein neues Bild mit Ausbreitung der Diffusionsstörung rechts und Verdacht auf ausgedehntes entzündliches Geschehen der weißen Substanz rechts.

Die nächsten MRT zeigen weiter zunehmende Marklagerläsionen rechts. Ausschlussdiagnostik speziell infektiologisch/ kardiologisch/ Thrombophiliediagnostik/zerebrovaskulär blieben negativ. Bewusstsein, Augen, Allgemeinzustand immer unbeeinträchtigt, nie Krampfsymptome. Eine Liquorpunktion zeigt mäßig Zellvermehrung, erhöhten Eiweißquotient und positive oligoklonale Banden. MRT-Angio und MRT Rückenmark waren unauffällig. EEG unspezifisch. Bei Verdacht auf ADEM oder fulminante Multiple Sklerose wird 2-mal über je 5 Tage Hochdosis-Cortison i.v. verabreicht und Plasmapherese 5-mal durchgeführt.

Weitere MRT-Kontrollen zeigen zunächst Ödem und kleine Kontrastmittelanreicherungen als sekundäre Veränderungen, später auch Volumenabnahme und tw. zystischen Umbau, aber keine Zunahme mehr sondern Stabilisierung. Unter Physiotherapie und symptomatischer Medikation besserte sich die ausgeprägte Hemisymptomatik links langsam, mit weiterer deutlicher Verbesserung in den nächsten Wochen im Rahmen eines Reha-Aufenthaltes. Nach 9 Monaten kam es zu einem leichteren Schub mit Ataxie und milder zusätzlicher Hemissymptomatik rechts, rasch regredient nach Cortison-Pulstherapie, 
mit mäßigen MS-typischen Läsionen im MRT (links und pedunculus cerebelli, neben den Residualläsionen rechts.). Danach wurde eine MSDauertherapie mit Interferon $\beta_{1 a}$ begonnen, seither war sie bis zur letzten Kontrolle rezidivfrei mit gebesserter Hemiparese links.

Nach negativer Differentialdiagnostik und aus dem MRT-Verlauf sowie dem 2. Schub scheint die Diagnose einer Sonderform der Multiplen Sklerose mit fulminanter akuter und einseitiger Manifestation sicher. Beispiele der MRT-Bilder im Verlauf werden vorgestellt.

\subsection{Craniocervical arterial dissection in a 5-year-old girl}

\section{A. Radinger, B. Jauk, R. Kraschl, W. Kaulfersch}

Department of Paediatrics \& Adolescent Medicine, Klinikum Klagenfurt am Wörthersee
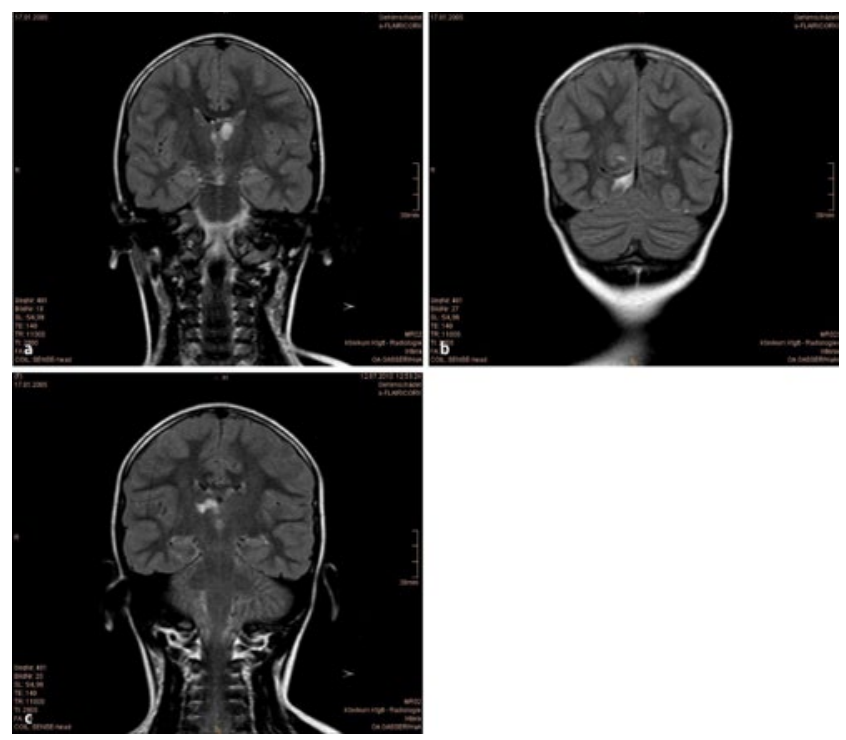

Abb. 24

A 5-year-old girl syncopated in Kindergarten and was unconscious for some minutes and very tired afterwards. Previously she had recurring head aches. She was admitted under the presumptive diagnosis of cerebral seizure. Initial laboratory findings (blood screening test) and EEG were normal. The MRI of the brain showed hyperintense signal alteration in the thalamus, the occipital lobe on the right side characterizing multiple cerebral infarctions. No vascular abnormalities were detected. A follow up MRI 11 days later showed a new infarct lesion in the left anterior thalamus, the previous detected lesions were found to be regressing into lacunary defects. Again, no vascular defects were seen.During the entire investigation period the girl was in good neurologic condition and all laboratory values (especially serum and CSF lactate, anti-phospholipide antibodies, catecholamines, cerebrospinal fluid examinations, thrombophilia screening) were normal. All neurotropic viruses and bacteria could be excluded. Investigations for MELAS (mitochondrial myopathy-encephalopathy-lactic acidosis-stroke syndrome, Morbus Fabry, CDG (congenital disorders of glycosilation) and aminoacidopathies were negative. Echocardiography, ECG, ultrasonography of the kidneys and abdomen were normal. Despite clear diagnosis a prohylactic treatment with low molecular heparin and cortisone pulse therapy was initiated.

Three months later, MRI angiography showed a short occlusion of the left vertebral artery, with collateral bypasses above the occlussion. A retrospective evaluation of the previous MRI revealed a minimal stenosis of the left vertebral artery and we therefore assume that this lesion was caused by a dissection. The girl is kept on heparinisation until today. Regular MRI scans are mandatory to decide upon further therapy. This case resembles others in the literature, pointing to the rare but detectable possibility of craniocervical arterial dissections in children.
14.9 Canavan disease - clinical course of a non-Jewish child with a novel mutation

H. Schober', J. Lütschg' ${ }^{1}$, I.Höliner' ${ }^{1}$ A. Jäger ${ }^{1}$, S. Kalb² , M. Witsch-Baumgartner ${ }^{1}$, B. Simma ${ }^{1}$

${ }^{1}$ Akademisches Lehrkrankenhaus Feldkirch, ${ }^{2}$ Medizinische Universität Innsbruck

Introduction. Canavan disease is a severe, progressive leukodystrophy with an autosomal recessive inheritance caused by aspartoacylase (ASPA) deficiency. The deficiency results in increased brain $\mathrm{N}$-acetylL-aspartic acid (NAA)-levels and reduced myelin lipid synthesis. The incidence in middle Europe is rare with 1:200,000-1:400,000 (nonJewish population). The disease is characterized by typical clinical, laborchemical and MRI/MRS findings. While two mutations comprise the majority of mutant alleles in Jewish patients, mutations in the ASPA gene among non-Jewish patients are different and more diverse. We present a female infant with an infantile form caused by compound heterozygosity for a known missense mutation and a novel mutation of the ASPA gene.

Case report. The female infant was first presented at the age of 6 months with developmental delay. It is the first child of a native, unrelated and healthy couple. The clinical examination showed a macrocephaly ( $>997$ ), sparse social interaction, severe hypotonia, and feeding problems. MRI showed a leucodystrophy and spectroscopy an elevated NAA peak in the white matter. The diagnosis was approved by metabolic screening which revealed elevated levels of NAA in the urine. Molecular analysis of the ASPA gene showed compound heterozygosity for p.P181T (c.541C > A in exon 4 ), a known missense mutation, and c.432G $>A$ in exon 2 . This novel mutation at the last base position of exon 2 is expected to affect splicing of intron 2. Symptomatical therapy was started with physiotherapy and oral baclofen to treat intermittent hypertonicity. Two months later a gastrostomy tube was inserted because of poor weight gain.

Conclusion. Canavan disease is a severe and in middle europe rare illness. So far only supportive therapy is known. Currently the diagnosis is based on specific clinical, metabolic and radiological abnormalities. Mutation analyses still show novel mutations of the ASPA gene particularly in non-Jewish patients.

\subsection{Das 10q26-Mikrodeletionssyndrom - eine seltene Ursache für Entwicklungsretardierung, Strabismus und Kleinhirnwurm- hypoplasie - ein Fallbericht}

\section{A. Schwerin - Nagel' ${ }^{1}$, K. Rötzer ${ }^{2}$, P. Kroisl ${ }^{2}$, K. Wagner ${ }^{2}$, B. Plecko' ${ }^{1}$}

${ }^{1}$ Universitätsklinik für Kinderheilkunde und Jugendmedizin, Neuropädiatrie,Graz, ${ }^{2}$ Institut für Humangenetik, Medizinische Universität Graz

Einleitung. Das Mikrodeletionssyndrom-10q26 ist ein seltenes Krankheitsbild mit etwa 60 beschriebenen Fällen. Symptome sind motorische, geistige und sprachliche Retardierung unterschiedlichen Ausmaßes, Strabismus, charakteristische Fazies (u. a. breiter Nasenrücken, tiefliegende Augen), Mikrocephalie, Wachstumsretardierung, sowie variabel Ernährungsprobleme, Verhaltensauffälligkeiten, muskuläre Hyotonie, Hördefizit, Fehlbildungen an Herz, Niere Genitalien, Händen und Füßen. Die klinische Variabilität kann erklärt werden durch unterschiedliche Größe der Deletionen.

Patient und Methode. Wir berichten über ein 10 Jahre altes Mädchen mit mäßiger globaler Entwicklungsretardierung, Strabismus convergens alternans, leichter Ataxie und Intentionstremor. Schwangerschaft mit vorzeitiger Wehentätigkeit, Geburt 41.SSW per sectionem, APGAR 3/8/9. Länge und Gewicht entlang 50. Perzentile. Kopfumfangswachstum konform zur 10. Perzentile. MRT Schädel im Alter von 2,5 Jahren: Kleinhirnwurmunterhypoplasie, ansonsten unauffällig. Aminosäuren i. S., organische Säuren i. U., Schilddrüsenparameter, Lactat, Transferrinelektrophorese, Acylcarntitin unauffällig. EEG: unauffällig. Urodynamische Untersuchung wegen rezidivierender Harnwegsinfekte: unauffällig. MRT LWS: Bogenschlussanomalie L5/S1. 
Resultat. Micro-Array-CGH: Mikrodeletion $10 \mathrm{q} 26$ von $6,92 \mathrm{Mb}$. Bestätigung des Befundes durch Real-time-PCR. Untersuchung beider Eltern mit Micro-Array-CGH und Real-time-PCR negativ.

Schlussfolgerung. Das bei unserer Patientin vorliegende vorliegende Krankheitsbild konnte im Alter von 10 Jahren einem Mikrodeletionssyndrom zugeordnet werden. Die Pathogenität wird durch das „de novo“-Auftreten sowie die Größe der Deletion $(>4 \mathrm{Mb})$ belegt. Zudem handelt es sich um einen Symptomenkomplex, der bei 60 weiteren publizierten Patienten beschrieben ist. Neben der für das 10q26-Mikrodeletionsyndrom typischen Symptomen findet sich hier eine Kleinhirnunterwurmhypoplasie, die zu Intentionstremor und milder Ataxie führt. Der erweiterte Phänotyp könnte durch die über die übliche Größe der Mikrodeletion 2oq26 herausgehende Region erklärt werden.

\subsection{Kongenitale Myasthenie mit episodischer Apnoe bei einem 8-jährigen Knaben}

A. van Egmond-Fröhlich ${ }^{1}$, H. Rauschka ${ }^{2}$, B. Streubel ${ }^{3}$, H. Kurz² ${ }^{2}$ B. SchmidEipeldauer ${ }^{2}$

${ }^{1}$ Abt. für Kinder- und Jugendheilkunde, ${ }^{2} \mathrm{Abt}$. für Neurologie SMZ-Ost

Donauspital Wien, ${ }^{3}$ Klinisches Institut für Pathologie der Universität Wien.

Anamnese. Der 8-jähriger Knabe fiel im Säuglingsalter durch Dyspnoe und Zyanose beim Trinken auf. Im 2. Lebensjahr zeigte sich eine proximal betonte, nicht progrediente Muskelschwäche mit Trendelenburg-Hinken und rascher Ermüdbarkeit. Hochfieberhafte Infekte führten ohne pulmonale Erkrankung zu Dyspnoe, Einsatz der Atemhilfsmuskulatur und Atemstillstand, sodass eine Versorgung mit Tracheostoma und Heimrespirator erfolgte. Ein Bruder mit gleicher Symptomatik verstarb zweijährig im Atemversagen bei Varizelleninfektion.

Körperliche Untersuchung. Geringe diffuse Muskelatrophie, beidseitiges Trendelenburg-Hinken, angedeutetes Gower-Zeichen.

Diagnostik. Serum Laktat, Creatin Kinase, Schädel-MRTs, EEGs sowie EMG und Elektroneurographie waren unauffällig. Eine Muskelbiopsie zeigte geringgradige unspezifische Veränderungen. Bei Konsanguinität der gesunden Eltern (gemeinsame Urgroßeltern) und suspiziertem rezessivem Erbgang wurde ein hoch auflösender Microarray durchgeführt, um auf homozygote genomische Areale zu untersuchen, die in 3 Blöcken auf den Chromosomen 6, 9, 10 gefunden wurden. Eine Analyse aller in diesen Bereichen vorhandenen Gene ergab, dass lediglich das CHAT-Gen (Cholin Acetyltransferase) als Kandidatengen übrig blieb (OMIM \#254210). Bei repetitiver Stimulation (3 Hz) des M. abductor dig. min. betrug das Dekrement in Ruhe 1\%, nach 90" Belastung $-15 \%$

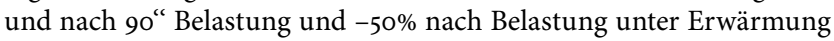
auf $40^{\circ} \mathrm{C}$ im Wasserbad. Therapie: Mestinon ( $1,5 \mathrm{mg} / \mathrm{kg} /$ Dosis) verbesserte Laufstrecke $(+17 \%)$, Rumpfbeugen $(+200 \%)$ und Decrement nach $90^{\prime \prime}$ Belastung bei $40^{\circ} \mathrm{C}(-33 \%)$.

Diskussion. Das kongenitale Myasthenie-Syndrom mit episodischen Apnoen ist eine seltene autosomal rezessive Erkrankung mit Dysfunktion der Cholin-Acetyltransferase. Die demonstrierte Temperaturabhängigkeit der Muskelermüdbarkeit erklärt das fieberinduzierte Atemversagen, die Stammbetontheit sowie die Verschlechterung im Sommer und erleichtert die Diagnose bei diesem Krankheitsbild.

\subsection{Fallbeispiel mitochondriale Myopathie (November 2010, Abteilung für Kinder und Jugendheilkunde, KH Barmherzige Brüder, Eisenstadt)}

\section{Weigmann}

Abteilung für Kinder- und Jugendheilkunde, Krankenhaus Barmherzige Brüder, Eisenstadt

Ein 17 Jahre 6 Monate alter Patient kam mit Rettung sitzend in die Kinderambulanz. Er war beim Fußballspielen zusammengebrochen und verspürte retrosternale stechende Schmerzen.
Laborchemisch imponierte bei Aufnahme eine deutliche Lactatazidose mit Lactat bis zu 10,8 mmol/l. Auffällig waren auch die deutlich erhöhten CPK-Werte bis zu 675 U/l. Nebenbefundlich erhöhte LFP, Hypercholesterinämie und Hyperurikämie. Der Patient war bereits mit Allopurinol anbehandelt. Außerdem bestand bereits trotz seines jugendlichen Alters eine Hypertonie und Glomerulopathie mit Proteinurie. Stationär litt er v. a unter Müdigkeit, Somnolenz, ausgeprägten Muskelschmerzen am Stamm und den Extremitäten. Hochpathologische Belastungsergometrie mit Laktatbestimmung - muskuläre Erschöpfung bei 30 Watt, Lactatanstieg von 10 auf $17 \mathrm{mmol} / \mathrm{l}$

Eine Muskelbiopsie (Prof. Dr. Bittner) ergab einen kombinierten Komplex-I-IV-Mangel und eine mitochondriale DNA-Mutation $\mathrm{A}_{3243 \mathrm{G}}$ (MELAS); Muskelgewebe 85-90\%, Blut 40-45\%. Kontaktaufnahme mit Prim. Prof. Dr. Sperl: Beginn einer Therapie mit Carnitin, Coenzym Q10, Riboflavin und kohlenhydratreicher Diät, woraufhin sich eine subjektive Besserung der Beschwerden einstellt.

Die weitere Betreuung und genetische Beratung der betroffenen Familie erfolgt nun an der Uniklinik Salzburg bei Prof. Prim. Dr. Sperl, welcher bei unserem Patienten auch eine Fibrattherapie zur Induktion der Atmungskettenenzyme begonnen hat. Ein Reha-Aufenthalt ist geplant.

\subsection{Septo-optische Dysplasie - Bedeutung der frühzeitigen Diagnose}

J. Aigner', J. Berger', G. Zoder', D. Prayer², G. Mann³ , A. Lischka', S. Riedl ${ }^{3}$

${ }^{1}$ Kinderklinik Glanzing, Wilhelminenspital der Stadt Wien, ${ }^{2}$ Abteilung für Neuroradiologie,MedizinischeUniversitätWien, ${ }^{3}$ St.AnnaKinderspital,Wien

Septo-optische Dysplasie (SOD), erstmals 1956 von deMorsier beschrieben, ist eine seltene, klinisch heterogene Erkrankung. Sie ist charakterisiert durch eine Agenesie bzw. Hypoplasie der Mittellinienstrukturen des Gehirns (Nn. optici, Septum pellucidum, Hypophyse), eventuell kortikalen (Polymikrogyrie) und weiteren zerebralen Malformationen (Balkenmangel) sowie den daraus folgenden ophthalmologischen, endokrinologischen und neurologischen Symptomen. Wir berichten über 3 Säuglinge mit SOD.

Patient 1 war postpartal auffällig durch einen verminderten Muskeltonus, Apnoen, Subarachnoidalblutung, Hypoglykämien, Ikterus prolongatus und Hypothyroxinämie. Patient 2 hatte eine konnatale Infektion, Hypoglykämien und einen Ikterus. Patient 3 war neonatal bis auf einen Ikterus prolongatus unauffällig. Wachstum und Gedeihen waren während der ersten Lebensmonate regelrecht. Die Diagnose SOD wurde bei allen 3 Patienten im 3 . Lebensmonat aufgrund der ophthalmologischen Symptomatik (Nystagmus, fehlendes Fixieren) und sonographisch fehlendem Septum pellucidum gestellt.

In der Schädel-MRT zeigten sich eine Septumagenesie (3/3), ein dünnes Chiasma opticum (3/3), eine ektope Neurohypophyse (2/3), eine hypoplastische Adenohypophyse (2/3) sowie eine Schizencephalie assoziiert mit Polymikrogyrie (1/3). Bei den Patienten 1 und 2 mit Hypophysenanomalie waren eine Hypothyreose sowie ein Hypocortisolismus nachweisbar.

SOD-Patienten bedürfen einer frühzeitigen Hormonsubstitution bei endokrinologischer Mitbeteiligung, auf die bereits neonatale Hypoglykämien und ein Ikterus prolongatus hinweisen können. Bei Verdacht auf hypophysäre Insuffizienz sind Hormonbestimmungen, Fundoskopie und Schädelsonographie essentiell, um eine Mittellinienfehlbildung frühzeitig zu erfassen. Hormondefizite entwickeln sich bei SOD öfter auch allmählich während des ersten Lebensjahres. Morphologisch nachweisbare Veränderungen in der MRT korrelieren mit dem klinischen Phänotyp und erlauben eine prognostische Einschätzung. 


\section{Pneumologie}

\subsection{Ciliary beat frequency in nasal and bronchial epithelial cells in patients with cystic fibrosis}

S. Alikadic, F. Horak, T. Frischer, E. Nachbaur, S. Renner, S. Gruber Universitätsklinik für Kinder- und Jugendheilkunde der Medizinischen Universität Wien

Background. The extent to which altered ciliary function plays a role in the decrease in mucociliary clearance in cystic fibrosis (CF) patients is unclear.

Objective. To study ciliary beat frequency (CBF) in nasal and bronchial epithelial cells of children with CF.

Methods. Nasal and bronchial brushings were performed on $11 \mathrm{CF}$ children (mean age: $8.86 \pm 4.54$ ) undergoing bronchoscopy. In 15 healthy controls (mean age: 11.47 \pm 4.7 ) undergoing endoscopic procedures, nasal brushings were performed. The biopsies were performed using an Olympus BC-202D-2010 disposable brush. The samples were transported in a Medium 199 HEPES buffer and immediately analyzed. Slides were put into a climate chamber preheated to $37^{\circ} \mathrm{C}$ and viewed through an inverted phase contrast video microscope (Olympus IX-51). Short videos of ciliated cell groups were filmed with a high-speed video camera (Olympus i-Speed 2) at 300 frames/s. The videos were then played back and the frequencies of several cell conglomerates per patient were determined. Mean values were used for further analysis.

Results. Nasal CBF in CF patients was higher when compared to that of healthy controls (mean/SD: $15.4 \pm 3.03$ vs. $12.92 \pm 2.37$, p<0.05). Furthermore, nasal CBF in CF patients was found to be higher than bronchial CBF (mean/SD: $13.23 \pm 2.38, \mathrm{p}<0.01$ ), and the values were found to correlate $(\mathrm{r}=0.7, \mathrm{p}<0.01)$.

Conclusion. Our results indicate that CF patients indeed have altered nasal ciliary function. Whether these findings could have therapeutic implications requires further study.

\subsection{Fremdkörperaspiration mit Komplikationen und Dislozie- rung bei einem intubierten Kind}

K. Graw-Panzer', S. Wadowski ${ }^{2}$, H. Lee ${ }^{2}$

${ }^{1}$ Kinderklinik Glanzing, Wilhelminenspital der Stadt Wien, ${ }^{2}$ The Children's Hospital at Downstate, SUNY Downstate College of Medicine, Brooklyn, NY

Einleitung. Fremdkörperaspiration ist ein signifikantes Problem im Kindesalter. Typischerweise verschluckt sich das Kind, hustet plötzlich oder giemt, jedoch kann es auch unbemerkt verlaufen und zu schwerwiegenden Komplikationen führen. Wir berichten einen sehr untypischen Verlauf einer Fremdkörper Aspiration und damit verbundenen Komplikationen.

Fallbericht. Ein 2 jähriges Kind wurde mit einem generalisierten tonisch-klonischen Krampfanfall, dem ein 2-tägiger febriler Infekt der oberen Atemwege vorangegangen war, vorstellig. Aufgrund wiederholender Krampfanfälle wurde das Kind intubiert und beatmet. Initiale Diagnose war komplizierter Fieberkrampf mit zugrunde liegender rechts basaler Pneumonie, Atemversagen und akutes „respiratory distress syndrom“. Unter mechanischer Beatmung führte am 4. Tag eine Hustenatacke zu Atemnot und Kollaps der linken Lunge. Erhöhte Atemwegsdrucke führten zur Reexpansion. Es folgten Fieber, erhöhter Sauerstoffbedarf und nichtreversibles Giemen. Auskultiert wurde monophones zentrales Giemen mit vermindeter Belüftung der linken Lunge. Die Thoraxröntgenaufnahmen Tag 1-4 zeigten einen $6 \mathrm{~mm}$ großen runden Schatten im rechten Bronchus intermedius und ab dann im linken Hauptbronchus mit zunehmender Überblähung der linken Lunge. CT bestätigte den Fremdkörper. Via ragider Bronchoskopie wurde ein $6 \mathrm{~mm}$ (Durchmesser) glattes, ovales Plastikteil entfernt. Nach Extraktion entwickelte sich ein postobstruktives Lungenödem. Die Patientin erholte sich vollständig.
Schlussfolgerung. Die Kombination von plötzlicher klinischen Verschlechterung und einseitiger Lungenüberblähung ist sehr verdächtig auf Obstruktion der Atemwege durch einen Fremdkörper. Dieser Fall demonstriert dass Fremdkörperaspiration zu schwerwiegenden Krankheitsfolgen führen kann. Da es keine spezifischen klinischen und radiologische Zeichen zum Ausschluss gibt, muss die Fremdkörperaspiration differentialdiagnostisch bei jeglichem akuten Prozess der Atemwege erwogen werden.

\subsection{Hämoptyse und bilaterale pulmonale Kavernen - was könnte das sein?}

J. Kenn-Schürz' ${ }^{1}$, B. Kaller ${ }^{1}$, T. Lindmira' ${ }^{1}$, M. Bogyi' ${ }^{1}$ A. Lischka' ${ }^{1}$ W. Rebhandl ${ }^{2}$, T. Frischer ${ }^{2}$, H. Auer ${ }^{2}$

${ }^{1}$ Kinderklinik Glanzing, Wilhelminenspital der Stadt Wien, ${ }^{2}$ Kinderchirurgie, AKH Wien

Die Echinokokkose zählt zu den gefährlichsten Wurmkrankheiten des Menschen. Auch in Österreich treten einheimische und importierte Erreger auf, welche die alveoläre und zystische Echinokokkose hervorrufen können. In der vorliegenden Fallpräsentation berichten wir über ein 12-jähriges Mädchen, welches wegen Hämoptysen und therapieresistentem Husten zum TBC-Ausschluss an unsere Abteilung zugewiesen wurde. Die durchgeführte TBC-Abklärung war unauffällig. Die weitere Diagnostik zeigte eine Eisenmangelanämie und im Lungenröntgen Infiltrationen. Untersuchungen auf CF und Kollagenosen waren unauffällig. Die Serummikrobiologie waren Antikörper von Mykoplasma pneumoniae, Chlamydia pneumonie und Bordetella pertussis (V. a. Kreuzreaktion) positiv. Im CT-Thorax fanden sich Kavernen in beiden Lungen. Eine Abklärung bzgl. Parasitosen zeigte einen positiven Befund auf Echinokokken. Eine Mitbeteiligung anderer Organsysteme wurde ausgeschlossen.

Nach Einleitung einer oralen antihelmintischen Therapie (Benzimidazolderivate), erfolgte die chirurgische Sanierung an der kinderchirurgischen Abteilung des AKH Wien. Der postoperative Verlauf gestaltete sich komplikationslos. Weiters möchten wie die geographische Verbreitung, den Lebenszyklus der Erreger, Übertragung, Diagnostik, Therapie und auch Prophylaxe der alveolären und zystischen Echinokokkose beleuchten.

Zusammenfassend ruft dieser Fallbericht in Erinnerung, dass bei unspezifischen Beschwerden wie Hämoptysen und Husten neben häufigen pulmonalen Krankheitsbildern seltene Parasitosen mit oft schwerwiegenden Krankheitsverläufen differentialdiagnostisch in Betracht zu ziehen sind. Ein abgestimmtes interdisziplinäres Vorgehen in der Diagnostik und Therapie sind hier von größter Bedeutung.

\subsection{Biphasischer Krankheitsverlauf bei pädiatrischen Patien- ten mit Pleuraempyem}

Elisabeth Lindner, R. Kerbl

LKH Leoben, Abteilung für Kinder- und Jugendheilkunde

Hintergrund. In den letzten Jahren zeigte sich ein deutlicher Anstieg der pädiatrischen Fälle mit Pleuraempyem trotz Einführung der Pneumokokken-Impfung und frühzeitig eingeleiteter antibiotischer Therapie. Ziel dieser Studie war es, mögliche Ursachen für den Anstieg der Fälle von Pleuraempyemen bei pädiatrischen Patienten zu finden. Des Weiteren wurden die Daten einer Gruppe von fünf Patienten mit einem biphasischen Krankheitsverlauf analysiert.

Methoden. Bei dieser deskriptiven Studie wurden die Daten von 19 Kindern und Jugendlichen während eines Zeitraumes von elf Jahren (2000-2010) analysiert. Das Patientenkollektiv umfasste Patienten, bei denen ein Pleuraempyem als Komplikation einer Pneumonie diagnostiziert wurde. Die Datenerhebung erfolgte im LKH Leoben.

Resultate. Bei der Analyse des gesamten Patientenkollektivs konnte ein Anstieg der Inzidenz von Pleuraempyemen nach der Einführung von PCV-7 („7-valent pneumococcal conjugate vaccine") festgestellt werden. Fünf Kinder zeigten einen biphasischen Krankheitsverlauf, 
der nach der Einführung von PCV-7 beobachtet werden konnte. Nach Einleitung einer symptomatischen und antibiotischen Therapie kam es bei allen fünf Kindern zu einer klinischen Besserung. Darauf folgte eine zweite Krankheitsphase, in der sich unerwartet ein Pleuraempyem entwickelte. Die fünf Kinder mit biphasischem Krankheitsverlauf zeigten eine längere Hospitalisierungsdauer, eine längere Verweildauer der Pleuradrainage und eine längere antibiotische Therapie als die Kinder mit monophasischem Krankheitsverlauf. Bei drei Kindern aus der biphasischen Gruppe konnten Pneumokokken nachgewiesen werden. Schlussfolgerung. Die Ergebnisse sprechen für die Hypothese, dass es durch die Einführung der Impfung zu einem Serotypen-Replacement -durch die NVSTs- gekommen sein könnte. Die NVSTs besitzen Unterschiede in ihrer Invasivität und könnten somit vermehrt zu Empyemen führen, sowie den beobachteten, neu aufgetretenen, biphasischen Krankheitsverlauf auslösen.

\subsection{Childhood asthma control test: relationship with GINA levels of asthma control, lung function and exhaled nitric oxide}

V. Waibel ${ }^{1}$, E. Horak ${ }^{1}$, H. Ulmer ${ }^{2}$

${ }^{1}$ Universitätsklinik für Kinder- und Jugendheilkunde Innsbruck, Pädiatrische Pneumologie und Allergologie, ${ }^{2}$ Department für Mediznische Statistik, Informatik und Gesundheitsökonomie

Background. According to current GINA guidelines the former classification by asthma severity was replaced by level of asthma control. The childhood asthma control test (C-ACT) is a validated symptom score for assessing asthma control in children. We used a slightly modified version $\left(\mathrm{C}-\mathrm{ACT}^{\mathrm{M}}\right)$ of the German C-ACT and explored the agreement between C-ACT and and GINA levels of asthma control, as well as the relationship between $\mathrm{C}-\mathrm{ACT}^{\mathrm{M}}$ and lung function and exhaled nitric oxide (FeNO).

Methods. We investigated 107 children with a diagnosis of asthma. The study protocol consisted of a clinical examination, assessment of asthma control according to GINA guidelines, administration of C$\mathrm{ACT}^{\mathrm{M}}$, lung function and $\mathrm{FeNO}$.

Result. Of our patients $66 \%$ had, according to GINA, partly controlled-/uncontrolled asthma, $18 \%$ were uncontrolled according to $\mathrm{C}-\mathrm{ACT}^{\mathrm{M}}$. Children with partly controlled-/uncontrolled asthma according to GINA had lower C-ACT ${ }^{\mathrm{M}}$ scores than did children with controlled asthma (16.1 $\pm 3.6 \mathrm{SD}$ vs. $25.4 \pm 1.8 \mathrm{SD}$; $\mathrm{p}<0.000)$, and children with a C-ACT ${ }^{\mathrm{M}}$ score $\leq 19$ had poorer lung function (mean $\mathrm{FEV}_{1 \%} \%$ predicted $81.5 \pm 13.5$ SD vs. $94.2 \pm 12.1 \mathrm{SD} ; \mathrm{p}=0.002$ ). Multiple linear regression adjusted for age, gender, $\mathrm{FEV} 1$ and $\mathrm{FeNO}$ demonstrated a significant relationship between $\mathrm{C}-\mathrm{ACT}^{\mathrm{M}}(\mathrm{p}<\mathrm{0.00o})$, but no significant correlation between C-ACT ${ }^{\mathrm{M}}$ and $\mathrm{FeNO}$.

Conclusion. The German version of $\mathrm{C}-\mathrm{ACT}^{\mathrm{M}}$ is valid and useful for monitoring children with asthma along with tests aimed to follow up lung function and airway inflammation. Concordance between $\mathrm{C}-\mathrm{ACT}^{\mathrm{M}}$ and GINA is moderate, because asthma control assessed by $\mathrm{C}-\mathrm{ACT}^{\mathrm{M}}$ allows more symptoms and lung function is not included in the scoring.

\subsection{Unkonventionelle TBC - Diagnostik}

\section{Weingarten', A. Mogaji' ${ }^{1}$, M. Bogyi ${ }^{1}$, A. Lischka', S. Winkler² ${ }^{1}$ Wilhelminenspital, Kinderklinik Glanzing, ${ }^{2}$ Allgemeines Krankenhaus Wien, Klinische Abteilung für Infektionen und Tropenmedizin}

Hintergrund. Ziel des Posterbeitrags ist die Vorstellung einer unkonventionellen Diagnoseerhebung einer Tuberkulose am Fallbeispiel eines 14-jährigen Mädchens. Bei einer Reihenuntersuchung wurde eine Pleuropneumonie festgestellt, weshalb die Verdachtsdiagnose einer TBC gestellt wurde. Klinisch präsentierte sich die Patientin mit rezidivierendem Fieber, Gewichtsverlust, nächtlichem Schwitzen seit 2 Wochen, Husten sein 1 Monat sowie abdominellen Beschwerden, die seit Jahren bestanden und rezent zunahmen.
Methoden. Stationär erfolgte eitere Abklärung durch: MM, Quantiferon, C/P, Sonographie, CT, Sputumdiagnosik, zytologischer Befung, Aszietes-/Pleurapunktat, molekulargenetische und immunologische Untersuchungen, Stuhl-/ Harnkultur sowie eine durchflusszytomerische Untersuchung.

Resultate. Pleurapunktat/Aszites/Harn/Sputum: Mikroskopie und PCR auf Mycobacterium tuberculosis (M. tub.): negativ. C/P: Infiltrat, Pleuraerguss, Lymphadenpathie. CT Abdomen: peritoneale Formation, mesenteriale Lymphandenopathie. Durchflusszytometrie des Aszites: Anreicherung von M. tub. spezifischen CD4+-T-Zellen im Ergussmaterial als Hinweis auf aktive Tuberkulose. Quantiferontest: positiv. Differentialdiagnostische Untersuchungen lieferten negative Befunde im Hinblick auf familiäres Mittelmeerfiber, Malignom sowie Leishmanien-Antikörper. Eine immunologische Untersuchung war Chlamydien positiv. Nach Einleitung einer tuberkulostatischen Therapie kam es klinisch, sowie in der Bildgebung nachweisbar, zu einer raschen Besserung. Nach über einem Jahr konnte die medikamentöse Therapie abgesetzt werden, und die Patientin galt als geheilt.

Diskussion. die Durchflusszytometrie lieferte einen wesentlichen Hinweis auf eine aktive TBC, während bis auf Quaniferon die üblichen Diagnosekriterien negative Befunde erbrachten. Dieses Fallbeispiel soll demonstrieren, dann unkonventionelle Wege der Diagnoseerhebung bei Tuberkulose in Erwägung gezogen werden müssen.

\subsection{Multidrugresistente Tuberkulose (MDR-TB) und Multi- organbefall, multidiziplinäre Herausforderung in Diagnose und Therapie}

C. Mori, M. Gegenbauer, L. Thereska, M. Bogyi, A. Lischka

Kinderklinik Glanzing im Wilhelminenspital

Einleitung. MDR-TB ist in den Industrieländern selten, jedoch sind zunehmend Fälle in Osteuropa zu vermerken. Patienten mit Migrationshintergrund stellen unsere Gesundheitsversorgung vor eine große diagnostische, therapeutische und finanzielle Herausforderung.

Kasuistik. Wir berichten über einen 8-jährigen Patienten, der seit Oktober 2010 als ukrainischer Flüchtling in Österreich lebt. Er wird wegen Thoraxschmerzen bei rezidivierenden Pneumonien vorstellig, anamnestisch ist eine Meningitis und Appendizitis und kindliches Rheuma zu erheben. Mittels CT wird eine Lungentuberkulose mit Knochenbeteiligung und Brustwirbelkörpereinbruch suspiziert. Aus dem Biopsiematerial eines zervikalen Lymphknotens und aus dem Pus einer Blase im Finderbereich erfolgt der Keimnachweis mittels PCR. Fünf Wochen später zeigt die positive Kultur aus dem Magensaft Resistenzen auf Isoniacid und Rifampicin. Zusätzlich werden kalte Abszesse paravertebral und in Nähe des os pubis und festgestellt. Es erfolgt die Therapieumstellung auf eine fünffache antituberkulotische Therapie (Ethambutol, Pyrazinamid, Capreomycin, Moxifloxacin, Prothinamid). Es werden auch Veränderungen im Gehirn und den langen Röhrenknochen gefunden, unter Therapie zeigt sich eine Besserung der spezifischen Infiltrate.

Im Verlauf treten unklare Fieberschübe mit CRP-Erhöhung auf, wodurch eine weitere Differenzialdiagnostik in Bezug auf unspezifische Infektionen, Rheumaaktivität, immunologische Ursachen oder Fieber im Rahmen der Grunderkrankung notwendig wird. Erschwerend sind die Sprachbarriere und psychische Probleme beim chroisch kranken Kind unter der Isolation.

Schlussfolgerung. Die Komplexität der Erkrankung erfordert eine multidisziplinäre Behandlungsstrategie. Anhand unserer Fallbeschreibung sollen Schwierigkeiten beim Management eines multimorbiden Patienten mit MDR-Tb im Kindesalter aufgezeigt werden. 


\section{Psychosomatik}

\subsection{Insulin manipulation as an indicator of psychiatric comorbi- dity in children and adolescents with type 1 diabetes mellitus}

G. Berger ${ }^{1}$, I. Barrientos ${ }^{2}$, G. Wagner ${ }^{2}$, D. Gerber ${ }^{2}$, B. Rami ${ }^{1}$, M. Fritsch' ${ }^{1}$, T. Hörtenhuber ${ }^{1}$, A. Karwautz ${ }^{2}$, E. Schober ${ }^{1}$

${ }^{1}$ Universitätsklinik für Kinder- und Jugendheilkunde der Medizinischen Universität Wien, ${ }^{2}$ Universitätsklinik für Psychiatrie des Kindes- und Jugendalters, Medizinische Universität Wien

Background. Good metabolic control in adolescence is a challenge. Psychiatric comorbidity is known to be connected to worsening of metabolic control although the mechanisms are not completely clear. Insulin omission is a commonly known symptom in eating disorders. For other psychiatric diseases systematic data on insulin manipulation is missing. In our study we aimed to assess how insulin manipulation is associated with psychiatric comorbidity and metabolic control.

Methods. 241 type 1 diabetes patients (10-22 years) with a diabetes duration of $>1$ year from 21 diabetes outpatient clinics in Austria were included in the cross sectional study. $103(42.7 \%)$ patients were males. Medical data was derived from medical records. Patients were interviewed with standardized instruments, the Diabetes Self-Management Profile (DSMP) interview and the Kinder-DIPS.

Results. Based on the DSMP-Interview adherence to prescribed insulin dosage was assessed. $42.7 \%$ of the patients $(n=103)$ were found to be compliant, $27.8 \%(n=67)$ had management problems and $29.5 \%(v=71)$ patients reported deliberate insulin manipulation in terms of underdosing (24.1\%) and over-dosing (22.8\%). With the Kinder-DIPS psychiatric comorbidity was screened in all patients. Current psychiatric comorbidity was highest in the manipulating subjects (21.1\% vs. $10.4 \%$ in subjects with management problems vs. $3.9 \%$ in compliant subjects, $\mathrm{p}<0.001)$. Significantly elevated levels of depression, specific phobia, social phobia, eating disorders and subclinical specific phobia were found. HbA1c levels were higher among manipulating patients $(8.65 \%$ vs. $7.81 \%, p=0.001$ ), Manipulating subjects were older ( 15.00 years) than compliant subjects (14.00 years, $\mathrm{p}=.004)$ and more girls $(69 \%)$ than boys $(31 \%)$ were found in the manipulating group $(\mathrm{p}=0.001)$.

Conclusion. Insulin manipulation can be surmised as an indicator of psychiatric comorbidity in adolescents with diabetes. Older girls are more at risk and there is a significant impact on metabolic control.

\subsection{Die Entwicklung von Gehirn und Psyche bei Kindern - Normalität und traumatische Störung}

G. Roth

Universität Bremen, Institut für Hirnforschung

Die psychische Entwicklung des Kindes ist aufs Engste mit der Entwicklung des Gehirns verbunden. Dies bedeutet nicht, dass diese Entwicklung rein neurobiologisch verstanden werden kann. Vielmehr treffen im Gehirn mehrere Faktoren zusammen und interagieren in komplexer Weise miteinander. Hierzu gehören (1) genetische Prädispositionen und Eigenheiten der Hirnentwicklung, (2) frühe Bindungserfahrung, (3) psychosoziale Prägung und Erfahrung im Kleinkindalter und (4) Erziehung und Bildung im späteren Kindes- Jugend- und Erwachsenenalter.

Im Laufe der kindlichen Entwicklung entstehen nacheinander sechs psychobiologische „Grundsysteme“. Das erste System ist das Stressverarbeitungssystem. Es befähigt den Organismus zur Bewältigung körperlicher und psychischer Belastungen und Herausforderungen und beruht auf der Produktion und Regulation der Neurotransmitter Adrenalin-Noradrenalin sowie des Hormons Cortisol und seiner Vorstufen (CRF, ACTH). Das zweite psychische Grundsystem ist das interne Beruhigungssystem. Es ist überwiegend vom Neuromodulator Serotonin bestimmt. Beide Systeme beginnen ihre Entwicklung vor der Geburt, stabilisieren sich aber erst in den ersten 3 Jahren nach der Geburt und sind sehr anfällig für Psychotraumatisierungen (vorgeburtlich über das Gehirn der Mutter).
Das dritte System ist das interne Bewertungs- und Motivationssystem, das mit der Ausschüttung endogener Opiate (Belohnung) und Dopamin (Belohnungserwartung und -bewertung) verbunden ist. Das vierte ist das Impulshemmungssystem. Es bewirkt eine Hemmung starker Affekte und eine Toleranz gegenüber Belohnungsaufschub. Es ist an die Ausbildung der hemmenden Wirkung limbischer corticaler Areale (z. B. orbitofrontaler Cortex) auf limbische subcorticale Zentren (Amygdala, Nucleus accumbens u. a.) gebunden. Das fünfte ist das Bindungs- und Empathiesystem, das mit der Produktion und Regulation von Oxytocin zu tun hat. Alle drei Systeme beginnen mit ihrer Entwicklung in der frühen Kindheit, setzen diese aber bis in das Erwachsenenalter hinein fort. Das letzte ist das System des Realitätssinns und der Risikowahrnehmung. Es entwickelt sich im Laufe der späteren Kindheit bis weit in das Erwachsenenalter hinein und ist an die Ausreifung des dorsolateralen präfrontalen und anterioren cingulären Cortex gebunden.

Affektive Störungen, Persönlichkeits- und Verhaltensstörungen gehen sämtlich einher mit Störungen mindestens drei dieser Grundsysteme, wobei solche der ersten beiden Systeme die schwerstwiegenden sind. Die Ursachen dieser Störungen sind in der Regel zu 20-30\% genetisch (über Störungen der Gen-Expression) bedingt, zum größeren Teil durch traumatische Erfahrungen in früher Jugend (körperliche Misshandlung, Vernachlässigung, sexueller Missbrauch) und durch ausgrenzende und beschämende Ereignisse in Kindheit und Jugend gebunden. Diese Störungen lassen sich neurobiologisch nachweisen.

\subsection{Somatoforme Schmerzstörung: Diagnoseweg und Therapieoptionen}

\section{E. Sadek, S. Wölzl, S. Meznik, A. Lischka \\ Kinderklinik Glanzing, Wilhelminenspital der Stadt Wien}

Charakteristisch für die somatoforme Schmerzstörung ist ein andauernder, schwerer und quälender Schmerz, der durch einen physiologischen Prozess oder eine körperliche Störung nicht hinreichend erklärt werden kann. Er tritt in Verbindung mit emotionalen Konflikten oder psychosozialen Belastungen auf, denen die Hauptrolle für Beginn, Schweregrad, Exazerbation oder Aufrechterhaltung der Schmerzen zukommt. Die Folge ist meist eine beträchtlich gesteigerte persönliche oder medizinische Hilfe und Unterstützung. Der Schmerz verursacht in klinisch bedeutsamer Weise Leiden und Beeinträchtigungen in sozialen, beruflichen oder anderen wichtigen Funktionsbereichen. Die meisten betroffenen Jugendlichen haben bereits eine lange und oft komplizierte Patientenkarriere hinter sich. Anhand zweier Fallbeispiele möchte ich den Weg zu dieser Diagnose beschrieben, der eine gute Zusammenarbeit zwischen Ärzten verschiedener Fachrichtungen (Pädiater, Allgemeinmediziner, Orthopäden, Psychiater, Neurologen etc.) und Psychologen erfordert. In einem Fall handelt es sich um einen Patienten, der zunächst aufgrund eines Morbus Scheuermann in orthopädischer Behandlung war. Über mehrere Jahre hinweg veränderte sich das Schmerzbild, der Patient wurde dann in einer Schmerzambulanz vorstellig. Von dort erfolgte die Überweisung an die psychosomatische Ambulanz.

Der andere Patient zeigte zunächst Verhaltensauffälligkeiten in der Schule, die Schmerzsymptomatik trat erst kurz vor der Aufnahme an der Station auf. In beiden Fällen wurde die Diagnose einer somatoformen Schmerzstörung gestellt. Die therapeutischen Ansätze von Psychotherapie bis Pharmakotherapie sind ebenso vielfältig, wobei auch hier ein multimodaler Weg zu bevorzugen ist.

\subsection{Ernährungsstufenplan im Rahmen der Stationären Therapie der Anorexia nervosa}

E. Sadek, S. Wölzl, S. Meznik, A.Lischka

Kinderklinik Glanzing, Wilhelminenspital der Stadt Wien

Die stationäre Therapie der Anorexia nervosa beinhaltet einen multimodalen Ansatz aus Einzelpsychotherapie, Gruppen- und Elterntherapien, Ernährungstherapie und fallweise psychopharmakologischer 
Unterstützung. Indiziert ist sie bei Patienten mit einem niedrigen BMI $(<14)$ bzw. mangelnder Gewichtszunahme am ambulanten Setting. Um einen kontrollierten Nahrungs- und Gewichtsaufbau zu Erreichen, ist ein Ernährungskonzept von Vorteil. Am Pavillon 15 und 18 - des Wilhelminenspitals Psychosomatik für Jugendliche bzw. Kinder erfolgt der Aufbau nach einem Stufenplan, der darauf abzielt, auf der einen Seite vor allem bei PatientInnen mit sehr niedrigem Gewicht eine ausreichende Nährstoffzufuhr zu gewährleisten, PatientInnen mit einem etwas höheren Gewicht auf der anderen Seite aber die Möglichkeit zum Wiedererlangen eines normalen Essverhaltens zu geben. Diesen Stufenplan vor dem Hintergrund der Psychopathologie der Anorexia nercosa vorzustellen, ist ein Ziel dieses Vortrages. Einen weiteren Schwerpunkt stellt der Zusammenhang und die Vernetzung zwischen Ernährung/Ernährungszustand und den anderen Therapien dar.

\section{Rheumatologie}

\subsection{Das Inflammasom als Zielstruktur therapeutischer Intervention}

\section{G. Artacker}

Donauspital/SMZO Wien

In den letzten zehn Jahren konnte die zentrale Bedeutung der „,innate immunity" für das menschliche Immunsystem erkannt werden: Ausgehend vom IL1-Rezeptor konnte ein Weg der Entzündungskaskade bis zu den zellulären Rezeptoren zurückverfolgt werden, er erhielt den Namen „Inflammasom“. Die Inflammasome detektieren Infektionen, verarbeiten Information, leiten sie weiter und aktivieren Interleukin 1 als hochpotenten Entzündungsmediator. Angeborene und erworbene immunologische Erkrankungen können zu einem „loss of function“ (Immundefekte) oder zu einem „gain of function“ („autoinflammatory, autoimmune diseases“) führen. „Autoinflammatory diseases“ beruhen auf Gendefekten, durch die im Zellkern fehlerhafte Proteine für das Inflammasom exprimiert werden.

Seit 1997 konnte für 11 „autoinflammatory diseases“ der Nachweis der Gendefekte und deren Produkte durchgeführt werden. Die Aufnahme von Erkrankungen von Komplement, Makrophagenaktivierung, NFאB sowie Krankheiten, die auf IL1-Blockade ansprechen, in dieses System wird diskutiert. Durch die Blockade verschiedener Signalübertragungswege (Interleukin 1,6, TNFa, T-cell costimulation, Komplementfaktor 5) können wir die Kommunikation zwischen verschiedenen Zellen und humoralen Faktoren des Immunsystems und ihre Aktivierung hemmen.

Unter dem Überbegriff „Biologika“ haben sich seit etwa 10 Jahren unsere Therapiemöglichkeiten bei immunologischen Erkrankungen mit "gain of function“ erheblich verbessert. Auch bei etablierten immunsuppressiven Therapien wie Cortison, Methotrexat, Hydroxychloroquin, Leflunomid, Sulfasalazin, Gold zeigen sich Hinweise für Wirkmechanismen vorwiegend im Bereich der innate immunology.

Die aktuelle Forschung beschäftigt sich derzeit mit „targets“ im Bereich des Stoffwechsels der Makrophagen, dendritischen Zellen, FcReceptorblockade, Komplement, der "pattern recognition receptors“ und des Inflammasomes.

\subsection{Fieberschübe und Exanthem beim Neugeborenen}

\section{A. Skrabl-Baumgartner}

Univ. Klinik für Kinder- und Jugendheilkunde, Graz

Ein Frühgeborenes der 34.SSW fiel durch urtikarielle Exantheme, Fieberschübe und Hyperexzitabilität auf. Im Verein mit exzessive erhöhten Akutphase-Proteinen und einer typischen Physiognomie, sowie erhöhten Liquorzellzahl wurde trotz initial negativem Mutationsnachweises im Exon 3 des $\mathrm{NLRP}_{3}$-Gens die Diagnose eines NOMID-Syndroms gestellt und der Patient erfolgreich mit einem Interleukin1-
Rezeptoranatgonisten behandelt. Nach Beschreibung einer neuen Y859C-Substitution bei einem Patienten mit einem NOMID-ähnlichen Phänotyp wurde diese auch bei unserem Patienten detektiert, womit die klinische Verdachtsdiagnose auch genetisch untermauert werden konnte. Bislang ist es bei unserem Patienten durch die frühe Diagnose und raschen Einsatz der Antizytokintherapie zu keinen typischen Krankheitsfolgen gekommen.

\subsection{Infliximab - eine Therapieoption bei generalisierter Psoriasis pustulosa}

\author{
A. Skrabl-Baumgartner ${ }^{1}$, Prof. Salmhofer ${ }^{2}$ \\ ${ }^{1}$ Univ.-Klinik für Kinder- und Jugendheilkunde, Graz, ${ }^{2}$ Univ.-Klinik für \\ Dermatologie
}

Ein 9-jähriger Knabe mit Psoriasis pustulosa wird wegen akuter Verschlechterung des Hautbildes unter lokaler Steroidtherapie und UVBBehandlung an der Kinderklinik zur Einleitung einer immunmodulativen systemischen Therapie mit Methotrexat zugewiesen. Nach initialer geringer Besserung der Hautveränderungen akquirierte der Knabe eine Norovirus-assoziierte Enteritis, sowie eine akute CMVInfektion, weswegen der Therapie unterbrochen werden musste. Nach antiviraler Therapie wird ein neuerlicher Versuch von Seiten der Dermatologen unternommen den Patienten lokal zu therapieren, was zu einer weiteren Verschlechterung des Hautbildes führte. Ein neuer Versuch mit Methotrexat wird unternommen, was diesmal gut toleriert wurde, aber keinerlei Besserung der Symptomaik brachte. Es entwickelt sich in weiterer folge eine schwere exsudative Verlaufsform mit über 90\% Befall des Integuments mit stark gestörtem Allgemeinbefinden in Form von hohem Fieber, starken Schmerzen und hohem Entzündungslabor. Bei bedrohlichem Allgemeinzustand wird eine Antizytokintherpie mit Remicade in einer Dosierung von $5 \mathrm{mg} / \mathrm{kg} \mathrm{KG}$ eingeleitet. Darunter zeigte sich ein dramatischer Response mit Sistieren der Allgemeinsymptome und Abklingen der Hauteffloreszenzen innerhalb 1 Woche. Unter 8-wöchentlicher Gabe von Infliximab ist der Patient in den letzten 9 Monaten erscheinungsfrei geblieben.

\subsection{Reduzierende vs. native Elektrophoresetechniken für die Biomarkersuche bei juveniler idiopathischer Arthritis (JIA)}

A. Bohn', K.Tendl', K.R. Herkner' ${ }^{1}$, H. Kenzian ${ }^{2}$

'Universitätsklinik für Kinder- und Jugendheilkunde der Medizinischen Universität Wien (Forschungs Core Unit f. Pädiatrische Biochemie und Analytik), ${ }^{2}$ Abteilung für Kinder- und Jugendheilkunde, LKH Villach

Hintergrund. Die frühzeitige Diagnostik der JIA stellt nach wie vor eine diagnostische Herausforderung dar. Die vorliegende Studie befasste sich mit der Anwendung unterschiedlicher Elektrophoresetechniken mit dem Ziel, einen weitgehend spezifischen und sensitiven Biomarker im Serum zu identifizieren. Zusätzlich wurde eine frühzeitige Unterscheidung der JIA Subklassen anhand eines Markerproteins im Patientenserum einzelner Indexpatienten mit oligo- und polyartikulärer Subform sowie systemischer Arthritis angestrebt.

Material und Methoden. Die Proteine von Fibroblastenzellen werden mittels zweidimensionaler Gelelektrophorese (2D-PAGE) aufgetrennt (Proteom) und mittels Western Blotting auf ihre immunologische Affinität zu Serumantikörpern getestet. Da neben reaktiven Immunglobulinen in den Patientenseren vor allem aber bereits komplexierte Antigen-Antikörper Verbindungen anzunehmen sind, sollte die Aussage des Bindungsverhalten neben den in der SDS-PAGE, nach Reduktion der komplexbildenden Wasserstoff-Brückenbindungen getrennten Komplexe auch durch eine eben diese Komplexe intakt anzeigende Methode unterstützt werden („Blue Native Elektrophorese“).

Ergebnisse. Primär konnte in Patientenseren eine stärkere Affinität der Antikörper zu den Cytoskelettproteinen Tubulin und Vimentin, sowie auf $\beta$-Fibrinogen festgestellt werden. In den Seren der Kontrollgruppe wurde eine Bindung von IgG-Molekülen auf $\mu$-IgM nachgewie- 
sen, dies jedoch nicht in Seren definierter JIA-Patienten, was auf die Anwesenheit von gelösten Immunkomplexen in letzteren schließen lässt. Es konnte gezeigt werden, dass sowohl das Bindungsverhalten der Antikörper als auch die Proteinkomplexmuster der Patienten im Vergleich mit einer gesunden Kontrollgruppe deutliche Unterschiede aufwiesen, welche die Anlage eines Marker-Index gestatten.

Schlussfolgerung. Die Anwendung eines solchen Index könnte es ermöglichen, JIA schon sehr früh zu diagnostizieren und dadurch den Patienten schneller einer Therapie zuzuführen.

\subsection{Plasmapherese und Cyclophosphamid bei zerebralem, systemischem Lupus erythematodes (SLE) eines 8-jährigen Mädchens}

\section{A. Ulbrich', I. Lanator ${ }^{1}$, D. Csaicsich ${ }^{1}$, M.T. Schmook ${ }^{2}$, R. Seidl' , W. Emmin- ger $^{1}$ \\ ${ }^{1}$ Univ. Klinik für Kinder- und Jugendheilkunde, ${ }^{2}$ Univ. Klinik für Radiodiag- nostik, Medizinische Universität Wien, Allgemeines Krankenhaus Wien}

Ein 8-jähriges Mädchen mit bereits seit zwei Jahren bekanntem systemischen Lupus erythematodes (SLE) entwickelte während einer Fieberepisode plötzlich eine verwaschene und verlangsamte Sprache mit Hemiparese rechts, leichten Tremor der oberen Extremitäten und ein unsicheres Gangbild. Während Polyarthralgien und serologischen Aktivitätszeichen des SLE wurden Prednisolon, Naproxen und Methotrexat von Dezember 2008 bis August 2009 verabreicht, danach wegen Myalgien bei Komplementverbrauch niedrig dosiertes Prednisolon. Die akut durchgeführte MRT des Gehirns zeigte T2 hyperintense Signalalterationen rechts zerebellär im Marklager unmittelbar periventrikulär mit geringem raumfordernden Effekt, beidseits im Putamen und frontalem Marklager links. Im Serum aufgebrauchtes Komplement $\left(\mathrm{C}_{3}, \mathrm{C}_{4}\right.$ und $\mathrm{CH}_{50}$ ), hohe ANA und AK gegen ds DNA, bekannt waren erhöhte AK gegen SSA (Ro) und SSB (La) sowie grenzwertig hohe AK gegen u1RNP und SM. Es fanden sich keine erhöhten Kardiolipinantikörper und kein Lupusantikoagulans. Eine Methylprednisolonstoßtherapie über drei Tage ( $30 \mathrm{mg} / \mathrm{kg} / \mathrm{Tag}$ ) führt zu einer scheinbaren Besserung der rechtsbetonten Schwäche, allerdings entwickelte sich ein erhöhter Tonus des rechten Armes und rechten Beines. Die Sprache besserte sich nicht wunschgemäß. Zusätzlich entwickelte unsere Patientin ein organisches Psychosyndrom mit Verwirrtheit, Aggressivität, Verlust des Kurzzeitgedächtnisses und der Orientierung. Es wurden Methylprednisolonstöße verabreicht und eine Plasmapherese an drei aufeinanderfolgenden Tagen durchgeführt. Nach der 2. Plasmapherese kam es zu einer Episode mit Blick nach links, Mundastlähmung links, Wendung des Halses nach links und fehlender Ansprechbarkeit. Ein akut MRT zeigte neue T2 hyperintense Läsionen beidseits, rechts occipito-parieto-temporal bis zur Mantelkante reichend, sowie frontal beidseits, keine Kontrastmittelanreicherung im Sinn einer Diffusionsstörung rechts occipito-temporo-temporal (Grenzzonenverteilung). Früher bekannte Läsionen zeigten sich in Rückbildung. Neun Tage nach Beginn der Plasmapherese und 7 Tage nach der ersten Cyclophosphamidgabe zeigte sich schließlich eine deutliche Besserung des organischen Psychosyndroms. Die Patientin war orientiert, kontaktierbar, die Sprache exakt und die kurze Phase des rechtsbetont erhöhten Tonus war abgeklungen. Vier Wochen nach Beginn der zerebralen Symptomatik waren die Signalalterationen in der MRT rückläufig, das Kind normal kontaktierbar und normal gehfähig und der Komplementverbrauch normalisiert. Unter Fortsetzung der immunsuppressiven Therapie und therapeutischer Antikoagulierung zeigt das Mädchen eine noch gering verlangsamte Sprache und eine leichte Muskelschwäche der unteren Extremitäten ohne sonstige neurologische oder neuropsychiatrische Auffälligkeiten.

\section{Schlafmedizin}

\subsection{Preliminary Results. Vergleich spontaner Arousals in Rü- cken- und Bauchlage bei schlafenden Säuglingen}

M. Hausegger', J. Pansy' ', W. Sauseng ${ }^{2}$, R. Kerbl ${ }^{3}$, G. Pichler', W. Müller', B. Urlesberger $^{1}$, H. Zotter ${ }^{1}$

${ }^{1}$ Universitätsklinik für Kinder- und Jugendheilkunde Graz, Abteilung für Neonatologie, ${ }^{2}$ Universitätsklinik für Kinder- und Jugendheilkunde Graz, Abteilung für allgemeine Pädiatrie, ${ }^{3}$ LKH Leoben, Abteilung für Kinder und Jugendliche

Hintergrund. Arousals stellen im Säuglingsalter wichtige „survival mechanisms“ im Schlaf dar. Eine erhöhte „Arousability“ wird als möglicher Pathomechanismus für den protektiven Effekt der Rückenlage bezüglich des Plötzlichen Säuglingstodes (SIDS) diskutiert. Ziel der Studie war es zu untersuchen, ob sich die Dichte und Dauer spontaner Arousals bei Säuglingen in Rücken- und Bauchlage unterscheidet.

Methoden. Bei 10 gesunden Säuglingen mit einem mittleren Alter von $53,5 \pm 16,2$ Tagen wurde eine Polysomnographie in Bauchlage durchgeführt. Anschließend wurden spontane kortikale Arousals (CA) und subkortikale Arousals (SCA) entsprechend den Kriterien der „International Pediatric Work Group on Arousals" analysiert. Ermittelt wurden die mittlere Dauer der Arousals sowie deren mittlere Anzahl pro 10 Minuten Schlafzeit, wobei die Auswertung auch getrennt für CA, SCA und nicht eindeutig zuordenbare Arousals (UCA) erfolgte. Als Kontrollgruppe dienten 10 gesunde Säuglinge (Alter 49,8 $\pm 16,5$ Tage), die in Rückenlage schliefen.

Ergebnisse. Bei den Säuglingen in Bauchlage betrug die mittlere Schlafzeit 124,1 $\pm 28,8$ Minuten. Insgesamt wurden 187 Arousals mit einer Dauer von $13,3 \pm 2,5$ Sekunden analysiert. Pro 10 Minuten Schlafzeit traten $1,4 \pm 0,6$ Arousals auf $(0,7 \pm 0,4$ CA, $0,4 \pm 0,3$ SCA, $0,3 \pm 0,3$ UCA). Die Schlafzeit der Säuglinge in Rückenlage betrug 95,5 $\pm 18,9$ Minuten, wobei insgesamt 225 Arousals mit einer Dauer von 13,9 $\pm 3,1$ Sekunden registriert wurden. Pro 10 Minuten Schlafzeit traten $2,3 \pm 1,3$ Arousals auf $(1,4 \pm 1,1 \mathrm{CA}, 0,6 \pm 0,5$ SCA, $0,4 \pm 0,4$ UCA). Die Gesamtzahl der Arousals sowie der CA pro Zeiteinheit war in Rückenlage signifikant höher als in Bauchlage. Bezüglich der SCA war der Unterschied gerade nicht signifikant. Es zeigten sich keine signifikanten Unterschiede in der Dauer der Arousals.

Diskussion. Der protektive Effekt der Rückenlage bezüglich SIDS könnte somit durch das vermehrte Auftreten spontaner Arousals erklärbar sein.

\subsection{Speeding up clinical decision making with home-based video screening studies in populations with neurodevelop- mental conditions (NDC)}

O. Ipsiroglu', A. Vilela Barbosa ${ }^{2}$

${ }^{1}$ Sleep Research Group at BC Children's Hospital, University of British Columbia, ${ }^{2}$ Cognitive Sciences Lab, Department of Linguistics, University of British Columbia

Background. Children with NDC are at high risk for developing sleep problems (SP). As most patients have underlying conditions which are associated with significant developmental delays and challenging behaviour, the significance of clinical daytime symptoms (e.g. cognitive impairment, hyperactivity) might be missed or underestimated. Results of clinical assessments and research suggest that screening studies (SS) would be helpful in triaging patients for further clinical sleep assessments. Thus we investigated the applicability of a replicable, durable, and inexpensive video monitoring solution as a screening tool.

Purpose. To improve the recognition of SP, and to investigate the feasibility of unattended home based sleep SS in children with NDC.

Method. All patients had history of severe NDC requiring chronic care. 93 overnight video SS with an infrared light camera and a small 
laptop were conducted in 35 patients ( 15 preschool, 20 school-aged); the equipment was couriered to the home, setup and filming was done by parents; internet connection enabled remote access from the research lab to facilitate home setup.

Results. All measurements were successful and equipment was returned without any damage; a better clinical understanding of SP could be achieved by using home based SS leading to treatment or referral to a clinical sleep assessment only if appropriate. 12 patients were identified with restless legs syndrome and treated successfully.

Discussion. To our knowledge our study is the first to apply overnight videos in paediatric patients with NDC. Results of our clinical pilot project suggest that home based sleep screening studies are helpful in triaging patients for appointments in the interdisciplinary sleep clinic before further assessments.

\subsection{Das pädiatrische Schlaflabor als Bindeglied der Betreu- ungsteams bei einem Kind mit Treacher Collins Variante}

R. Rath-Wacenovsky, D. Paulsen

Abteilung für Kinder- und Jugendheilkunde, Landesklinikum Mödling

Jacob wurde am 27.10.2009 geboren und wies deutliche faciale Dysmorphiezeichen (bds. Ohrmuschelfehlbildung, Gaumenspalte Dysostosis otomandibularis mit Deformation des Schläfenbein und Kiefergelenken und fehlender Pfanne, Deformierung der Mandibula, besonder der aufsteigende Äste) auf. Er benötigten immer wieder $\mathrm{O}_{2}$-Vorlage und wies Trinkschwierigkeiten auf. Eine Anpassung einer Gaumenplatte war wiederholt frustran und er wurde primär über eine nasogastrale Sonde ernährt und benötigte immer wieder $\mathrm{O}_{2}$-Vorlage. Nach Wechsel auf eine Tübingerplatte brachte deutliche Besserung und sein Zustand stabilisierte sich. In der folgenden Diagnostik ergaben sich okulär, zerebral und kardial unauffällige Befunde, jedoch eine Schallleitungsstörung bei GHG Agenesie mit nachfolgenden Hörgeräte Versorgung. Jacob entwickelte so gut, dass in Graz eine Sondenentwöhnung gelang. In den folgende Jahren wurde er von den Teams der Kieferchirurgie, HNO, Logopädie, Entwicklungsambulatorium und den Pädiatern (niedergelassen + Krankenhaus) punktuell betreut. Die Mutter mit ihren Anliegen und Beobachtung und die Befundbriefe waren die Informationsbindeglieder zw. den Betreuern. In Laufe der Zeit kam es zu langsamen Verschlechterung bei Jacob. Er gedieh schlechter, machte Entwicklungsrückschritte, veränderte sein Verhalten und war deutlich geschwächt. Die Mutter fühlte ihre Fragen nicht ausreichend beantwortet und machte über eine Internetrecherche Kontakt zu unsere Schlaflabor. Im Erstkontakt fanden wir einen schlafende Jungen mit entsprechende facialen Dysmorphiezeichen vor. Er war ca.1,5 Jahre alt, wog nur $9 \mathrm{~kg}$, wies einen massiven inspiratorischen Stridor, IC, juguläre und sternale Einziehungen auf, war grau- livid mit ausgeprägter Lippenzyanose. Die transcutane $\mathrm{O}_{2}$-Messung ergab $30 \%$ $\mathrm{O}_{2}$-Sättigung bei einer Herzfrequenz von $140 \mathrm{bpm}$.

In diesem Poster soll an diesem spannenden Fall, die weiteren therapeutischen und diagnostischen Möglichkeiten, aber auch die Vernetzung zwischen den betreuenden Teams über das pädiatrische Schlaflabor diskutiert werden.

\subsection{Kann der Schnuller den plötzlichen Säuglingstod verhin- dern?}

H. Zotter ${ }^{1}$, W. Sauseng' ${ }^{2}$, M. Hausegger ${ }^{1}$, R. Kerbl' ${ }^{3}$, G. Pichler ${ }^{1}$, J. Pansy', F. Reiterer', B. Urlesberger ${ }^{1}$, W. Müller ${ }^{1}$

${ }^{1}$ Klinische Abteilung f. Neonatologie u. ${ }^{2}$ Klinische Abteilung f. Allgemeinpädiatrie, Univ. Klinik f. Kinder- und Jugendheilkunde Graz, Österreich, ${ }^{3}$ Abteilung für Kinder u. Jugendliche, LKH Leoben, Österreich

Hintergrund. Seit November 2005 empfiehlt die „American Academy of Pediatrics (AAP)“ den Schnuller als Präventionsmaßnahme gegen den plötzlichen Säuglingstod (SIDS).
Methodik. Die aktuelle Literatur zum Thema „Schnuller und SIDS“ und insbesondere die Metaanalyse von Hauck et al. (Pediatrics 2005; 116:716-723), die zur AAP-Empfehlung geführt hat, werden diskutiert. Ergebnisse. Alle Studien ergaben bei Schnuller-Verwendung während des letzten Schlafes eine Odds-Ratio unter 1. In Hinblick auf „üblichen Schnullergebrauch" zeigten 6 Studien ebenfalls eine Odds-Ratio unter 1, während eine irische Studie dafür in einer multivarianten Analyse eine Odds-Ratio von 1,47 angab.

Schlussfolgerung. Die Metaanalyse von Hauck et al. hat berechnet, dass durch eine generelle Schnullerverwendung ein Todesfall unter 2733 Lebendgeborenen verhindert werden kann. Auch die Österreichische Gesellschaft (SIDS Austria) hat ihre Empfehlungen zur Verhinderung des plötzlichen Säuglingstodes insofern erweitert, als dass der Beruhigungsschnuller als zusätzliche Präventionsmaßnahme empfohlen wird. In welcher Weise der Schnullergebrauch vor dem Plötzlichen Säuglingstod schützen soll, bleibt allerdings unklar. In der Zukunft werden prospektive Studien den tatsächlichen Stellenwert des Schnullers in Hinblick auf SIDS Prävention belegen müssen.

\section{Sonographie}

\subsection{Uterus didelphys mit einseitiger Vaginalatresie (Herlyn- Werner-Wunderlich-Syndrom): multizystisch dysplastische Niere als Schlüssel zur Diagnose beim Neugeborenen}

I. Gaßner', U. Kiechl'², T. Geley², K. Maurer ${ }^{1}$

'Department Radiologie, Innsbruck, ${ }^{2}$ Department für Kinder- und Jugendheilkunde, Innsbruck

Einleitung. Uterus didelphys mit obstruierter Hemivagina (UDMOH) ist ein seltenes typisches Missbildungssyndrom, das meist erst nach der Menarche mit zunehmenden Unterbauchschmerzen, vor allem während der Menstruation, symptomatisch wird. Bei dieser Fehlbildung wird fast immer eine Nierenagenesie ipsilateral zur Vaginalatresie beschrieben, in Einzelfällen eine Nierendysplasie und/oder ein ektop in die atretische Vagina mündender Ureter. Wir beobachteten bei 5 Neugeborenen die Assoziation von UDMOH mit einer multizystisch-dysplastischen Niere (MCDK) und stellten den gesamten Fehlbildungskomplex sonographisch dar.

Patientinnen und Methode. Bei 5 Neugeborenen mit pränatal entdeckter einseitiger zystischer Nierenfehlbildung untersuchten wir sonographisch die Nieren und das innere Genitale. Zur klaren Darstellung der Genitalfehlbildung wurde in die Vagina o,9\% $\mathrm{NaCl}$ instilliert. Ergebnis. Bei allen 5 Neugeborenen bestand eine MCDK, die in 4 Fällen kaudal ektop gelegen war, und ein UDMOH. In 3 Fällen war zusätzlich ein dilatierter Ureter von der MCDK bis in Höhe der Vagina sichtbar, davon einmal auch die Uretereinmündung in die atretische Vagina. Die MCDK bildete sich bei allen Patienten bis zum 2. Lebensjahr zurück.

Schlussfolgerung. 1. Bei Mädchen mit MCDK oder einseitiger Nierenagenesie (Die multizystisch dysplastische Niere kann sich schon intrauterin zurückbilden!) soll nach einem UDMOH gesucht werden. Beim Neugeborenen ermöglicht der durch mütterliche und Plazentahormone stimulierte Uterus in Kombination mit Füllung der Vagina mit o,9\% $\mathrm{NaCl}$ die vollständige Darstellung der komplexen Fehlbildung mittels Ultraschall. Die frühe Diagnose erlaubt die rechtzeitige Resektion des obstruierenden Vaginalseptums vor Auftreten von Komplikationen (Hämatometrokolpos, Endometriose etc.). 2. Die MCDK ist Folge der ektopen Uretermündung in die obstruierte Vagina. Die Involution der MCDK täuscht die mit UDMOH bekannte assoziierte Nierenagenesie vor. 
19.2 Thelarche, Pubarche und Menarche als Leitsymptome eines seltenen Ovarialtumors

\author{
C. Heher, C. Weitzer \\ Universitätsklinik für Kinder- und Jugendheilkunde, Medizinische Uni- \\ versität Graz
}

Einleitung. Als Pubertas praecox bezeichnet man die vorzeitige Entwicklung der äußeren Geschlechtsmerkmale. Man unterscheidet die zentrale (Pubertas praecox vera), von seltenen peripheren Formen (Pseudopubertas praecox, PPP), welche durch einen Geschlechtshormon freisetzenden Prozess abseits der Hypotahlamus-HypophysenGonaden-Achse entstehen. Wir präsentieren ein Mädchen, bei dem ein Ovarialtumor Grund für das Auftreten einer PPP war.

Fall. Ein 2,5 Jahre altes Mädchen wurde an der endokrinologischen Ambulanz vorgestellt. Die Mutter berichtete von Brustwachstum seit einem Monat. Im Status weiter auffällig: Scham- und Achselbehaarung. In der Sonographie der Brust war vergrößertes Brustdrüsengewebe darstellbar. Im LH-RH-Test waren bei erhöhten Androgenen und Östrogenen, FSH oder LH nicht stimulierbar. Bei einer Kontrolle 3 Wochen später beschrieb die Mutter Blutspuren in der Windel. Im Status jetzt zusätzlich auffällig eine leicht vorgewölbte Bauchdecke mit palpabler derber Masse im Unterbauch. In der Abdomen-Sonographie darstellbar war ein Uterus mit hohem Schleimhautaufbau und am Beckeneingang eine $10 \times 12 \times 5 \mathrm{~cm}$ messende inhomogene, gut begrenzte Expansion. Im Hormonlabor zeigten sich erhöhte Inhibine und als Tumormarker eleviertes NSE. Nach MRT und PET-CT zum Ausschluss einer atypischen Präsentation eines McCune-Albright-Syndroms, wurde der später histologisch verifizierte juvenile Granulosazelltumor des linken Ovars operativ entfernt.

Konklusion und Diskussion. Die Pubertas Praecox wird zu $1 \%$ durch einen Granulosazelltumor verursacht. Zur Diagnose führt meist die Trias aus palpabler Masse im Unterbauch und erhöhten Serumöstrogenwerten bei niedrigen Gonadotropinen. Prognose bestimmend ist das Tumorstadium bei Diagnose. Um ein diagnostisches Fenster zu vermeiden, ist bei Brustdrüsenschwellung eine Sonographie der Brustdrüse und des Abdomens standardmäßig gefordert.

\subsection{Fulminante Alveolitis Necroticanc durch Bordetella pertus-} sis

\section{Heher, C. Weitzer, W. Müller}

Medzinischische Universität Graz, Universitätsklinik für Kinder- und Jugendheilkunde

Einleitung. Bordetella pertussis (BP) ist Erreger krampfartigen Hustens, der bei ungeimpften Säuglingen fulminant verlaufen kann. Keuchhusten ist Ursache von über 200.000 kindlichen Todesfällen jährlich. Wir präsentieren ein Mädchen, dass in der 10. Lebenswoche noch vor der ersten Teilimpfung mit BP infiziert wurde.

Fall. Die Erstvorstellung des kleinen Mädchens erfolgte aufgrund Rhinitis und obstruktiver Bronchitis, eine stationäre Aufnahme wurde abgelehnt. Nach 5 Tagen wurde der Säugling wieder an die Ambulanz gebracht. Diesmal präsentierte er sich in reduziertem Allgemeinzustand, im Thorax-Röntgen wurden großflächige Infiltrate dargestellt. Aufgrund rasch progredienter Verschlechterung erfolgten die Intubation und eine Transferierung an unsere Intensivstation. Schließlich wurde die kleine Patientin mit einer extrakorporalen Membranoxygenierung versorgt. In Nasensekret und Bronchialsekret wurde als Erreger BP identifiziert. In sonographischen Untersuchungen konnten unterbelüftete und minderperfundierte Areale, später Nekrosezonen in der Lunge der kleinen Intensivpatientin, sowie große Ergüsse nachgewiesen werden. Eine pathologische Nierenperfusion im Ultraschall bestätigte den laborchemischen Hinweis auf ein beginnendes Nierenversagen, als weitere Komplikation wurde eine Dünndarminvagination aufgezeigt.

Konklusion. Die fulminant verlaufende BP ist charakterisiert durch Leukozytose, nekrotisierende Bronchiolitis, Hämorrhagie und Ergüs- se, welche bei Säuglingen eine intensivmedizinische Versorgung nötig machen. An der Intensivstation stellt die Sonographie als dynamische, minimalinvasive Untersuchung eine der unverzichtbaren Untersuchungsmethoden dar.

\subsection{Ovarialtorsion bei einem präpubertären Mädchen getarnt als unklare abdominelle Beschwerden}

M. Höller, F. Weitzer, C. Weitzer

Kinderklinik Graz, Medizinische Universität Graz

Einleitung. Ovarialtorsionen sind im Kindesalter selten und werden oft mit anderen Krankheitsbildern verwechselt. Der akute oder chronische Unterbauchschmerz ist ein typisches Symptom. Differenzialdiagnostisch kommen Appendizitis, Obstipation, Ileus, Nierensteine, Pyelonephritis oder eine rupturierte Ovarialzyste in Frage. Bei der Ovarialtorsion kommt es initial zu einem Stau der venösen und lymphatischen Gefäße und führt schließlich, falls nicht rechtzeitig entlastet, zum arteriellen Stau. Konsekutiv wird das Ovar rasch nekrotisch und gangränös, was letztlich zur Peritonitis führt.

Fall. Ein 10,5-jähriges Mädchen klagte zu Hause am Abend vor der ambulanten Vorstellung bei uns über starke Bauchschmerzen. Am Vorstellungstag wurde zunächst die Ambulanz einer auswärtigen, chirurgischen Abteilung aufgesucht. Dort wurde eine Sonographie des Abdomens durchgeführt und als unauffällig befundet. Zur weiteren Abklärung verwies man von dort an unsere Kinderklinik. Bei uns bot die Patientin einen starken, streng begrenzten Druckschmerz median im Unterbauch oberhalb der Symphyse. Deshalb wurde eine erneute sonographische Unersuchung veranlasst, bei der sich obige Diagnose ergab. Beim Bildvergleich mit den auswärtigen Bildern zeigte sich, dass die genialen Organe hinter der Harnblase aufgrund von Schallverstärkung durch die volle Blase nicht dargestellt werden konnten, und somit auch nicht beurteilt werden konnten. Trotzdem wurden sie von auswärtigen Sonographeur als normal beurteilt!

Konklusion. Die Sonographie als diagnostische Maßnahme bei abdominellen Beschwerden ist hoch sensitiv. Daher ist ihr Einsatz als schnell zugängliche und unkomplizierte Methode auch in zentrumsfernen Ambulanzen wünschenswert und empfohlen. Jedoch muss auch dort der diagnostische Standard durch regelmäßige Anwendung und Übung aufrecht erhalten bleiben, um die hohe Sensitivität gewährleisten zu können.

\subsection{Vorwölbung im rechten Unterbauch bei einem jungen Säugling}

\section{N. Memaran, G. Zoder, J. Berger, A. Lischka}

Kinderklinik Glanzing im Wilhelminenspital der Stadt Wien

Wir berichten über einen 2 Monate alten männlichen Säugling mit Gedeihstörung, sowie einer Schwellung im rechten Unterbauch. Als weitere Symptome waren Kryptorchismus rechts, glanduläre Hypospadie, Zungengrundzyste, sowie diskrete Dysmorphiezeichen (Ohrmuscheldeformität, weiter Mamillenabstand) festzustellen. Sonographisch stellt sich die Vorwölbung als ektop in der ventralen Bauchwand gelegener rechter Hoden und Nebenhoden dar, die durch die begleitende Hydrocele besonders deutlich abgrenzbar waren.

Ein subkutan in der ventralen Bauchwand gelegener ektoper Hoden ist sehr selten. Differentialdiagnostisch kommt eine Spigel'sche Hernie in Betracht, die im Kindesalter eine Rarität ist. Eine Assoziation der Spigel'schen Hernie bei Kindern mit ipsilateralem Kryptorchismus wird berichtet, so dass bei diesen Patienten ein neues kongenitales Syndrom diskutiert wird. Sonographisch erscheinen Muskel und Aponeurose intakt, endgültige Klärung wird die Operation bringen. 


\subsection{Katheter - ein sonographisches Thema?}

S. Reithmayr, G. Zoder, D. Endress, A. Ramasani, A. Lischka

Kinderklinik Glanzing der Stadt Wien

Nach wie vor ist die radiologische Lagekontrolle zentraler Gefäßkatheter Standardmethode. Zumindest bei Anlage von Nabelvenenkathetern scheint dies jedoch nicht gerechtfertigt: Oft gleitet die Katheterspitze vom Recessus umbilicalis ausgehend in einen kranialen Portalvenenast, statt durch den Ductus venosus in das rechte Atrium. In der a.p.-Projektion lässt sich diese typische Fehllage oft nicht erkennen, die Folge: Durch Infusion von (Nor)Adrenalin, Kalzium oder hochosmolaren Substanzen kann es zu Lebernekrosen kommen. Durch sonographische Lagekontrolle kann diese Komplikation vermieden werden: die Lokalisation der Katheterspitze im rechten Atrium lässt sich durch die Turbulenzen eingespritzter Kochsalzlösung per Videoclip dokumentieren, ebenso lässt sich die exakte Vermessung zur Positionskorrektur durchführen.

Auch die Lage anderer zentraler Gefäßkatheter sowie die endotrachealer Tuben kann sonographisch erfasst und somit unnötige Strahlenbelastung vermieden werden. Die sonographische Darstellung der Katheterspitzen (proximal und distal) von ventriculoperitonealen/atrialen Shunts bei Hydrocephalus gehört schon zur Routine. Auch die Darstellung eines liegenden Blasenkatheters kann bei bestimmten Fragestellungen sinnvoll sein.

Eine wesentliche Aufgabe der Sonographie ist es, bei eingetretenen Katheterkomplikationen die Schäden (Nekrosen) zu erfassen und drohende Gefahren (Thrombosen) durch rechtzeitige Therapie (Heparinisierung) abzuwenden.

Fazit. Die sonographische Katheterdarstellung kann die Patientensicherheit durch Vermeiden von Komplikationen und Verminderung der Strahlenbelastung erhöhen.

\subsection{Die Doppelniere - eine Anomalie mit vielen Facetten}

\section{G. Zoder}

\section{Kinderklinik Glanzing, Wilhelminenspital der Stadt Wien}

Doppelnieren treten oft bilateral auf und zählen zu den häufigsten Fehlbildungen des oberen Harntraktes. Neben einer Zweiteilung des Nierenhohlsystems können sich einerseits beide Ureteren vor Einmündung in die Harnblase im Sinne eines bifiden Systems teilen. Eine komplette Doppelbildung besteht, wenn beide Ureteren getrennt voneinander in die Blase münden. Erfolgt die Ureterenmündung orthotop innerhalb des Trigonums, ist durch die normale antirefluxive Funktion ein asymptomatischer Verlauf zu erwarten.

Die pathologische Doppelniere stellt eine potentielle Gefahr für den Patienten dar. Schlüssel zum Verständnis der komplexen möglichen assoziierten Anomalien der ableitenden Harnwege ist die Kenntnis der embryonalen Fehlentwicklungsmöglichkeiten. Die Ostienpathologie ist von essentieller Bedeutung für das Entstehen eines primären vesikoureterealen Refluxes (VUR); dieser betrifft in 50\% den unteren Nierenpol. Das Ausmaß der Lateralisation des kranial ektop mündenden Unterpolureters korreliert mit dem Schweregrad des Refluxes. Seltener sind beide Ureteren oder der obere Anteil des Duplexsystems refluxiv; Voraussetzung dafür sind auch hier ektop mündende Ureteren. Folge einer Ektopie sind Oberpolsdysplasien, die in ihrer extremsten Ausprägung in einem kompletten Funktionsverlust münden Potentiell komplizierend sind Ureterocelen, die in $60-80 \%$ in ektoper Lage zu finden sind. Große Ureterocelen können obstruieren, und sogar auf der kontralateralen Seite ein Abflusshindernis darstellen.

Es soll ein Überblick über Doppelnieren mit ihren variantenreichen sehr oft komplexen Begleitanomalien der ableitenden Harnwege gegeben werden. Zielsetzung ist die Vermeidung rezidivierender, schwerer Harnwegsinfekte, um die Nierenfunktion zu erhalten und um Spätschäden zu vermeiden bzw. zu minimieren.
20 Sport

20.1 Prävalenz von EKG-Auffälligkeiten bei sporttreibenden Kindern und Jugendlichen

\section{K. Niedermayr, N. Genser}

Schwerpunktpraxis Kinderkariologie und Sportmedizin

Einleitung. Es wird oft diskutiert, ob ein EKG im Rahmen von Sporttauglichkeitsuntersuchungen sinnvoll ist.

Methoden. In einer kinderkardiologischen Praxis wurden alle konsekutiv aufgezeichneten EKGs bei 6- bis 18-Jährigen analysiert. EKGIndikationen: A. Nichtkardiologisch (OP- oder Sporttauglichkeit, Adipositas, Anorexie/Dystrophie). B. Kardiologisch (Systolikum, Arrhythmien, Synkopen, Pektangina); EKG-Interpretation: 1. Unauffällig oder Normvarianten (respiratorische Sinusarrhythmie, vereinzelte SVES) 2. kontrollbedürftige EKG-Auffälligkeiten: AV-Arrhythmien, VES, Überleitungsstörungen (verlängerte PQ-/grenzwertige QT-Zeiten, Delta-Welle etc.) 3. EKG-Auffälligkeiten \pm Symptome (Hinweis für Ventrikelhypertrophie oder Myokarditis, Long-QT-Syndrom, Tachyarrhythmien, unter Belastung zunehmende VES), die eine klinische Konsequenz (Schonung, Sportverbot) oder medikamentöse Therapie zur Folge hatten.

Ergebnisse. Von insgesamt 1010 Patienten fanden wir 25 mit AVBlock $^{\circ} 1,29$ mit transientem AV-Knotenersatzrhythmus, 72 mit auffälliger QT-Zeit und 23 mit benignen VES. Jeweils ein Patient wurde wegen hämodynamisch wirksamen ASD bzw. VSD operiert und ein Geschwisterpaar erhielt aufgrund rezidivierender Synkopen bei katecholaminsensitiver Tachyarrhythmie einen intrakardialen Defibrillator. Um die Prävalenz von auffälligen EKGs bei Sportlern (SP, n=253) $\mathrm{zu}$ analysieren, wurden sie mit drei Kontrollgruppen verglichen: 1 . nichtkardiologische Gründe (NK, n=249), 2. Patienten mit Systolikum $\left(K_{1}, \mathrm{n}=249\right)$, 3. andere kardiologische Gründe $\left(K_{2}, \mathrm{n}=236\right)$. Kontrollbedürftige EKGs fanden wir bei $12 \%(n=31)$ der SP vs. $16 \%(n=39)$ bei NK, $10 \%(n=24)$ bei K1 und 22\% $(n=53)$ bei K2.

Diskussion. Obwohl kardiologische Patienten mehr kontrollbedürftige EKG-Auffälligkeiten zeigten, war die Prävalenz bei Sportlern gleich häufig wie bei Patienten, die zur kardiologischen Abklärung eines Systolikums u. ä. zugewiesen wurden. Daher halten wir ein EKG bei Sporttauglichkeitsuntersuchungen für gerechtfertigt.

\section{Stoffwechsel}

\subsection{LPIN1-Genmutation als Ursache schwerer Rhabdomyolysen im frühen Kindesalter}

\section{F. Ertle' ${ }^{1}$, R. Bittner ${ }^{2}$, R. Birnbacher ${ }^{1}$}

${ }^{1}$ Abteilung für Kinder- u. Jugendheilkunde, LKH Villach, ${ }^{2}$ Abteilung für Angewandte Anatomie, Medizinische Universität Wien

Einleitung. Autosomal rezessive Mutationen in LPIN1 wurden jüngst als eine Ursache für im Kindesalter beginnende rezidivierende Rhabdomyolysen (RM) beschrieben. Zumeist liegen Defekte in der mitochondrialen Fettsäureoxidation (FSO), der Atmungskette (AK) und/oder Störungen der Glykogenolyse vor. Lipin-1 ist ein 890 AS umfassendes Protein, welches hauptsächlich in Muskel- und Fettgewebe exprimiert wird. Es besitzt eine Doppelfunktion als Phosphatidat-Phosphatase 1 (PAP) für die Triacylgycerol- und Phospholipid-Biosynthese und als TranskriptionsCo-Aktivator durch seine Assoziation mit PPARa und PGC-1a zur Regulation der Genexpression von Enzymen der FSO und AK. Die Expression von LPIN1 ist darüber hinaus wichtig für die Differenzierung und Funktion von Adipozyten. Lipin-1 besteht aus zwei hochkonservierten Domänen, einer N-LIP-Domäne, deren Funktion unbekannt ist, und einer CLIP-Domäne, welche das DXDXT-Motiv für die PAP-Aktivität und das LXXIL-Motiv für die nukläre Rezeptorbindung beinhaltet. 
Fallbericht. Im 4. Lebensjahr kam es bei dem bisher gesunden Jungen im Rahmen eines gastrointestinalen Infektes zu der ersten schweren RM mit Myoglobinurie. Ein knappes Jahr später trat im Rahmen eines respiratorischen Infekts eine erneute RM auf. Nach eine symptomfreien Intervall von zwei Jahren kam es erneut in Prodomalstadien von Infekten zu rezidivierenden RM. Eine letzte, milder verlaufende RM trat nach exzessiver sportlicher Aktivität auf. Nach unauffälligen Befunden in den Untersuchung des Metabolismus inklusive Studien in Muskelzellen und Fibroblasten konnte letztendlich eine Mutation nachgewiesen werden.

Schlussfolgerung. In den seltenen Fällen einer schweren Rhabdomyolyse im Kindesalter sollte an einen Lipin-1 Defizienz gedacht werden. In einer Kohorte lag eine solche bei $59 \%$ der Kinder mit einer solchen RM vor. Nach Ausschluss einer Störung der FSO bietet sich eine Genanalyse vor einer Muskelbiopsie bzw. Fibroblastenkultur zur Diagnosestellung an.

\subsection{Historischer Rückblick auf die Entwicklung der Diagnostik und Therapie von Mukopolysaccharidosen}

S. Kircher

Institut für Medizinische Chemie und Institut für Medizinische Genetik, Zentrum für Pathobiochemie und Genetik, Medizinische Universität Wien

Die Mukopolysaccharidosen (MPS) bilden mit 11 krankheitsverursachenden Enzymdefekten die größte Gruppe der lysosomalen Speichererkrankungen. Schon 1835, als Charles Darwin auf der HMS Beagle gerade die Welt umsegelte, wurden MPS-Patienten nachweislich in einem Reisebericht von Washington Irving beschrieben, doch erst vor etwa hundert Jahren sind die ersten Fachpublikationen durch den schottischen Arzt Charles Hunter und den Österreicher Prof.Meinhard von Pfaundler und seiner deutschen Kollegin Gertrude Hurler veröffentlicht worden. Während es zu Beginn eher die klinischen und radiologischen Auffälligkeiten waren die zur Diagnose führten, bekannt als „Gargoylismus" und „Dysostosis multiplex“, so wurden erst in den letzten 50 Jahren nach und nach die biochemischen Grundlagen und Enzymdefekte erkannt. Die Möglichkeiten der Molekulargenetik haben erst in den letzten Jahren zur Identifizierung aller beteiligten Genloci geführt. Damit wurde die Diagnostik der Patienten, aber auch die Möglichkeiten einer vorgeburtlichen Diagnose wesentlich verbessert. Gerade die zuverlässige enzymatische und molekulargenetische Diagnostik hat es ermöglicht, Patienten mit milderen Verlaufsformen von MPS zu erkennen, welche früher aufgrund der untypischen Symptomatik wahrscheinlich nicht erkannt wurden. Während zu Beginn die Therapie bestenfalls eine symptomatische war, hat das Verständnis um den Transport der Enzyme aus und in die Körperzellen dazu geführt, fehlende Enzyme mittels Knochenmarks- bzw. hämatopoetischer Stammzelltransplantation zuzuführen. Eine Zufuhr fehlender Enzyme in Form einer kontinuierlichen Enzymersatztherapie ist seit wenigen Jahren für einzelne MPS-Formen möglich. Alle Therapieformen sind umso effektiver, je früher sie begonnen werden. Daher wird zur Zeit an Screeningmethoden, selektiv oder im Rahmen des Neugeborenenscreenings, geforscht.

\subsection{Neue Mutation des mitochondrialen ATP6-Gens bei einem Säugling mit cerebralen Krampfanfällen und hypertropher Kardiomyopathie}

J.Koch ${ }^{1}$,J.A.Mayr ${ }^{1}$,F.Baumgartner ${ }^{2}$,C.Rauscher ${ }^{1}$,F.A.Zimmermann ${ }^{1}$,W.Sperl ${ }^{1}$ ${ }^{1}$ Universitätsklinik für Kinder- und Jugendheilkunde, Paracelsus Medizinische Privatuniversität Salzburg, ${ }^{2}$ Abteilung für Kinder- und Jugendheilkunde, Kardinal Schwarzenberg'sches Krankenhaus Schwarzach

Wir berichten über einen Knaben, viertes Kind gesunder, nichtkonsanguiner Eltern, Geburt 39. SSW, Apgar 9/10/10, Geburtsgewicht $2155 \mathrm{~g}$, Länge $47 \mathrm{~cm}$, Kopfumfang $32,5 \mathrm{~cm}$. Im Alter von 7 Monaten kam er stationär zur Abklärung wegen muskulärer Hypotonie, Dystrophie und motorischer Entwicklungsverzögerung. Als auffällige Befunde zeigten sich echokardiographisch eine linksventrikuläre Hypertro- phie, konstant erhöhte Laktatwerte (4-5 mmol/l) und im MRI des ZNS fand sich eine Erweiterung der äußeren sowie deutlich basal betonte Erweiterung der inneren Liquorräume bei altersentsprechender Myelinisierung und regelrechter Darstellung der Stammganglien. In der Folge entwickelte sich beim Knaben auch eine partielle Hypsarrhythmie. In der Muskelbiopsie im Alter von 8 Monaten fand sich in der funktionellen Untersuchung des mitochondrialen Energiestoffwechsels eine auffällige Ratio der ADP-vs. CCCP-stimulierten Atmung als Hinweis für eine Störung der ATP Synthese. In der Messung einzelner Enzyme fand sich eine moderate Verminderung der Oligomycin-sensitiven ATPase Aktiviät. Eine genetische Untersuchung der mitochondrial codierten Untereinheiten zeigte eine Mutation m.9134A>G p.Glu203Gly im ATP6 Gen. Der Anteil der mutierten Form betrug ca. 90\% im untersuchten Muskelgewebe. Diese Mutation betrifft eine phylogenetisch hochkonservierte Aminosäure und wurde bisher noch nicht beschrieben.

Zusammenfassend finden wir eine neue Mutation im ATP6 Gen der $\mathrm{F}_{1} \mathrm{~F}_{\mathrm{o}}$-ATP Synthase bei einem Säugling mit Laktatazidose, Entwicklungsverzögerung, Epilepsie und linksventikulärer Kardiomyopathie. Bei der häufigeren Mutation T8993G im ATP6 Gen, die vor allem bei maternalem Leigh Syndrom bekannt ist, wurden auch kürzlich zwei weitere unabhängige Patienten mit neonataler Kardiomyopathie gefunden [Freisinger et al. J Inherit Metab Dis (2010) 33 (Suppl 1):S939]. Bei hypertropher Kardiomyopathie in der Neugeborenenperiode sind daher nukleäre Defekte der ATP Synthese (ATP5E, TMEM7o, $\mathrm{SLC}_{25} \mathrm{~A}_{3}$ ) aber auch Mutationen der $\mathrm{F}_{\mathrm{o}}$ Untereinheit der ATP-Synthase differentialdiagnostisch in Betracht zu ziehen.

\subsection{Erste Lebertransplantation bei Zitrullinämie Typ I in Österreich}

A. Roscher', J. Becker ${ }^{2}$, W. Huber ${ }^{2}$, B. Bidmon-Fliegenschnee ${ }^{2}$, F. Mühlbacher $^{3}$, R. Ratschmann ${ }^{1}$, M. Herle ${ }^{1}$, D. Möslinger ${ }^{1}$, V. Konstantopoulou ${ }^{1}$

${ }^{1}$ Abteilung für pädiatrische Pulmologie, Allergologie und Endokrinologie, Medizinische Universität Wien, ${ }^{2} \mathrm{Abteilung}$ für pädiatrische Nephrologie und Gastroenterologie, Medizinische Universität Wien, ${ }^{3}$ Abteilung für Transplantation, Medizinische Universität Wien

Harnstoffzyklusdefekte werden üblicherweise konventionell medikamentös und diätetisch behandelt. Die Langzeitprognose, insbesondere bei neonatalem Beginn, geht jedoch weiterhin mit einer hohen Mortalitätsrate sowie mit der Entwicklung neurologischer Defizite einher. In den letzten Jahren etablierte sich international die Lebertransplantation als eine erfolgreiche Therapieoption. Bei transplantierten Patienten zeigte sich eine Verbesserung des neurologischen Outcome und der Lebensqualität. Die kumulative 5-Jahres-Überlebensrate beträgt derzeit über $90 \%$.

Von den seit April 2003 durch das österreichische Neugeborenenscreening identifizierten Patienten mit erhöhter Zitrullinkonzentration im Trockenblut präsentierte sich nur 1 Patient mit dem klassischen neonatalen Beginn. Vor Erhalt des Screeningergebnisses kam es am 4. Lebenstag zu einer milden Hyperammonämie von $590 \mu \mathrm{mol} / \mathrm{l}$ bei einer Zitrullinkonzentration im Plasma von $2384 \mu \mathrm{mol} / \mathrm{l}$ (Ref. <35). Unmittelbar nach Diagnosestellung wurde den Eltern die Möglichkeit einer Leber- bzw. Leberzelltransplantation vorgeschlagen. Trotz guter Therapiecompliance kam es rezidivierend zu metabolischen Krisen wodurch mehrmalige stationäre Aufenthalte erforderlich waren.

Im Alter von 8 Monaten erfolgte die Listung zur orthotopen Lebertransplantation welche im Alter von 13 Monaten komplikationslos durchgeführt werden konnte. Innerhalb von 3 Wochen kam es zu einer akuten Abstoßungsreaktion welche jedoch mit Umstellung der immunsuppressiven Therapie sowie Cortison-Stoßtherapie gut behandelt werden konnte. Seit der Lebertransplantation kam es zu keinen weiteren metabolischen Krisen, die Zitrullinkonzentration im Plasma ist 2 Tage danach um die Hälfte abgefallen und beträgt aktuell $306 \mu \mathrm{mol} / \mathrm{l}$. Die entwicklungspsychologische Diagnostik im Alter von 19 Monaten ergab eine altersentsprechende psychomotorische Entwicklung sowie deutliche Verbesserung der Lebensqualität. 
Konklusion. Der klassische neonatale Beginn der Zitrullinämie Typ I weist in der Regel eine schlechte Langzeitprognose auf. Zur Vermeidung residualer neurologischer Defizite stellt die frühzeitige Lebertransplantation die Therapie der Wahl dar. Unser Patient ist der erste Fall in Österreich bei dem diese Therapie erfolgreich durchgeführt wurde.

\subsection{Panzytopenie und Hepatosplenomegalie als initiale Weg- weiser für das Vorliegen einer Sphingolipidose - ein Fallbericht}

S. Samueli', U. Habeler', G. Mann'1, V. Konstantopoulou ${ }^{2}$

${ }^{1}$ St. Anna Kinderspital, UKKJ, MUW, Wien, Österreich, ${ }^{2}$ Univ. Klinik für Kinder- und Jugendheilkunde, MUW - AKH Wien, Österreich

Einleitung. Morbus Niemann-Pick Typ A (NPA) und B (NPB) sind autosomal rezessiv vererbte Stoffwechselerkrankungen, die auf einer mangelnden Aktivität des Enzyms saure Sphingomyelinase beruhen und mit einer pathologischen Speicherung von Sphingolipiden in Organen einhergehen. Der NPA hat eine infauste Prognose, durch die Sphingolipidspeicherung im ZNS kommt es innerhalb der ersten 3 Lebensjahre zu einer raschen neurologischen Verschlechterung und zum Tod. Bei NPB konzentriert sich die Symptomatik auf das respiratorische System, die Kinder erreichen meist das junge Erwachsenenalter. Fallbericht. Ein 14 Monate altes Mädchen wird mit hohem Fieber, Panzytopenie, Bauchschmerzen, Gedeihstörung, Entwicklungsverzögerung und Hepatosplenomegalie zur Abklärung vorgestellt. Die initial durchgeführte Abdomensonographie bestätigte die Hepatosplenomeglie. Echokardiographie, EKG und $\mathrm{C} / \mathrm{P}$ waren unauffällig. Im neurologischen Status erhärtete sich der Verdacht auf eine Speichererkrankung und es erfolgte eine umfassende laborchemische Abklärung. Den pathognomonischen Hinweis ergab die Knochenmarkspunktion. Es fanden sich für Lipidspeichererkrankungen typische Speicherzellen, am ehesten im Sinne eines NP A/B und nicht eines Mb. Gaucher. Die augenärztliche Untersuchung bestätigte diesen Verdacht, da ein kirschroter Fleck bds. nachgewiesen werden konnte. Die Aktivität der sauren Sphingomyelinase in Leukozyten ließ sich nicht nachweisen und die der Glukocerebrosidase lag im Normbereich. Somit konnte das Vorliegen von Mb. Gaucher ausgeschlossen werden. Die Diagnose NP konnte auch molekulargenetisch bestätigt werden. Der bisherige klinische Verlauf weist eher auf das Vorliegen eines Typ B. Derzeit ist nur eine symptomatische Therapie möglich. Eine Enzymersatztherapie ist in Entwicklung.

\subsection{Ketonkörper-Konzentrationen im Nabelschnurblut von gesunden Neugeborenen}

S. Scholl-Bürgi, R. Philippitsch, P. Wondrak, D. Karall

Medizinische Universitätsklinik Innsbruck, Department für Kinder- und Jugendheilkunde, Univ.-Klinik für Pädiatrie IV

Einleitung. Die Ketonkörper Acetoacetat und $\beta$-Hydroxybutyrat können als Substrate der Energiegewinnung dienen. Insbesondere im Neugeborenenalter könnte dies im Rahmen von Hypoglykämien bedeutend sein.

Ziel der Studie. Bestimmung der Acetoacetat- und $\beta$-Hydroxybutyrat-Konzentrationen im Nabelschnurblut von gesunden Neugeborenen (Erstellung von Referenzwerten).

Material und Methode. Im Serum aus Nabelschnurblut von 82 gesunden Neugeborenen wurden die Acetoacetat- und $\beta$-HydroxybutyratKonzentrationen mittels einer adaptierten manuellen zyklisch-enzymatischen Methode (Wako Autokit $\beta$-Hydroxybutyrate/Total-Keton Bodies, FA Wako) bestimmt. Die photometrische Messung erfolgte bei $405 \mathrm{~nm}$ (UV-Visible Spektralphotometer CARY $1 \mathrm{E}$, Varian).

Ergebnisse. Im Serum aus Nabelschnurblut lagen die $\beta$-Hydroxybutyrat-Konzentrationen bei $286 \mu \mathrm{mol} / \mathrm{l}$ (Range 22-929; Median 212; SD 234), die Acetoacetat-Konzentrationen bei $36 \mu \mathrm{mol} / \mathrm{l}$ (Range 2-190; Median 26; SD 32) und das Verhältnis von --Hydroxybutyrat zu Acetoacetat bei 20 (Range 2-382; Median 7; SD 49).
Schlussfolgerung. Die $\beta$-Hydroxybutyrat-Konzentrationen von gesunden Neugeborenen waren höher als die von Erwachsenen (Referenzbereich 56-164 $\mu \mathrm{mol} / \mathrm{l})$. Des Weiteren war das Verhältnis von $\beta$ Hydroxybutyrat zu Acetoacetat und der Range von allen Parametern deutlich höher. Dies ist ein Hinweis, dass nach der Geburt im Stoffwechsel eines gesunden Neugeborenen mehr $\beta$-Hydroxybutyrat gebildet wird und vermehrt als Glukose-Ersatzstoff zur Energiegewinnung zur Verfügung steht.

\section{Young investigators corner}

\subsection{Welchen Einfluss hat Sport auf Muskelfunktionen und "Lifestyle" bei Kindern und Jugendlichen?}

\section{K. Niedermayr ${ }^{1}$, N. Genser', G. Gräss|2 , D. Karall ${ }^{3}$}

${ }^{1}$ Schwerpunktpraxis Kinderkardiologie und Sportmedizin, ${ }^{2}$ Schwerpunktpraxis Kinderlungenerkrankungen und Allergien, Hall in Tirol, ${ }^{3}$ Department für Kinder- und Jugendheilkunde, Pädiatrie IV (Neonatologie, Neuropädiatrie und angeborene Stoffwechselstörungen), Medizinische Universität Innsbruck

Hintergrund. Muskeldysfunktionen kommen bei sporttreibenden Kindern und Jugendlichen häufiger vor als vermutet, wobei übergewichtige bzw. adipöse Sportler signifikant öfter Muskeldysfunktionen aufweisen. Regelmäßig betriebener Vereinssport könnte sich positiv auf den Muskelstatus auswirken und auch Grund für ein verändertes „Lifestyle“-Verhalten sein.

Methoden. Wir verglichen Muskelfunktionen bei 160 Vereinssportlern (122 Knaben, 38 Mädchen) von 6 bis 18 Jahren (im Mittel 11,3), wovon 15 übergewichtig bzw. adipös waren $(S P, B M I=22,1 \pm 3,3)$, mit denen von 15 adipösen Probanden, die keinen regelmäßigen Sport betrieben (NonSP, BMI 27,2 $\pm 6,5$ ). Fünfzehn Muskelgruppen wurden auf Abschwächung (Schulterblattfixatoren, Bauchmuskulatur, M. glutaeus medius, minimus und maximus, Rückenextensoren) oder Verkürzung (M. triceps und biceps brachii, Unterarmflexoren und -extensoren, M. iliopsoas, M. rectus femoris, Ischiocrurale, Wadenmuskulatur) getestet. Ein eigens gestalteter Fragebogen erhob zusätzlich Medienkonsum (PC/TV) sowie Bewegungs- und Essverhalten.

Ergebnisse. NonSP hatten signifikant mehr Muskeldysfunktionen als übergewichtige SP $(\mathrm{p}<0,001)$, schauten im Mittel viel länger fern (TV; $\mathrm{p}<0,001)$, bewegten sich in ihrer Freizeit signifikant weniger $(\mathrm{p}<0,001)$ und aßen mehr fett- und kohlehydratreiche Kost $(\mathrm{p}=0,01)$. Ähnliche Signifikanzen ergaben sich im Vergleich mit normalgewichtigen Sportlern. Schlussfolgerung. Regelmäßig Vereinssport zu betreiben hat bei übergewichtigen bzw. adipösen Kindern und Jugendlichen nicht nur einen günstigen Einfluss auf Gewicht und BMI, sondern auch auf Freizeit- und Essverhalten. Weiters verhilft Sport auch zu einer signifikanten Reduktion von Muskeldysfunktionen, welche häufig zu Verletzungen und auch bleibenden Schäden führen können.

\subsection{Der diagnostische Wert von Interleukin 6 bei der neonatalen Sepsis}

K. Biller', B. Simma ${ }^{2}$, C. Huemer ${ }^{3}$, A.K. Walli ${ }^{4}$, P. Fraunberger ${ }^{1}$

${ }^{1}$ Medizinisches Zentrallabor Feldkirch, ${ }^{2}$ Abteilung für Kinder- und Jugendheilkunde, Landeskrankenhaus Feldkirch, ${ }^{3} \mathrm{Abteilung}$ für Kinder- und Jugendheilkunde, Landeskrankenhaus Bregenz, ${ }^{4}$ Institut für klinische Chemie, Klinikum Großhadern, Klinikum der Universität München

Hintergrund und Ziel. Obwohl die Therapiemöglichkeiten und -richtlinen der neonatalen Sepsis in den letzten Jahren zugenommen haben und deutlich verbessert wurden, ist die Diagnose der neonatalen Sepsis aufgrund vielfältiger und unspezifischer Symptome immer noch schwierig. Ziel der Studie war zu prüfen, ob der Interleukin-6(IL-6)-Spiegel als früher und spezifischer Marker einer neonatalen Sepsis geeignet ist und zur Verbesserung der Differentialdiagnose beitragen kann. 
Methoden. Im Plasma von 87 Neugeborenen, die auf neonatologischen Intensivstationen den klinischen Verdacht einer Sepsis boten, wurde die Konzentration von IL- 6 bestimmt. Gleichzeitig wurden Daten zur Geburt, dem Alter, der Liegedauer, der Mortalität, Kreislaufparameter, Diagnosen, mikrobiologischen Befunde, dem klinischen Verlauf und der Therapie erhoben und in Zusammenschau aller Befunde festgelegt, ob eine Neugeborenensepsis vorlag. Der klinische Verdacht einer Sepsis wurde durch folgende Symptome definiert: Tachypnoe, doppelte Anzahl an Apnoen oder Bradykardien im Vergleich zum Vortag, Nasenflügeln, Stöhnen, interkostale Einziehungen, Marmorierung, Zentralisation, Zyanose, Rekapilarisierungszeit $>2$ Sekunden, Fieber bzw. Temperaturinstabilität, Lethargie oder Irritabilität. Die gemessenen Interleukinwerte wurden mit dem Gesundheitszustand der Neugeborenen korreliert.

Ergebnisse. Die erste Auswertung der Daten zeigt einen signifikanten Unterschied $(\mathrm{p}<0,05)$ zwischen den IL-6-Spiegeln der Kinder mit und ohne neonataler Sepsis. Der mediane IL-6-Wert der Kinder ohne Sepsis liegt bei $16,15 \mathrm{pg} / \mathrm{ml}$, der mit Sepsis bei 192,5 pg/ml. Verlaufsuntersuchungen zeigen einen frühen IL-6-Anstieg.

Schlussfolgerung. Interleukin 6 ist zur frühen und spezifischen Diagnose einer neonatalen Sepsis geeignet. Durch weitere Auswertungen kann möglicherweise ein Cut-off oder zumindest eine „Ampel“ zu Diagnose einer Neugeborenensepsis definiert werden.

\subsection{Bronchiale Reagibilität und Adipositas bei Kindern und Jugendlichen}

P.Gruber

Einleitung. In den letzten Jahrzehnten war bei Kindern und Jugendlichen ein zunehmender Anstieg von Asthma bronchiale und Adipositas zu verzeichnen. Derzeit leiden in Österreich ca. 10\% aller Kinder und Jugendlichen an Asthma bronchiale bzw. sind 5\% übergewichtig oder adipös. Zahlreiche Studien zeigen eine Verbindung zwischen diesen beiden Gesundheitsstörungen, andere wiederum nicht.

Zielsetzung. In dieser Arbeit sollte untersucht werden, ob es einen etwaigen Zusammenhang zwischen bronchialer Hyperreagibilität und Adipositas bei Kindern und Jugendlichen (Altersbereich: 6-20 Jahre) gibt.

Methoden. Es wurden retrospektiv biometrische Daten sowie Lungenfunktionsparameter (Basislungenfunktion und Kaltluftprovokation) von 2226 Patienten erhoben. Anhand der erhobenen Daten wurde der Body-Mass-Index (BMI) jedes Patienten berechnet und danach eine Gruppeneinteilung in Anlehnung an die Perzentilenkurven für den BMI nach Kromeyer-Hauschild et al. vorgenommen. Anschließend wurde für die relevanten Gruppen eine exakte Datenerfassung mit Hilfe der vorhandenen Arztbriefe und Untersuchungsergebnisse durchgeführt.

Ergebnisse. In dieser Studie konnte in der Gesamtpopulation kein signifikanter Zusammenhang zwischen bronchialer Hyperreagibilität und Body-Mass-Index festgestellt werden, ebenso keine Assoziation zwischen der Diagnose Asthma bronchiale und dem Body-Mass-Index. Ein signifikanter Zusammenhang zwischen bronchialer Reagibilität und Body-Mass-Index findet sich bei einer Analyse der Normal- und Übergewichtigen, jedoch nicht der Normalgewichtigen und Adipösen. Nicht überraschend war ein hochsignifikanter Zusammenhang zwischen bronchialer Hyperreagibilität und Atopie.

Schlussfolgerung. Diese Untersuchung zeigte, wie auch andere Studien davor, keinen Zusammenhang zwischen bronchialer Hyperreagibilität und Adipositas. Lediglich in einer Subanalyse zeigte sich bei Betrachtung von Normalgewichtigen und Übergewichtigen eine Korrelation zwischen bronchialer Reagibilität und BMI.

\subsection{Langzeit-Follow-up von Kindern mit kongenitalem Chylothorax}

M. Halmer', W. Müller' ${ }^{2}$,E. Eber' ${ }^{3}$, B. Resch ${ }^{1,2}$

${ }^{1}$ Forschungseinheit für neonatale Infektionserkrankungen und Epidemiologie; Medizinische Universität Graz, Österreich, ${ }^{2}$ Klinische Abteilung für Neonatologie, Univ. Klinik für Kinder- und Jugendheilkunde Graz, Österreich, ${ }^{3}$ Klinische Abteilung für pädiatrische Pulmonologie und Allergologie, Univ. Klinik für Kinder- und Jugendheilkunde Graz, Österreich

Hintergrund. Der kongenitale Chylothorax ist die häufigste Ursache für einen fetalen Hydrothorax. Aufgrund der Seltenheit der Erkrankung wurden nur wenige Fallbeschreibungen in der englisch- und deutschsprachigen Literatur dokumentiert. Insbesondere die mögliche Beeinträchtigung der Lungenfunktion durch den meist schon intrauterin bestehenden Pleuraerguss wurde bisher kaum erarbeitet.

Zielsetzung. Zielsetzung war es, die wichtigsten medizinischen Parameter bezüglich des Krankheitsverlaufs und der weiteren Entwicklung zu beschreiben und mögliche Beeinträchtigungen der Lungenfunktion zu dokumentieren.

Methoden. Die Daten aller Kinder, die in den letzten 15 Jahren an der Universitätsklinik für Kinder- und Jugendheilkunde in Graz mit der Diagnose eines kongenitalen Chylothorax behandelt wurden, wurden retrospektiv ausgewertet. Zur Dokumentation der Entwicklung wurden von April bis August 2010 eine standardisierte telefonische Befragung der Eltern und eine Lungenfunktionsdiagnostik durchgeführt.

Ergebnisse. Sechs Kinder wurden mit kongenitalem Chylothorax dokumentiert. Die pränatale Diagnose wurde bereits in fünf Fällen mittels fetaler Sonographie gestellt. Bei drei wurde eine intrauterine Pleurapunktion durchgeführt. In drei Fällen wurde Octreotid eingesetzt. Eine operative Intervention musste bei einem Säugling durchgeführt werden. Alle Kinder überlebten. Ein Langzeit-Follow-up war bei allen sechs Kindern möglich und erfolgte im Durchschnitt im Alter von sieben Jahren. Drei Kinder leiden an rezidivierenden respiratorischen Infekten, bei einem Kind wurde Asthma diagnostiziert. In einem Fall wurde die Diagnose eines Noonan-Syndroms, bei einem anderen die eines Autismus gestellt. In der Lungenfunktionsuntersuchung zeigte sich bei drei Kindern ein grenzwertig pathologischer Befund.

Zusammenfassung. Der klinische Verlauf und die Prognose sind vorwiegend von den assoziierten Begleiterkrankungen abhängig. In der Lungenfunktionsuntersuchung wurden annähernd normale Ergebnisse dokumentiert.

\subsection{Therapieoptionen bei kongenitalem Chylothorax - ein systematischer Review der Literatur}

\section{Halmer', W. Müller², E. Eber ${ }^{3}$, B. Resch ${ }^{1,2}$}

${ }^{1}$ Forschungseinheit für neonatale Infektionserkrankungen und Epidemiologie; Medizinische Universität Graz, Österreich, ${ }^{2}$ Klinische Abteilung für Neonatologie, Univ. Klinik für Kinder- und Jugendheilkunde Graz, Österreich, ${ }^{3}$ Klinische Abteilung für pädiatrische Pulmonologie und Allergologie, Univ. Klinik für Kinder- und Jugendheilkunde Graz, Österreich

Hintergrund. Der kongenitale Chylothorax ist die häufigste Ursache für eine Flüssigkeitsansammlung im Pleuraraum bei Feten. Aufgrund der Seltenheit stützen sich jedoch die derzeitigen Therapieempfehlungen lediglich auf einzelne Fallbeschreibungen.

Zielsetzung. Zielsetzung war es die wichtigsten medizinischen $\mathrm{Pa}$ rameter bezüglich des Krankheitsverlaufs und der Komplikationen zu erfassen und Therapieempfehlungen zur Behandlung des kongenitalen Chylothorax zu entwickeln.

Methoden. Eine systematische Literaturrecherche in wissenschaftlichen Datenbanken zu Erhebung sämtlicher Publikationen in der englisch- und deutschsprachigen Literatur wurde zwischen November 2009 und September 2010 durchgeführt. Einschlusskriterien waren der Nachweis eines kongenitalen Chylothorax mittels biochemischer Analyse der aspirierten Flüssigkeit (Lymphozyten-Rate $>80 \%$ oder der Nachweis von Chylomikronen) und ein spontanes Auftreten innerhalb der ersten zwei Lebensmonate. 
Ergebnisse. Insgesamt wurden 361 Fälle für eine genauere Analyse berücksichtigt. Die Ansammlung pleuraler Flüssigkeit war in $70 \%$ bilateral. Eine intrauterine Diagnosestellung erfolgte in $61 \%$, eine intrauterine Intervention in $68 \%$ aller Fälle. $75 \%$ zeigten bereits bei der Geburt respiratorische Symptome. Eine MCT-Diät wurde bei $29 \%$ und seit 2003 Octreotid in $19 \%$ aller Fälle eingesetzt. Eine operative Sanierung musste bei $14 \%$ durchgeführt werden. Die Mortalitätsrate betrug $26 \%$, wobei als häufigste Todesursache eine respiratorische Insuffizienz dokumentiert wurde (44\%).

Zusammenfassung. Klinisch kontrollierte Studien bezüglich Therapieempfehlungen bei kongenitalem Chylothorax fehlen. In den meisten Fällen gelingt ein Ausheilen des Chylothorax mittels konservativer Therapie. Ein stufenweise konservatives Vorgehen mittels Pleuradrainage, totaler parenteraler Ernährung, MCT-Diät und adjuvanten Therapiemaßnahmen ist somit zu empfehlen. Bei fehlendem Ansprechen sollte vor operativer Intervention eine Therapie mittels Octreotid erfolgen.

\section{6 Österreich - ein Entwicklungsland in der Kinder- und Jugendrehabilitation}

I. Koller

In Österreich haben Kinder und Jugendliche bis dato nur in Ausnahmefällen die Möglichkeit, Rehabilitationsbehandlungen in eigens für sie adaptierten Kliniken zu erhalten. Stattdessen ist die stationäre Rehabilitation zum Teil in die Erwachsenenrehabilitation eingegliedert, wobei diese Möglichkeit nicht für alle Indikationsgruppen vorhanden ist und auch nur eine eingeschränkte Anzahl an Betten zur Verfügung steht. Stolpersteine in der Umsetzung einer systemischen Kinder- und Jugendlichenrehabilitation in Österreich stellen vor allem die Finanzierung, als auch die Definition von Rehabilitation als „Wiedererlangung der Arbeitsfähigkeit“ im Gesetzbuch dar.

In Deutschland gibt es seit vielen Jahren gut organisierte Kinder- und Jugendrehabilitationsprogramme und eigene Kliniken für eine Vielzahl von Indikationen. Eine telefonische bzw. elektronische Umfrage in deutschen Rehabilitationskliniken, in der die angebotenen Therapien und zu Verfügung stehenden Betten erfragt wurden, ergab allerdings, dass das Angebot den tatsächlichen Bedarf deutlich überschreitet. Die schlechte Auslastung führte in der Vergangenheit auch bereits zu einigen Schließungen von Kliniken in Deutschland. Auch findet sich eine Dominanz bestimmter Indikationsgruppen, während andere, seltenere Krankheitsbilder vernachlässigt werden.

Ziel der Entwicklung der Kinder- und Jugendrehabilitation in Österreich sollte es sein, die bewährten Systeme zu übernehmen, aber auch aus den Fehlern der Nachbarn zu lernen und in der Eröffnung von neuen Kliniken genau auf die Indikationsgruppen und Bettenverteilung $\mathrm{zu}$ achten, um ein ökonomisches und vor allem bedarfsorientiertes und qualitätsgesichertes System in diesem Bereich zu gewährleisten.

\subsection{Langzeitergebnisse der Ballonvalvuloplastie von kongenitalen valvulären Aortenstenosen \\ P. Mileder \\ Medizinische Universität Graz}

Einleitung. Während die Ballonvalvuloplastie (BVP) von angeborenen valvulären Aortenstenosen (AS) in vielen Studien sehr gute akute Ergebnisse zeigte, sind Untersuchungen über den Langzeitverlauf (>5 Jahre) relativ selten.

Patienten und Methoden. In diese retrospektive Untersuchung wurden alle 98 AS-Patienten (Pat.) - darunter 24 Neugeborene (NG) - inkludiert, die zwischen 3/1986 und 4/2009 an der Univ.-Klinik für Kinder- und Jugendheilkunde Graz mittels BVP therapiert wurden.

Ergebnisse. Zwei kardial dekompensierte NG verstarben während der BVP, bei zwei Pat. wurde diese aus technischen Gründen abgebrochen. Bei den verbleibenden 94 Pat. wurde der maximale Doppler-Gradient von im Mittel $80,5 \pm 25,2$ auf $35,8 \pm 17,8 \mathrm{mmHg}$ gesenkt (mittlere Reduktion 53,2 $\pm 22,1 \%$; $\mathrm{p}<\mathrm{0}, \mathrm{OO} 1$ ), lediglich 12 Pat. hatten Restgradienten $\geq 60 \mathrm{mmHg}$. Die postinterventionelle Echokardiographie zeigte in 36/94 Fällen $(38,3 \%)$ eine Zunahme der Aortenklappeninsuffizienz (AI). Von den 94 Pat. konnten 88 über im Mittel 7,6 $\pm 5,6$ Jahre nachkontrolliert werden. Der maximale Doppler-Gradient bei der aktuellsten Kontrolluntersuchung bzw. der letzten Kontrolle vor einer Reintervention betrug im Mittel 46,4 $\pm 24,1 \mathrm{mmHg}$ und lag bei $24 \mathrm{Pat}$. $\geq 60 \mathrm{mmHg}$. Eine AI zeigten 69/88 Pat. $(78,4 \%): 33 \times \mathrm{Grad}$ I, $21 \times \mathrm{Grad}$ II, $14 \times \mathrm{Grad}$ III, $1 \times$ Grad IV. Nach im Mittel 4,7 $\pm 4,1$ Jahren wurde bei $35 / 88$ Pat. (39,8\%) eine Reintervention (10×BVP, $25 \times$ Operation) vorwiegend wegen einer Re-AS oder AI erforderlich. Fünf der 88 Pat. (5,7\%) verstarben aus kardialer Ursache. Das ereignisfreie Überleben war in der NG-Gruppe signifikant schlechter als bei den Pat. $>1$ Monat zum Zeitpunkt der BVP $(\mathrm{p}=0,028)$. Eine bereits präinterventionell nachweisbare AI war mit einer höheren Reinterventionsinzidenz verbunden $(\mathrm{p}=0,012)$.

Konklusion. Die BVP bietet hervorragende Kurzzeitergebnisse, ist aber insbesondere bei NG mit einer relevanten Reinterventionsrate vergesellschaftet. Im Langzeitverlauf ist die Zunahme der AI von prognostischer Bedeutung.

22.8 Prävention von Kindesmisshandlung durch institutionelle Zusammenarbeit - Evaluation der Vernetzungsarbeit der Kinderschutzgruppe Feldkirch, Vorarlberg

E. Verocai ${ }^{1,2}$, F Juen², I Kitzelmann', B Simma ${ }^{1}$

${ }^{1}$ Akademisches Lehrkrankenhaus, Landeskrankenhaus Feldkirch, ${ }^{2}$ Institut für Psychologie, Universität Innsbruck, Innrain 52, A-6020 Innsbruck

Einleitung. Die institutionelle Zusammenarbeit bei Kindesmisshandlung ist notwendig für betroffene Kinder und deren Familien (Kitzelmann et al. 2005). Aufbauend auf dieser Studie verfolgt die vorliegende Untersuchung folgende Fragestellungen. Bestätigt sich der Verdacht der Kinderschutzgruppe auf Kindesmisshandlung? Wie wirkte sich die Meldung der Kinderschutzgruppe an die Jugendwohlfahrt auf die Lebenssituation der gemeldeten Kinder und deren Familien sowie auf die Mitarbeiter der Jugendwohlfahrten aus?

Methode. Es wurde die Schnittstelle Kinderschutzgruppe - Jugendwohlfahrt evaluiert. Untersucht wurden 40 der Jugendwohlfahrt gemeldete Fälle aus den Jahren 2003 bis 2009. Die Angaben der Jugendwohlfahrtsmitarbeiter im strukturierten Interview dienen als Indikator für eine sinnvolle Vernetzung. Bei zo Kindern gibt es eine Rückmeldung. Bei den restlichen 10 Fällen war der jeweilige Mitarbeiter nicht mehr im Dienst oder der Fall lag zeitlich zu lange zurück (Verjährung).

Resultate. Der Verdacht bestätigte sich bei 12 von 30 (40\%) Kindern. Positive Veränderungen durch die Meldung wurden bei 18 von $30(60 \%)$ der Kinder berichtet. Die schriftliche Meldung der Kinderschutzgruppe an die Jugendwohlfahrt war in $76 \%$ der Fälle hilfreich für deren Mitarbeiter.

Schlussfolgerung. Eine Kinderschutzgruppe ist in der Lage Misshandlungsfälle korrekt zu identifizieren. Die Ergebnisse geben sehr gute Rückmeldungen über die Vernetzungsarbeit der Kinderschutzgruppe Feldkirch nach außen: die Arbeit der Kinderschutzgruppe hat positive Konsequenzen auf die Lebenssituation der betroffenen Kinder, deren Familien sowie auf die Mitarbeiter der Jugendwohlfahrten.

\subsection{Longitudinaler Verlauf des Schlafverhaltens von Volks- schulkindern in Abhängigkeit von der Jahreszeit}

B. Wimmer, R. Kerbl

LKH Leoben, Abteilung für Kinder und Jugendliche

Hintergrund. Schlafstörungen und Tagesmüdigkeit sind auch im Kindes- und Jugendalter ein weit verbreitetes Problem. Verschiedene Studien deuten darauf hin, dass auch die Schulbeginnzeiten zum chronischen Schlafmangel vieler SchülerInnen beitragen. Weniger erforscht 
sind hingegen saisonale Auswirkungen auf Schlafverhalten und Tagesmüdigkeit. Unsere Studie hatte daher das Ziel, saisonale Unterschiede im Schlafverhalten und im Auftreten von Tagesmüdigkeit zu untersuchen. Weiters soll mit dieser Arbeit ein Beitrag zur Diskussion „optimaler Schulbeginn“ geleistet werden, beispielsweise ob ein späterer Schulbeginn während der Wintermonate sinnvoll wäre.

Methode. 66 Kinder der ersten bis dritten Schulstufe einer Grazer Volksschule wurden in die Studie eingeschlossen. Mit Hilfe eines selbst konzipierten Fragebogens wurden die Eltern an zwei definierten Stichtagen (15. Juni, 15. Dezember) über das Schlafverhalten, Schlafstörungen, Fernsehgewohnheiten und Tagesmüdigkeit ihrer Kinder befragt. Die Fragebögen wurden anschließend statistisch ausgewertet und die Sommer-Daten mit den Winter-Daten verglichen.

Ergebnisse. Die Gesamtschlafdauer, die Zubettgeh- und Aufstehzeiten an Schultagen und die Zubettgehzeiten am Wochenende zeigten keine signifikanten saisonalen Unterschiede. Signifikant später waren jedoch die Aufstehzeiten am Wochenende im Winter (Wilcoxon-Test, $\mathrm{p}=0,044)$. Die Erhebung der Schlafstörungen ergab, dass „unruhiger Schlaf" und "Schwitzen im Schlaf" im Sommer signifikant häufiger auftraten (Wilcoxon-Test, $\mathrm{p}=0,025$ und $\mathrm{p}=\mathrm{o}, 000$ ). Parameter der Tagesmüdigkeit, wie z. B. „Schwierigkeiten beim Aufstehen“ oder „morgendliche Müdigkeit“ zeigten keinen saisonalen Unterschied.

Schlussfolgerung. Die Ergebnisse der Studie liefern für das untersuchte Alter keine Hinweise auf eine erhöhte Tagesmüdigkeit oder auf vermehrte Schwierigkeiten beim Aufstehen im Winter. Ein späterer Schulbeginn nur während der Wintermonate kann daher nicht empfohlen werden. Zur Beantwortung der Frage, ob VolksschülerInnen von einem generell späteren Schulbeginn profitieren würden, sind weiterführende Untersuchungen notwendig.

\subsection{Impfstatus bei Kindern mit soliden Organtransplantatio- nen und deren Haushaltskontakten}

M. Diane Zettl, G. Cortina, T. Müller, T. Jungraithmayr, J. Hofer, R. Geiger, M. Edelbauer, R. Trofer, J. Schönlaub

Universitätsklinik Innsbruck, Abteilung Pädiatrie

Einleitung. Impfpräventable Erkrankungen bleiben nach wie ein großes Risiko für Transplantatempfänger. Dabei gibt es klare Richtlinien für Impfungen bei organtransplantierten Kindern. Jedoch ist nicht immer möglich alle empfohlenen Impfungen vor der Transplantation durchzuführen. Außerdem ist der Impfschutz auf Grund der Immunsuppression unsicher. Die Haushaltskontakte der Patienten stellen eine große Ansteckungsquelle dar. Aus diesem Grund beinhalten neue Empfehlungen eine adäquate Immunisierung aller im Haushalt lebenden Personen um eine „Herdenimmunität" um den Patienten zu bilden.

Methoden. Wir evaluierten den Impfstatus von 30 Kindern mit soliden Organtransplantationen (14 Niere, 14 Leber, 3 Herz), 26 Geschwistern und 30 Elternteilen.

Resultate. Von den Transplantatempfängern haben 18 (60\%) zum Zeitpunkt der Transplantation ihre "Grundimmunisierung“ abgeschlossen mit mindestens 2 Dosen des 6-fach-Impfstoffes (Tetanus/Diphterie/ Pertussis/Polio/HiB/HepB) sowie mindestens 1 Impfung gegen Masern/ Mumps/Röteln (MMR). Bei 10 Patienten fehlte die MMR-Impfung. Des Weiteren wurden 26 (87\%) Patienten gegen Pneumokokken, 14 (47\%) gegen Meningokokken C, 6 (20\%) gegen Varizellen und 10 (33\%) gegen Influenza geimpft. Von den 26 Geschwistern haben 20 (77\%) mindestens 2 Dosen des 6-fach-Impfstoffes erhalten sowie 1 Dosis des MMRImpfstoffes. Nur 2 (8\%) wurden gegen Meningokokken, 3 (11\%) gegen Pneumokokken, 2 (8\%) gegen Varizellen und 4 (15\%) gegen Influenza immunisiert. Von den 30 befragten Eltern war in $20(67 \%)$ Fällen kein Impfnachweis mehr auffindbar. 16 (53\%) Elternteile konnten eine Diphterie/Tetanus Impfung aufweisen, 16 (53\%) wurden gegen Polio, 3 (10\%) gegen Hep B, 8 (27\%) gegen Pertussis, 5 (17\%) gegen Masern und Mumps, 7 (23\%) gegen Röteln sowie 7 (23\%) gegen Influenza geimpft. Keiner war gegen $\mathrm{HiB}$, Pneumokokken oder Meningokokken geimpft.
Schlussfolgerung. Unsere Studie belegt dass bei den meisten Transplantatempfängern ein ausreichender Impfschutz besteht. Die Immunisierung der Haushaltskontakte ist jedoch unzureichend. In Transplantationszentren sollte zukünftig in Anlehnung an existierende Guidelines neben einer adäquaten Immunisierung der Patienten ebenfalls auf einen ausreichenden Impfschutz der Haushaltskontakte geachtet werden. 
Autorenindex

A

Aigner, J.
Aldover-Macasaet
Alikadic, S.
Arbeiter, K.
Artacker, G.
Attarbaschi, A.
Auer, H.
Aufricht, C.

14.13

4.3

15.1

$13.3,13.4,13.15$

17.1

8.1

15.3

5.2, 13.3, 13.4, 13.5,

$13.9,13.10,13.12$,

13.15

Ausserer, B.

8.1

Avian, A.

1.6

\section{B}

Bachmann, M. $\quad 12.5$

Bar-Server, Z. $\quad 7.22$

Barbosa, A. $\quad 18.2$

Barrientos, I. $\quad 16.1$

Bauer-Wais, E. $\quad 4.1$

Baumgartner, $\mathrm{F}$. $\quad 21.3$

Baumgartner, K. $\quad 12.11$

Baumgartner, $S$. $\quad 12.6$

Baumgartner-Parzer, S. $\quad 3.7$

Baumgarnter-Sigl, S. $\quad 4.2$

Becker, J. $\quad 21.4$

Bejaoui, M. $\quad 12$.

Benesch, $M$. $\quad 7.5,7.7,7.8,7.9,7.11$,

$7.12,7.13,7.15,7.16$,

$7.17,7.18$

Berger, A. $\quad 8.4,9.2,9.8,12.12$,

12.17

Berger, F. $\quad 5.4$

Berger, G. $\quad 3.2,3.6,16.1$

Berger, J. $\quad 14.13,20.5$

Bidmon-Fliegenschnee, B. 5.2, 13.12, 21.4

Biebl, A. $\quad 7.19,14.3$

Biller, K. $\quad 22.2$

Binder, C. $\quad 10.2,12.1,12.2$,

Birnbacher, R. $\quad 1.11,5.3,14.4,14.7$,

21.1

Bittermann, C. $\quad 5.4$

Bittner, R. $\quad 14.6$

Blecher, C. $\quad 14.4$

Bogyi, M. $\quad 15.3,15.6,15.7$

Böhm, J. 9.2, 9.8

Böhm, M. $\quad 13.4,13.9,13.10$

Bohn, A. $\quad 17.4$

Boubaker, A. $\quad 7.22$

Boztug, $\mathrm{H}$. $\quad 7.1,8.6$

Brandner, A. $\quad 10.2,12.1$

Breuer, T. $\quad 1.7$

Brock, P. $\quad 7.21$

Brunner, B. $\quad 12.3,12.18,13.13$

Brunner, J. $\quad 8.5$

Brunner, 0 . $\quad 4.5$

Brunner-Krainz, M. 14.1, 14.2
C

$\begin{array}{ll}\text { Cardona, F. } & 9.2 \\ \text { Cargill, J. } & 7.2 \\ \text { Castel, V. } & 7.21 \\ \text { Castellani, M. } & 7.22 \\ \text { Cimenti, Ch. } & 13.1,13.2 \\ \text { Colleselli, V. } & 1.14 \\ \text { Cortina, G. } & 10.1,13.7,22.10 \\ \text { Csaichsich, D. } & 13.3,13.4,13.15, \\ \text { Cummins, M. } & 7.2 \\ \text { Czaba, C } & 12.13\end{array}$

D

Dangl, A. $\quad 1.4$

Deigner, $\mathrm{H}$. $\quad 12.8$

Dertinger, $\mathrm{S}$. $\quad 6.2$

Dettmar, A. $\quad 13.13$

Deutschmann, A. $\quad 5.1$

Diakos, C. $\quad 3.1$

Diener, K. $\quad 1.4$

Dobrovoljski, G. $\quad 7.2$

Dufek, St. $\quad 13.3$

Dworzak, M. $\quad 7.3,7.4,7.10,7.16,8.1$

\section{E}

Eber, E. $\quad 22.4,22.5$

Ebetsberger-Dachs, G. $\quad 7.14,7.19,8.1,8.2$

Ebner, C. $\quad 14.2$

Edelbauer, M. $\quad 22.10$

Edlinger, $M$. $\quad 14.2$

Egger, K. $\quad 3.4$

Ehringer-Schetitska, D. $\quad 5.4$

Eibisberger, M. $\quad 12.19$

Eichberger, $M$. $\quad 14.3$

Eitelberger, F. $\quad 8.3$

Ellard, S. $\quad 3.6$

Emminger, W. $\quad 18.5$

Endress D. $\quad 9.4,9.7,20.6$

Engstler, G. $\quad 7.3$

Enot, D. $\quad 12.8$

Ertle, F. $\quad 5.3,21.1$

Eyermann, R. $\quad 1.1,11.1$

\section{F}

Fandl, A.

Feierl, G.

Felderhoff-Muser,

Finding, $\mathrm{K}$.

Fink, F. $\quad 12.15$

Fischer, G. $\quad 8.5$

Flanagan, $\mathrm{S}$. $\quad 3.6$

Fodor, S. $\quad 13.3$

Förster- Waldl, E. $\quad 8.2,8.4,8.5$

Fraunberger, $P$. $\quad 22.2$

Freilinger, M. $\quad 14.6$

Frey, E. $\quad 2.1$

Friesenbichler, W. $\quad 7.4$

Frischer, T. $\quad 15.1,15.3$

Fritsch, G. $\quad 7.1$

Fritsch, M. $\quad 3.2,3.3,3.6,4.3,16.1$

Fritsch, P. $\quad 1.6,1.7,1.8,1.13,3.3$,

$7.1,7.9,9.1$

Frühwald, U. $\quad 14.4,14.7$

Frühwith, M. $\quad 10.1$
Fürnkranz, H.

Fussenegger, B.

Fußenegger, J.

4.1

12.20

3.5

\section{G}

Gabriel, H. $\quad 1.10$

Gadner, H. $\quad 8.1$

Galliste, S. $\quad 14.5$

Gamillscheg, A. $\quad 1.6,1.7,1.8,1.12$,

$1.13,3.3,9.1$

Gaßner, I. $\quad 19.1$

Gebauer, V. $\quad 1.7$

Gegenbauer, M. $\quad 15.7$

Geiger, R. $\quad 1.14,8.7,10.1,22.10$

Geley, T. $\quad 19.1$

Genser, N. $\quad 1.2,1.3,20.1,22.1$

Gerber, D. $\quad 16.1$

Gindl, E. $\quad 8.4$

Giner, $T$.

Giordano, V.

$3.4,13.6,13.7,13.8$

Gnigler, M.

Gögele, C.

Göttling, A.

Gramm, S.

Grangl, G.

Grässl, G.

Graw-Panzer, K.

Greber-Platzer, S.

Griesmaier, E.

Grisold, A.

Großauer, K.

Gruber-Sedlmayr, U. $\quad 14.1,14.2$

Gruber, K.

Gruber, P.

Gruber, $\mathrm{S}$.

Gutenberger, $\mathrm{H}$.

12.13

12.21

8.7

4.1, 12.7

12.14

14.5

22.1

16.2

1.4

$12.4,12.5,12.8$,

12.11

9.9

7.5

13.4

22.3

15.2

12.15

H

Haas, 0.

Habeler, U.

Haberland, C.

Hager, J.

Haiden, $\mathrm{N}$.

Haidl, P.

Halb, V.

Halmer, M.

Hanchock, P.

Haninger, $N$.

Hanslik, A.

Hartlieb, C.

Haslinger, $\mathrm{V}$.

Hauer-Almuthe, C.

Hauk, P.

Hauptmann, M.

Hauschild, $P$.

Hausegger $M$.

Hauser, J.

Hayde, M.

Hecher, E.

Heher, Ch.

Heichlinger, A.

Heinzl, B.

8.1

21.5

12.15

12.4

$12.2,12.12,12.17$

9.4

1.6

$22.4,22.5$

7.2

$8.2,9.2$

1.9

12.7

$3.5,9.5$

5.1

1.11

4.5

$1.2,1.3$

18.1, 18.4

1.5

9.7, 12.17

4.4

$19.2,19.3$

4.2

1.6, 1.7, 1.8, 1.13,

$3.3,9.1$

Heitzer, E. 


\begin{tabular}{ll} 
Helmer, H. & 8.4 \\
Hengl, B. & 12.13 \\
Herbrüggen, H. & 7.6 \\
Herkner, K. & $9.8,17.4$ \\
Herle, M. & 21.4 \\
Herzog, R. & $13.5,13.10,13.12$ \\
Hettegger, S. & 1.8 \\
Höck, M. & 12.3 \\
Hof, K. & 4.2 \\
Hofer, J. & $13.6,13.7,13.8,22.10$ \\
Hofer, N. & 12.19 \\
Hofer, S. & 3.4 \\
Hoffmann, K. & 5.1 \\
Höliner, I. & $3.5,6.2,14.9$ \\
Höller, M. & 19.4 \\
Horak, A. & 12.12 \\
Horak, E. & 15.5 \\
Horak, F. & 15.1 \\
Horcher, E. & 7.3 \\
Hörtenhuber, T. & $3.2,3.6,16.1$ \\
Hruby, J. & 9.3 \\
Huber, G. & 11.2 \\
Huber, J. & 3.8 \\
Huber, M. & 4.2 \\
Huber, W. & 21.4 \\
Hubmann, H. & $7.7,7.11$ \\
Hubmann, V. & 7.13 \\
Huemer, C. & 22.2 \\
Husslein, P. & 8.4 \\
\hline
\end{tabular}

$\mathrm{I} / \mathrm{J}$

$\begin{array}{ll}\text { Ihm, U. } & 9.5 \\ \text { Ipsiroglu, O. } & 18.2 \\ \text { Jäger, A. } & 14.9 \\ \text { Jahnel, J. } & 5.1 \\ \text { Jauk, B. } & 14.8 \\ \text { Jeitler, V. } & 12.6 \\ \text { Jeller, A. } & 13.6 \\ \text { Jeller, V. } & 13.8 \\ \text { Jilka, K. } & 7.19 \\ \text { Jones, N. } & 8.1 \\ \text { Juen, F. } & 22.8 \\ \text { Jungraithmayr, T. } & 13.6,13.7,13.8,13.13, \\ & 13.14,22.10\end{array}$

K

$\begin{array}{ll}\text { Käfer, A. } & 4.1,12.7 \\ \text { Kalb, S. } & 14.9 \\ \text { Kaller, B. } & 15.3 \\ \text { Kaltenbrunner, K. } & 14.4 \\ \text { Karall, D. } & 4.2,21.6,22.1, \\ \text { Karwautz, A. } & 16.1 \\ \text { Kaspar, C. } & 1.3 \\ \text { Kasper, D. } & 8.5,9.8 \\ \text { Kaufmann, L. } & 3.4 \\ \text { Kaulfersch, W. } & 8.1,12.9,12.10,14.8, \\ \text { Keck, B. } & 7.10 \\ \text { Keller, M. } & 12.5,12.8,12.11, \\ \text { Kenn-Schürz J. } & 15.3 \\ \text { Kenzian, H. } & 5.3,17.4 \\ \text { Kerbl, R. } & 8.1,15.4,18.1,18.4, \\ & 22.9 \\ \text { Khazen, C. } & 1.5\end{array}$

Kiechl-Kohlendorfer, $U$.

$\begin{array}{ll} & 12.8,12.10,12.11, \\ & 2.15,12.18,12.20, \\ & 12.21,13.13,19.1, \\ \text { Kircher, S. } & 21.2 \\ \text { Kitzelmann, I. } & 22.8 \\ \text { Kitzmüller, E. } & 1.9,1.10,1.11 \\ \text { Klebermaß- Schrehof, K. } & 12.12,12.13,12.17 \\ \text { Koch, J. } & 21.3 \\ \text { Kofler, S. } & 9.10 \\ \text { Koller, D. } & 11.3 \\ \text { Koller, I. } & 22.6 \\ \text { Konstantopoulou, V. } & 21.4,21.5 \\ \text { Kortschak, A. } & 14.2 \\ \text { Koslowski, C. } & 11.3 \\ \text { Köstenberger, M. } & 1.6,1.7,1.8,1.12, \\ & 1.13,3.3,9.1 \\ \text { Krappinger, H. } & 1.11 \\ \text { Kraschl, R. } & 12.9,12.10,14.8 \\ \text { Kratochwill, K. } & 13.5 .13 .9,13.10, \\ & 13.12 \\ \text { KreißI, A. } & 4.3 \\ \text { Kriegshäuser, G. } & 3.7 \\ \text { Kroisl, P. } & 14.10 \\ \text { Kronberger- Vollnhofer, M.7.3, 7.4, 7.10 } \\ \text { Kronberger. G } & 6.1 \\ \text { Kröpfl, T. } & 14.1 \\ \text { Kurath, St. } & 12.9,12,10 \\ \text { Kurz, H. } & 9.5,14.11 \\ \text { Kuster, L. } & 13.9,13.12 \\ & \end{array}$

L

Lackner, H. $\quad 7.5,7.8,7.7,7.9,7.11$, $7.12,7.13,7.15,7.16$, $7.17,7.18$

Ladenstein, $\mathrm{R}$. $\quad 7.3,7.21,7.22,7.23$

Lambert, B. $\quad 7.22$

Lanator, I. $\quad 14.6,18.5$

Landauer, F. $\quad 11.2$

Langer-Wegscheider, B. $\quad 13.2$

Laureys, G. $\quad 7.21$

Lechner, E. $\quad 12.19$

Lee, $\mathrm{H}$. $\quad 15.2$

Lewington, $\mathrm{V}$. $\quad 7.22$

Lichentauer, A. $\quad 13.10$

Liechtenstein, C. $\quad 1.11,5.3,14.4,14.7$

Lindmira, T. $\quad 15.3$

Lindner, $\mathrm{E}$. $\quad 15.4$

Lingitz, K. $\quad 5.3$

Lischka, A.

Luksch, R.

Lüftinger, R.

Lütschg, J.

4.1, 4.5, 8.6, 9.7 12.7,

$14.13,15.3,15.6$,

$15.7,16.3,16.4,20.5$, 20.6

7.21

5.2

$3.5,6.2,14.9$

M

Mache, C.

Mädel, C.

Maier, R.

Male, C.

Mallouhi, A.

Mang, A.

Mann, G.
Mark, W.

$14.13,21.5$

Marx, M.

13.7

14.6

Masoud, L.

Matthes-Martin, $\mathrm{S}$.

9.9

Maurer, K.

Mayr, J.

Meister, B.

Memaran, $\mathrm{N}$.

Meraner, D.

Messerschmidt, A.

Meznik, S.

Michel-Behnke, I.

Mikuz, G.

Mileder, L.

Minkov, M.

Mischkreu, M.

Mlczoch, E.

Mogaji, A.

Moppett, J.

Mori, C.

Moser, E.

Möslinger, D.

Mottl-Link, S.

Muntean, W.

Mühlbacher, F.

Müller-Schacherer, $T$

Müller, G.

Müller, W.

$7.1,8.6$

$12.4,12.18,13.13$,

19.1

21.3

8.1

9.4, 19.5

3.4

12.17

$16.3,16.4$

$1.5,1.9,1.10,1.11$

13.13

22.7

$7.6,7.20$

1.11

1.9

15.6

7.2

16.7

2.1, 9.7

21.4

11.4

$3.3,14.5$

21.4

13.3, 13.4, 13.14,

$13.15,22.10$

3.5

9.9, 10.2, 12.1, 12.14,

12.15,12.16, 18.1,

$18.4,20.3,22.4,22.5$

N

Nachbauer, E.

15.1

Nagel, B.

1.6, 1.7, 1.8, 1.12,

$1.13,3.3,9.1$

Navarro- Psihas, S. $\quad 12.21$

Nemeth, $\mathrm{S}$.

3.7

Neophytou, B.

Neu, $\mathrm{N}$.

7.10

10.1

12.5, 12.11,

9.7

20.1, 22.1

Niedermayr

Norooz, F.

12.12

0

Oberkanins, C. $\quad 3.7$

Oberleitner, A. $\quad 9.2$

Obwegeser, E. $\quad 12.13$

Offner, F. $\quad 6.2$

Olischar, M. $\quad 12.13$

Ollerieth, $\mathrm{R}$. $\quad 9.4$

Ovsenk, T.

1.11

P

Pansy, J.

$7.9,18.1,18.4$

Panzer-Grümayer, R. $\quad 8.1$

Papadakis, C. $\quad 7.21$

Paulsen, D. $\quad 18.3$

Pees, C. $\quad 1.5,14.6$

Pfurtscheller, K. $\quad 14.1,14.2$

Philippitsch, R. $\quad 21.6$ 


$\begin{array}{ll}\text { Pichler, G. } & 10.2,12.1,12.14, \\ & 12.16,18.1,18.4 \\ \text { Pichler, H. } & 7.10 \\ \text { Pichler-Stachl, E. } & 12.14,12.16 \\ \text { Pillhatsch, A. } & 13.1 \\ \text { Pixner, S. } & 3.4 \\ \text { Plecko, B. } & 14.1,14.2,14.10 \\ \text { Pocivalnik, M. } & 10.2,12.1,12.16 \\ \text { Pollak, A. } & 8.4,8.5,9.8,12.2, \\ & 12.12,12.17 \\ \text { Pontasch, C. } & 5.3 \\ \text { Portugaller, R. } & 13.1 \\ \text { Pötsch, A. } & 14.7 \\ \text { Pötschger, U. } & 7.21,7.22 \\ \text { Pracher, E. } & 3.1 \\ \text { Prayer, D. } & 14.13 \\ \text { Preisel, M. } & 7.10 \\ \text { Prelog, M. } & 8.7,9.10 \\ \text { Prohazka, Z. } & 13.15 \\ \text { Prusa, A. } & 9.7 \\ \text { Pupp- Peglow, U. } & 12.20\end{array}$

\section{R}

$\begin{array}{ll}\text { Radauer, W. } & 13.11 \\ \text { Radinger, A. } & 4.4,14.8 \\ \text { Ralser, E. } & 12.15 \\ \text { Ramasani, A. } & 9.4,20.6 \\ \text { Rami, B. } & 3.2,16.1 \\ \text { Rath-Wacenovsky, R. } & 18.4 \\ \text { Ratschek, M. } & 13.2 \\ \text { Ratschmann, R. } & 21.4 \\ \text { Rauchenzauner, M. } & 1.14 \\ \text { Rauscher, C. } & 21.3 \\ \text { Rauschka, H. } & 14.11 \\ \text { Ravekes, W. } & 1.6 \\ \text { Rebhandl, W. } & 15.3 \\ \text { Rehak, T. } & 1.6,1.7,1.8,1.12, \\ & 1.13,3.3 \\ \text { Rehbein, F. } & 11.6 \\ \text { Reinehr, T. } & 3.3 \\ \text { Reiterer, F. } & 18.4 \\ \text { Reithmayr, St. } & 19.6 \\ \text { Renner, E. } & 15.1 \\ \text { Repa, A. } & 12.2,12.12 \\ \text { Resch, B. } & 9.9,12.9,12.10,12.19, \\ & 22.4,22.5 \\ \text { Resch, E. } & 9.5 \\ \text { Rhomako, M. } & 8.3 \\ \text { Ribeiro, S. } & 13.11 \\ \text { Riedl, M. } & 13.6,13.7,13.8 \\ \text { Riedl, S. } & 3.1,3.7,3.8,14.13 \\ \text { Ring,E. } & 13.1,13.2 \\ \text { Rittinger, O. } & 6.1,13.11 \\ \text { Rödl, S. } & 14.2 \\ \text { Rojacher, T. } & 9.6 \\ \text { Rona, Z. } & 12.13 \\ \text { Rosales, A. } & 13.6,13.7,13.8 \\ \text { Roscher, A. } & 21.4 \\ \text { Rossegg, U. } & 14.3 \\ \text { Rostasy, K. } & 12.20 \\ \text { Roth, G. } & 17.2 \\ \text { Rötzer, K. } & 14.10 \\ \text { Rüdiger, M. } & 12.21 \\ \text { Ruepp, M. } & 1.14 \\ \text { Rusai, K. } & 13.12,13.15 \\ & \\ & \end{array}$

\section{$S$}

Sacherl, S.

Sadeghi, K.

Sadek, E.

Salmhofer

Säly, C.

Salzer-Muhar, U.

Samueli, S.

Sander, G.

Sauseng, W.

Schacherer, W.

Schermer, E.

Schlenz, B.

Schmid- Eipeldauer, B.

Schmidt, P.

Schmidt, S.

Schmidt, W.

Schmitt, K.

Schmoock, M.

Schneider, J.

Schober, E.

Schober, $\mathrm{H}$.

Schocke, M.

Scholl-Bürgi, S.

Schönlaub, J.

Schüller, $\mathrm{S}$.

Schuster, E.

Schwarz, R.

Schwarz-Gerö, J.

Schweigmann, $U$.

Schwerin-Nagel, A.

Schwindt, J.

Schwinger, W.

Sebkova-Thaller, Z.

Seick Barbarini, D.

Seidel, M.

Seidl, $R$.

Silka, K.

Simma, B.

Skacel, G.

Skrabl-Baumgartner, A.

Sorantin, E.

Sovinz, P.

Sperl, W.

Spittler, A.

Springer, A.

Starke, M.

Staudenherz, A.

Stein, J.

Steiner, R.

Stifter, E.

Straub, J.

Streif, W.

Strenger, V.

Streubel, B.

Strobl, R.

Szilagyi, A.

Szkwarek, M.
T

Tamesberger, M. 7.14, Tappauf, M.

Tax, N.

Tendl, K.

Thereska, L.

Tragwöger, R.

Trofer, R.

Trojer, R.

$7.15,7.21,14.5$

12.16

17.4

15.7

$12.18,13.13$

22.10

Tschemmernegg, $\mathrm{V}$. $\quad 14.3$

$\begin{array}{ll}\text { Tunstall, } 0 . & 7.2\end{array}$

U

$13.7,13.13,13.14$

12.21

11.5

$7.7,7.8,7.11,7.12$

$7.13,7.15$

14.6

$7.19,14.3$

18.5

1.14

$3.2,3.6,6.2,16.1$

$6.2,14.9$

3.4

4.2, 21.6

22.10

8.4

11.3

14.3

4.5

10.1

14.10

12.17

7.5,7.7, 7.8, 7.9, 7.11,

$7.12,7.13,7.15,7.16$,

$7.17,7.18,8.2,8.5$

1.3

3.5

$8.2,8.5$

$9.3,14.6,18.5$

7.14

$3.5,6.2,14.9,22.2$,

22.8,

4.3

$18.2,18.3$

$14.1,14.5$

7.5, 7.7, 7.8, 7.9, 7.11, $7.12,7.13,7.15,7.16$,

$7.17,7.18$

21.3

$8.4,13.9$

3.8

3.4

7.22

1.14

7.14

9.7

9.2, 9.8,

$12.3,13.13$

7.5, 7.7, 7.8, 7.11 7.12,

$7.13,7.15,7.16$

$7.17,7.18,9.9$

14.11

12.15

13.15

8.6
Ulbrich, A.

Ulmer, $\mathrm{H}$.

Ulreich, R.

Unsinn, K.

Urban, $C$.

18.5 15.5

$7.16,7.17$

$12.4,13.13$

7.5, 7.7, 7.8, 7.9, 7.11, $7.12,7.13,7.15,7.16$,

$7.17,7.18,8.1,12.8$

Urlesberger, B. $\quad 9.9,10.2,12.1,12.14$, $12.16,18.1,18.4$

V

Valteau-Couanet, D. $\quad 7.21,7.22$

Van Egmond-Fröhlich, A. $\quad 14.11$

Verocai, $\mathrm{E}$.

22.8

Virgo, J.

7.2

Vlasak, I

6.1, 13.11

Vogl, W.

13.14

W

Wadowski, S. $\quad 15.2$

Wagner, G. $\quad 19.1$

Wagner, $\mathrm{K}$. $\quad 5.4,14.10$

Wagner, $0 . \quad 12.19$

Wagner, $\mathrm{T}$. $\quad 9.5$

Waibel, V. $\quad 15.5$

Wald, $M$. $\quad 12.6,12.17$,

Waldhauser, F. $\quad 3.7$

Waldhör, T. $\quad 12.6$

Walli, A. $\quad 22.2$

Walser, N. $\quad 12.20$

Wanz, U. $\quad 7.18$

Wasserbauer, J. $\quad 12.14$

Weghuber, D. $\quad 11.2$

Weigmann, C. $\quad 14.12$

Weingarten, $C$. $\quad 15.6$

Weiss, A. $\quad 9.4$

Weiss, K. $\quad 7.7$

Weissensteiner, M. $\quad 12.19$

Weitzer, C. $\quad 19.2,20.3,20.4$

Weitzer, F. $\quad 20.4$

Weninger, $\mathrm{M}$. $\quad 12.13$

Widhalm, K. $\quad 4.3$

Wiesinger- Eidenberger, G. 12.19

Wild, B. $\quad 4.2$

Wimmer, B. $\quad 22.9$

Winkler, S. $\quad 15.6$

Wintergerst, U. $\quad 8.5$

Witsch-Baumgartner, M. 14.9

Witt, V.

7.10
Wegleitner, K. $\quad 12.4,12.18$

Wimmer, S. $\quad 4.2$ 


$\begin{array}{ll}\text { Wolf, C. } & 1.13 \\ \text { Wolf, H. } & 8.6 \\ \text { Wölzl, S. } & 16.3,16.4 \\ \text { Wondrak, P. } & 21.6 \\ \text { Wurm, S. } & 7.19 \\ \text { Würzner, R. } & 8.7,13.6,13.7,13.8\end{array}$

Y

Yaniv, I.

7.21

Z

Zaller, V. $\quad 13.15$

Zanier, U. $\quad 3.5$

Zarfel, A. $\quad 9.9$

Zettl, M. $\quad 22.10$

Ziehenberger, E. $\quad 10.2,12.1,12.16$

Zimmerhackl, L. $\quad 8.7,13.8$

Zimmermann, $\mathrm{F}$. $\quad 21.3$

Zimmermann, N. $\quad 1.13$

Zimpfer, D. $\quad 7.3$

Zimprich, A. $\quad 7.10$

Zlamy, M. $\quad 8.7,9.10$

Zobel, G. $\quad 9.1,14.2$

Zoder, G. $\quad 4.1,12.7,14.13,19.7$,

Zotter, H. $\quad 12.1,12.16,18.1$,

18.4,

Zotter, S. $\quad 3.4,12.20$

Zoubek, P. $\quad 7.20$ 